\title{
“A NEW VIEW OF BODY IMAGE”: A SCHOOL-BASED PARTICIPATORY ACTION RESEARCH PROJECT WITH YOUNG ABORIGINAL WOMEN
}

\author{
A Thesis Submitted to the College of \\ Graduate Studies and Research \\ in Partial Fulfillment of the Requirements \\ for the Degree of Doctorate of Philosophy \\ in the College of Kinesiology \\ University of Saskatchewan \\ Saskatoon
}

By

Tara-Leigh F. McHugh

(C) Copyright Tara-Leigh F. McHugh, September 2008. All rights reserved 


\section{PERMISSION TO USE}

In presenting this thesis in partial fulfillment of the requirements for a Postgraduate degree from the University of Saskatchewan, I agree that the Libraries of this University may make it freely available for inspection. I further agree that permission for copying of this thesis in any manner, in whole or in part, for scholarly purposes may be granted by the professor or professors who supervised my thesis work or, in their absence, by the Head of the Department or the Dean of the College in which my thesis work was done. It is understood that any copying or publication or use of this thesis or parts thereof for financial gain shall not be allowed without my written permission. It is also understood that due recognition shall be given to me and to the University of Saskatchewan in any scholarly use which may be made of any material in my dissertation.

Requests for permission to copy or to make other use of material in this thesis in whole or part should be addressed to:

Dean of the College of Kinesiology

University of Saskatchewan

Saskatoon, Saskatchewan

S7N 5B3 


\begin{abstract}
Research continues to suggest that young women experience body image concerns; nevertheless, the majority of this body image research has focused on white women, and the experiences of young Aboriginal women have typically been overlooked. When research has included Aboriginal women, it has generally been quantitative in nature (e.g., Gittelsohn et al., 1996; Marchessault, 2004; Story et al., 1995) and has highlighted body dissatisfaction that is equal to and even greater than that experienced by white women. Despite the alarming statistics suggesting that body image concerns are common among Aboriginal women, few researchers have engaged young Aboriginal women in qualitative research projects that seek to highlight their unique experiences. My previous research with young Aboriginal women (i.e., Fleming et al., 2006; McHugh \& Kowalski, in press) are some of the first Canadian studies to have an exclusive focus on Aboriginal women's body image experiences. This research suggested that young Aboriginal women's body image experiences may not be as negative as previous quantitative research has suggested, but highlighted the need to work with young women to develop strategies for positively managing body image experiences. Therefore, the purpose of this research was to engage in a collaborative, school-based participatory action research (PAR) project in partnership with a local high school to provide young women, primarily young Aboriginal women, with an opportunity to manage their body image experiences in an effective manner.

Students, teachers, and staff of Nutana Collegiate participated in this project, which took place over a 10-month period from September 2006 to June 2007. All Nutana school members were welcomed to participate and many took part in the various action initiatives that were developed. A group of seven young Aboriginal women formed a core group of participants who were primarily responsible for the development and implementation of most action initiatives. A five phase PAR model, which was based on the work of Stringer and Genat (2004), was proposed as the methodological framework for this project. However, given the emergent and dynamic nature of PAR processes, and the unique features of the school community, the manner in which the project actually
\end{abstract}


unfolded was quite different from the original plan. This project ultimately had two phases, the Relationship Building Phase and the Action Phase.

In an effort to develop relationships with school community members, during the Relationship Building phase I engaged in the three general processes of: familiarization, making connections, and giving back to the school. My commitment to these processes supported my initial goal to develop trusting relationships with community members, which subsequently formed a strong foundation for the development of effective and successful action initiatives. Eight action initiatives, which were represented by three themes, were developed and implemented as part of the Action phase. The three themes were: (1) Promoting Positive Body Image Experiences, (2) Self-Expression, and (3) Creating Awareness.

The development and implementation of action at various levels (i.e., individual, school, provincial, and national) was the most significant outcome of this research. The success and relevance of the various action initiatives was demonstrated by the words of the participants, the overall support of various school members, and the commitment of the core group to the goals of this PAR project. Although there were methodological challenges and considerations that needed to be navigated throughout this PAR project, findings from this research suggest that universities and local high schools can and should work together to develop school-based body image programs for young Aboriginal women. As well, and maybe most importantly, this research highlights the strength of using PAR methodologies when engaging young Aboriginal women in body image research. 


\section{ACKNOWLEDGEMENTS}

I would like to thank my supervisor, Dr. Kent Kowalski, for being such an amazing mentor throughout this research process. Thank you for taking the journey with me towards a more feminist perspective and for always asking the tough questions about my research. Your honesty and dedication to quality research have been instrumental in my development as a researcher.

I would also like to thank my committee members Dr. Martin Cannon, Dr. Louise Humbert, and Dr. Jennifer Nicol, and my external advisor, Dr. Wendy Frisby, for your individual and collective support. Your contributions to this research are greatly appreciated.

In addition, I would like to acknowledge the Canadian Institutes of Health Research for funding this research through a Doctoral Award. As well, I would like to acknowledge the Public Health and Agricultural Rural Ecosystems Training Program for the Fellowship award that also supported this research.

Finally, I would like to thank Nutana Collegiate, particularly the seven wonderful young women who were dedicated to this research project. I am so thankful that I was able to spend 10 months working alongside a group of incredible young women who were so committed to change. 


\section{DEDICATION}

I dedicate this dissertation to my husband Patrick, the one person who has been by my side throughout this entire journey. Your unwavering support and encouragement continue to help me reach my goals; I am forever thankful to have you, my soul-mate, in my life. 


\section{TABLE OF CONTENTS}

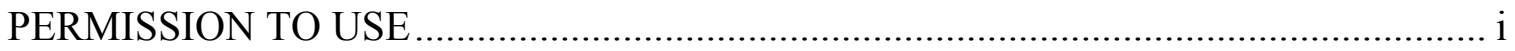

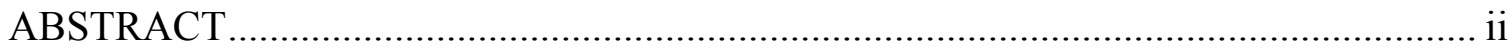

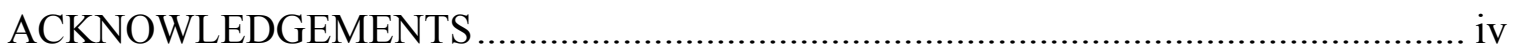

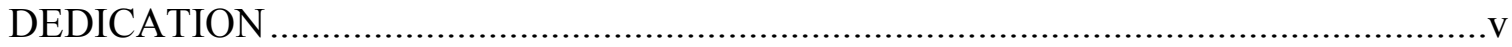

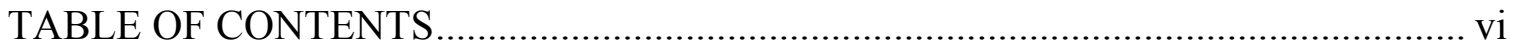

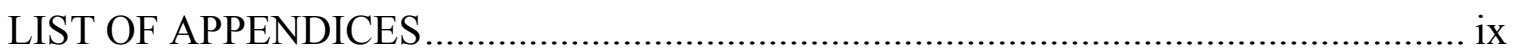

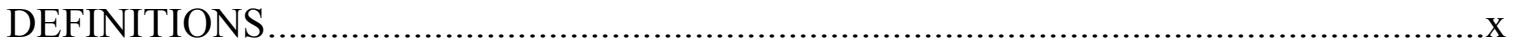

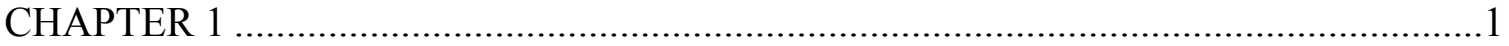

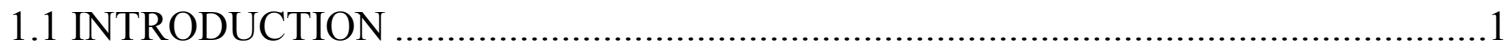

1.2 GUIDING PERSPECTIVE ........................................................................

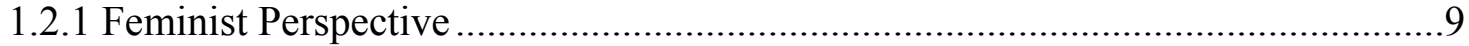

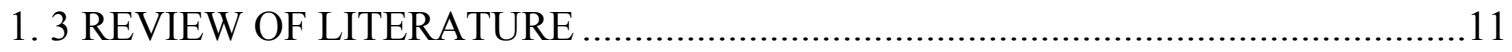

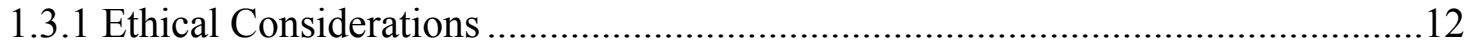

1.3.2 Aboriginal Women's Health and Body Image Experiences ...............................19

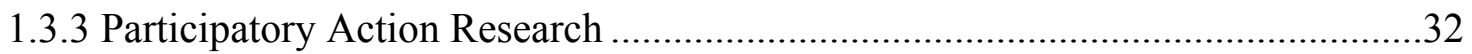

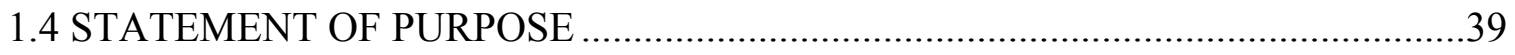

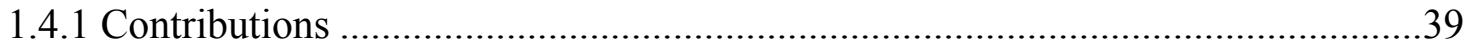

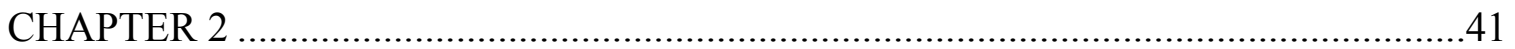

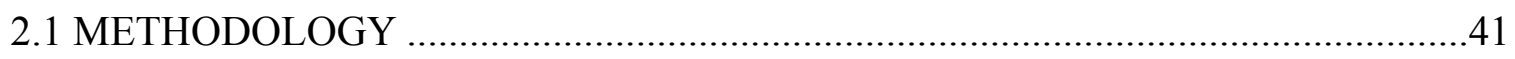

2.1.1 Role of Theory in Participatory Action Research...........................................41

2.1.2 Five Phase Participatory Action Research Approach ......................................43

2.1.2.1 Phase One: Research Design ............................................................ 45

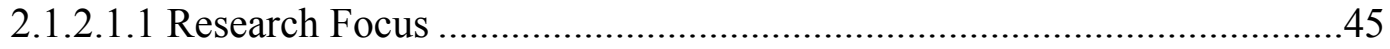

2.1.2.1.2 Research Frame..............................................................................46

2.1.2.1.2.1 Integrated School-Linked Services (ISLS) Model........................49

2.1.2.1.2.2 School Strategic Plan For The Year 2006-2007 ............................51

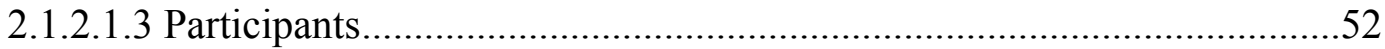


2.1.2.1.3.1 Known Sponsor...............................................................................53

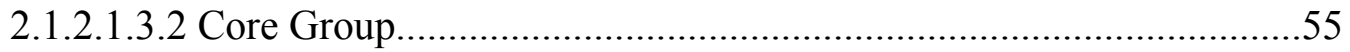

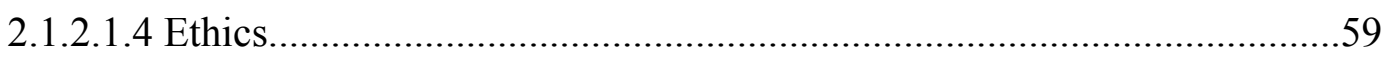

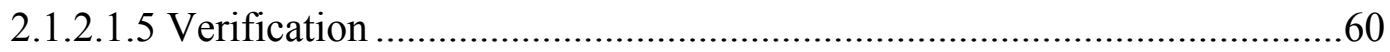

2.1.2.2 Phase Two: Data Gathering .........................................................................64

2.1.2.2.1 Interviews (One-on-one and Group Discussion) ...................................64

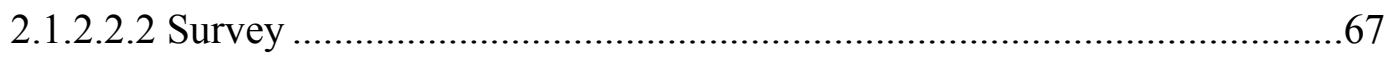

2.1.2.2.3 Alternative Methods of Data Gathering....................................................69

2.1.2.3 Phase Three: Data Analysis .....................................................................70

2.1.2.4 Phase Four: Communication.....................................................................72

2.1.2.5 Phase Five: Act ...................................................................................

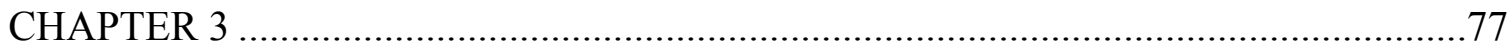

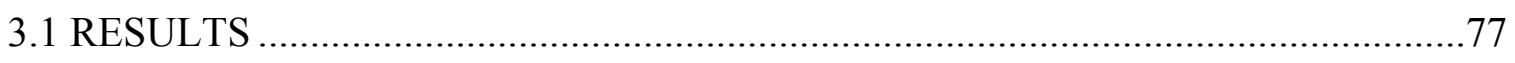

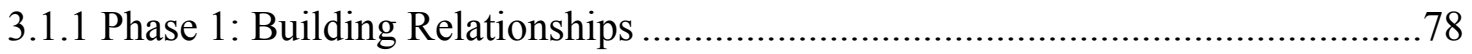

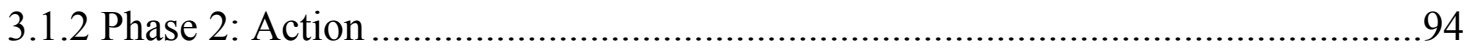

3.1.2.1 Promoting Positive Body Image Experiences................................................96

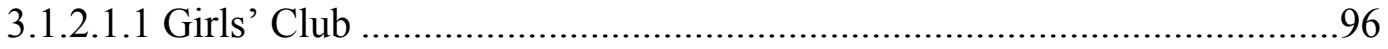

3.1.2.1.2 Yoga

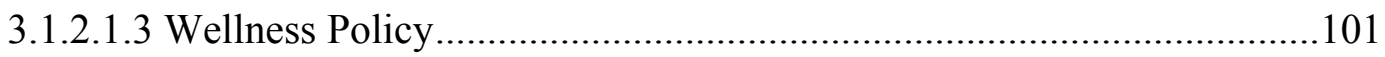

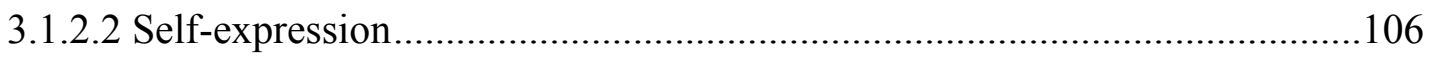

3.1.2.2.1 Body Talk ...........................................................................................107

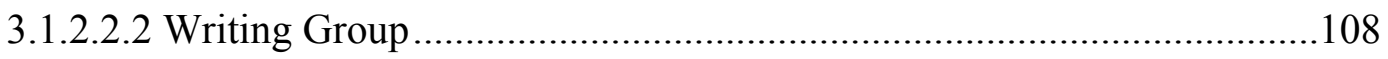

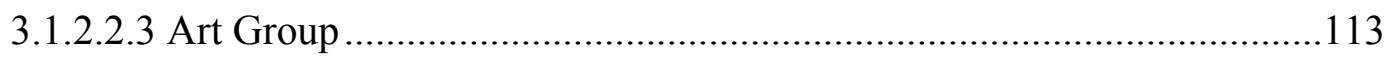

3.1.2.3 Creating Awareness ................................................................................116

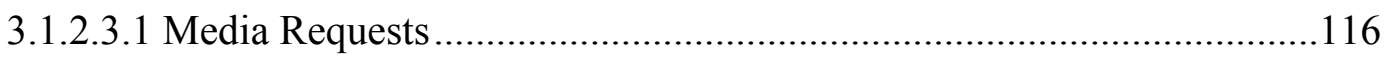

3.1.2.3.1.1 Saskatoon Star Phoenix and Regina Leader Post ...........................117

3.1.2.3.1.2 CBC Radio …………………………........................................118

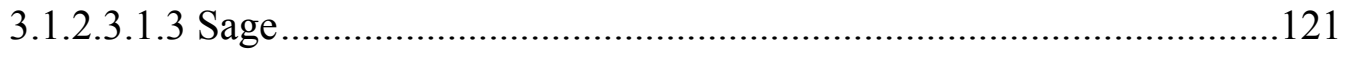

3.1.2.3.1.4 Missinipi News Radio ..............................................................123

3.1.2.3.1.5 Aboriginal Peoples Television Network ..........................................123

3.1.2.3.2 Youth as Leaders and Facilitators.......................................................126 


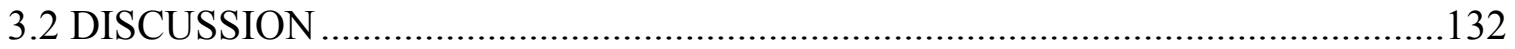

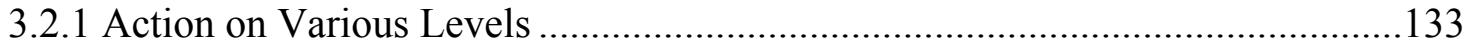

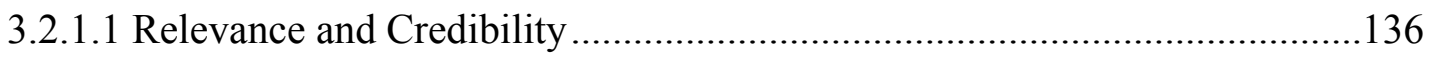

3.2.1.2 Need for School-based Body Image Programs ..........................................142

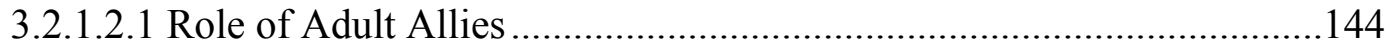

3.2.2 Methodological Considerations and Challenges................................................149

3.2.2.1 Integration of Five Phase Research Plan....................................................149

3.2.2.2 Working within a Community School ......................................................153

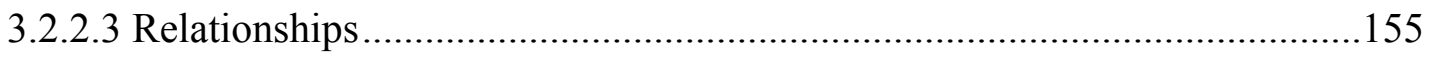

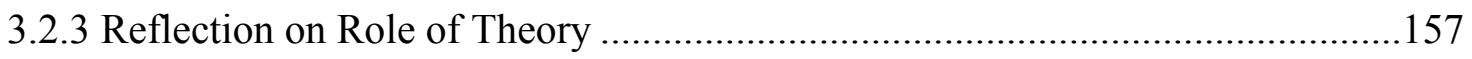

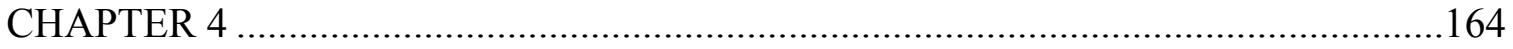

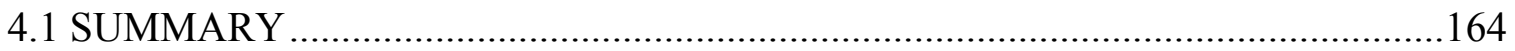

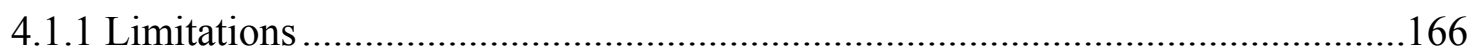

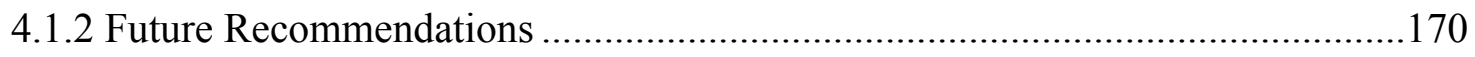

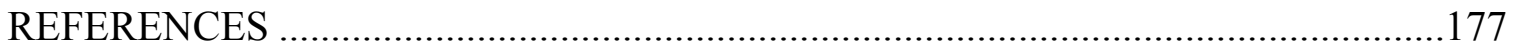

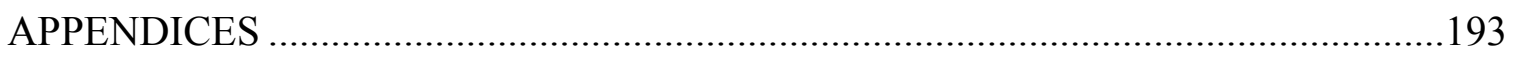




\section{LIST OF APPENDICES}

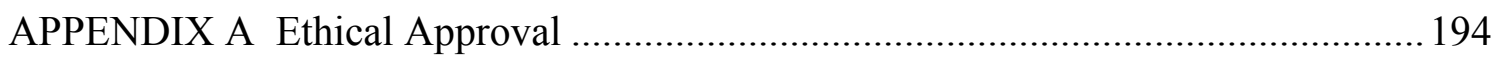

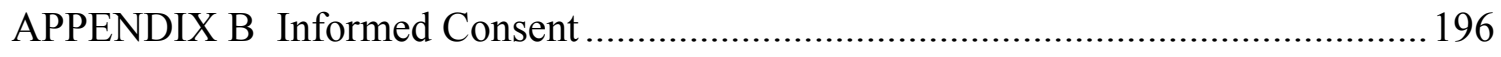

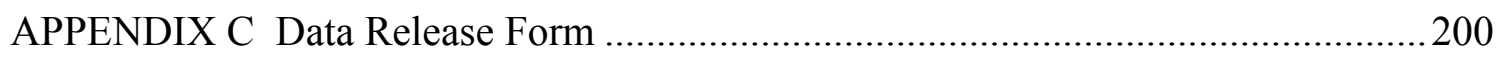

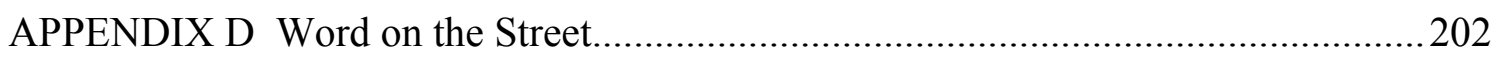

APPENDIX E Star Phoenix Newspaper Article.................................................... 204

APPENDIX F Sage Newspaper Article............................................................... 206

APPENDIX G Letters Outlining Perceived Success of Action Initiatives....................208 


\section{DEFINITIONS}

Aboriginal: A term that encompasses those individuals who identify themselves as legal or status Indian, non-status Indian, Inuit, and Métis (Frideres \& Gadacz, 2001).

Body Image: “An umbrella term that encompasses perception cognitions, affect, and behaviors related to body image” (Bane \& McAuley, 1998, p.312).

Colonization: The process of "cultural exploitation that developed with the expansion of Europe over the last 400 years" (Ashcroft, Griffiths, \& Tiffin, 2000, p.45). Within the context of this dissertation, it is the process by which Aboriginal peoples had their lands and resources dispossessed, "and their economies and institutions suppressed, so that new-comers could monopolize the benefits of the territory" (McBride, 2001, p.23).

Community: Represents "a sense of belonging together" or a group of individuals who have particular characteristics in common (Canadian Institutes of Health Research [CIHR], 2005). A school may be a community within collaborative programs (Harrison, 2001).

Epistemology: Assumptions about the nature of the relationship between the knower and what can be known (Guba \& Lincoln, 2004).

Ontology: Assumptions about the form and nature of reality (Guba \& Lincoln, 2004).

Patriarchy: "A system of social structures and practices in which men dominate, oppress and exploit women" (Walby, 1989, p. 214).

Power: A term that is understood by various feminists as "something that 'belongs' to one group and is wielded over others who do not 'have' it. In patriarchal society, this means that the oppressors (men) 'have' power and exercise it over the oppressed (women)" (Blood, 2005, p. 48). 


\section{CHAPTER 1}

\subsection{INTRODUCTION}

When compared to the health and wellness of other Canadians, research consistently suggests that Aboriginal women fare the worst (Bent \& Ross, 2004). Despite this, the health concerns of Aboriginal and other non-white Canadian women are often neglected (McIntyre et al., 2001). In an effort to discontinue this pattern of neglect, it is important for health researchers to work together with Aboriginal women to address important health issues. Although researchers (e.g., Fox, 1997; Leary, 1995) have highlighted the link between body image concerns and health among the general population, few researchers have explored the body image experiences of young Aboriginal women. Action research projects, in particular, could provide young Aboriginal women with the opportunity to develop strategies to manage their body image experiences in an effective and collaborative manner. It is important for researchers to engage Aboriginal youth in community-based participatory action research projects because, as stated by the Royal Commission on Aboriginal Peoples (1996), Aboriginal youth want to develop the skills that are required to address the challenges within their communities.

\subsection{GUIDING PERSPECTIVE}

"Struggle constantly forces us to identify and review what we stand for and what we stand against" (Smith, 2000, p. 210).

As a young woman in my late twenties, I am conscious of the many power struggles that individuals face in a socially constructed world. More specifically, I am aware that women's bodies are a site of struggle and contestation. My sentiments echo those of Orbach (1998) who conceptualized the body as socially produced and a medium for social control and power. All individuals are unique, and it is my opinion that the power struggles that women endure with respect to their bodies' form a common link between all women. My interest in the area of Aboriginal women's body image is guided 
by a feminist perspective; ultimately, this perspective impacts the way I view the world. My feminist perspective is part of my identity in that it shapes my beliefs and values. Although countless experiences and personal struggles form the foundation of my perspective, my passion for working with women and their body image experiences has been most strongly influenced by my family.

I am a young, privileged, white woman who grew up in a middle-class white neighborhood in Nova Scotia. I am privileged in that I have never experienced family violence, I have never gone hungry, and I was provided with educational opportunities that not everyone is fortunate enough to experience. I grew up in a family in which I was constantly made aware of my privilege because my parents were foster parents who often cared for less fortunate children. Because my home was often shared with foster children, at a very young age, I was aware of the many social and power inequalities that plague society. Whether or not I was able to specifically identify these inequalities as such was irrelevant; I knew that I had a number of privileges that my foster siblings did not. Some of the children that came into our home stayed with our family for long periods of time, and then foster services would attempt to put them back into their original home environment or the children would be placed into new permanent foster homes. My older sister was adopted by my family when she was just a toddler and I was only one year old; they were able to provide her with a life of opportunity. My parents made a positive difference in the lives of not only my sister but also all of the other children who were cared for in their home. Mt motivation to make a positive difference in the lives of young women stems from the compassion I learned from my parents.

Although I am interested in the experiences of all women, I became particularly interested in the body image experiences of Aboriginal and other non-white women because of my upbringing in a family that consists of more than just white women. My adopted sister has "olive" skin, which she attributes to her biological father who is Egyptian, and my two female cousins identify themselves as Aboriginal. I became more interested in the experiences of Aboriginal women since living in the prairies. Within the prairie provinces I feel that there is a racial division among non-Aboriginal ${ }^{1}$ and

\footnotetext{
${ }^{1}$ The term "non-Aboriginal" will be used throughout this dissertation to represent all individuals who are non-Aboriginal. When referring exclusively to white people, the term "white" will be used rather than
} 
Aboriginal peoples that is particularly apparent to "outsiders" such as myself who did not grow up in the prairies. My feminist perspective leads me to believe that young Aboriginal women's experiences, particularly with their body image, are influenced by the various social and cultural divisions that are inherent within this prairie province that I live.

The above-mentioned reasons have fostered my interest in the body image experiences of Aboriginal women. Interest in this area has also been furthered by the assumptions, and many of what I perceive to be the limitations, associated with much of the previous research that has explored women's body image. The ontological and epistemological assumptions that have shaped much of the previous body image research have promoted a limited understanding of women's body image experiences.

Body image is a construct that has received much attention in the academic domain, and body image discourse is also common among the general pubic. The term body image has been conceptualized by Bane and McAuley (1998) as "an umbrella term that encompasses perception cognitions, affect, and behaviors related to body image" ( $p$. 312). Although it has been recommended that body image be viewed as a multidimensional construct (Bane \& McAuley, 1998), perceptual measures of body image have typically been used by researchers interested in assessing body image (Blood, 2005). As a result, the diverse and complex emotions that individuals experience with respect to their bodies are often overlooked.

One of the primary ontological assumptions of traditional body image research is that the mind and body are separate, whereby perception is the connection between the two entities (Blood, 2005). Perception allows the body to be reduced to an object that the mind is able to see and think about. Given that the body has been envisioned simply as an object of perception, the body has typically been conceived as a stable object that is not invested with meanings (Blood, 2005). The realist ontological assumptions that have guided previous research have suggested that realities exist outside of the mind, and there is a truth or a reality that is apprehendable (Crotty, 1998). As well, the realist assumptions that have guided body image research have perpetuated the notion that

"Caucasian" in an effort to be consistent with classification standards used by Statistics Canada (n.d.). As well, compared to the term Caucasian, the term white is more consistent with other body image research that has included Aboriginal peoples (e.g., Marchessault, 2000; Story, French, Resnick, \& Blum, 1995). 
women's experiences with their bodies can be completely understood, and context-free generalizations can be applied to all women.

The realist ontological assumptions that have typically guided body image research have subsequently led to the epistemological assumption that there is an objective, knowable body image that can be measured and understood (Blood, 2005). Ontological and epistemological assumptions are more or less intertwined and, conceptually, researchers often have a difficult time trying to keep them apart (Crotty, 1998). For example, realist assumptions that realities exist outside the mind are often accompanied by objectivism, which is the epistemological assumption that consciousness is not needed to bring meaning to an object. Within the context of body image research, realist assumptions have often led researchers to believe that women are able to objectively and accurately perceive their own bodies (Blood, 2005). Subsequently, objective measures, such as the Body Cathexis Scale (Secord \& Jourard, 1953), which was developed over a half a century ago, are still being used in body image research to quantify women's experiences with their bodies. The majority of body image measures often highlight the body as women's “problem” (Bayer \& Malone, 1996); researchers have assumed that women have body image disturbances if they are unable to accurately estimate or perceive their body size. What is not recognized is that there are likely problems and limitations associated with such objective measures of body image (Bayer \& Malone, 1996). Women's experiences with their bodies can be very context specific, in that the body may be associated with different feelings at different times (Blood, 2005). However, objective measures do not support the subjective nature of women's body image experiences.

Body image research has consistently been guided by realist ontology and objective epistemology. Such assumptions are inconsistent with my own guiding assumptions, and are also contested by other feminist theorists (e.g., Bordo, 1993). Although the epistemological and ontological assumptions that constitute my world view may be shared by some other feminist researchers, I recognize that there are multiple feminisms associated with different epistemological and ontological assumptions. With regards to ontological assumptions, I support those of Creswell (1998) who said that there are multiple realities, such as the realities of the researcher, the participants, and the 
readers interpreting the research. In addition, these multiple realities are influenced by a number of social, political, gender, and ethnic factors (Guba \& Lincoln, 2004).

As a result of the power that is ascribed to the body, it is my assumption that most women, at some level, experience body-related concerns. I recognize that body concerns may be more prevalent among some women, but women are never able to totally escape such concerns; women's experiences with their bodies are socially produced and a product of power (Blood, 2005). Society perpetuates the notion that a women's body is her best attribute and that she should be able to adhere to the idealized norm of white, thin, toned, and flawless (Blood, 2005). Consequently, a woman's body is in the control of strong powers that impose constraints and obligations. More specifically, society imposes obligations of conforming to the norms of white, toned, and flawless, and when women feel that they are not achieving "normal" standards, it is inevitable that they experience feelings of inadequacy with respect to their bodies (Blood, 2005). Given the manner in which women's experiences with their bodies have been socially produced, their experiences are often embedded with similar themes. Having said this, there is considerable difference in the manner in which women understand and give meaning to such experiences.

My epistemological assumptions are consistent with those that have been articulated by Blood (2005). That is, individuals do not live in social vacuums and, therefore, women's experiences with their bodies are subjective. Thus, researchers must promote environments that support the subjective nature of women's body image experiences; the diversity and context-specificity of women's experiences must no longer be overlooked by traditional objective measures of women's body image. By engaging in group discussions and interviews with young Aboriginal women, it may be possible to better understand their experiences surrounding the body. Such methods allow for the illumination of women's experiences, which have been previously misunderstood or unexplored (Reinharz, 1992). Contrary to objective scales, interviews can promote a supportive environment for participants to express their ideas using their own words (Esterberg, 2002).

Epistemologically, my belief is consistent to that of Reinharz (1992) who stated that there needs to be a sense of connectedness between the feminist researcher and the 
participants. This sense of connectedness has been noticeably absent from conventional body image research. The relationship between the researcher and the participant in body image research has generally been, what Harding (2004) deems, politically unequal. Traditionally, it is the researcher who decides what social situation will be studied, what is problematic about the situation, and how the study will be organized, conducted, and interpreted (Harding, 2004). By involving participants in the various aspects of the research project I was committed to trying to alleviate the power imbalances that are so common in research (for further discussion see section 1.2.1). Despite strong efforts to alleviate power imbalances, I agree with Reid's (2000) contention that it is not possible to completely eliminate power imbalances between researchers and participants.

Nevertheless, by trying to minimize power imbalances, a sense of connectedness was fostered between myself and the participants, which subsequently supported the development of mutual trusting relationships.

I have outlined what I perceive to be my guiding assumptions, but as I grow and my own situational context changes, my feminist perspective and my underlying assumptions change with me; my standpoint is not static. Throughout this research process I had to, as stated by Doucet and Mauthner (2002), recognize my standpoint in terms of "personal, interpersonal, institutional, pragmatic, emotional, theoretical, epistemological and ontological influences" (p. 134). All aspects of research, including the design, interpretation, and reporting, are influenced by a researcher's assumptions (Crotty, 1998). Subsequently, Crotty emphasized the importance of researchers clarifying their assumptions. Having said this, Harding (2004) argued that researchers are not able to voluntarily identify all of the relevant assumptions that guide their research. She stressed that various philosophers and historians feel that this liberal assumption is self-deluding. Although Harding's position is justified, I still saw the need to explore my assumptions for the participants, future readers, and for myself. Highlighting my assumptions was important when trying to build trust and rapport with the participants. I am confident that the foundations of our relationships partially emerged from what the participants were able to understand about my guiding assumptions. In addition, future readers may be able to better understand what assumptions guided the various aspects of the research process (e.g., purpose, methods); 
thus allowing them to draw their own conclusions from the research. Finally, it was important for me to articulate my guiding assumptions because in doing so, I became more aware of my own values and beliefs. Because I do not typically need to explore and describe my values and beliefs, they are often easy to lose sight of. Therefore, although this process was challenging, it was also a rewarding experience.

The underlying assumptions of my feminist perspective was guided my recent Master's research (Fleming et al., 2006) whereby I worked to better understand young Aboriginal women's body-related emotional experiences. In addition, the limitations associated with previous body image research among Aboriginal women (see section 1.3.2) prompted my interest in this area. Particularly, the guiding assumptions of previous research encouraged me to engage in a research process that allowed for the voices and the multiple realities of young Aboriginal women to be heard. A brief description of my Master's research is provided below (a more detailed description of this research is provided in section 1.3.2).

The voices of the four young women who participated in my Master's research (Fleming et al., 2006) have contributed to the current body image literature in a number of ways. First, the young women indicated that their body-related emotional experiences may not be as negative as previous research has led us to believe. The feminist perspective that guided that research fostered an environment in which young women were provided with an opportunity to share their body-related emotional experiences, which may be in part why the findings varied from previous research. Second, the participants highlighted the complexity and context-specificity of young Aboriginal women's body-related emotional experiences. For example, the young women explained how they often feel that they are faced with conflicting views between their Aboriginal culture and mainstream white culture with respect to appropriate body size, eating habits, and clothing. Third, despite their belief that their experiences might not be as negative as depicted by previous research, they recognize that their body-related emotional experiences impact their health in a number of ways. Consequently, the participants recognized the importance of working with young women to implement some sort of action that is aimed at alleviating body concerns. 
In terms of this doctoral research, my previous research has played a fundamental role in furthering my interest and understanding of Aboriginal women's body image experiences. In addition, it strengthened my desire to engage in a participatory action research project with young Aboriginal women. As noted above, the young women in my previous research made the request for action; their request was consistent with my motivation to make a positive difference in the lives of young women.

Although I was motivated to continue engaging in research with young Aboriginal women, Gillies and Alldred (2002) indicated that some feminist researchers do not feel that researchers should speak for others. They highlighted how some feminist researchers argue that researchers should be limited to representations of themselves and their immediate communities; this remains an ongoing debate and dispute. The notion as to whether white and other non-Aboriginal peoples should engage in research with Aboriginal peoples, is a fairly controversial topic. Having said this, not all researchers (e.g., Bishop, 2005) are opposed to non-Aboriginal peoples being involved in research with Aboriginal peoples; but they are against non-Aboriginal peoples being involved "in the impositional ways of the past" (Bishop, 2005, p. 113; see section 1.3.1 for further discussion on Ethical Considerations). At the same time, some researchers feel that we may paralyze the development of important research projects if we get too caught up in "identity politics" (Smith, 1999). There are non-Aboriginal peoples who have the desire to support Aboriginal peoples, and they should be welcomed into research with Aboriginal peoples (Bishop, 2005).

I support Smith's (1999) contention that non-Aboriginal peoples have the potential to be allies in research with Aboriginal peoples. There are a number of nonAboriginal peoples who are becoming bicultural and who are willing to work in contexts that are controlled by Aboriginal peoples (Bishop, 1996). Bishop further asserted that it is the responsibility of non-Aboriginal peoples as treaty-partners to support Aboriginal peoples in research. Having said this, if non-Aboriginal peoples do engage in research with Aboriginal peoples, they must begin by establishing relationships at the beginning of research (Bishop, 1996). This doctoral research was carried out in the same school that I did my Master's research. Therefore, my previous research within that particular school allowed me the opportunity to readily establish relationships for my doctoral research. 


\subsubsection{Feminist Perspective}

A feminist perspective guided this research. Feminism is generally conceptualized as a perspective, rather than a method, because it can be applied to a range of existing methods in various fields of inquiry; thus, there are a variety of feminist perspectives and definitions of feminist research (Reinharz, 1992). Given the diversity of feminist perspectives, feminism has been described as a complex perspective in which there is no single feminist voice (Alway, 1995). Although there is variety among feminist research, the social construction of gender is typically at the center of inquiry; gender shapes the existing conditions and the experiences of individuals (Lather, 1991). Maguire (2001) furthered this discussion by explaining how gender intersects with various other forms of oppression such as class, race, and sexual orientation. Feminist researchers argue that the distribution of power and privilege is shaped by gender (Lather, 1991). As a result, feminist researchers often focus on critiques of patriarchal assumptions in an effort to shed light on the politics of gendered differences in society (Luke, 1992).

Although feminist research is varied, this type of research has a number of common distinguishing characteristics. Generally speaking, feminist research is politically motivated in that it originated from the social movement that challenged the subordination of women (Alway, 1995; Maguire, 2001). Feminist research is also distinct from traditional research in that it is a voice-centered approach to research; it is grounded in the experiences and stories of women (Way, 2001). An attempt to alleviate power imbalances between the researcher and the participants is also a common characteristic of feminist research (Alway, 1995; Taylor, 1998; Way, 2001). Many feminist researchers engage in research that involves participatory methods in an effort to break down the often perceived hierarchy between the researcher and the researched (Taylor, 1998). Finally, commitment to action might be one of the most distinguishing characteristics of feminist research. Olesen (2000) emphasized how feminist research often sets the stage for action and change, and Taylor (1998) described how feminist research often leads to some form of action that benefits a particular group of women. Denzin and Lincoln (2000) took this notion one step further by declaring that feminist research is always committed to action. These basic defining attributes of feminist 
research, particularly the commitment to action, coincide with my own motivations and goals as a researcher, thus justifying my identification as a feminist researcher.

Using feminism as a paradigm for researching women's experiences has been recommended by Alway (1995). Similarly, Piran (1996) acknowledged the important role feminism plays in supporting young women in sharing stories about their bodies. Power discourse is inherent within feminist research and research involving women's bodies; thus, there was strength in approaching this study from a feminist perspective. Contrary to conventional positivist worldviews, research that is approached from a feminist paradigm can be used to "produce less false, less partial, and less perverse representations without making any claims about what is absolutely and always true" (Alway, p. 225). In other words, feminist research has the ability to highlight and respect the diversity among women. In turn, feminist research has the potential to uncover the complexities surrounding women's health issues, such as body image experiences. The positivist methodologies that have generally dominated health research have provided a limited understanding of women's health issues (Stein, 1997). Feminist research allows researchers the opportunity to hear women's voices; consequently, it may help to advance women's health research. Such possibility for advancement and change has been put forward by Piran (2001) who acknowledged how transformation lies within the lived experiences of young women, which are often discovered through dialogue.

Although I support feminist perspective, Weenie (2000) argued that privileged white feminists are not able to reflect the experiences of Aboriginal women. Feminism has also been criticized because some believe that such a perspective continues to marginalize the concerns of women of color and ignores the issue of racism. For example, Thornhill (1989) argued that the term "woman" within feminist theory has become synonymous with "white woman", which in turn implies that nonwhite women are "others" and "nonhumans" (p. 27). Similarly, Ouellette (2002) declared that many feminist theories are incompatible with the beliefs of various Aboriginal women. She stressed that it is racism and not sexism that is the main barrier to "liberation" for Aboriginal women. Along the same lines, Stevenson, Johnson, and Greschner (1992) suggested that feminists and Aboriginal women are in similar but separate movements. They explained, "while feminists and Indigenous women have a lot in common, they are 
in separate movements. Feminism defines sexual oppression as the Big Ugly. The Indigenous women's movement sees colonization and racial oppression as the Big Uglies" (Stevenson et al., 1992, p. 159). Stevenson et al. (1992) recognized that there are similarities between the two movements and Weenie (2000) explained how the similarities are the result of the unequal power relationships that constitute the foundation of patriarchy, racism, and sexism.

It is a somewhat contested issue as to whether feminist perspective is the most appropriate guiding perspective for those individuals engaging in research with Aboriginal peoples. However, some Aboriginal scholars (e.g., Cannon, 1998) have supported the use of feminist theory when engaging in research with Aboriginal peoples because they see colonialism and patriarchy as synonymous. Despite critique of the use of feminist perspective in research with Aboriginal peoples, it is important again to point out that there is variety among feminist perspectives. Therefore, the label of "feminist research" is not most important; what is important is that research is approached from a standpoint that is consistent with the values and beliefs of the researchers (see section 1.3.3 for further justification of using a feminist approach to participatory action research with Aboriginal peoples). Regardless of the guiding assumptions, researchers need to become more aware and responsive to the ethical considerations that have unfortunately been commonly overlooked by health researchers who have engaged in research with Aboriginal peoples.

\section{3 REVIEW OF LITERATURE}

This section will begin with an overview of the general Ethical Considerations (section 1.3.1) that were used to guide this research. Next, an overview of the research literature that has explored Aboriginal Women's Health and Body Image Experiences (section 1.3.2) will be provided. A broad exploration of the reported health of Aboriginal peoples will provide a foundation for the body image experiences of Aboriginal women to be better understood. This research will also be discussed in terms of how the health of Aboriginal women has been influenced by colonization. Although there are a variety of factors that influence health, the body image experiences of young Aboriginal women will be explored in detail throughout this section. This section will end with a description 
of Participatory Action Research (section 1.3.3) and the strengths of employing such an approach when engaging in health research with young Aboriginal women.

\subsubsection{Ethical Considerations}

Prior to engaging in research with Aboriginal peoples, it is important to identify and describe the Eurocentric assumptions that have guided and, subsequently, limited previous research. By acknowledging the detrimental role of Eurocentric assumptions it is possible to shed light on some of the assumptions that contemporary researchers, such as myself, need to avoid. Furthermore, by exploring the detrimental impacts of Eurocentric assumptions it is possible to identify important ethical considerations that must not be overlooked when engaging in research, particularly cross-cultural research, with Aboriginal peoples.

Eurocentrism has been defined by Battiste and Henderson (2000) as an imaginative context that is used to inform much of society. It is the process by which European cultural assumptions are constructed as "reality"; thus, it suggests European superiority over non-Europeans (Ashcroft, Griffiths, \& Tiffin, 2000). Eurocentric dominance has continually challenged the knowledge of Aboriginal peoples (Battiste, 2002). Because of Eurocentric assumptions and the process of colonization, Aboriginal worldviews and other conceptions of reality were often perceived as "primitive", and Western reality was thought to represent something "better" (Smith, 1999). Furthermore, since research is often deeply embedded in colonization, many Aboriginal peoples view research itself as a colonizing tool (Smith, 2005). As noted by Smith (1999), research has led to policies that have intruded into every aspect of Aboriginal peoples lives; subsequently, "research, is probably one of the dirtiest words in the indigenous world's vocabulary" (p. 1). Because of its colonizing potential, research should not be viewed as an innocent exercise, but instead as an activity in which something is at stake (Smith, 1999).

Researchers engaging in science research, or positivist research, have to be particularly cautious of the Eurocentric assumptions that guide their research because the notion of what constitutes "science" is often at odds with Indigenous ways of thinking (Smith, 2000). Smith (2000) argued that positivism, which is derived from empiricism, assumes that the natural world can be examined and understood. Furthermore, the notion 
of science initiates a positivist worldview that encourages individuality, competition, and regulations. This worldview contrasts an Indigenous perspective, which is rooted in collectivity, cooperation, and responsibility (Smith, 2000).

In an effort to expose the colonizing potential of science research, researchers need to develop a critical perspective on science (Smith, 2000). Battiste and Henderson (2000) explained that Eurocentric assumptions about the natural world are not well supported by research, yet colonization is still being used to carry these assumptions. If researchers continue to support assumptions surrounding science within the research community, they are in danger of supporting the belief of Eurocentric superiority (Smith, 2000). Building upon this notion, Smith (2005) explained how researchers have to try to decolonize the epistemological foundations that support this research. Similar to the majority of body image research, objective epistemological assumptions have guided the research that has been traditionally undertaken in Aboriginal communities.

Consequently, Aboriginal peoples have been distanced from the construction and legitimization of knowledge (Bishop, 2005). As part of the process of decolonization, Battiste and Henderson explained that Aboriginal and non-Aboriginal scholars are interrogating contemporary knowledge systems within all fields of social thought. By way of interrogation, these scholars have been able to expose the Eurocentric underpinnings of social research that have been accepted as a result of the widely held belief that Eurocentric thought is superior (Battiste \& Henderson, 2000).

Because of the various consequences of colonization on research institutions, Aboriginal peoples have asked for new standards of ethics that "speak to the multiple responsibilities of researchers and institutions" (Battiste, 2002, p. 34). The intent of the remainder of this section is to identify the multiple responsibilities of researchers and institutions, and to highlight the various ways in which I tried to foster an environment that adhered to these responsibilities.

The single most important ethical principle of Aboriginal research is that Aboriginal peoples should have control of their own knowledge (Battiste, 2002). This principle is particularly important for those people engaging in research in cross-cultural contexts because, generally speaking, this principle has not been adhered to. Since customary approaches to research have typically distanced Aboriginal peoples from the 
construction and legitimization of knowledge, Bishop (2005) noted that Aboriginal peoples have many concerns about who is in control of the research and who will benefit from this research. Ethical conduct is generally about protecting the individual and, therefore, issues of ownership and benefit are often overlooked (Smith, 2005). Battiste stressed that the only way researchers can ensure that Aboriginal peoples are in control of research is to involve Aboriginal peoples throughout the whole research process. The methodological approach utilized within this research (i.e., participatory action research) provided participants with the opportunity to participate throughout the whole research process. However, as noted in section 4.1.1, participants chose not to be actively involved in some of the more academic aspects of this research (e.g., writing of dissertation).

In addition to exploring the ethical principle of who controls and benefits from research, Smith (2005) explained how, at a very basic level, research ethics is about "establishing, maintaining, and nurturing reciprocal and respectful relationships" (p. 97). She explained how in addition to entering preexisting relationships, researchers need to build and maintain relationships. In an effort to do this, throughout my research I constantly focused my efforts on building rapport and developing trust (see section 3.1.1). The development and maintenance of relationships is crucial for researchers; relationships are even more important for those engaging in research in cross-cultural contexts because these researchers often enter new environments without preexisting relationships. Thus, researchers have the added responsibility of establishing many new relationships within a culture that may be different than the culture with which they are more familiar (Harrison, 2001). Smith argued that the process of research, especially in terms of relationship development, is often more important then the outcome of research.

Issues of ethical conduct for research within Aboriginal contexts are generally framed around the concepts of humanity and "human rights" (Smith, 2005). Nevertheless, since ethical discussions are often entrenched in Western moral philosophy, she argued that research ethics are generally about institutional or professional codes of conduct rather than the aspirations and/or needs of Aboriginal communities. The Guidelines for Ethical Research in Indigenous Studies (as developed by the Australian Institute of Aboriginal and Torres Strait Islander Studies) highlighted human rights as an 
important ethical consideration when engaging in research with Aboriginal peoples (Smith, 2005). The guidelines speak to the importance of intellectual property rights, even though this is something that has typically been overlooked by researchers engaging in cross-cultural research (Battiste, 2002). As a consequence of this critical oversight, intellectual property rights are a dimension of ethical conduct that needs specific consideration (Harrison, 2001). Furthermore, because there is little legal protection for the intellectual property rights of Aboriginal peoples, it is particularly important for nonAboriginal people to work as advocates for these rights.

In addition to the recognition of the importance of intellectual property rights, the Guidelines developed by the Australian Institute of Aboriginal and Torres Strait Islander studies highlighted three primary principles. The principles are particularly useful for individuals engaging in cross-cultural research because they highlight topics typically overlooked in ethical guidelines that have been developed from a more Western perspective. The three principles include consultation, respect, and benefits (Smith, 2005). The principle that Aboriginal communities must benefit from the research has already been briefly discussed. Similarly, I will briefly discuss the principles of consultation and respect.

An important aspect of consultation is negotiation and mutual understanding (Smith, 2005). As one aspect of negotiation, Smith (1999) encourages researchers, especially those engaging in research in cross-cultural contexts, to critically examine the process of consent. Generally speaking, contemporary researchers are familiar with the process of gaining informed consent because it is a requirement from most ethics committees within research institutions. However, it has only been within the last few decades that informed consent has become an important ethical issue (Harrison, 2001). Along with informed consent, Harrison described the importance of confidentiality. For Aboriginal peoples consent and confidentiality is often about credibility and trust, which must be constantly negotiated because of its dynamic nature (Smith, 1999). As well, given the ever-changing contexts in which qualitative research generally takes place, Munhall (2001) argued that informed consent should be "renegotiated" over time and it should be a continuous process. In describing their "ethics-as-process approach", Cutcliffe and Ramcharan (2002) described how researchers should make an initial 
attempt to obtain informed consent, but it is also critical to reassure participants that matters of consent will be readdressed throughout the research process and whenever the participants deem necessary. As suggested by Smith (1999), the process of consent and confidentiality are not simply ethical processes in which the participants tick a box, but they are processes of negotiation that researchers must continually engage in. Again, by involving participants throughout the whole research process, it was possible to constantly negotiate consent and confidentiality.

Many Aboriginal communities might not understand the history of ethical codes of conduct given their Western roots, but they do understand when respect has been breached (Smith, 2005). The principle of respect is embedded in all ethical protocols and it embraces a number of complex social meanings (Smith, 2005). Building upon the notion that respect embraces multiple meanings, Smith (1999) illustrated how respect can be described by Aboriginal communities in a variety of ways (e.g., trustworthiness, integrity). Furthermore, respect is evaluated in terms of everyday practice, and Aboriginal communities make assessments of integrity (respect) at every interaction. Researchers might be assessed based on the way they speak, dress, or even eat (Smith, 1999). Therefore, in an effort to define ethical behaviours for a particular community, it is important to work with community members to develop "bottom-up" definitions of respect (Smith, 1999). Similarly, Harrison (2001) suggested that researchers seek out opinions on ethical behaviours from the people of the community in which they intend to work. Therefore, within this research, I continually engaged in informal conversations with the participants in an effort to better understand the types of behaviors that they deemed ethical.

As previously mentioned, there is some dispute as to whether non-Aboriginal peoples should engage in research with Aboriginal peoples. Although I trusted in my intentions as a researcher, there were a number of additional considerations that $I$, as a non-Aboriginal woman, could not overlook when engaging in this research with Aboriginal peoples. Based on her own experiences as a non-Aboriginal person engaging in research with Aboriginal peoples, Haig-Brown (2001) described how non-Aboriginal researchers must ensure that Aboriginal peoples speak first and last in research. This speaks to the importance of critically examining who is in control of the text (Borland, 
2004). Researchers might assist Aboriginal peoples in articulating their concerns, but speaking for them is only denying them self-determination (Battiste, 2002). By ensuring Aboriginal peoples are involved in the entire research process it was possible to avoid a type of discourse (Eurocentric discourse) that Smith (1999) described as never innocent. Throughout this research, I was committed to encouraging Aboriginal peoples to be involved in the research process so that they felt that their ownership over their knowledge was respected.

Regardless of whether it is non-Aboriginal or Aboriginal peoples who are engaging in research with Aboriginal peoples, ethical guidelines have been developed by a number of organizations and researchers and these guidelines were adhered to throughout this research. The organizations include, but are not exclusive to, the Royal Commission on Aboriginal Peoples (RCAP), the Canadian Institutes of Health Research (CIHR), and the Saskatoon Aboriginal Women's Health Research Committee. According to Smith (2005), many concepts of respect or ethics have been defined through Western eyes and, in light of this, the above-mentioned organizations and committees requested the help of various Aboriginal peoples in the development of their guidelines. Prior to describing specific guidelines, CIHR (2007) emphasized the importance of establishing an ethical space, whereby the values and beliefs associated with research projects are expressed and negotiated (CIHR's [2005] Draft Guidelines were originally used during the proposal stage of this PAR project). They explained how the establishment of such a space requires dialogue throughout all phases of the research process. The collaborative and participatory nature of this research project fostered an environment where such dialogue could continuously occur. The development of an ethical space was particularly important for this research that involved Aboriginal and non-Aboriginal peoples because such a space offered "a valuable means of negotiating norms and understandings and bridging gaps between Aboriginal and non-Aboriginal societies" (CIHR, 2005, p. 12).

Prior to the development of guidelines by CIHR (2007), RCAP (1996) proposed guidelines for engaging in research with Aboriginal peoples; these guidelines have been described as the standard of "best practice" that are accepted by this Commission. Similar to those outlined by CIHR, RCAP proposed guidelines that address, for example, 
the importance of gaining informed consent, the level of confidentiality that can be assured, and the importance of not pressuring participants to participate. In addition to guidelines that have been developed for research involving the general Aboriginal population, the Saskatoon Aboriginal Women's Health Research Committee with support form the Prairie Women's Health Centre of Excellence developed ethical guidelines that are specific to Aboriginal women's health research (Prairie Women's Health Centre of Excellence, 2004). The Aboriginal women on this committee felt that it was important to develop guidelines that could help create relevant and accurate research; the guidelines were developed for the committees own work as well as for other researchers. The committee described guidelines that include the importance of informed consent, engaging in collaborative research, reviewing research results with the Aboriginal community prior to publication, and assuring that researchers consider the benefits and costs of the research to the community. The guidelines have been developed so that researchers can engage in research that gives respect to the knowledge, cultures, values, and languages of Aboriginal peoples. Again, these various guidelines played a strong role in guiding this research.

Consistent with the suggestions, principles, and guidelines outlined by various Aboriginal scholars (e.g., Battiste, 2002; Battiste \& Henderson, 2000; Bishop, 2005; Harrison, 2001; Smith, 1999, 2005) and various organizations and committees (e.g., RCAP; CIHR; Saskatoon Aboriginal Women's Health Research Committee), Smith (1999) also identified a number of ethical questions that should be addressed by researchers engaging in research in cross-cultural contexts. These questions address issues such as whom will benefit from research and for whom the research is relevant. This list is not exclusive with respect to the ethical questions that must be addressed by researchers involved in cross-cultural contexts; nevertheless, it does provide a good starting point. Throughout this research process, I continually addressed the questions that are specific to my role as a non-Aboriginal person engaging in research with Aboriginal peoples.

Finally, in addition to addressing the above-mentioned questions and adhering to ethical guidelines set forth by various Aboriginal scholars and organizations, prior to beginning this research I participated in a number of activities in an effort to strengthen 
my ability to engage in ethical and respectful research with Aboriginal peoples. In her recent research with an Aboriginal man with Quadriplegia, Lloyd (2008) also explained how she "undertook preparation to carry out research with an Aboriginal person" (p. 45). Among other things, she described her participation in a community outreach program in Native Studies and a seminar that focused on research ethics associated with working with Aboriginal populations. Similar to Lloyd, I participated in two workshops offered through the University of Saskatchewan; one workshop was focused on respectful research with Aboriginal peoples and the other was a forum on the cultural representation of Aboriginal peoples. In addition, I engaged in an online Aboriginal Awareness Program that was offered by Achak Solutions in Saskatoon; this program shed light on the manner in which Aboriginal peoples should be respectfully accessed and understood. I also completed a course, Decolonizing Aboriginal Education, which was offered at the University of Saskatchewan and was lead by Marie Battiste, a leader in the area of ethics in research with Aboriginal peoples. I am confident that the experiences I gained from engaging in these activities have supported my development as a researcher who is committed to engaging in respectful research with Aboriginal peoples.

\subsubsection{Aboriginal Women's Health and Body Image Experiences}

Canada is often rated as one of the best countries to live because of its high quality of life but, as RCAP (1996) indicated, there is a large gap between the quality of life of Canada's Aboriginal and non-Aboriginal peoples. The Commission identified two realities in Canada; one in which individuals are experiencing a high quality of life and another where Aboriginal peoples are experiencing physical, emotional, and social ill health. Regardless of the manner in which ill health is conceptualized (e.g., physical, emotional, individual, community), Aboriginal peoples, and Aboriginal women in particular, experience more ill health than the general Canadian population (Bent \& Ross, 2004; RCAP, 1996). Nevertheless, research has not placed enough focus on the unique health needs of women (Young, 2003). Receiving even less attention are the health needs of non-white Canadians (McIntyre, 2001), including Aboriginal women. The health of young Aboriginal women is an important area of research because, in terms of the

general Canadian population, there are a large number of young Aboriginal women residing in Canada, with the most Aboriginal women living in Saskatchewan and 
Manitoba (Prairie Women's Health Center of Excellence, 2001). Although the health of all Aboriginal peoples is important, the majority of Aboriginal peoples (i.e., 56.2\%) in Canada are under the age of 25 (RCAP, 1996). Therefore, by working with Aboriginal youth in addressing important health issues, researchers are ultimately addressing the health of the broader Aboriginal population.

Numerous studies have described the ill health of Aboriginal peoples. For example, MacMillan, MacMillan, Offord, and Dingle (1996) stated that Aboriginal peoples' morbidity and mortality rates are higher than those of the general Canadian population. Similarly, Wilson and Rosenburg (2002) noted that although infectious diseases are declining, experiences with chronic illnesses are rising among the Aboriginal population. In terms of indicators of ill health, researchers have said that Aboriginal peoples have life expectancies that are below the life expectancies of non-Aboriginal Canadians, and infant mortality among Aboriginal peoples is two times higher than that of non-Aboriginal Canadians (Statistics Canada, 2003).

The health of Aboriginal peoples is influenced by a number of physical, mental, emotional, and spiritual factors (RCAP, 1996). Similarly, the Public Health Agency of Canada (n.d.) has indicated that a number of health determinants help us to better understand what influences the health of Canadians. Factors such as gender, income and social status, and education have been identified as determinants of health and have been integrated into the Population Health Approach. This approach to determining health appears to be fairly consistent with Aboriginal concepts of health, and researchers in Aboriginal communities agree that the health of Aboriginal peoples is influenced by a number of social, political, and economic factors (Deiter \& Otway, 2001).

When engaging in health research with Aboriginal peoples, therefore, it is important for researchers to explore the various factors that contribute to the poor health status of Aboriginal peoples. Fortunately, many contemporary researchers are including a discussion of the various factors, particularly those associated with colonization, that contribute to poor health. For example, Deiter and Otway (2001) explained how the health and well being of Aboriginal peoples in Canada, particularly Aboriginal women, was negatively affected by colonization. The role of Aboriginal women in society changed when colonizers introduced male-dominated family structures in which women 
were encouraged to become economically dependent on men. Bent and Ross (2004) argued that the poor health of Aboriginal women may be the result of the contentious belief that they are doubly marginalized in terms of their Aboriginal and female status. This belief is consistent with the work of various feminist researchers (e.g., Collins, 1986; Olesen, 2000) who insist that the experiences of women, including their health experiences, are influenced by a number of interrelated factors, such as gender, ethnicity, and class.

The inequalities in health status that have resulted from colonization are ever present and are not the result of an "inherent Aboriginal trait" but instead political, economical, and social disparities (Adelson, 2005; McIntyre et al., 2001). Various aspects of Aboriginal peoples' lives, including their identities, have been influenced by colonization. Aboriginal peoples have had their languages and customs stripped from their lives, and the process of colonization has led to laws that regulate their identities (Smith, 1999). For example, in 1876 the government of Canada implemented the Indian Act, which provided the first constitutional definition of who was an "Indian" (Frideres \& Gadacz, 2001). However, since this time, the federal government has continued to revise the legal definition of "Indian". Various revisions and amendments (e.g., Bill C-31) have been made to the Indian Act (Cannon, 2008; Newhouse, 1999), but Aboriginal peoples' identities are still defined, at least in a political sense, by the Canadian government. As well, as a result of the manner in which the identities of Aboriginal peoples have been regulated by the Canadian government, no single definition of Aboriginal peoples has been agreed upon.

The intent of this discussion of colonization is not to classify or generalize Aboriginal peoples' experiences with colonization because, as stated by Battiste (2000), it is important to understand the "multiple layers of experience and knowledge about colonization" (p. xvii). A thorough review of the multiple layers of knowledge about colonization would be well beyond the scope of this dissertation. The intent here is to recognize that colonization has had, and still continues to have, a direct impact on the health of Aboriginal peoples. More specifically, the intent is to recognize the role that colonization may have on the body image experiences of young Aboriginal women. To do so, it may be beneficial to begin with a brief overview of the work of previous 
researchers who have attempted to expose the various ways in which colonization has impacted the health of Aboriginal peoples.

The removal of children into residential schools, the creation of the reserve system, and providing inadequate services (including health services) to those individuals living on reserves, have all been described as various acts of colonization (Adelson, 2005). Adelson (2005) argued how such poor treatment has likely influenced the health of Aboriginal peoples. Similarly, RCAP (1996) has indicated that ill health experienced by Aboriginal peoples is the consequence of a number of social and economic factors such as racism and discrimination. A similar statement has been echoed by Adelson who said that colonization has been linked to the poor health of Aboriginal peoples because colonization has created "inherently racist attitudes towards Aboriginal peoples" (p. 46). Racist attitudes continue to promote the belief of Eurocentric superiority and, unfortunately, individuals who possess such attitudes are often the ones to define the health "problems" experienced by Aboriginal peoples. This is particularly troublesome since the way a problem is viewed will inevitably impact the way the problem is studied and solved (O’Neill, 2005).

Although colonization has negatively impacted the health of Aboriginal peoples, Aboriginal peoples are gradually regaining control over the various conditions that affect their health (McIntyre et al., 2001). Similarly, Newhouse (1999) argued that although various forms of poverty are masking the incredible achievements (e.g., political move towards self-governance) of Aboriginal peoples, Aboriginal peoples have managed to build a strong foundation for future generations. The future of Aboriginal peoples looks hopeful given the strong focus on "Aboriginal issues" by many government agencies. In addition to political achievements, Newhouse explained how numerous other areas such as health care are seeing strong developments. For example, Aboriginal health centres have been established in various locations across Canada. Nevertheless, Aboriginal people continue to be described as victims, and attention is continuously focused on the social problems experienced rather than on the profound, positive changes that are occurring.

When Aboriginal peoples are viewed as a "social problem", or when research involving Aboriginal peoples is carried out using a "social problems approach", realities 
are consequently distorted (Laroque, 1993). Individuals are often viewed as the problem, while the problems with the larger systemic social conditions are often overlooked (O’Neill, 2005). Laroque (1993) argued that although Aboriginal peoples experience a number of socioeconomic problems, there is more to the lives of Aboriginal peoples (e.g., positive political changes). Nevertheless, the view that Aboriginal peoples are a social problem is so widespread that various aspects of our society (e.g., television, radio, academic works) are unable to see that there are healthy Aboriginal individuals and communities (Laroque, 1993). Research that uses objective measures (e.g., traditional body image research) continues to perpetuate the belief that Aboriginal people are unhealthy; such measures do not allow for the illumination of diverse experiences. For example, the young Aboriginal women who participated in my Master's research (Fleming et al., 2006) suggested that body-related concerns might not be such a "problem" among young Aboriginal women. Therefore, the problem could likely be attributed to the voiceless, objective measures that have typically been used to measure Aboriginal women's body image.

The voices of Aboriginal peoples have been noticeably absent from the discourse that has classified Aboriginal peoples as a social problem. Steckley (2003) highlighted the works of various sociologists who have omitted, disqualified, or criticized the voices of Aboriginal peoples. Consequently, Aboriginal peoples are often depicted as powerless, whereas all other individuals or "ordinary citizens" (i.e., anyone who is not Aboriginal) have the potential to take action on social problems (Steckley, 2003). The notion that Aboriginal peoples have the power to combat the various social problems seems to be completely overlooked. However, such a notion should not be so readily dismissed given that many Aboriginal peoples have experienced changes in the ways they view themselves. Generally speaking, Aboriginal peoples now see themselves as having power and the ability to create change (Newhouse, 1999). This notion is quite different than that of fear, which was the case just a few decades ago when the government introduced "A statement of Indian Policy", or the "White Paper" as it is commonly referred (Newhouse, 1999). The White Paper proposed the repeal of the Indian Act; which resulted in feelings of fear and anger among Aboriginal peoples (Newhouse, 1999). In an effort not to perpetuate feelings of fear and distrust among Aboriginal 
peoples, it is important to include Aboriginal peoples in all Aboriginal discourse and Aboriginal research. Participatory action research promotes the belief that Aboriginal peoples have the knowledge and power to control the situations in their lives.

Even though much of the research exploring the health of young Aboriginal women emphasizes the persistence of ill health, researchers such as Adelson (2005) have highlighted the ways in which the health of some Aboriginal peoples may be improving. For example, Aboriginal children are staying in school longer than they have in the recent past, which may be particularly good news in the area of health research because health is positively associated with educational achievement. In addition, self-reported measures of health among young Aboriginal women appear to tell a more optimistic story. The Aboriginal Peoples Survey (APS), which included measures of self-reported health, indicated that only $6.4 \%$ of non-reserve Saskatchewan Aboriginal women between the ages of 15 and 24 years identified their health as "fair" or "poor", whereas $69 \%$ described their health as "very good" or "excellent" (Statistics Canada, 2003). Such findings are comparable to the general population of young Canadian women.

As indicated by self-reported measures of health in the APS, young Aboriginal women may not be experiencing ill health more than non-Aboriginal women (Statistics Canada, 2003). Such findings highlight a discrepancy between research that includes self-reported measures of health and those that do not. Although young Aboriginal women may experience a disproportionate burden of ill health, it is also possible, as stated by Maar (2004), that many of the health disparities are poorly understood from the typical biomedical perspective, which suggests that the physical body is the sole indicator of health. Such a perspective on health is inconsistent with an Aboriginal perspective, as health involves not only the physical aspects of a person, but emotional, mental, and spiritual (RCAP, 1996). Aboriginal health is a very complex issue (Deiter \& Otway, 2001). Therefore, if we, as researchers, continue to adhere to traditional assumptions regarding health when engaging in research with Aboriginal peoples and do not try to understand the complexities surrounding the health of Aboriginal peoples, research may be limited in that the findings may be founded on possible misconceptions surrounding the term health. 
A first step is to explore what health means to Aboriginal peoples. When asked to define health, Aboriginal women who took part in Deiter and Otway's (2001) survey explained how health includes exercise, good diet, adequate food and rest, and no substance abuse. In addition to the various aspects of the physical self that are important to consider for overall health, the women in Deiter and Otway's (2001) study explained how health is holistic in that it also involves emotional and spiritual components. As previously noted, this comprehensive description of health is very consistent with RCAP's (1996) definition of health. Interestingly, and expanding upon contemporary conceptualizations of health, many of the women in Deiter and Otway's study explained how a positive attitude is important in maintaining good health, and some even explained how happiness is important for health. Furthermore, some of the participants explained how it is important to deal with stress if an individual is to be healthy.

As noted in the above examples, many of the women in Deiter and Otway's (2001) study explained how health is holistic. Building upon this notion of health being holistic, the women described the importance of community and how health is not just an individual responsibility but also a community responsibility. Participants explained how the health of one person can affect the health of others in the community. Along the same lines, RCAP (1996) described how community and social dynamics are partially responsible for the health and well-being of individuals, and that ill health can only be alleviated through collective action. The recognition of health as a community responsibility provided initial justification for this proposed community-based participatory action research project.

Although there are a number of factors that influence health, overweight status is often linked to poor health. Many people are aware of the detrimental effects of overweight status on physical health (e.g., increased likelihood of diabetes); however, overweight status is also associated with negative body perceptions (e.g., body dissatisfaction), which in turn may have a serious impact on the emotional health of women (Paquette \& Raine, 2004). Researchers have highlighted the various ways in which body-related concerns can impact health among the majority white population, but few have extended this research to include young Aboriginal women. The little research that has included Aboriginal women has typically utilized quantitative methods (e.g., 
Gittelsohn et al., 1996; Marchessault, 2004; Neumark-Sztainer, Story, Resnick \& Blum, 1997; Story et al., 1994; Story, French, Resnick, \& Blum, 1995), and has generally indicated a high prevalence of body dissatisfaction among young Aboriginal women. For example, Story et al. (1995) found that Aboriginal women tend to be less satisfied with their bodies than young white women from similar rural areas. Similarly, Gittelsohn et al. (1996) showed that $61.3 \%$ of a total 729 individuals living in an Ojibway-Cree community in Northern Canada desired a thinner shape and that only $16 \%$ of these individuals were satisfied with their current shape. Likewise, Neumark-Sztainer et al. (1997) conducted a study that included over 11,000 Aboriginal peoples and found that increasing overweight status was associated with increase in low body pride, body dissatisfaction, and weight concerns.

Although the above-mentioned studies that have explored Aboriginal women's body image experiences have been able to provide statistical information on large groups of individuals, the findings from such studies are limited primarily because they are generated from quantitative research that does not provide information on context. As previously mentioned (see section 1.2), the majority of body image research is limited by the ontological and epistemological assumptions that guide such research. The closedended response surveys used in the majority of body image research are guided by the assumption that women's experiences with their bodies are singular; the possibility that a woman can have different feelings about her body at different times is not considered (Blood, 2005). The outcomes of such survey research present findings that suggest that women are one homogeneous group; differences of ethnicity, culture, physical ability, and sexual orientation that influence women's experiences are ignored (Blood, 2005). The notion that all women, or even that all Aboriginal women, experience the exact same body image experiences is inconsistent with my feminist assumptions.

Regardless of the limitations, findings from previous body image research with Aboriginal women should be concerning to health researchers because a relationship has been highlighted between body dissatisfaction and a variety of health compromising behaviours. More specifically, concerns with body appearance, particularly among white women, have been associated with smoking, avoidance of physical activity, decreased self-worth, and dietary restraint (Fox, 1997; French, Perry, Leon, \& Fulkerson, 1994; 
Friedstad \& Klepp, 1997; Leary, 1995; Page \& Fox, 1997). In trying to understand the link between body-related concerns and health behaviours, self-presentation theory might be useful. Self-presentation or impression management is the process by which individuals try to control how they are perceived by other people; almost all behaviours are affected by self-presentational motives (Leary, 1995). Like most other social behaviours, self-presentation can vary in the extent to which it involves controlled or automatic processes (Schlenker, 2003). Individuals exist in a social world, and whether it is of primary or secondary concern they are rarely free of the concerns of how others perceive them (Leary, 1995).

Although self-presentation concerns generally encourage us to behave in socially appropriate ways, Leary (1995) explained how concerns with others' impressions could also be problematic. For instance, individuals may become too concerned with trying to manage others' impressions that they engage in behaviours that are harmful to themselves and others. Therefore, if young women feel that smoking or dieting may help them to look better, it is possible that they will engage in these harmful health behaviours in an effort to manage other's impressions. Although the bulk of current self-presentation research has been based on studies that involved white participants, it is likely that the health of young Aboriginal women would also be impacted in a number of ways, if they experience concerns surrounding their bodies. Nevertheless, research that has involved Aboriginal women has typically utilized quantitative methods, and such methods provide little detail about young Aboriginal women's body image experiences or the impact of these experiences on health.

Few researchers have used qualitative methods to explore the health of Aboriginal women, despite research demonstrating the strength of utilizing qualitative methods when engaging in exploratory research with Aboriginal women (e.g., Wilson, 2004). Of the few who have utilized qualitative methods, Marchessault (2000) employed semistructured interviews as one method for comparing weight perceptions among Aboriginal and non-Aboriginal girls and their mothers. Findings from the interviews suggested that Aboriginal women do not view weight as a central component to female identity; nevertheless, findings from the use of quantitative surveys suggested that body dissatisfaction was higher in Aboriginal women and girls when compared to non- 
Aboriginal women and girls (Marchessault, 2000). These somewhat contradictory results highlight the complexity surrounding Aboriginal women's body image experiences, thus highlighting the need for more qualitative research.

Recognizing the manner in which qualitative methods can shed light on issues that are not well understood, Poudrier and Kennedy (2008) engaged six Aboriginal women from the Battleford Tribal Council region of Saskatchewan in a community consultation (i.e., sharing circle and focus group) in an effort to better understand their perspective on healthy body weight and body image. The women in their study suggested that notions of the "healthy body" should not be based on weight; they argued that feeling positive about one's body is also important. As well, the participants suggested that it is important to have a positive attitude and to promote community wellness if healthy body weight and body image are going to be maintained. Overall, their findings suggest that in order to enhance community programming that is focused on healthy body weight and body image, it is important to work with women to better understand the meanings that Aboriginal women give to the "healthy body".

My Master's research, carried out with the guidance of my committee members, is one of the first studies that used qualitative methodologies to exclusively shed light on the body-related emotional experiences of young Aboriginal women (Fleming et al., 2006). Using qualitative methods such as focus groups and one-on-one interviews, the participants were able to articulate how the body-related emotional experiences of young Aboriginal women are complex and context specific. These young women provided many examples of how they are faced with conflicting cultures, thus emphasizing the complexities of their body-related emotional experiences (Fleming et al., 2006). The young women explained how they often feel that they are faced with conflicting views between their Aboriginal culture and mainstream white culture with respect to appropriate body size, eating habits, and clothing. This finding is supported by Newhouse (1999) who suggested that many Aboriginal youth are living in a curious blend of two worlds. They are learning about their own Aboriginal histories and practices from family members and written curricula, while at the same time being influenced by more western cultures through music artists and television programs (Newhouse, 1999). 
Individuals may experience a type of identity crisis when they acknowledge that their views are inconsistent with their current situation or behavior (Cross \& Gore, 2003). The participants from our research explained how it is not just Aboriginal culture and white culture that they find themselves traversing; they often find themselves negotiating various cultures (e.g., urban Aboriginal culture; Fleming et al., 2006). Although it is possible that young women who traverse multiple cultures experience an identity crisis, it is also possible for these young women to develop a separate and "bicultural self" that is adaptive (Cross \& Gore, 2003). More specifically, Cross and Gore argued that bicultural people are able to interpret the environment and adhere to the cultural views that fit the situation best. Regardless of the manner in which the various cultural views have been internalized by these young women, it was apparent that their body-related emotional experiences were confounded by the complexities surrounding conflicting cultures.

Another important finding that emerged from our research is that the body-related emotional experiences of young Aboriginal women may not be as negative as previous research has led us to believe (Fleming et al., 2006). Consistent with other feminist research, our research was based on the voices and the experiences of young women. However, contrary to most body image research in which young women are not provided with the opportunity to describe the meanings associated with their body experiences, the young women in our study were encouraged to articulate the complexities of their bodyrelated emotional experiences. The methodologies within our research provided the young women with the opportunity to share their positive experiences. Although feminist perspective guided our study, Cognitive-Motivational-Relational Theory was utilized as a conceptual framework. By exploring the key components of CognitiveMotivational-Relational Theory (i.e., appraisal, coping), we were able to gain a better understanding of young Aboriginal women's body-related emotions. CognitiveMotivational-Relational Theory describes emotions as complex psychophysiological states that have adaptive functions and are part of an ever-changing process due to a constant shift in the way we interact with and interpret our environment (Lazarus, 1991). Cognitive appraisal and coping are the two basic processes within Lazarus' theory. Both processes make every transaction extremely dynamic, although recurrent patterns do emerge. With respect to cognitive appraisal, Lazarus described how a person ascribes 
meaning to a given context. This process of appraisal is particularly important because a person must deem the situation as relevant to their well-being otherwise emotion will not be generated. A number of environmental conditions (e.g., social conditions) and personal characteristics (e.g., values, goals, beliefs) constitute the person-environment relationship that shapes the appraisal. In addition, Cognitive-Motivational-Relational theory recognizes that there are a number of factors (e.g., culture) that may influence personal characteristics. Cognitive-Motivational-Relational Theory was drawn upon throughout our analysis (i.e., Fleming et al., 2006) so that we remained cognizant of the various environmental conditions and personal characteristics that likely influence young Aboriginal women's emotional experiences.

In addition to appraisal, coping has also been identified as an important component in the emotion process (Lazarus, 1991). Coping has been defined as the cognitive and behavioral efforts that are employed to manage demands that are appraised as taxing or exceeding ones personal resources (Lazarus, 1991). An individual may attempt to change the person-environment relationship (problem-focused coping) or the way in which they interpret the person-environment relationship (emotion-focused coping). Cognitive-Motivational-Relational Theory helped us (i.e., Fleming et al., 2006) to better understand the strategies (e.g., avoidance) that young women use to cope with their body-related emotional experiences.

Cognitive-Motivational-Relational Theory was utilized as the conceptual framework within our research (i.e., Fleming et al., 2006) because it allowed for the exploration of a variety of emotions (e.g., pride, anger), which is quite different than previous research that has typically focused on the body dissatisfaction experienced by young Aboriginal women. The Indigenist Stress-Coping model was also utilized as part of the conceptual framework because it articulates how the stress and coping processes of Aboriginal women are influenced by their situational existence in a colonized society (Walters \& Simoni, 2002). Given the encompassing nature of Lazarus' (1991) theory of emotion, it was possible to incorporate the Indigenist Stress-Coping model, which encouraged us to be conscious of the various ways in which colonization has impacted the experiences of young Aboriginal women. 
One of the primary strengths of our research (i.e., Fleming et al., 2006) is that Cognitive-Motivational-Relational Theory illuminated the complexity and contextspecificity of young Aboriginal women's body-related emotional experiences. These findings are consistent to those of Paquette and Raine (2004) who also explained how women's body image is not static but instead it is very dynamic and fluctuating. Similar to our research, Paquette and Raine explained how in-depth research methodologies uncovered the complexities surrounding women's experiences with their bodies. Another strength of our research is that it highlighted the need for researchers to work towards change. The young women expressed a desire for change; they said that we need to make Aboriginal women more prominent in society and there should be "rallies towards freedom of the body" (Fleming et al., 2006, p. 534). As was the case in our study, and as suggested by Creswell (1998), feminist research often attempts to identify areas that are in need of change.

Building upon the findings from my Master's research, I engaged two rural Aboriginal women (both 15 years of age) in one-on-one interviews in an effort to better understand their body-related experiences (i.e., McHugh \& Kowalski, in press). Although it was not our original intent, both young women were the only teenaged Aboriginal women living in their communities at the times of the interviews; thus, this research highlighted two very unique stories. Similar to findings from my Master's research, the two young women who participated in this study described a general level of body satisfaction. They also suggested that women's experiences with their bodies are very complex and they explained how it is important to "fit in"; one young woman stated that it is very difficult to fit in since "there is hardly no Aboriginal people around". In light of the complexities surrounding their body-related experiences, the young women argued that it is important to have positive role models and to engage in body talk. Both young women felt that it is important, particularly within school contexts, to talk about body image and "what it can do to you". One of the young women explained how concerns about the body are "a big problem for like young girls, everyone". They argued that by talking about the body with positive role models, it might be possible for young women to develop positive attitudes towards their bodies (McHugh \& Kowalski, in press). 
The health of Aboriginal women is complex but physical appearance appears to be a factor that strongly influences the health of young Aboriginal women. It is imperative that we engage Aboriginal women in qualitative research if we want to increase our understanding of factors that influence health and want to attempt to change health outcomes (Meadows, Lagendyk, Thurston, \& Eisener, 2003). Furthermore, researchers need to adopt a positive framework when engaging in health research with Aboriginal peoples (McNaughton \& Rock, 2003). Participatory action research (PAR) provides researchers with the opportunity to focus on the positive because it offers a framework by which participants and researchers can work together for the common goal of positive change.

\subsubsection{Participatory Action Research}

As suggested by the CIHR (2007), when developing research projects that involve Aboriginal peoples, communities must be given the option of a participatory research approach. This section will begin with a description of PAR's distinguishing characteristics; the multiple intersections of the underlying principles of feminist perspective and PAR will also be explored. Subsequently, the strength of approaching PAR from a feminist perspective while engaging in research with Aboriginal peoples will be described. The intent of this section is to demonstrate the appropriateness of engaging in PAR for this doctoral research, given my motivation as a feminist researcher who was interested in working with young Aboriginal women.

Participatory action research has been defined as an emerging process that engages participants in research and results in a practical outcome that is related to the experiences of the participants (Stringer, 1999). Similarly, Stringer and Genat (2004) described action research as a participatory approach to inquiry that provides people with the opportunity to further their understanding of issues and to develop actions that are directed at the resolution of such issues. Researchers such as Kemmis and McTaggart (2000) and Stringer (1999) have recognized that there are numerous interpretations of action research and participatory action research. In addition, they have acknowledged that there are a number of common themes (e.g., research results in practical outcomes, engages peoples) that link the two. Given that the terms are basically synonymous, the 
terms participatory action research and action research have been used interchangeably throughout this dissertation.

As stated by Kemmis and McTaggart (2000), PAR emerged as a deliberate form of resistance to traditional research practices that were perceived as a colonizing tool by participants in the research process. Issues of social justice were not adequately addressed using traditional positivist approaches to inquiry (Creswell, 2003). Similarly, Stringer and Genat (2004) described how various "scientific" techniques are unable to provide adequate insight into the social and cultural issues that are deeply embedded in human issues. For example, typical body image scales do not shed light on the complex cultural or social factors (e.g., media images) that may influence individuals' perceptions or experiences with their bodies. It has been assumed that body image is a singular and fixed characteristic that is measurable (Blood, 2005). However, traditional techniques "come up short as vehicles for providing explanations for the socio-cultural aspects of human life" (Stringer \& Genat, 2004, p. 20). As an alternative, Stringer and Genat explained how PAR utilizes strategies of exploration that are more attuned to people's realities.

Participatory action research is founded on the belief that people are knowledgeable about their intentions and actions and thus they can take a "realistic" approach in changing their lives (Kemmis \& McTaggart, 2000). Although there are a number of definitions of PAR, Kemmis and McTaggart (2000) described three defining attributes that distinguish PAR from conventional research. These three attributes include shared ownership, community-based analysis of social problems, and orientation toward action. Consistent with these defining attributes are the underlying principles of PAR that have been identified by Stringer and Genat (2004). They suggested that PAR is a form of inquiry that is based on the working principles of relationships, communication, participation, and inclusion.

The above mentioned defining attributes and principles of PAR are similar to the guiding principles of feminist action research (FAR) that have been outlined by Reid (2004). Reid defined FAR as a conceptual and methodological framework that explores 
and pursues opportunities for social justice ${ }^{2}$. A FAR framework was developed in response to the current lack of appropriate tools that allow researchers to measure the impact of women's health inequalities. Reid argued that women's health experiences need to be explored and social justice promoted; she proposed a FAR framework to do so. The guiding principles of FAR are inclusion, participation, action, social change, and researcher reflexivity, which as noted, are very similar to the guiding principles of PAR. Since the underlying principles of FAR are very similar to PAR, it raises the issue as to whether there is really a need for a separate FAR framework. Understandably, FAR maintains a particular focus on the experiences of women; nevertheless, Maguire (2001) argued that feminisms have "informed and grounded action research" (p. 59). Similarly, Stringer (1999) explained how many PAR projects are rooted in feminist theory. Reid has acknowledged the similarities of FAR with various other community-based action research projects, which again leads to the question as to whether or not there is a need for a separate FAR framework. Frisby, Reid, Millar, and Hoeber (2005) argued that Feminist Participatory Action Research (FPAR) is a specific form of PAR that places the diversity of women's experiences at the center of analysis. Basing their argument on the work of other feminists (e.g., Maguire, 1987), they stated that it was not until the 1980's that the diversity of women's experiences were acknowledged in PAR projects. Taking into account the arguments made by Frisby et al. and Reid I am confident that researchers, such as myself, who engage in PAR from a feminist perspective will achieve goals that are similar to those outlined in FAR or FPAR.

In an effort to be consistent with my own motivations as a feminist researcher, I engaged in PAR from a feminist perspective. Approaching research from a feminist perspective while utilizing a PAR framework made sense given the consistency between the underlying premises of feminist perspective and PAR's defining attributes (as described by Kemmis \& McTaggart, 2000). For example, feminist perspective and PAR both have action as one of the most important defining features. As well, there is the belief that PAR and feminist research both emerged as a form of resistance to traditional positivist research approaches. Furthermore, feminist perspective calls for an alleviation

\footnotetext{
${ }^{2}$ Social justice in this context is used to explain the fair and impartial distribution of power; power that has typically been used to subordinate groups based on various factors (e.g., gender, ethnicity).
} 
of power imbalances, which may be why many feminist researchers choose to engage in approaches such as PAR that foster a sense of shared ownership. In addition, feminist perspective is a voice-centered approach that is politically motivated to create change. These motivations are consistent with the defining attributes of PAR, in which there is a community-based analysis of problems with a subsequent orientation toward action.

Engaging in PAR from a feminist perspective was particularly important for my research because I engaged in health research with young Aboriginal women. In terms of engaging in health research, Angeles (2004) suggested that researchers directly involve humans because it is more effective if participants are actively engaged "in the design, logistics, and the implementation of the project" (p. 56). Furthermore, since this research involved Aboriginal women, and an inadequate amount of research has been conducted on the unique lives of Aboriginal and other non-white women, feminist theory supported these women in the sharing of their experiences (Vasquez \& Fuentes, 1999).

In addition to the strength that a feminist perspective brings to research involving young Aboriginal women, PAR has also been documented as a research approach that is consistent with the desires of Aboriginal participants. Making the link between PAR and research with Aboriginal peoples, Bishop (2005) described how both approaches emerged as a form of resistance to traditional positivist approaches (as did feminist theory). As a result, Wheeler (2001) advocated for the use of community-based approaches to research when working with Aboriginal peoples. She said it is needed because "history has demonstrated that outside 'solutions' for the 'Indian problem' simply do not work in our best interests. We are the only ones with the insight and capabilities to identify our 'problems' and come up with our own answers” (p. 101). As previously alluded to, in the discussion of "social problems", the voices of Aboriginal peoples must be included in all discourse and research involving Aboriginal peoples; they are the ones who have the power to create change.

The inclusion of Aboriginal youth within this research process was supported by RCAP (1996) who contended that Aboriginal youth are ready to face the challenges, including the health challenges, confronting their communities. Some Aboriginal youth have indicated that they are ready to take part in the development of the solutions that will strengthen their nations; they want their voices heard (RCAP, 1996). Furthermore, 
RCAP described how youth want to be empowered by developing the skills and capacities that will help them to tackle their own challenges. A participant in Wilson's (2004) research argued, "Aboriginal women are already empowered-we just need to start showing it to others". Regardless of whether youth are already empowered or want to be empowered, participatory action research can provide them with the opportunities to develop solutions and strategies in an effort to address the challenges that their communities face.

The strengths of Stringer's (1999) approach to community-based action research has been highlighted by Aboriginal scholars such as Smith (1999) who suggested that this approach fits within the goals of an Aboriginal research agenda. By engaging in PAR, researchers assume that people know their own lives, have questions of their own, and have skills that can drive any community-based project (Smith, 1999). Bishop (2005), Harrison (2001), and Smith (1999, 2005), all of whom are leaders in the area of Aboriginal research methodologies, also highlighted the strength of engaging in PAR when involved in research with Aboriginal peoples.

As previously suggested, there are a number of ethical guidelines that should be adhered to when engaging in research with Aboriginal peoples. Again, these ethical guidelines are similar to PAR's defining attributes and principles (as outlined by Stringer, 1999; Stringer \& Genat, 2004), which suggest that PAR can be utilized as a respectful approach to research with Aboriginal peoples. For example, an ethical guideline outlined by Battiste and Henderson (2000) is that researchers should be more responsive and responsible to the knowledge of the participants by having direct input of the participants in the development of research projects. Similarly, Smith (1999) explained how researchers need to ensure Aboriginal peoples are benefiting from research by actively involving participants in the research process and in the creation of knowledge. These ethical guidelines are consistent with principles of action research, which explain how participants engaging in action research should be involved in the attainment, construction and deconstruction, and dissemination of knowledge of all research projects (Conrad, 2004). Building upon this assertion, Smith (2005) and Harrison (2001) explained how Aboriginal research should be a transformative project that is active in the pursuit for social change, which has positive outcomes for the participants. 
As noted above, there are a number of strengths associated with PAR approaches, particularly with research that involves Aboriginal peoples. However, as with most research methodologies, there are also challenges associated with PAR. In describing the PAR methodology that was utilized within their study, Gosin, Dustman, Drapeau, and Harthun (2003) outlined the challenges that are inherent in PAR. For example, they explained how the collaborative nature of such an approach has the potential to highlight conflicts that arise when there are differing perspectives among participants. In addition, they explained the challenges that could arise when trying to define the 'community' and appropriate community representatives. Within this study, I constantly engaged participants in open discussions; thus, it was possible to decide upon a definition of community and to identify appropriate community representatives (see section 3.2.2.2 for definition).

In addition to the challenges that are inherent in PAR, there are a number of additional challenges associated with the use of PAR for doctoral research (Gibbon, 2002). Gibbon explained how some of the challenges inherent in PAR, such as its timeconsuming nature, seem to be particularly problematic for doctoral students because of their limited time within doctoral programs. In addition, because PAR processes are typically not linear, and therefore difficult to report in conventional ways, doctoral students are often faced with institutional obstacles. It was important to recognize that challenges would arise when engaging in PAR for my doctoral research; thus, I had to be cautious to engage in research that is consistent with the constraints posed by the university and the community within which I work.

Regardless of the limitations associated with PAR, it is clear that there is a strong interconnection between the philosophical assumptions of my feminist perspective, the guiding principles of PAR, and the ethical guidelines for engaging in health research with Aboriginal peoples. Because of this interconnection, I felt that PAR was the most appropriate approach for working with young Aboriginal women to promote action and change and to develop strategies for managing body-related concerns.

Although action and change can take many forms and change can be implemented at many levels, Heilman (1998) has recommended that schools be considered as possible areas for implementing change. Youth spend much of their time in school settings and, 
as Heilman explained, schools could be used to promote support systems that try to reduce social, class, and gender difference. Similarly, a participant in Wilson's (2004) research explained how school is a place where young people can be taught "about the importance of women and their roles" (p. 18). In terms of potential opportunities for change, Bostock and Freeman (2003) explained how it is important to work with youth and include youth when promoting recommendations and generating change. They further explained how collaborative relationships have the ability to foster an environment in which youth feel that they have control of processes and outcomes.

Schools are an appropriate setting to engage in research with young Aboriginal women around issues surrounding the body because schools are a place where one's body can be ridiculed. For example, James (2001) described how "Krysta" entered a new school and she was called "fat, ugly, and other names like that" (p. 78). Similarly, Humbert (1995) described how young women in physical education class often have to endure remarks about their bodies, particularly from boys. Because young women are typically required to change clothes for physical education class, the change room has also been identified as a place that can "reinforce difference and feeling of shame about one's body" (Champagne \& Halas, 2003, p. 87). Feelings of difference and shame are likely precipitated by the dominant commercial image of the thin, beautiful, white woman; as a result, many young Aboriginal women drop out of the class and/or stop attending (Champagne \& Halas, 2003).

Research has indicated that the school setting might be one in which body-related concerns are often heightened, and it can also be an important place for intervention. As noted by Paxton (1993), intervention within a school has the potential to foster the creation of a healthier system or a subculture, in which the adverse effects of the larger culture are buffered. In addition, schools might be an important place for intervention because they are a place where young women can be taught to understand, deconstruct, and reconstruct their emerging identities (Heilman, 1998). This is especially important given that identity in adolescence is in a formative stage (James, 2001) and that physical appearance "overly determines identity in adolescent girls, leading to forfeiture of a strong self and voice" (Sweeney, 2001, p. 74). A participatory action research approach allows for the creation of spaces that foster the exploration of individual, school, and 
community experiences and concerns (McIntyre, 2000). In addition, McIntyre explained how the discussion of experiences has the potential to lead to the initiation of proactive strategies (McIntyre, 2000). Improvements may emerge when young women talk about their body experiences (Piran, 1996). Because youth spend a large majority of time in a school setting, it is important for them to feel that school is a safe place where they can talk about their experiences. By talking about their experiences with their bodies, the young Aboriginal women within this study were supported in their efforts to identify and to initiate various strategies to manage their body image experiences in an effective and collaborative manner.

\subsection{STATEMENT OF PURPOSE}

Previous research has indicated that young Aboriginal women experience negative emotions about their bodies (Gittelsohn et al., 1996; Neumark-Sztainer et al., 1997; Story et al., 1995). More recent research has indicated that young Aboriginal women's body-related emotional experiences are very complex and influence health in a variety of ways; subsequently, young Aboriginal women have voiced the need for action (Fleming et al., 2006). In an effort to be consistent with my own feminist beliefs and consistent with the guidelines that have been set forth by the various researchers and organizations committed to fostering respectful research with Aboriginal peoples, this study took the form of a participatory action research project. More specifically, the purpose of this research was to engage in a school-based participatory action research project in partnership with a local high school to provide young women, primarily young Aboriginal women, with an opportunity to manage their body image experiences in an effective and collaborative manner.

\subsubsection{Contributions}

Justification for this research was founded on the belief that it had the potential to make three significant contributions by addressing important gaps in the research literature. First, other than my own Master's research, I am unaware of any research that has had an exclusive focus on fostering opportunities for young Aboriginal women to share their body image experiences with the research community. Similarly, I am not aware of any research that has engaged young Aboriginal women in a collaborative 
project that aims to develop strategies to manage their body image experiences. Therefore, this research is important because it provided young Aboriginal women with the opportunity to be involved in research that respects them as the experts of their experiences. Similarly, this project fostered an environment that honored the authority of young Aboriginal women in the decision making process. This was particularly important because, as previously suggested, the process of research is often more important than the outcomes of research (Smith, 2005).

Second, this research is important because the participants and I were provided with opportunities to create change at the individual, school, and the broader community level. It is well documented that negative perceptions of the body and physical appearance may have a detrimental impact on a young woman's health. Therefore, the ability to create change at any level could be perceived as a positive aspect of this research. Although certain forms of action could have been initiated at the individual level, Stringer and Genat (2004) explained how action may subsequently spiral to include larger groups of people (school, city). The various forms of action that were developed and implemented have been outlined in the results section (see section 3.1.2).

Finally, this research has the potential to be viewed as a framework for future researchers with similar areas of interest. As previously noted, I am unaware of any other PAR project with a similar purpose. However, the recent publication of my Master's research (Fleming et al., 2006) in the "Pearls, Pith, and Provocation" section of the Journal of Qualitative Health Research demonstrates the uniqueness and importance of continuing to explore young Aboriginal women's body image experiences, and working collaboratively with young women to develop effective strategies for managing body image experiences. It is possible that this project may act as a guide or framework for future researchers looking to work with young Aboriginal women on projects that have similar goals. 


\section{CHAPTER 2}

\subsection{METHODOLOGY}

Participatory action research is employed in various disciplines and settings; therefore, it is often designed and carried out in a variety of ways (Kemmis \& McTaggart, 2000; McIntyre, 2000). Given the diverse background from which PAR stems, there are no prescriptive set of methods to accompany this approach. Furthermore, because PAR is based on collaborative efforts, developing a predetermined program for a PAR project can foster a research environment that constrains the emergence of participants' experiences (McIntyre, 2000). However, as described by McIntyre (2000), it is important to outline the framework of how the research will likely unfold. The approach that was originally proposed for this research study was based on the action research approach that was developed by Stringer and Genat (2004). The research process is presented in five phases: research design, data gathering, data analysis, communication, and action (see section 2.1.2). However, as will be noted in the results section (see section 3.1), the research process did not necessarily unfold in this manner.

In addition to trying to adhere to the various phases of action research, it is important to recognize that the working principles of action research (i.e., relationships, communication, inclusion, participation) defined by Stringer and Genat (2004) were adhered to throughout this project. More specifically, good relationships were promoted in an effort to build trust, to increase motivation, and to promote feelings of equality among all participants. Effective and consistent communication was also promoted because such communication is needed if participants are to listen, to understand, and to respect one another. Participation among all participants was also encouraged because it fosters an environment whereby participants feel that their worth is acknowledged, which can be empowering for many people. Finally, the inclusion of relevant groups and the various relevant issues that may influence the research question were promoted throughout the research project.

\subsubsection{Role of Theory in Participatory Action Research}


Prior to providing a detailed description of the five phases, it is important to highlight the role of theory in PAR. More specifically, it is important to draw attention to the theory that was used to guide various aspects of this research. One of the primary defining attributes of PAR is that it is a form of research that has an orientation towards action (Kemmis \& McTaggart, 2000). More specifically, it is a collaborative research approach in which there is hopefully a practical outcome that is linked to the experiences of the participants (Stringer, 1999). In saying this, it is important to note that there is a strong relationship between action and theory. Wadsworth (1998) explained how those engaged in PAR typically seek to develop deeper understandings and more useful theory about particular phenomena, with the intent of generating new knowledge and informing action. Similarly, Friedlander (2001) explained how theory must be used to drive action because theory helps people understand why a phenomenon occurs, which is a necessity if action is to be effective. He explained how there should not be action without theory because without theoretical reasoning, there is no reason to exclude or include alternative actions or interventions. Similar sentiments were also expressed by Winter (as cited in O'Brien, 2001) who explained how a person's actions are derived from his/her implicitly held assumptions or theories, and every action or observed result will enhance a person's theoretical knowledge. Winter argued that theory and practice are two interconnected features of the change process; thus, it is important for researchers to describe explicitly the theoretical justifications for the actions.

Feminist theory is the primary theory that was used to guide this research, but Cognitive-Motivational-Relational Theory (Lazarus, 1991) was also drawn upon throughout this research process. The main focus of this research was on the body image experiences of young Aboriginal women and, therefore, Lazarus' theory influenced my interpretations of young women's experiences. Cognitive-Motivational-Relational Theory is a theory of emotion that provides a detailed and probable description of the emotion process. Emotions have been described as complex psychophysiological states that emerge from interactions between a person, behaviour, and the environment (Lazarus, 1991).

Given that Cognitive-Motivational-Relational Theory supports the belief that emotion is a complex process, this theory had the potential to shed light on the 
complexities surrounding body image of young Aboriginal women. The encompassing nature of this theory supports the notion that a variety of factors (e.g., culture) may influence the appraisal and coping processes. In addition, by trying to better understand the young women's appraisal and coping processes (the two key components of emotion that have been described by Lazarus), it was possible to work with the young women to develop more effective strategies for managing their body image.

Seeing as feminist theory and Cognitive-Motivational Theory influenced my interpretations of participant experiences, my original intent was to share with the participants, during our first few meetings, a general description of these theories so that they would have an understanding of the basis of my assumptions. However, after various informal conversations with school members, I knew that a thorough description of the various theories could potentially "turn them off" of this research project and quickly make them disinterested in the goals of this research. Therefore, I was particularly aware not to use jargon when describing my guiding theories, yet I was able to explain to participants the general underpinnings of each theory. The honest sharing of my assumptions helped in the development of trusting relationships, especially since I invited their responses to my assumptions. Despite being provided with this opportunity, school members did not seem particularly interested in engaging in too much discussion about my guiding assumptions.

Although I shared my guiding assumptions, I was particularly cautious in ensuring that my theoretical beliefs did not limit my understandings of participant perspectives. More specifically, I used these theories as a guide but I made a strong effort not to force participant experiences into "fitting" either theory. For example, if it happened that the stories of the participants were inconsistent with the theories that I had proposed, I would have been sure to accept their stories and not to alter the meanings of their experiences to "fit" any particular theory. Nevertheless, given the broad and encompassing nature of each theory, I do not recall any incidents whereby participant experiences did not fit within these theories. As well, as noted in section 3.2.3, this PAR project made a number of contributions to the above-mentioned theories.

\subsubsection{Five Phase Participatory Action Research Approach}


The five phases that were proposed for this PAR project are presented in a fairly sequential and linear form; however, action research should be conceptualized as a cyclical and reiterative process (Stringer \& Genat, 2004). Within some contexts, Stringer (1999) conceptualized action research as a spiral helix, in which the processes of look, think, and act are repeated over time. Similarly, Stringer and Genat (2004) noted that participants will initially look at the issue or problem, think about the manner in which individuals are affected by the problem, and then act by determining the action to take. This cyclical process of look, think, and act continues until participants perceive that they have attained an effective solution to the problem. Although this presentation of action research as a spiral helix is appropriate for some contexts, Stringer and Genat explained how individuals, such as myself, who work in university environments often engage in more complex models of action research, such as the five phase model. This five phase model allows for more detail in terms of the types of activities that participants engage in when trying to systematically investigate the issue or problem that has been identified (Stringer \& Genat, 2004). The various components of each phase are outlined in Figure 1; again, the phases are presented in a linear form for purposes of clarity, but they should be envisioned as a cyclical process.

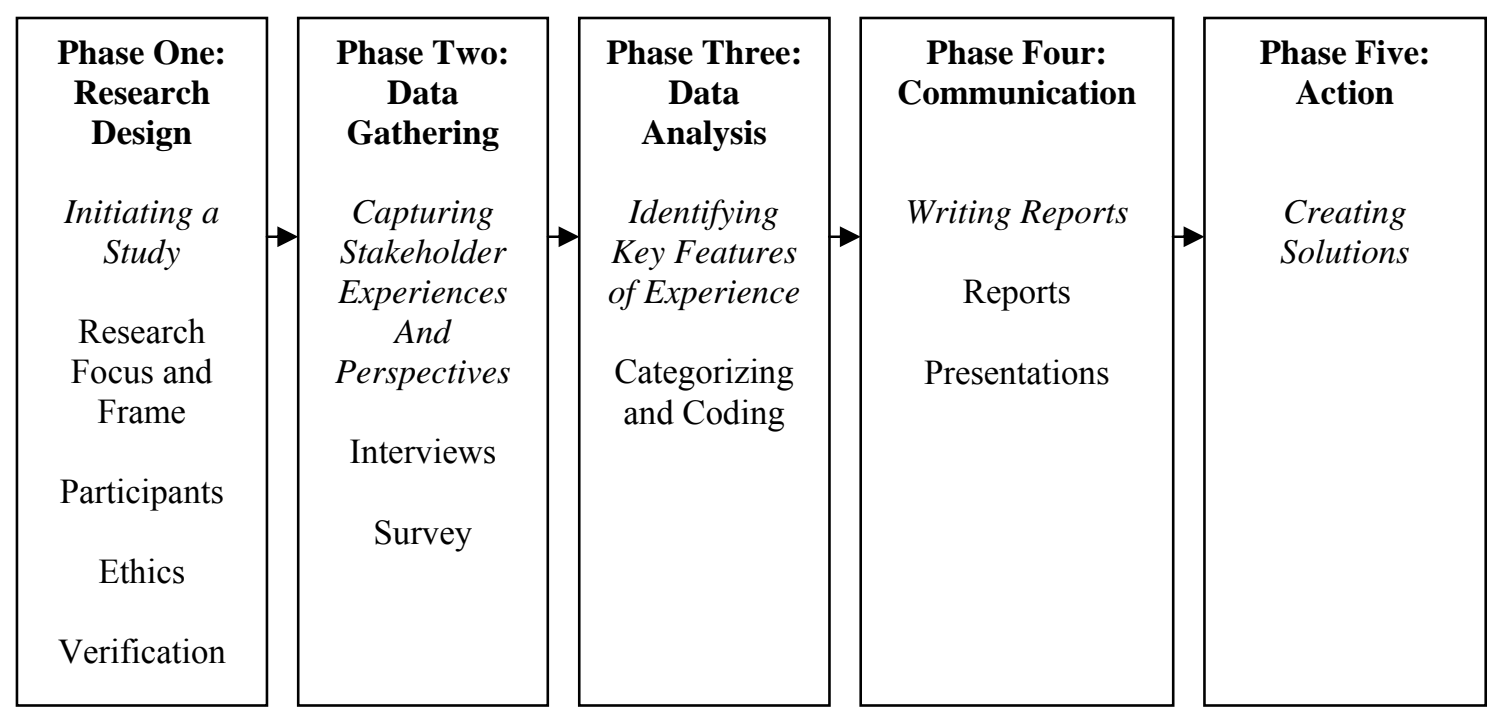

Figure 1. Five Phase Participatory Action Research Framework based on the work of Stringer and Genat (2004) 
It is important to note that although the five phase model was proposed as a framework for this PAR project, the manner in which the project unfolded did not neatly fit within this framework. More specifically, although phase one occurred, phases two through five were more or less integrated into two distinct phases (i.e., Building Relationships and Action, see section 3.1 for more detail). Nevertheless, given that this five phase model was proposed as the framework for this study, and various elements from this model were integrated into the two phases that emerged in this project, it is important to highlight the manner in which this study was proposed so that readers may have a better understanding of how this research project transformed.

\subsubsection{Phase One: Research Design}

The objective of this first phase was to construct a preliminary picture of the context and to identify the key issues and the people who are affected by the issues (Stringer \& Genat, 2004). Researchers are encouraged to tentatively state an issue and then to refine and reframe the study as they proceed throughout the research process. The focusing (see section 2.1.2.1.1) and framing (see section 2.1.2.1.2) of this research occurred during the process of developing the proposal for this research. As well, within this first phase the participants were identified (see section 2.1.2.1.3), and ethical protocols and methods of verification were outlined (see section 2.1.2.1.4 and 2.1.2.1.5 respectfully).

\subsection{Research Focus}

This research was focused by refining the research issue, question, and objectives. The following was identified as the focus:

Issue: It has been widely documented that women experience body image concerns. In addition, recent quantitative research suggests that body dissatisfaction and negative body image are experienced by at least some Aboriginal adolescents (Story et al., 1994, 1995). However, the broad range of body image experiences that may be experienced by young Aboriginal women have rarely been explored. One of the guiding assumptions of this research is that all young women experience some degree of body image concerns. Although body image may not be a top priority of concern for all young women, such concerns can still negatively impact their lives. Despite this fairly widely held assumption, there have been little, if any, qualitative and/or action research studies 
that have tried to understand the body image experiences of young Aboriginal women and how they are coping with these emotions. Their voices appear to be absent in the current body of literature.

Question: What are the body image experiences (both negative and positive) of young Aboriginal women and what strategies are they using, or what do they think they should be using, to cope with such experiences?

Objectives: To provide insight into body image experiences and to take a schoolbased participatory action research approach to provide young women, primarily young Aboriginal women, the opportunity to systematically manage their experiences in an effective and collaborative manner.

\subsection{Research Frame}

In addition to focusing the research proposal, the research was also framed by identifying where and when the research would take place, and how long the research was expected to take (Stringer \& Genat, 2004). This research project took place over a 10 month period (September 2006-June 2007) within an urban high school (i.e., Nutana Collegiate) in the city of Saskatoon (see Figure 2). Saskatoon is the largest city in Saskatchewan and it is geographically located along the banks of the South Saskatchewan river in the centre of the province (City of Saskatoon, n.d.). The city of Saskatoon has a population of approximately 207,200 and almost $10 \%$ of the population self-identifies as an Aboriginal person (Statistics Canada, 2003).

Nutana Collegiate (hereafter used interchangeably with the name Nutana) was chosen as the site for this research project primarily because of some of the connections that I had established with staff members of Nutana during my Master's research. One staff member was a graduate of the College of Kinesiology and she was particularly enthusiastic about the goals of my research. Thus, she helped to facilitate my integration into the school community by introducing me and my research goals to key school members (e.g., administrators). As well, during my Master's research I developed a strong relationship with Ms. Phyllis Fowler, the director of Nutana's Integrated SchoolLinked Services (ISLS) program, who in turn became my known sponsor for this PAR project (see section 2.1.2.1.3.1). As a result of the time I spent at Nutana during my previous research, I was able to see the potential strengths of working in this school for 
my Ph.D. research. More specifically, Nutana seemed like an ideal location because I had already developed some relationships with members of the Nutana school community and the school has a large Aboriginal population which, given the goals of this research project, was a critical deciding factor in identifying an appropriate site for this research project. As well, as will be described below, I perceived Nutana to be a supportive school that had a number of programs and services that could support my proposed PAR project. Thus, in addition to Nutana's student population, Nutana was identified as a convenient and accessible site to engage in this PAR project.

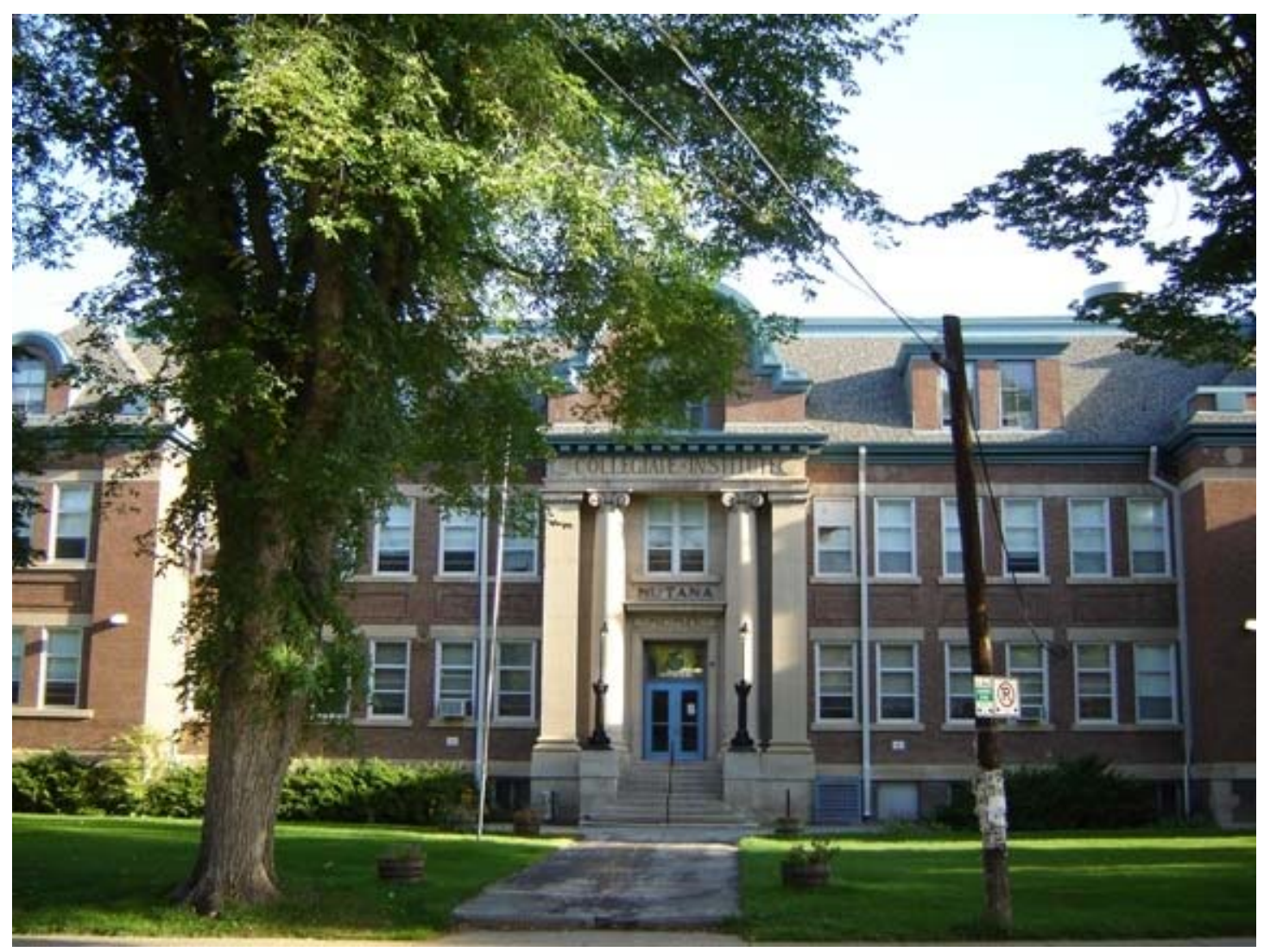

Figure 2. Nutana Collegiate.

Nutana Collegiate was established in 1910, and it is recognized as Saskatoon's first high school. The school is located in the Saskatoon neighbourhood known as Nutana, one of the first settlements in the city (City of Saskatoon, n.d). As of September 2006, Nutana Collegiate had a student enrollment of 644 students, and approximately $38 \%$ of those students self-identified as Aboriginal persons. Young people from virtually 
every neighbourhood in Saskatoon attend Nutana, yet a large portion of the students who attend Nutana live in Saskatoon's core neighbourhood. As well, Nutana's academic year is broken into quarters whereby students focus on just one subject during the morning period and one subject in the afternoon period of each quarter. By focusing on just two subjects in each quarter, students are provided with the opportunity to gain class credit in a shorter amount of time, when compared to other Public Schools that are organized by semesters. Therefore, Nutana is comprised of a number older students (i.e., 18 years or older) who are trying to obtain a few final credits for graduation, often in a short amount of time.

Nutana Collegiate is a vibrant community school that is part of the Saskatoon School Division \#13 of Saskatchewan, also known as Saskatoon Public Schools. Having immersed myself into Nutana Collegiate for the duration of this PAR project, I realized that this school is unique in a number of ways. First, the actual physical environment of the school is somewhat unique in that it is home to the Memorial Art Gallery, which was developed in an effort to recognize the 29 students of Nutana Collegiate who lost their lives in World War I. The Gallery features Canadian works of art, displayed throughout Nutana's main hallway and in the library. Therefore, although much of Nutana's interior space is quite old, the Art Gallery adds a sense of contemporary beauty to compliment the school's history.

Second, with respect to the students, Nutana is very diverse. In contrast to other schools in Saskatoon Public Schools, which are typically deemed "athletic schools" or “preppy schools" by students, Nutana appeals to a range of students. When walking through the hallways of Nutana, it is visibly obvious that there are students from a variety of ethnic groups and social classes; thus, the overall student population can not be easily classified. The diverse student population offers a welcoming environment for newcomers such as myself; newcomers generally do not feel the need to try to fit a typical Nutana stereotype because there really is not one. Third, in terms of the teachers and staff, they seemed particularly committed to supporting the success of students. It was very obvious to me that the staff and teachers of Nutana are constantly providing students with the academic or social support that they need to be successful. Although I am sure that there are support systems in other schools, the general atmosphere at Nutana 
seemed to be more supportive than what I had experienced in other schools (e.g., my own high school).

Fourth, Nutana is unique to Saskatoon in terms of the various services and programs that it offers to its students. It would be beyond the scope of this dissertation to give a comprehensive overview of the history, programs, and services that combine to make this school a supportive environment for students. Nevertheless, the following two subsections will provide a general overview of Nutana so that one may gain a better understanding of the context within which this project was situated. As well, these subsections will outline the manner in which Nutana's programs and strategic plan support the overall goals of this PAR project. This section will briefly outline Nutana's Integrated School- Linked Services (ISLS) Model (section 2.1.2.1.2.1), and the School Strategic Plan for the year 2006-2007 (section 2.1.2.1.2.2).

\subsection{Integrated School-Linked Services (ISLS) Model}

As outlined in Nutana Collegiate's School Planning Document, this school is unique in that "it is a leader in the delivery of educational programs through an Integrated School-Linked Services (ISLS) model” (Saskatoon Public Schools, 2006, p. 1). In 1994 there was a recognized need for more collaborative processes between schools, community human service agencies, and Aboriginal organizations (Saskatchewan Learning, 1994). Thus, an ISLS plan was implemented in Saskatchewan. The purpose of ISLS is to identify methods of service delivery that address the complex and diverse needs of youth at risk and to provide such services in a way that are more inclusive and responsive to student needs. Growing numbers of youth are coming to school with complex social, emotional, health and developmental problems, which make it hard for children to do well in school and in life (Fowler, n.d.). By integrating and linking services, it is possible to address the complex needs of youth, and to support the wellbeing of youth (Fowler, n.d.).

Schools have been identified as an ideal location to offer community services and programs because of their central location in the community (Totten, 1972). There a number of terms used to describe schools that work in collaboration with various human service agencies to offer programs (e.g., school-based clinic, community school; Dryfoos, 1994). Despite various appropriate terms, schools in Saskatchewan, such as Nutana 
Collegiate, have been designated "integrated school-linked services" (ISLS). However, it should be noted that the more common term "community school" is often used interchangeably with ISLS when describing Nutana within this dissertation. Through this ISLS initiative, schools, families, communities, governments, and human service agencies are working together to address the needs of school-aged youth. Schools and/or communities coordinate and integrate services based on needs identified locally, and take into account the specific needs of the children and their families and the resources in their communities.

The objectives and defining characteristics of ISLS are consistent with those of this PAR project. That is, ISLS has identified "collaboration and partnerships" and "bottom-up change initiative" as two of its key defining characteristics (Fowler, n.d.). Since Nutana offers education through an ISLS model, students are provided with a number of community support services and community partners within the school. Some highlights of Nutana's ISLS include, but are not exclusive to: an on-site Primary Health Care Nurse Practitioner; an on-site Ministry of Social Services Social Worker; an on-site CanSask Career Consultant; Youth Launch; Millie's Early Learning Centre; The Student's and Kids Centre (SAKs); the daily services of the Salvation Army Breakfast Van; and weekly services provided by, for example, the Saskatoon Police Services School Resource Officer Program, Corrections and Public Safety, and the Family Support Centre. All of these services are available to students from within the school and they do not have to leave the school premises in order to access these services.

Given that students and staff at Nutana Collegiate have so much experience working with partners, it made my transition into the school community and partnership with the school that much more successful. I was welcomed into the school as a collaborator and as an individual who would work towards Nutana's common goals. Given the manner in which I was readily welcomed into the school, I do not feel that I was perceived as either an intruder or an outsider (which has been highlighted as a potential obstacle when engaging in PAR). Although a smooth transition into a school that does not adhere to the ISLS model could also have been possible, the ISLS support system in place within Nutana (e.g., weekly meetings for ISLS partners) fostered my smooth transition into the school. As well, I am confident that the consistencies between 
the goals of ISLS and this PAR project greatly contributed to the success of this PAR project.

\subsection{School Strategic Plan For The Year 2006-2007}

The Nutana school strategic plan for the year 2006-2007 outlined Nutana's vision to establish a learning environment that encouraged excellence, hope, joy, and caring; as well, four key priorities were outlined by the school for the 2006-2007 school year. The key priorities were: 1) literacy for life, 2) student retention, 3) community connections, and 4) wellness. Nutana administrators recognized their "challenge" to create a learning environment that, among other characteristics, promoted competence and social conscious; all four priorities attempted to address this challenge. Despite the equal importance and emphasis that the school placed on each priority, I will specifically focus on the "wellness" priority because of its consistency with the priorities of this PAR project.

The "intended outcome" of the wellness priority was twofold in that it focused on the wellness of both staff and students. The wellness priority stated that staff wellness must be maintained if staff are to effectively support students. As well, the wellness priority emphasized the importance of enhancing students' awareness of health. The wellness priority document stated that the success of this priority could be demonstrated by an increase in the number of students who engaged in physical activity and made healthier food choices.

The goals of the wellness priority are consistent with the goals of this PAR project since physical activity and healthy eating are two factors that are often strongly associated with body image. The Saskatchewan School Boards Association (2004) has also acknowledged the strong relationship between physical activity, healthy eating, and body image. The Association developed a research report that highlighted proposed nutrition guidelines for Saskatchewan schools, and in an effort to provide justification as to why schools should be concerned about nutrition, the Association outlined 10 health issues that are currently facing Saskatchewan communities. "Body image issues" within the school environment were highlighted, and a model of healthy eating and enjoyable physical activity were proposed as a strategy for managing body image issues. The goals

of this PAR project support the overall goals and intended outcomes of Nutana's wellness 
priority, which I also think helped foster my transition and acceptance into Nutana's school community.

\subsection{Participants}

Participants, or stakeholders as they are often called in PAR, are those individuals who have a "stake" in the research because they are affected by the issue being explored or influence events related to the issue (Stringer \& Genat, 2004). Stringer and Genat explained how researchers, or "research facilitators" as they are often called in PAR, are also considered stakeholders. For the purpose of this dissertation, the term stakeholder and participants will often be used interchangeably.

The primary stakeholders, or key participants, within this PAR project were the Known Sponsor (see section 2.1.2.1.3.1) and a group of seven young Aboriginal women who represented the Core Group (see section 2.1.2.1.3.2). Primary stakeholders, as defined by Stringer and Genat (2004), are those individuals who are most centrally involved in the issue. Therefore, for this research project, the intent was to work with young Aboriginal women, between the ages of 14-18 years of age. Although the known sponsor did not fit these criteria, her relationship with young Aboriginal women facilitated her active role in this research project. Frideres and Gadacz (2001) explained how the term Aboriginal encompasses those individuals who are legal or status Indian, non-status Indian, Inuit, and Metis. However, given the various definitions that are often used to identify Aboriginal peoples (for further discussion see section 1.3), and in an effort not to promote the belief that the identities of Aboriginal peoples can be determined by others, the participants in this study were asked to self-identify. The criteria for age selection of the participants was based on one of the largest studies with Native American youth living on or near a reserve, which showed that females in grades 10 through 12 were more worried about their weight and their appearance compared to females in grades 7-9 (Story et al., 1994). Because Nutana has a relatively large population of young Aboriginal women, and is comprised of those students from grades 9-12, this school was an ideal setting for this particular PAR project.

The intent of this project was to include Aboriginal and non-Aboriginal young women because, as stated by RCAP (1996), “only when the deep causes of Aboriginal ill health are remedied by Aboriginal and non-Aboriginal people working together will 
balance and harmony-or health and well-being- be restored" (Health and Healing section, p. 3 ). Similarly, participants from my previous research described the importance and demonstrated the strength of engaging both Aboriginal and non-Aboriginal young women in research (Fleming et al., 2006). As the primary facilitator of that research, I felt that excluding non-Aboriginal participants simply on the basis of ethnicity would have been detrimental to rapport and disrespectful to participants (particularly since Aboriginal participants had requested the participation of non-Aboriginal participants). Despite this justification, as will be noted in section 2.1.2.1.3.2, all of the women in the core group identified themselves as Aboriginal. Nevertheless, Aboriginal and non-Aboriginal school members participated in the various strategies that were developed.

Rather than trying to work directly with all young Aboriginal women within the school, the intent was to work developmentally. That is, the intent was to start with a small group (i.e., core group) and then gradually increase the breadth of people and activities involved in the research process (Stringer \& Genat, 2004). As stated by Stringer and Genat (2004), action research projects may start with limited objectives but increase as understanding increases. In addition, they explained how the potential for positive change may increase as the number of people involved increases. More specifically, they developed a visual illustration as to how action can spiral from the individual to the group, organization, and community level. As will be noted in the Results section (see section 3.1), the core group was centrally involved in the development and implementation of most action initiatives, but various other school members also participated in the action initiatives.

\subsection{Known Sponsor}

A known sponsor has been identified by Patton (2002) as a person who has a legitimate relationship with the particular groups of interest, and the known sponsor for this PAR project was the Program Director of ISLS at Nutana, Phyllis Fowler. Having engaged in my M.Sc. research at Nutana about 3 years ago, I was fortunate to develop a relationship with Phyllis. Although we kept in contact over the past few years, I met with Phyllis in the spring of 2006 to tell her about my proposed Ph.D. research plans, and she explained how she was "thrilled" that I wanted to engage Nutana students in this research process. Given her enthusiasm about this PAR project, she really helped to facilitate my 
entrance into the school. More specifically, she spoke to school administrators, explained to them the goals of this research project, and helped to generate a sense of excitement about this project among the school community. After obtaining the permission of the school administrators, I began attending the ISLS weekly Liaison team meetings, which were chaired by Phyllis. Liaison team meetings are attended by all of those individuals who are ISLS partners; I assumed the role of a College of Kinesiology partner.

Given her role as the Director of ISLS, and the supportive role she plays in connecting students with a variety of community services, Phyllis has relationships with many of the Nutana students, including young Aboriginal women. As well, Phyllis' role as Director of ISLS has allowed her the opportunity to develop relationships with almost all of Nutana's partners. Thus, given the respect that Phyllis garners from students, staff, teachers, and Nutana partners, she played a critical role in introducing me to various school members for the purpose of developing relationships. The development of such relationships was imperative in the development of action strategies.

Not only did Phyllis introduce me to various school members and partners of Nutana, but she was instrumental in the support that she provided throughout this whole research process. Being new to Nutana, I initially had a number of questions (e.g., with respect to students, teachers, classes, programs, and services). For example, when the students and I had questions about who to talk to in order to book the gymnasium or certain classrooms for our action initiatives, or when we had questions about who we could approach for funding for our action initiatives, Phyllis could provide us with the answers. Compared to other staff at Nutana, Phyllis has been a member of the school for the longest period of time; therefore, even if she did not know the answer to a question, she knew who would. Not only did Phyllis offer support in terms of answering questions, but she continuously provided verbal support for my involvement in the school. There were days when I would question the extent to which I and this research were making a positive difference in the lives of young Aboriginal women at Nutana, which in retrospect was a natural feeling in that I probably would never feel that my efforts were enough. Nevertheless, Phyllis repeatedly told me how "awesome" this PAR project was and how "grateful" the school was to have me as part of their school community. Given that Phyllis is perceived as a leader by many of her peers and that she is respected by so many 
of the teachers, staff, and students, it was very motivating to know that she supported my involvement in the school and the various action initiatives that the students and I developed. In retrospect, I realize that Phyllis' encouragement played a key role in supporting me throughout this research project. I have met very few people who are as optimistic as Phyllis. She had, and continues to have, a positive energy that is completely contagious; and, maybe most importantly, she believes in the power of youth. Although she recognizes the various challenges that youth face, she never doubts the potential of youth to create change. Thus, her support and encouragement played a critical role in the success of this research, and I will forever be thankful to her.

Finally, Phyllis played an integral role in supporting my integration into the previously established Girls' Mentorship group, which ultimately became known as Girls' Club (see section 3.1.2.1.1). Phyllis strongly believed that Girls' Club would provide me with an opportunity to develop relationships with young women who would likely be interested in working to develop initiatives to manage young women's body image experiences. Having the support of Phyllis, an adult ally within the school that many of the young people trusted, provided me with an initial level of credibility among the young women. This initial level of credibility provided me with a strong foundation whereby I could work to develop the trust of the young women; I knew that such trust was going to be critical if the young women and I were going to be working collaboratively throughout the duration of this project.

\subsection{Core Group}

A core group of young women who were primarily responsible for the development and support of the various action initiatives that constituted this action research project was formed from relationships developed during Girls' Club (see section 3.1.2.1.1). Similar to McIntyre's (2000) participatory action research project within a school setting, relationships were established with various stakeholders, yet a core group of young women were most active in the research project. As previously stated, the goal was to work with a small group of women (i.e., core group) and then gradually increase the number of young women or other stakeholders involved in the project.

Given my previously established relationship with the school and my previous work with young women at Nutana, I was optimistic that trust and rapport would be fairly 
easy to establish enhancing the likelihood that young women would volunteer to participate in this research. Having said this, Girls' Club met every Monday from the beginning to the end of the school year and, given the initial lack of consistent attendance from the young women, I experienced some doubt throughout the first few months of Girls' Club as to whether it would be possible to develop a core group of young women who would be committed to the goals of this research project. However, by Winter Break (i.e., after approximately 4 months) a core group of seven young Aboriginal women had been established (see Figure 3 for a picture of some of the young women from the core group). The trust that was established between me and these young women helped to facilitate the development of this core group, and there are a number of ways that I worked to develop this trust. First, I was very up front with the young women about my goals as a Ph.D. candidate; I made it clear that I was committed to working with youth and supporting the voices of young Aboriginal women around body image issues. Second, I feel that the trust that was established was partially the result of the consistency that I demonstrated to this core group. I always followed through with any commitments that I made to students, and my constant presence in the school demonstrated to the core group that I would consistently be there to support them. Third, I perceive myself to be a genuine person and, because of this, the young women in the core group may have found it easy to relate to me. I am confident that these various reasons helped me to develop trust with the group of women who ultimately became the core group.

The seven young women who constituted the core group regularly attended Girls' Club, and made it clear that they were interested in being involved in the development of action initiatives aimed at helping other young women manage their body image experiences. Aside from these seven young women, other young women also attended Girls' Club; however, their attendance was not as consistent as the core group's. As well, in contrast to the core group of young women, these other young women did not express a specific interest in taking a leadership role in this PAR project. Therefore, although their opinions were still welcomed and valued when decisions were being made about action initiatives, compared to the core group they were not as active in the process of developing and implementing action initiatives. 


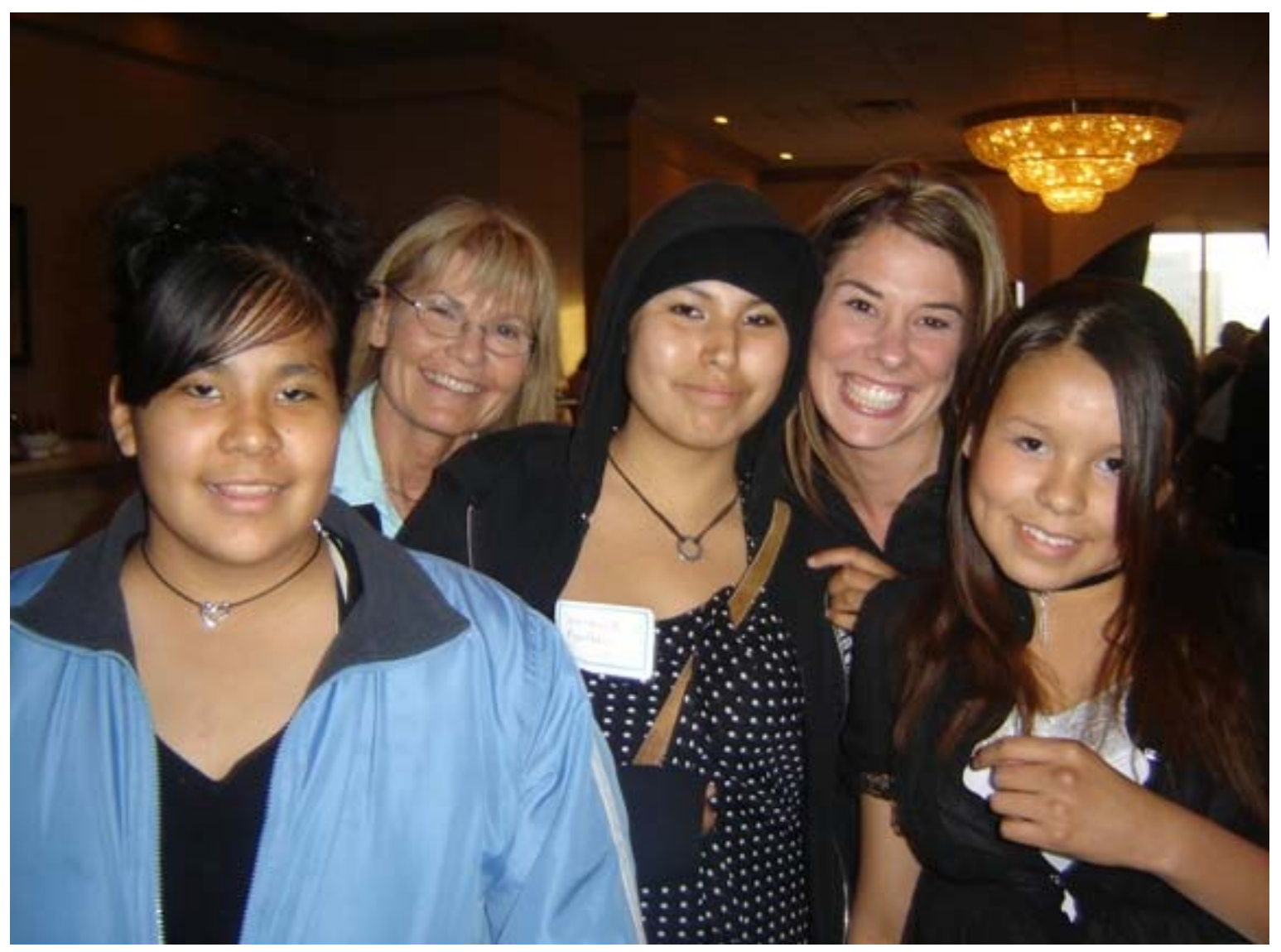

Figure 3. Three young women from the core group, Phyllis ( $2^{\text {nd }}$ from left), and Tara ( $4^{\text {th }}$ from left).

Interestingly, the young women who represented the core group were some of the younger women within the school. Given that a wide age range of young women attended Girls' Club, I had originally assumed that it would mostly be the older and potentially more mature students in grades 11 and 12 who would be interested in working with me to better understand some of the body image issues experienced by young Aboriginal women. However, the core group was made up of one young woman in grade 9 who was 14 years old, four young women in grade 10 (i.e., three 15 year olds and one 16 year old), and two young women in grade 11 (i.e., both 17 years old). In addition to being fairly young high school students, all of the young women in the core group also identified themselves as Aboriginal. Given that Nutana Collegiate has such a large number of students who self-identify as Aboriginal, I knew that many young Aboriginal 
women would attend Girls' Club. It was not stipulated that the core group could only consist of Aboriginal women; however, it was these seven young women who were interested in playing a leadership role in this action research project. Although there are likely a whole host of reasons as to why all Aboriginal women constituted this group, these young women knew that the primary focus of this research was on Aboriginal women, and it is possible that they wanted to play a role in the positive changes (i.e., development of action initiatives) that would result from this project.

The young women who constituted the core group were a unique group in that although they were acquaintances, prior to Girls' Club they were not part of a previously established peer group, although some of the young women had previous relationships with each other. Prior to developing the core group three of the young women in grade 10 were, what they described as, best friends, and the two young women in grade 11 were cousins. The other two young women (one grade 9 and one grade 10) came on their own to Girls' Club and ultimately became part of the core group. In terms of personalities, these two young women were completely opposite to one another. Similar to the other women in grade 10 and 11 , the young woman in grade 10 was very outgoing and outspoken, and she easily made herself fit in to the Girls' Club. These six young women considered themselves to be "average, outgoing students". The young woman in grade 9, on the other hand, was very shy; although I saw her virtually every day and continually tried to engage her in conversation, for the first eight weeks that she attended Girls' Club she would only nod her head for responses. The most I heard her say was "hello" or "good-bye". Despite being very shy, she was always the first to arrive and the last to leave Girls' Club, and even if it was just her and I in the room she would rarely speak. However, it is possible that her continued presence at Girls' Club was her way of showing she was interested in the goals of this PAR project. After attending about eight weeks of Girls' Club, this young woman began to speak more with me and the other young women. By the end of the academic year, she had been involved in the development and implementation of almost all of the action initiatives. Witnessing the transformation of a shy young woman into a relatively outgoing young woman who was committed to change, was truly a rewarding experience for me. 
Although I never specifically asked the young women why they, out of all of the students in the school, came together to form this core group, I have my own assumptions as to why they formed the core group. It is possible that compared to other students at Nutana, they saw Aboriginal women's body image issues as a particularly important topic that warranted action by high school students. Thus, they wanted to have their voices heard with respect to such issues, and they wanted to be part of a group that would make positive differences in the lives of others. Maybe at a more basic level, these young women enjoyed being involved in the development and implementation of initatives, which ultimately gave them something to look forward to and something to do during their spare time (e.g., lunch time). Most importantly, it is my belief that the core group was attracted to the opportunity to create change and make action.

The young women from the core group did not have regularly scheduled or formal meeting times whereby they would get together to describe proposed action initiatives. Instead conversations among the core group would often take place more informally (e.g., during Girls' Club). The dedication that the core group demonstrated to the goals of this research project was apparent, particularly in terms of the time and energy that the young women committed to the various action initiatives. The core group was comprised of an amazing group of young women who were confident in their potential to create change on a number of different levels.

\subsection{Ethics}

An important component of this first phase of research was to highlight the ethical protocols that were utilized to "protect the well-being and interests of the research participants" (Stringer \& Genat, 2004, p. 45). Participants, particularly the core group, spent extended amounts of time speaking about issues surrounding their body, which can be very personal for some people. Therefore, it was important to comply with ethical guidelines, especially those that address the importance of confidentiality.

Ethical approval was obtained from the University of Saskatchewan Behavioural Research Ethics Board (see Appendix A), prior to collaborating with the various stakeholders. As well, all of the young women in the core group, and other participants who were directly involved in this research (i.e., contributed writing or direct quotes to this dissertation; took part in media opportunities [see section 3.1.2.3.1]), returned 
completed informed consent forms (see Appendix B). Parent/guardian consent was also obtained from those participants who were younger than 18 years, and who were not living independently.

Many young people benefited from the various action initiatives that were developed as part of this PAR project. Nevertheless, written consent was only obtained if they were directly involved in the development of the initiatives (i.e., core group), their anonymity was sacrificed (i.e., media opportunities), or they specifically contributed something to this dissertation that required their permission (i.e., writing). As well, it should be noted that data release forms were signed by those participants (i.e., mostly the core group) who agreed to have their photographs and names included as part of this dissertation (see Appendix C). As stated by CIHR (2007), some communities or community members may wish to be identified and acknowledged in the research, and this was the case in this PAR project. Therefore, all of the names that are outlined within this dissertation are actual names and not pseudonyms.

I am confident that despite a number of challenges inherent in consent processes within PAR, I did my best to ensure that this research adhered to various guidelines set forth by the University of Saskatchewan Behavioral Research Ethics Board, as well as various Aboriginal researchers, RCAP, CIHR, and other health organizations such as the Prairie Women's Health Centre of Excellence (see section 1.3.1 for a more detailed description of ethical guidelines). In addition, the standards of ethics were very consistent with the principles of action research that have been outlined by Stringer and Genat (2004).

\subsection{Verification}

The last component that was considered as part of phase one of this PAR project was methods of verification. Participatory action research is typically naturalistic or qualitative in nature; therefore, the "truths" that emerge are always contingent upon a number of criteria (e.g., person, time, setting; Stringer \& Genat, 2004). Prior to engaging in action, participatory action researchers often employ a number of qualitative methods in an effort to shed light on the issue being explored. Lather (1991) emphasized how the "research process re-orients, focuses, and energizes participants towards knowing reality in order to transform it" (p. 68). Within this proposed research, various interviews and 
informal conversations fostered opportunities for participants to better understand their body image experiences, or to better understand their reality. This new knowledge was then used to develop strategies to manage these experiences. Thus, the information that was compiled from these methods was used to guide the action, which is a priority in PAR. Given the extent to which the information was used, Stringer and Genat (2004) highlighted the importance of establishing the trustworthiness and/or validity of the information collected.

As an important aspect of their five phase action research approach, Stringer and Genat (2004) described the trustworthiness procedures that should be employed throughout the research process; their procedures were adapted from those suggested by Lincoln and Guba (1985). Given the subjective nature of qualitative research, qualitative researchers (e.g., Lincoln \& Guba, 1985) recognized that validity criteria used within quantitative research could not sufficiently emphasize the quality of qualitative data. Therefore, Lincoln and Guba (1985) developed trustworthiness procedures to more adequately reflect the manner in which the quality of qualitative research should be assessed. Similar to trustworthiness procedures, Creswell (1998) described eight verification procedures that qualitative researchers may want to use to establish "quality" research. However, contrary to trustworthiness, verification involves a set of procedures that explore the accuracy of projects that are not dictated by the objectiveness sought in quantitative research.

Consistent with the recommendations of action researchers (e.g., Stringer \& Genat, 2004), procedures such as prolonged time in the field, persistent observation, triangulation, member-checking, and rich, thick descriptions, were employed throughout the various phases. By engaging in such procedures, it was possible to highlight the complexities surrounding young Aboriginal women's body image experiences. Subsequently, the action that was initiated benefited the young women since the action stemmed from their experiences and suggestions.

The PAR project took place within a school-setting over the duration of a 10 month period. Therefore, I spent prolonged time in the field, which was important in an effort to better understand the context of the participants (Creswell, 1998). Prolonged time in the field is needed if adequate trust and rapport are to be built with the 
stakeholders (Lincoln \& Guba, 1985). However, spending prolonged time in the field is not enough; it is also important to spend this time in persistent observation (Stringer \& Genat, 2004). Focusing and recording observations allowed for meaningful and worthwhile time in the field and observation helped to better understand participants' contexts.

Triangulation of methods, sources, and perspectives also took place as a verification procedure. The process of triangulation allows for the illumination of a particular phenomenon (in this case, the body image experiences) and clarifies the way by which the phenomenon is perceived (Creswell, 1998; Stake, 1995). Multiple methods (e.g., informal interviews and discussions), sources (e.g., reports, research literature), and perspectives of relevant stakeholders provide a framework in which descriptive and appropriate accounts can be developed (Stringer \& Genat, 2004). It was imperative that the participants and I worked together to understand the varying perspectives since action was initiated from these representative accounts.

In an effort to ensure that all reports from the research adequately reflected the stakeholders' perspectives, it was important to engage in the process of memberchecking. Member-checking has been identified as one of the most essential methods of gaining credibility (Lincoln \& Guba, 1985). To ensure that the information produced from the research adequately reflected the diverse perspectives of the participants, I consulted with participants throughout the study to ensure that their perspectives were being adequately represented. For example, during Writing Group (see section 3.1.2.2.2), the young people would give me pieces of their writing to include in my dissertation as they felt these pieces of writing were reflective of their experiences. Some of the pieces had to be shortened so that they would fit within my dissertation; however, I then consulted with the participants to ensure that the edited versions still adequately reflected their experiences.

Continual involvement of the participants in the process of member-checking was especially important for me because I engaged in cross-cultural research with young Aboriginal women. A particularly positive aspect of engaging in member-checking with Aboriginal peoples is that researchers recognize that participants are the "knowers" of their contexts and environments and thus they must be included in the reflection and 
reconstruction of their experiences and knowledge (Smith, 1999). As previously mentioned, Bishop (2005) described how research that has typically been approached from a Eurocentric standpoint has generally misrepresented or silenced the experiences and knowledge of Aboriginal peoples. Furthermore, Smith (1999) explained how this research assumes that Western ideas about Aboriginal peoples are the only ideas that are rational and the only ideas that make sense of human beings. If researchers do not engage participants in the process of member checking, they run the risk of being part of a Western culture that reaffirms a Western view that they are the center of "legitimate knowledge" and that they are the source of "civilized knowledge" (Smith, 1999). It is particularly important that researchers involve participants in member-checking their written work because, as indicated by Smith (1999), writing can be dangerous in that it can reinforce a type of discourse that is never innocent. As suggested by Bishop (2005), by engaging participants in the writing or member-checking of reports, it may be possible to co-construct a mutual understanding of the researcher and the participants. Therefore, throughout this PAR project I continually member-checked findings from this research with participants to ensure that I was adequately representing their experiences.

Finally, information regarding young Aboriginal women's body image experiences, and the action that was implemented, was communicated by using rich, thick descriptions throughout all reports and this dissertation. Rich, thick descriptions are used in an effort to convey to other audiences an understanding of the issues and people participating in the research (Stringer \& Genat, 2004). Furthermore, Creswell (2003) described how detailed descriptions foster opportunities for readers to gain a sense of shared experiences. By providing a detailed account of the issues, school-setting, participants, methods, and action, it is possible for other audiences to better understand this research project. As suggested by Creswell (1998), thick descriptions will allow future readers to formulate their own conclusions with respect to the research.

As noted above, numerous procedures (e.g., prolonged engagement) were employed throughout the various phases in an effort to demonstrate the "quality" of this research project. However, as this research project progressed and as I began to more deeply explore ways for establishing the quality or credibility of this research, I realized that there are a number of other methods for determining the quality of this research. 
Given that much of the criteria for judging the credibility of this research is based on the words of the participants and the relationships that were developed, this discussion is better situated in the Discussion section (see section 3.2.1.1).

\subsubsection{Phase Two: Data Gathering}

The original objective of this second phase was to provide opportunities for stakeholders to share their experiences and perspectives through interviews (one-on-one and group discussion) and a survey. However, once I was immersed into the school community and I had developed relationships with students and staff, I realized that formal interviews would not be the best method for working with young women to develop action initiatives. More specifically, after entering the school and getting a better feel for how this PAR project would unfold, it became clear that the organization of formal interviews with participants had the potential to foster unnecessary power structures between the participants and I, which could have been detrimental to the maintenance of the trust that had been established. As well, once I became part of the school community I realized that the school division was not supportive of school members administering formal surveys to their students, as there were concerns about how the results of such surveys would be utilized by survey administrators. Thus, a formal survey was not administered to students in this PAR project. Although a formal survey was not administered, other forms of data gathering did take place within this research. More specifically, information was gathered through interviews, a personal journal that I wrote in daily, observations, participants' writing, works of art, and media pieces. Despite changes to the original proposed plan for data gathering, it is still important to make reference to the original plan for this project, as future researchers may gain a better appreciation for the need of a flexible action research framework.

\subsection{Interviews (One-on-one and Group Discussion)}

Participatory action research is based on the assumption that people of all ages have a deep understanding of their own lives; thus, interviews tend to be a main component of this type of research (Stringer \& Genat, 2004). Interviews provide stakeholders with the opportunity to share their experiences and to extend their understanding of the issues being explored (Stringer \& Genat, 2004). Interviews, albeit fairly informal interviews, were conducted in an effort to better understand the 
participants' experiences. Because participants in this research spoke about issues that could be perceived as quite sensitive, Patton (2002) explained how rapport is needed so that researchers can express understanding without judgment and Lincoln and Guba (1985) argued that the building of trust is an ongoing and developmental process that one must engage in daily. Thus, as will be noted in section 3.1.1, a significant amount of time was spent developing trust and rapport.

The original plan for this PAR project was to meet with interested young women on a number of occasions prior to engaging in any "formal" data collection, so that I could try to build trust and rapport. However, as it turned out, participants and I never engaged in any formal interviews and all of the interviews or conversations that were carried out with the young women were fairly informal or casual. As stated by Stringer (1999), interviews may be formally organized or they may take place during a more natural social interaction. The interviews that took place within this PAR project always occurred as part of more natural interactions. Therefore, the participants and I did not follow an interview guide and the interviews were not audio-recorded. Researchers, such as Patton (1990) would argue that it is vital to audio record interviews as it provides data for verbatim transcriptions. However, Lincoln and Guba (1985) argued that audio recording can be intrusive, and Berthelette, Raftis, and Henderson (2001) explained that recording the interviews in their research with Aboriginal peoples would have been "inappropriate and intrusive" (p. 17). The traditional oral culture of the Aboriginal participants in Berthelette et al.'s study did not support the use of tape recording; the reporting of interviews was subsequently based on the memory of the facilitator and Elder. Although participants in this PAR project did not specifically state that it was inappropriate to audio record interviews, the casual nature of the interviews did not support such recording. As stated, many of the interviews occurred as part of natural interactions, and it did not seem natural or appropriate to record such interactions.

Informal interviews, whereby there is little interruption or structure from the researcher, are often referred to as conversations (Morse \& Richards, 2002) or informal conversational interviews (Patton, 2002). Unstructured interviews or conversations are typically used by researchers who have little information on a particular topic (Morse, 2001). Seeing as I was unaware of the participants' experiences and the types of 
initiatives that they would want to develop, these conversations would, as stated by Morse, allow participants to "tell their stories at their own pace" (p. 566). Given the richness of the conversations that I had with participants throughout this project, it is my assumption that the informal interviews or the various conversations that I had with the young women were just as effective, and likely even more effective, as more formal interviews would have been in the development of action initiatives.

When developing the proposal for this research project, it was anticipated that the young women in the core group would take part in various focus group interviews and one-on-one interviews throughout the research process. As well, the intent was to have various other stakeholders also engage in interviews but to a lesser extent. Although interviews (i.e., informal conversations) and group discussions did take place with the core group and other stakeholders throughout the duration of this research (i.e., from September 2006-June 2007), it is important to state that all of the group discussions were very informal. Again, participants and I did not follow interview guides, nor did we establish meeting times for formal discussions. Instead informal group discussions took place throughout the school year in a variety of settings (e.g., within Girls' Club). Thus, rather than using the term focus group, which Morse and Richards (2002) argued implies a more "focused" interview that is primarily driven by specific research questions, the term group interview is used to describe the type of data collection that took place within this research. Group interviews, as suggested by Morse and Richards, can include unguided conversations and multiple-respondent interviews.

Similar to the work of Bostock and Freeman (2003) who also engaged in PAR with youth, I thought that group discussions would be one of the primary methods for trying to better understand participants' perspectives. Informal group discussions were utilized because they have the ability to generate new knowledge, which subsequently "has the potential to guide school-wide systemic transformations making the school a safer and more equitable environment for adolescent women" (Piran, 1996, p. 327). In addition to generating new knowledge, group discussions provided participants with the opportunity to "open up" and to share their experiences. The process of opening up can be as valuable for individuals and communities as the results or the knowledge generated. 
The strength of employing focus group, or group discussion, when engaging in research with Aboriginal peoples has been demonstrated by various researchers (e.g., McIntyre et al., 2001; Thompson et al., 2002). Focus group has been recognized as a culturally sensitive method of data collection, in that individuals may feel supported when they hear others sharing similar stories (Madriz, 2000; Patton, 2002). Group discussion has the ability to uncover some of the complexities surrounding women's experiences because participants may feel that they can share the stories that they may not feel comfortable sharing in one-on-one interviews. Having said this, it is also possible that participants may not discuss sensitive issues in the group setting, especially if they feel that their experiences differ from other group members (Bostock $\&$ Freeman, 2003). Esterberg (2002) explained how it is important to include individuals who feel comfortable interacting, especially when discussing sensitive issues. Therefore, throughout this research process, nearly all of the group discussions that took place were with individuals who were part of an intact group (e.g., young women engaged in group discussions at Girls’ Club)

\subsection{Survey}

In addition to interviewing, Stringer and Genat (2004) described how surveys can also be a method for providing input into action research projects. Therefore, the intent was to use a survey to try to further understand the perspectives of young Aboriginal women. As stated by Stringer and Genat, surveys are a fairly inexpensive method to acquire information from larger groups of people. Similarly, Bowling (2005) described how a primary feature of surveys is that they can be used to cover large samples of people and the information that is collected is the same from each individual in the sample. Stringer and Genat also explained how surveys are typically employed in the latter stages of the project because it is important to provide participants the opportunity to frame the issues and questions in their own terms. In addition, they explained how the strength of a survey can be increased by ensuring that the concepts and questions are derived from the perspectives of those being surveyed (Stringer \& Genat, 2004).

It was proposed that young women from the core group would help to design a survey; thus, a survey was not designed prior to the beginning of the research project. The intent was to use the survey to expand upon the concepts and ideas that were voiced 
by the participants within the interviews. As well, it was proposed that survey questions would be developed from some of the findings that emerged from my previous research (i.e., Fleming et al., 2006). For example, it was anticipated that the survey could be used to further explore the notion that young Aboriginal women are faced with conflicting cultures with respect to their bodies. The intent was to share the findings from this previous research (i.e., Fleming et al., 2006) with the stakeholders of this particular project in an effort to determine whether they felt there was value in further pursuing such ideas.

Prior to entering this research process, it was proposed that young women in the core group would be centrally involved in the development of the survey; however, teachers, directors, and various other stakeholders would also be provided with the opportunity to provide input into the development of the survey. Although the design was to be emergent, it was anticipated that the survey would allow for open-ended responses so that participants would be encouraged to provide answers using their own terms. It was anticipated that a wide variety of body image experiences identified by young women in the partnership school would be explored.

The proposed plan was to include approximately 100 young Aboriginal and nonAboriginal women (ages 14-18) from the local partnership school to participate in the study. Although there are a variety of survey designs, it was anticipated that a crosssectional design would be employed, as it involves the collection of information from people at just one point in time (Bowling, 2005). Thus, a cross-sectional design would allow for the collection of information about current and past experiences with the issue (i.e., body image experiences) and it would allow for an exploration of associations between possible variables (Bowling, 2005).

Despite this proposed plan to utilize a survey to try to better understand the perspectives of a large group of stakeholders, once I entered the research process it quickly became apparent that the use of surveys within this school was frowned upon. During a staff meeting in early September a staff member had proposed the idea of using a survey to solicit student opinions on a particular topic that was unrelated to this project. However, some of the teachers and one of the Administrators made it clear that the School Board was not supportive of the use of surveys within the school, since there have 
historically been issues as to who has control over the use of survey findings. Therefore, although I saw value in the role that a survey could play in this study, and I was confident that the collaborative nature of this research would ensure that stakeholders felt comfortable with the manner in which survey findings were used, I decided that I would not pursue the idea of developing a survey with stakeholders. Furthermore, once the core group was established, I spoke to them and the known sponsor about some of the concerns that the school has with surveys. Everyone agreed that the development of action initiatives would be more effective if they were based on the opinions and ideas that were solicited during conversations and group discussions, and not through the use of surveys.

\subsection{Alternative Methods of Data Gathering}

When developing the proposal for this research project, it was anticipated that interviews (one-on-one and group) and surveys would be used as the primary methods of data gathering. However, shortly after becoming engaged in this research project it became clear that various other methods could be used in gathering data. As argued by Green et al. (1995), participatory action researchers rarely use a single method, and methods of data gathering are typically based on the needs of the research. Similarly, Park (2001) posited that participatory research typically involves the use of "noncanonical approaches", such as art and other expressive media. Given that there a variety of methods of data gathering that are deemed acceptable within participatory action research, I engaged in a number of data gathering activities. Everyday I recorded my research experiences in a journal or diary; ultimately, this journal allowed me to record my own experiences as I engaged in this research process and to take note of information about the research context. As suggested by Morse and Richards (2002), diaries can be an effective method for gathering data in virtually any qualitative study; thus, keeping a journal or diary seemed like an effective method for this particular research project. Observations were also another useful form for gathering information. Morse and Richards stated that observations are often used to supplement interviews, and Patton (2002) argued that observation may be one of the best forms of data gathering in that it allows researchers to better understand situations that may not be possible through interviews. Throughout the duration of this research project I observed the actions of 
participants while they engaged in one-on-one conversations with me or group discussions. As well, I observed participants as they took part in various action initiatives. These participant observations were recorded in my daily journal. Finally, information regarding participant experiences were gathered through participants' writing that was gathered during Writing Group (see section 3.1.2.2.2), works of art that were developed during Art Group (see section 3.1.2.2.3), and through various forms of media (see section 3.1.2.3.1).

\subsubsection{Phase Three: Data Analysis}

The objective of this third phase was to identify the information that appeared to be most pertinent to the issue or problem being explored. More specifically, Stringer and Genat (2004) explained how data analysis is used to reduce large quantities of data and to increase stakeholder understandings of issues. As suggested by Stake (1995), data analysis began the day the research process began because the analysis involves first impressions as well as final compilations. Four cognitive processes have been identified by Morse and Field (1995) as integral components to qualitative data analysis: comprehending, synthesizing (decontextualizing), theorizing, and recontextualizing. Therefore, all four of these cognitive processes were incorporated into trying to better understand stakeholder perspectives. Similar to Stake's suggestion, Morse and Field also explained how the analysis of the data begins the day data collection begins; therefore, these cognitive processes were ongoing in a fairly sequential manner throughout the whole research process.

It was originally proposed that the data would be analyzed by engaging in the four cognitive processes outlined by Morse and Field (1995), while simultaneously engaging in a more specific process of analysis (e.g., categorizing and coding) that has been outlined by Stringer and Genat (2004). However, given the very informal manner in which information was shared by the participants, the more specific processes outlined by Stringer and Genat did not fit well with this research project. The stories of the participants were not audio-recorded or transcribed; thus, line by line coding and categorizing of participant experiences did not fit well within this project. However, the more general cognitive processes that were outlined by Morse and Field did fit well within this project; thus, it is these cognitive processes that were used to analyze the 
information gathered from the various informal one-on-one interviews and group discussions.

The first cognitive process that was engaged in with respect to data analysis was comprehending. Data analysis is the process of "making sense of the data" and comprehension is reached when there is enough data to write a detailed description or when it is agreed that there is saturation (little new to be learned; Morse \& Field, 1995). This process allowed us (the participants and I) the opportunity to reflect on all of the information that had been gathered and to try to develop a detailed description of the issues.

The second cognitive process was synthesizing. The process of synthesizing takes place regardless of the specific type of data analysis used (e.g., categorizing and coding). This process in the data analysis requires the sorting of the data and it is completed when researchers and participants feel that they can describe collective stories (Morse \& Field, 1995). There are various ways to sift through this data, and it was originally proposed that categorization and coding would be the process utilized within this research. The intent was to develop categories and subcategories by looking for relationships between elements of experiences and perspectives and then categorizing similar elements together (Stringer \& Genat, 2004). Then, each category was going to be identified using a code or a term that represented the experiences of the participants. However, as previously noted, the process of data gathering (i.e., interviews) was much less formal than originally anticipated; thus, the subsequent data analysis was also much less formal than originally anticipated. Therefore, although the general cognitive process of synthesizing was used within this research process (i.e., we sorted through data), the more specific act of categorizing and coding was not utilized.

Once the participants and I felt that we could sufficiently describe collective stories, we attempted to engage in the third process of theorizing. Morse and Field (1995) explained how theory is rarely mentioned in qualitative inquiry but it is needed so that a comprehensible model for linking diverse perspectives in a useful way can be developed. By drawing upon feminist theory and Cognitive-Motivational-Relational Theory, it was possible to better understand the experiences of young Aboriginal women. Nevertheless, at various times throughout the research process I attempted to generally 
describe these theories, and to outline the various ways that they may shed light on young women's experiences with their bodies. However, as previously noted, the participants did not seem particularly interested in trying to make sense of their experiences using these theories. Therefore, rather than trying to push this cognitive process upon them, it was important to let the research unfold in a manner that was comfortable for all participants.

The fourth and final cognitive process that was utilized was recontextualization; this process was ultimately utilized by me during the writing of this dissertation. The goal of this particular process was to place the findings (as described in section 3.1) from the research into already established bodies of knowledge and to highlight those results that are consistent, contradictory, and those that are new contributions (Morse \& Field, 1995).

In summary, in terms of data analysis, the participants and I actively engaged in the general cognitive processes of comprehending and synthesizing. These processes subsequently supported the development of action initiatives in that they helped the participants and I to "make sense" of the data and to describe "collective stories". Again, participants were invited to participate in the processes of theorizing and recontextualization, but these processes, which were maybe a bit too "academic", were not approached very enthusiastically by the participants. Thus, I was primarily responsible for engaging in these processes. Finally, it is important to emphasize that although these specific terms (e.g., synthesizing) were never actually utilized by the participants, by listening to the manner in which they tried to make sense of information, it seemed as though these were the cognitive processes that were being utilized by the participants.

\subsubsection{Phase Four: Communication}

The objective of this fourth phase of the proposed five phase model was to provide stakeholders the opportunity to review their progress and to resolve any disputes about past events or proposed action (Stringer \& Genat, 2004). Prior to entering this research project, it was anticipated that two primary components of this proposed research would be communicated to the various stakeholders, as well as to the public, professional, and academic audiences. First, information about the phenomenon (i.e., 
body image experiences of young Aboriginal women), and the methods used to highlight such information (e.g., interviews) would be communicated to various audiences. The process of describing the phenomenon would allow stakeholders and other audiences with an opportunity to better understand the perspectives of others (Stringer \& Genat, 2004). This process would be particularly important within this proposed research because the body image experiences of young Aboriginal women have rarely been heard. Second, it was anticipated that the participants and I would report on the action that was implemented, and that we would describe the success of such action initiatives (the manner in which success was determined is described in section 3.2.1). Thus, the strategies implemented would have the potential to assist other young Aboriginal women in managing their body image concerns.

Generally speaking, researchers engaging in more conventional projects wait until the end of the study to share the research findings or results of the study. However, the research findings of this proposed project were communicated at various times throughout the project. As previously mentioned, although the five phases of this action research project have been presented in a linear manner, they should be conceptualized more as an integrated process. That is, the communication phase has been presented as phase four, even though communication took place throughout the research project. For example, after some action initiatives had been implemented (i.e., phase 5), such initiatives were shared with the broader community through regional newspapers (i.e, phase 4). Thus, the phases did not necessarily take place in a sequential or distinct manner.

As noted above, it was anticipated that information on the phenomenon (i.e., young women's body image experiences) and action would be communicated to public, professional, and academic audiences. Recognizing the diversity among groups, I knew that it would be important to work with participants to share results in a manner which would be appropriate for each group. Stringer and Genat (2004) explained that regardless of the group, all reports need to be written in a way that "evokes deeper forms of understanding" (p. 119). Thus, when communicating findings through various forms of media (see section 3.1.2.3.1) and presentations (see section3.1.2.3.2), the voices of the participants were used as the primary method of sharing. The words of the participants 
were used within this research since, as stated by Smith (1999), the story telling of women has become an important aspect of research involving Aboriginal peoples.

Communication of research findings took many forms and, to date, various forms of communication have already taken place. For example, the action initiatives that were developed as a result of this project, and the manner in which the initiatives were developed, were shared with the school community during an end of year staff meeting at the school. Although some of the young women from the core group attended this presentation, they did not feel comfortable presenting in front of a large group of school members; thus, I was responsible for the presenting the information. Nevertheless, some of the young women from the core group helped me to develop the ideas that were discussed during the presentation. As well, as mentioned, various forms of media were used to share this research with individuals from across Saskatchewan and even across the country (see section 3.1.2.3.1). Findings from this study were also communicated to youth from other schools during two conferences which were facilitated by young people from this research (see section 3.1.2.3.2). In addition to the communication that has already taken place, findings from this research will continue to be communicated to various audiences even though the time in the research field has concluded. For example, these findings will be communicated to the academic community through publications in academic journals and presentations at conferences.

Although I have just outlined the manner in which findings were communicated, it is important to reiterate that many of these acts of communication were also viewed as action initiatives by the participants. More specifically, although the media was used as a form of communication, the participants also viewed these media opportunities as forms of action, whereby they could shed light on young Aboriginal women's experiences.

\subsubsection{Phase Five: Act}

The proposed objective of the fifth and final phase was to proceed with the new understandings and knowledge in an effort to resolve the research issue (Stringer \& Genat, 2004). Prior to entering the research field, I knew that it seemed somewhat idealistic to assume that it would be possible to resolve all of the struggles associated with young Aboriginal women's body image experiences, especially given the widely held notion that "women's painful experiences of their female bodies might be culturally 
produced" (Blood, 2005, p. 2). If indeed women's experiences with their bodies are culturally produced, I do not think that it is reasonable to assume that it is possible to resolve all of their body-related concerns. Having said this, I hoped that we could begin to challenge the manner in which women's body experiences are culturally produced, and that it would be possible to work towards the development of strategies for managing body image concerns. The act phase was based on the assumption that it is possible to move from interpreting and analyzing issues, to practical action (Stringer, 1999). It was assumed that interpreting and analyzing the issues surrounding young Aboriginal women's body image experiences would provide a strong foundation by which realistic strategies could be implemented.

The importance of moving to the action phase was voiced by Tonya Makletzoff in RCAP (1996) who explained, "we could go on forever talking about solutions, but if we are just going to talk and we are not going to do anything, then these solutions mean nothing" (The Search for Belonging: Perspectives of Youth section, p. 42). Action researchers recognize that it is not enough just to suggest modes of action; action must be planned, implemented, and evaluated (Stringer, 1999). Regardless of the action, RCAP (1996) described how Aboriginal youth want to be part of the planning and implementing of action and community development.

Once again, because of the emergent nature of action research, this phase was dependent upon the ideas of the participants. Thus, prior to beginning the research project, it was difficult to provide a detailed description of this phase. However, given my previous experience working with young Aboriginal women on body image issues, and my own knowledge from reading the works of other body image researchers, I anticipated that certain action initiatives could be developed. As will be described in section 3.1.2, various action initiatives were developed as a result of this project, and some of these initiatives are consistent to what I had anticipated. As well, within the Discussion section (see section 3.2.1) I have highlighted some of the action initiatives that I had anticipated would be developed, as this may allow future researchers the opportunity to see how PAR often transforms from the proposal stages to the final stages of the project. 
Regardless of the type of action that was initiated, when planning the action I knew that it would be important to adhere to Stringer and Genat's (2004) suggestion to set action priorities, to construct a work plan, to review the plan, to support and to monitor progress, and to constantly evaluate. Within this research project, the voices and opinions of the young women were the primary method of evaluating the success of the action initiatives (see section 3.2.1 for a more detailed description of evaluation). The evaluation of the project was incorporated into the ongoing planning, action, and reflection of the proposed activities. Activities and/or strategies were initiated at different points throughout the duration of the project; thus, it was important to learn from, and build upon, the strengths and weaknesses of each initiative. The activities and initiatives were participant driven; thus, the activities were designed in a way that was accessible and appropriate to the young women. Therefore, it was their perception of success that was of the utmost importance. Success was primarily measured by exploring, through dialogue, what we (i.e., all stakeholders) had achieved as a group in terms of the development and implementation of prioritized activities. 


\section{CHAPTER 3}

\subsection{RESULTS}

The primary purpose of this PAR project was to work with young Aboriginal women to develop action initiatives for managing body image experiences. In an effort to highlight the manner in which the research unfolded, the results are comprised of two phases: (1) Phase 1: Building Relationships, and (2) Phase 2: Action (see Figure 4). As noted in the previous chapter, the original intent was to follow Stringer and Genat's (2004) five phase action research model, and various aspects of Stringer and Genat's five phases were carried out within this PAR project (e.g., data was gathered via informal interviews). However, once the research process began to unfold it quickly became clear that the results of the research were more adequately represented by using the two phases.

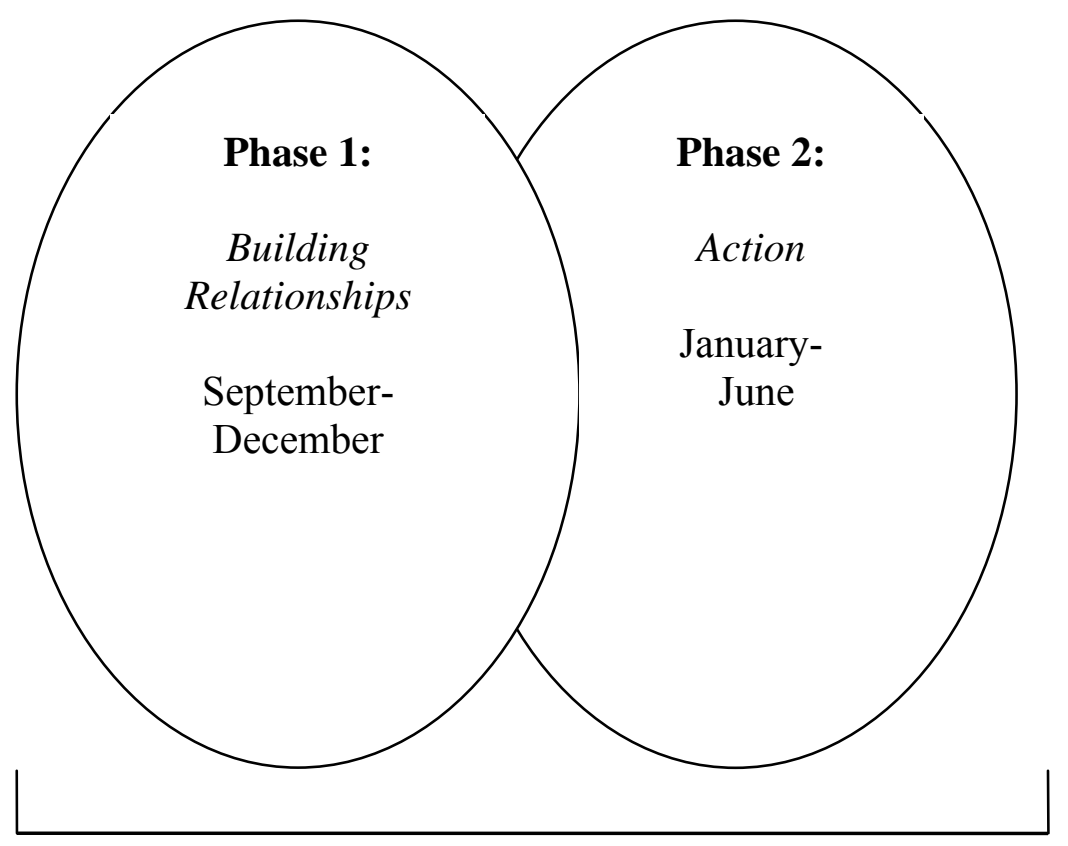

September 2006 - June 2007

Figure 4. Two phases of results. 
Within each phase, the dynamic body image experiences of young Aboriginal are highlighted. Having been fully immersed in Nutana for 10 months, I heard countless stories about how young women feel about their bodies, and I watched them work through the complexities of trying to develop strategies for managing their experiences. Part of the challenge of writing this Results section was trying to decide which of the many participant stories to include as part of the written text. Recognizing that it would be virtually impossible to include every story that was articulated throughout this school year, I decided to describe those experiences that ultimately fostered the development of action initiatives, or those that seemed to stand out within the various action initiatives.

\subsubsection{Phase 1: Building Relationships}

From my first day at Nutana on August 28, 2006 until Winter break, which began on December 22, I spent the majority of my time within the school working to build relationships with students and staff. Building and maintaining relationships was a critical process throughout the entire school year, but given that I was new to the school in September, building relationships was the primary focus from September until December. With rare exceptions, I spent five days a week, from 8:30 am-3:30 pm, trying to integrate myself fully into the Nutana school community. Although I knew that strong relationships were going to be needed if this project was to be successful, it was not until I began working with young women to develop action initiatives that I really understood the critical need for such relationships.

Looking back at the time I spent at Nutana, it is clear that three primary processes fostered the development of relationships with school community members. These three processes were: (1) Familiarization (2) Making Connections, and (3) Giving Back. In an effort to shed light on the types of activities that I engaged in prior to Winter break, this section will describe these three processes/themes. Each theme will be supported by excerpts from my daily journal, in addition to my brief interpretations and summaries of these excerpts. By including selections from my personal journal it may be possible to better understand my thoughts and actions during this relationship building period, which may be useful for future researchers who also intend to immerse themselves into similar relationship building processes within their own research. If I had included the more than 100 pages of journal entries that I wrote over the 10 months I spent at Nutana, the sheer 
volume of entries would have blurred the manner in which I engaged in this relationship building phase. However, by including specific excerpts from my journal, I have attempted to provide a chronological account of how I strived to familiarize myself, make connections, and give back to Nutana students, staff, teachers, programs, and services. Although excerpts from August until December will be included in this section, more detail will be provided for the earlier excerpts because it was during the first two months that I really found myself working hard to try to navigate and position myself within this new environment.

\section{Familiarization}

Becoming familiar with both physical and social aspects of Nutana was a critical first step for me in this relationship building process. Prior to entering the school community, I knew that I would need to take time to learn about members of the school community, community programs and services, as well as the schools' physical environment. As well, I thought that it was important to engage in informal conversations with various school members so that they could have a better understanding of my intentions as a Ph.D. researcher working within their school. Despite knowing that this familiarization process could take time, especially since I was a relatively new member to this community, I can now say that I did not really understand the time it would take to for me to have an in-depth appreciation for the various dimensions (e.g., services, programs) of the school community.

Through my journal excerpts, it should become clear that these first four months at Nutana were a critical time for me in this familiarization process. I spent virtually all day, everyday for four months trying to familiarize myself and make myself familiar to the school members and programs, and I genuinely do not think it would have been possible for me to develop the trust that is needed for strong relationships in a shorter time. Everything (e.g., people, programs, services) was so new to me when I first started working at Nutana, it took me this long to learn about Nutana and subsequently build relationships. Nevertheless, by the time Winter Break arrived I can claim with confidence that I had become comfortably familiar with the school community.

During my first few days at Nutana, I felt overwhelmed by the "newness" of it all; I was not sure how I would ever become familiar with all of the people and programs that 
make up Nutana. In an effort to begin to immerse myself into the Nutana community, I spent the first few days at Nutana in staff meetings, and trying to clean and organize an

office space that served as my home base for the next ten months.

August $28^{\text {th }}, 2006$

Today was the first day of school and I was unable to identify all of the different emotions I was feeling during my walk here. I know that I had a lot of butterflies in my stomach, but I was too overwhelmed to try to figure out what I was feeling. In retrospect, and now that it is the end of the day, I think I was mainly feeling anxious; emergent research is so exciting but it can be a bit stressful for organizers like me. Despite a year of preparation I am not really sure what I am getting myself into.

I arrived at school and met Phyllis in her office. She set me up with a key for the staff room, classrooms, and staff washroom. The simple act of receiving school keys made me feel like I am part of the school community. Phyllis told me how she had been working to find me an office and a space that I can call "home" while I am at Nutana. She showed me one office, room 109 , and although she seemed to think that it is a bit far out of the way I thought it looked perfect. It is a nice space with a desk, fridge, and round table that is great for focus groups; it is also very private. As long as I make myself visible in the hallways during the noon hours and breaks, I don't think that seclusion will be a problem in terms of trying to meet people. Phyllis told me to take over the room so that the staff knows it is mine and where they can find me.

After being given an office, which I am extremely pleased with, I went to the library where all the staff was meeting at 8:30am. I knew that for the first two days we (the staff) would be in meetings. I found walking into the library a bit overwhelming because there were probably about 70 people and I only saw a few familiar faces. I took a seat next to some other women who also looked "new" and I introduced myself. I am so thankful that I am really outgoing otherwise this process of walking into the library would have been even more intimidating. Shortly after the meeting began, new staff were introduced. Phyllis introduced me to the group and told them briefly about my research and that I would be a permanent fixture at Nutana until the end of the school year. I am glad I was introduced, because during breaks I felt more comfortable talking to people because they had a better idea of who I am and what my general purpose is within the school.

The office space that I was given (see Figure 5), or my physical location within the school, helped to facilitate the development of relationships. Within my office I had a desk, as well as a round table with comfortable chairs, a coffee maker, and a fridge to put juice and other refreshments. All of these elements made this office space an attractive space to have conversations with young women. It was wonderful to have this space, and I think it made students more familiar with me in that they perceived me to be a permanent fixture within the school. 


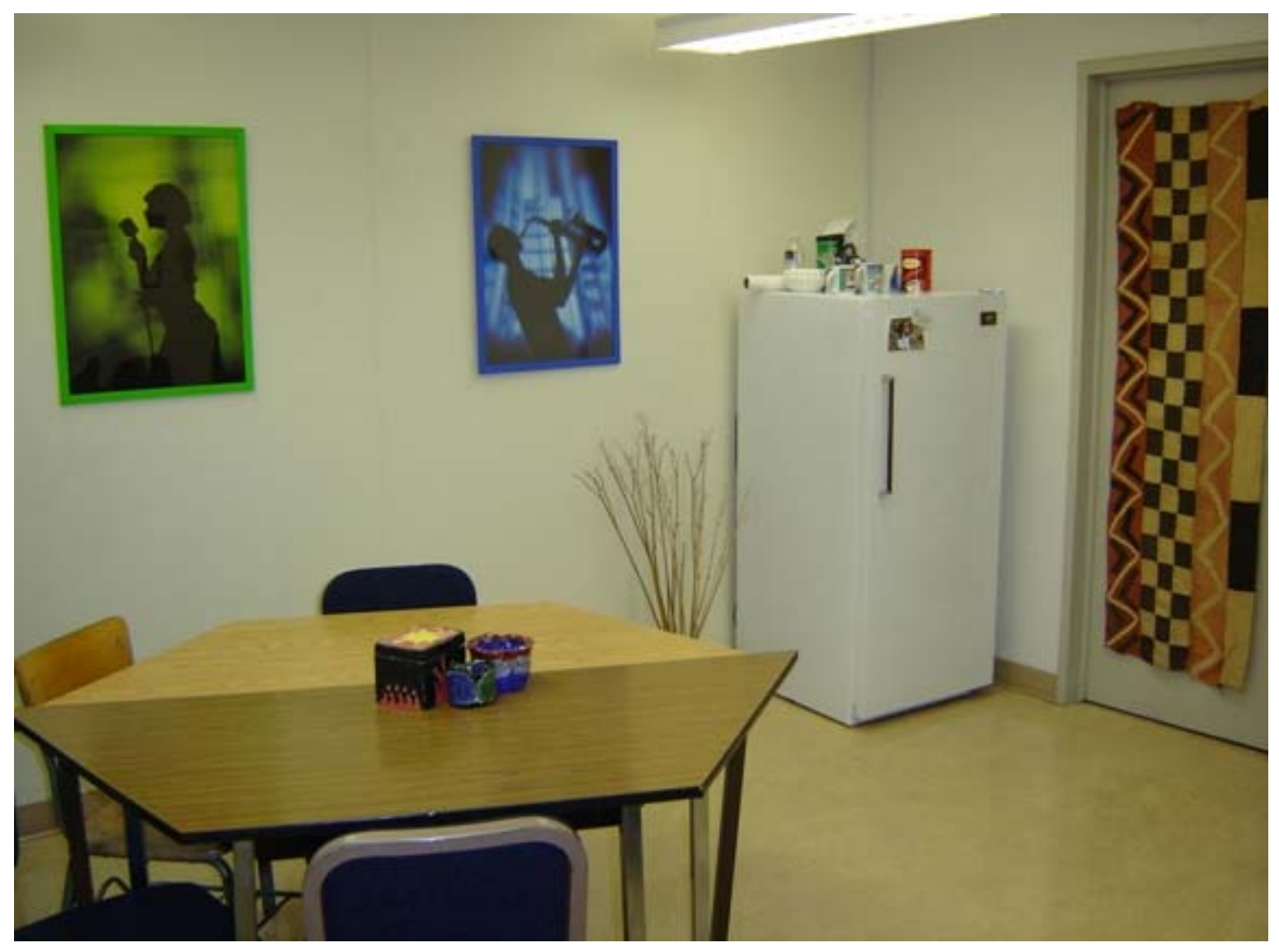

Figure 5. The office space that I called "home" during my 10 months at Nutana.

Although the beginning of the year staff meetings provided me with a quick glimpse of the many programs and services offered to Nutana students, it was my participation in the weekly ISLS Liaison meetings that provided me with the opportunity to familiarize myself with the various staff who were in charge of such programs and services. In an effort to begin building relationships with Nutana partners, I attended weekly ISLS Liaison meetings in the Spring of 2006 and continued until the end of the 2005-2006 academic year (i.e., before this PAR project was initiated in September 2006). As well, when this PAR project began in September 2006 I attended weekly ISLS meetings for the duration of the school year. By having a better understanding of the roles of various staff members, the students and I were able to draw upon these valuable resources when it came time to developing action initiatives. For example, a few instances arose throughout the project that I was unqualified to handle, and therefore I 
directed students to support staff (i.e., guidance counsellors) who helped handle such situations.

September $5^{\text {th }}, 2006$

I attended my first Liaison meeting of the school year this morning at 8:30am. Liaison meetings are held every Tuesday (except during summer break), and the meetings are attended by all individuals who are Nutana staff or partners, but are not teachers. Basically, the meeting is chaired by Phyllis and it is attended by all of those individuals, such as myself, who are linked to ISLS. I really enjoyed this meeting because we all introduced ourselves and it allowed me the opportunity to write down the names of other Nutana staff or partners.

After spending almost a week at Nutana, I began to realize that becoming familiar with Nutana was a critical component in the relationship building process. Although I had read ample literature that described the lengthy process of the relationship building phase, I still had some unrealistic expectations as to when I should begin meeting students. I was anxious to start engaging young women in conversations about body image-related topics and part of me, as idealistic as it sounds, wished that I could almost hurry through this initial familiarization phase and get to the action phase.

September $5^{\text {th }}, 2006$

Today I began to feel particularly restless because I am not sure how I am going to start connecting with students. I am trying to walk around in the hallways during breaks, but I really want to start engaging in conversations with students. I have been looking forward to entering the school since my dissertation proposal and now I want to talk to youth. I went to speak with one of the staff members of Youth Launch, because I knew she could provide me with some advice. Youth Launch, which is a positive youth leadership program housed in Nutana, is funded by the Students' Commission of Canada; this organization provides opportunities for youth engagement in an effort to encourage young people to use their voices to create positive change. The overall goal of Youth Launch is very similar to the general action goals of this PAR project. Thus, I knew that this staff member could likely provide me with some suggestions as to how to engage youth. She told me that she completely understands that I want to start meeting youth, and she assured me that it will happen but "when working with youth things just take time."

Talking with this staff member from Youth Launch forced me to open my eyes to the way in which this research would likely unfold. More specifically, given her experience in working with youth, she encouraged me to relax and to let the research unfold at a pace that is more natural to the school environment (i.e., slower).

During this time, I also became more familiar with the manner in which high school has changed since I was a student. I try not to think that I am too far removed from the high school experience, since it has been less than 10 years since I graduated high school. However, the safety issues that students are now faced with are quite different than I remember.

September $7^{\text {th }}, 2006$ 
We had a staff meeting today and all staff were taught the procedures for "security in place" and "lock down". It was today that I really began to realize how different high school is from when I used to go to school. All we ever practiced was fire drills, and now we have to know what to do in case there is a person with a gun in the school. Today's meeting really gave me a reality check.

Although I quickly familiarized myself with potential issues that could arise during my time at Nutana, I found it more difficult to get a thorough understanding of the various programs and services that are offered to Nutana students. The bi-annual 411 event at Nutana provided me with my first real opportunity to familiarize myself with the various programs offered at Nutana; as well, it provided me with the opportunity to introduce myself to many of the Nutana students.

September $13^{\text {th }}, 2006$

Today was Nutana's bi-annual 411 event. The goal of this event is to provide students with information on Nutana's various services, programs, and partners. Since I am a partner of Nutana, last week Phyllis suggested that I put a display in the event. I was a little unsure of what I should present because I am just trying to build relationships with students and staff and trying to introduce them to my research. Seeing as this is emergent research, I am not really sure what types of initiatives will be developed so I did not really know what to put as a display. However, after talking with Phyllis I decided to make a display with the College of Kinesiology sign. I stood at my booth and, when students came up to talk to me, I told them about my general research goals. Students demonstrated a surprising amount of interest in this research.

Events such as the 411 allowed me to learn about student services; however, the simple act of being immersed in the school community provided me with many opportunities to become more familiar with the types of body image-related issues that students face. By walking through the hallways during breaks and lunch hour, I would overhear conversations that young people were having about their bodies. This opportunity to hear young people talk was invaluable in that I often read about how prominent body experiences are to young people, but hearing young people engage in conversations really made me aware of the strong role that body image plays in young peoples' lives.

October $26^{\text {th }}, 2006$

As I was walking into my office this morning a young woman was sitting on a chair in the hallway and she was confronting two other girls. She was telling them that she heard from somewhere that they were saying that they didn't like her clothes and that she was ugly. Although I didn't catch the whole conversation or the outcome, I think it is interesting that this young woman confronted the others. I think that in order for her to do this she must have been thinking about it and it was bugging her.

Familiarizing myself with Nutana, and making myself familiar to members of the school community, was not a quick process. I knew that this process would take some 
time, especially since I was new to the school, and I did not initially know very many people or much about the programs and services that were available to students.

However, after spending virtually all day for four months in the school I really felt that I "fit in" to the school community. After four months I finally felt like I had a general understanding of the dynamic components that make Nutana so unique.

\section{Making Connections}

Making connections was another critical process in the relationship building phase. While becoming familiarized with the various people, programs, and services of of Nutana Collegiate was important, I realized that it would be beneficial to make "key" connections with certain people and groups of people at Nutana. More specifically, I felt that by connecting with certain people who had similar goals to this research (e.g., staff of Youth Launch), or by connecting with groups of young women who could potentially get involved in this research (e.g., young women from Girls' Club), that I would be able to more easily establish trusting relationships that would be critical when it came time to developing action initiatives.

Making a connection with young Aboriginal women at Nutana was one of my first priorities at Nutana. During the Spring and Fall of 2006 I had various discussions with Phyllis about how I would play a leadership role in the Girls' Mentorship program that is offered each year at Nutana. We both felt that my involvement in Girls' Mentorship would provide me with the opportunity to meet young women who ultimately could end up participating in this research project.

September $12^{\text {th }}, 2006$

This morning at the Liaison meeting we spent some time talking about the Girls' Mentorship group, which has historically been a group of young women in grade 12 who meet once a week at lunch time and engage in activities with the overall purpose of mentoring young women in grade 9. However, Phyllis and I met last week, and we discussed how we feel that it is important to open up the mentorship to all grades, and that we want to make it more like a "Girls' Club", where young women of all grades are welcome. The Liaison group seemed really supportive of this idea. In previous discussions with the Phyllis and a school counsellor, they explained how some of the young women had commitment problems. Thus, we feel that if we call it more of a "Girls' Club", then it might foster a more welcoming and fun environment. We decided that during the first Girls' Club meeting we would ask the young women if they liked this new format and then we could make changes based on their suggestions.

October $17^{\text {th }}, 2006$

We had our first official Girls' Club meeting today at lunch and it went great. About 15 young women showed up and they had a lot of suggestions for proposed activities. For the upcoming year, the young women suggested a number of sport-related activities and I thought that 
this was awesome. I am really excited because they seem like a really great group and they seem to be really keen.

The first Girls' Club meeting was a great success, in that 15 young women attended, which was significantly more than how many had been attending Girls' Mentorship in the previous years. At this first meeting I was able to introduce myself to the young women and I told them about this research project. The young women asked questions about the research process (e.g., Who gets to decide what activities we develop?), and their various questions seemed to me to indicate their genuine interest in the goals of the project.

At this first Girls' Club meeting the young women mentioned that during the weekly meetings they would like to engage in various physical activities. Through conversations with the young women it became clear that they recognize the manner in which physical activity influences their body image experiences. Although the young women had proposed to do a number of physical activities, I was a bit unsure as to how successful such activities would be, particularly since I had heard staff talk about how very few young women sign up for physical education class. Nevertheless, a number of physical activities that the young women and I planned for Girls' Club were really well attended, which resulted in our perceived success of the activities.

November $28^{\text {th }}, 2006$

Today was a super fun day because we had Girls' Club and we did line dancing and swing dancing with the Boys' Mentorship group. Although I, along with the other group facilitators, were not sure how many young people would show up, we had an excellent turn out. There were probably about 30 young people there in total, and they had a blast trying to learn the new dances.

Being involved in Girls' Club provided me with lots of opportunities to meet young women. However, I was also invited to participate as a member of Youth Launch, where I became connected with more young women. In early September, I was invited to the first Youth Launch staff meeting of the academic year and, although it was somewhat unexpected, it was here that I had my first discussion with young women about their body image experiences.

September $26^{\text {th }}, 2006$

After school today I met with Youth Launch for the first staff meeting of the year; what a great connection. I was invited to this meeting because of the various connections between my own research goals and the goals Youth Launch (as previously described in the September 5 excerpt). The three senior staff members, all of whom are employed by Youth Launch, lead the meeting, which was attended by me and 10 youth facilitators, 9 of which are women. The history 
and philosophy of Youth Launch was described, and then there was a discussion about potential projects that Youth Launch may become engaged in, or are already engaged in (e.g., youth facilitator training, sexuality conference).

In an effort to demonstrate how youth facilitators may try to engage other youth in a focus group discussion, one of the senior staff members posed a question to the group. She said, "what do you and/or your peers think of when you think of body image?" She chose a question that focused on body image because I was new to the group and she thought that this would give youth the chance to talk about my research. On a broader level, she wanted to show how it is important that all individuals in the focus group discussion get a chance to speak and how all opinions need to be respected.

One young woman, who self-identified as an Aboriginal woman, told me that when she was in Grade 8, she used to wear low cut clothes and she would want to show off her cleavage and her body. However, now that she is 17 years old she explained how she is learning to respect her body. When I asked how she is learning to respect her body, she said that she is getting back to her roots by attending cultural activities such as Powwows.

Throughout this focus group discussion, many stories about body image were shared. One young woman said it is important to be comfortable with herself and that she thinks women need to focus on their inner strength and not just outer appearance. Another young woman explained how she thinks that the body is so tied up with sexuality, and that the bodies of women are often perceived by others as being good for just one thing (i.e., sex). She also explained how there is a lot of disconnect between the way she perceives herself, and what she sees in the mirror. Similarly, another young woman explained how it is difficult to differentiate between media and reality. She said that what we see in the media is not necessarily attainable, yet we still have trouble differentiating. Another young woman explained how she feels that her friends and other women are often their own worst critic. She explained how her friends either argue that they are "not skinny enough" or their hair or clothes are not nice enough. She said that it is "really sick how that works".

To end the meeting we went around in a circle and each young person was asked to identify their passion. It was so inspiring to hear about the passions of young people! Today was a super long day; I was there for nearly 12 hours, but I made so many connections today that it was definitely worth it. This Youth Launch meeting provided me with the opportunity to make some really great connections with the youth, and I am so thankful that I was invited to participate.

Although I did not know that one of the senior staff members was going to ask the youth a question about their body image, I was happy that I was provided with this brief insight into how some of the young people at Nutana feel about their bodies. Hearing the young people speak so readily about their body image experiences made me realize that such experiences are something that young people are likely to share. As well, having been given the opportunity to share my own thoughts on body image and my own goals as a researcher, I was able to develop a connection with some of the members of Youth Launch.

The connection I made with Youth Launch continued to develop as the school year progressed. The many consistencies between the objectives of Youth Launch and my own goals as a researcher, made this relationship easy to establish and maintain. This connection with Youth Launch provided me with great opportunities to work with youth on important issues, including body image issues. 
December $4^{\text {th }}, 2006$

This afternoon I attended a Youth Launch meeting. We talked about the SHY (Sexual Health in Youth) conference, which will likely be held on February 8. Depending on whether or not we get funding, the conference and its scope will likely change. However, the Youth Launch leaders explained how they are hoping to have about 150 people and they want to invite students in grades 10-12 from all over the province. They said there would be a variety of sessions in the morning, including a body image session that they hoped would be led by myself and some other students.

I am really enjoying my connection with Youth Launch because at Youth Launch I am still considered a youth. Within Youth Launch, the definition of youth encompasses all of those individuals under the age of 30 , so that makes me feel wonderful. Youth Launch explained how they want youth leading the sessions at the conference, and I was asked to be a facilitator. Although I don't have Youth Launch Facilitator training, they are confident that my experience with youth and interviews will be just fine. I feel like when I am in this group, I have a bit of an easier time navigating my journey between youth and staff. Here, I can be a youth as well as a Nutana staff member and there is no conflict.

The initial connections that I made with young women through Girls' Club and Youth Launch provided a strong foundation for the development of relationships with young women. Being honest and openly sharing my research goals with the young women were critical processes in terms of developing these connections.

\section{Giving Back}

When I first knew that I would be engaging in this research process at Nutana, I realized that I would have to find ways to try to build relationships with students and staff so that they would feel comfortable having me, a researcher, as part of their school community. I felt that "giving back" to the school, by offering a service or simply by providing my support to programs, would be an important process in the relationship building phase. I wanted students, staff, and teachers to see how thankful I was for having them welcome me so readily into their school so, as described below, I worked hard to contribute to the school community in a variety of ways.

Given my relationship with two local community yoga instructors, and their enthusiasm about working with youth, I thought that offering yoga would be a great way to "give back" to the school. Yoga is well known for the focus that it places on the mindbody connection, and this was an activity that allowed me the opportunity to not only give something to the school, but it was an activity that fostered discussions about the body. Although I initiated the yoga classes (with the full support of Phyllis), I wanted to ensure that the students felt, and were, involved in bringing the classes to the school. Therefore, the students helped to advertise the classes in a "catchy" format.

September 21 $1^{\text {st }}, 2006$ 
This morning I went to the grade 10/11 art class and some of the students created "gesture drawings" of me in yoga poses. These drawings were then made into posters to advertise the upcoming yoga classes. I think the students enjoyed this activity because I got up on the table and did some yoga poses; by the looks on their faces I could tell that they thought this was fairly odd yet funny. It was really great that the students volunteered to help create posters because not only did it give me the opportunity to connect with students, but they appreciated the opportunity to have their drawings displayed in the hallways. As well, since they created the signs, they became familiar with the details (e.g., when, where) about the yoga classes.

After spending a few weeks advertising the yoga classes through the gesture drawing posters (see Figure 6), in-class announcements, and word of mouth, we had our first class. I was unsure as to how many young women would attend these sessions, particularly since yoga was quite unfamiliar to many of the students (I realized this when encouraging young people to attend the classes); however, once again I was somewhat surprised at how many young women attended.

October $4^{\text {th }}, 2006$

Today was the first day of yoga and it went great. I spent the morning walking around the halls and trying to encourage people to attend the class. We had about 9 young women show up for the class, in addition to myself, Phyllis, and another staff member. I thought the turnout was awesome. The instructor was really great; she kept emphasizing that there is not a "yoga olympics", and thus we are not competing with anyone else in the class. She also encouraged us to relax at the beginning and the end of the session and to give thanks for our breath because we don't always know when it will be taken away. I think the young women really enjoyed both the physical and spiritual aspects of the class, especially since I heard some of them telling their other friends about it after the class ended.

Hearing the young women talk so positively about their first yoga experience was really gratifying; I felt like I was able to facilitate a program that was well received by school members. Again, I did not know how well received this class would be, but those who attended really seemed to appreciate the opportunity to participate.

After being in the school for approximately two months I began to see other, perhaps more subtle, ways in which I was giving back to the school. I realized that I was perceived by many of the students to be an "adult ally", and this role allowed me the opportunity to support students. I began to see that the students did not necessarily see me as a researcher, and most of the students knew that I was not a teacher. To many of the students I was seen as a young adult that they could trust.

October $23^{\text {rd }}, 2006$

It was a very emotionally tough day at school today; there was a tragedy that involved a student from Nutana and many of the students were struggling to deal with their emotions throughout the day. One young woman was having a really tough time and she just wanted to talk to me about how she was feeling and what she was thinking. I can't even begin to imagine how these young people are able to deal with such tragedy, but I felt good knowing that I was there as a person who would listen. Today made me realize that I play a different role here at the school. I 
am not a teacher, but I am a young adult ally; I think that the students are beginning to see me as someone they can talk to and trust.

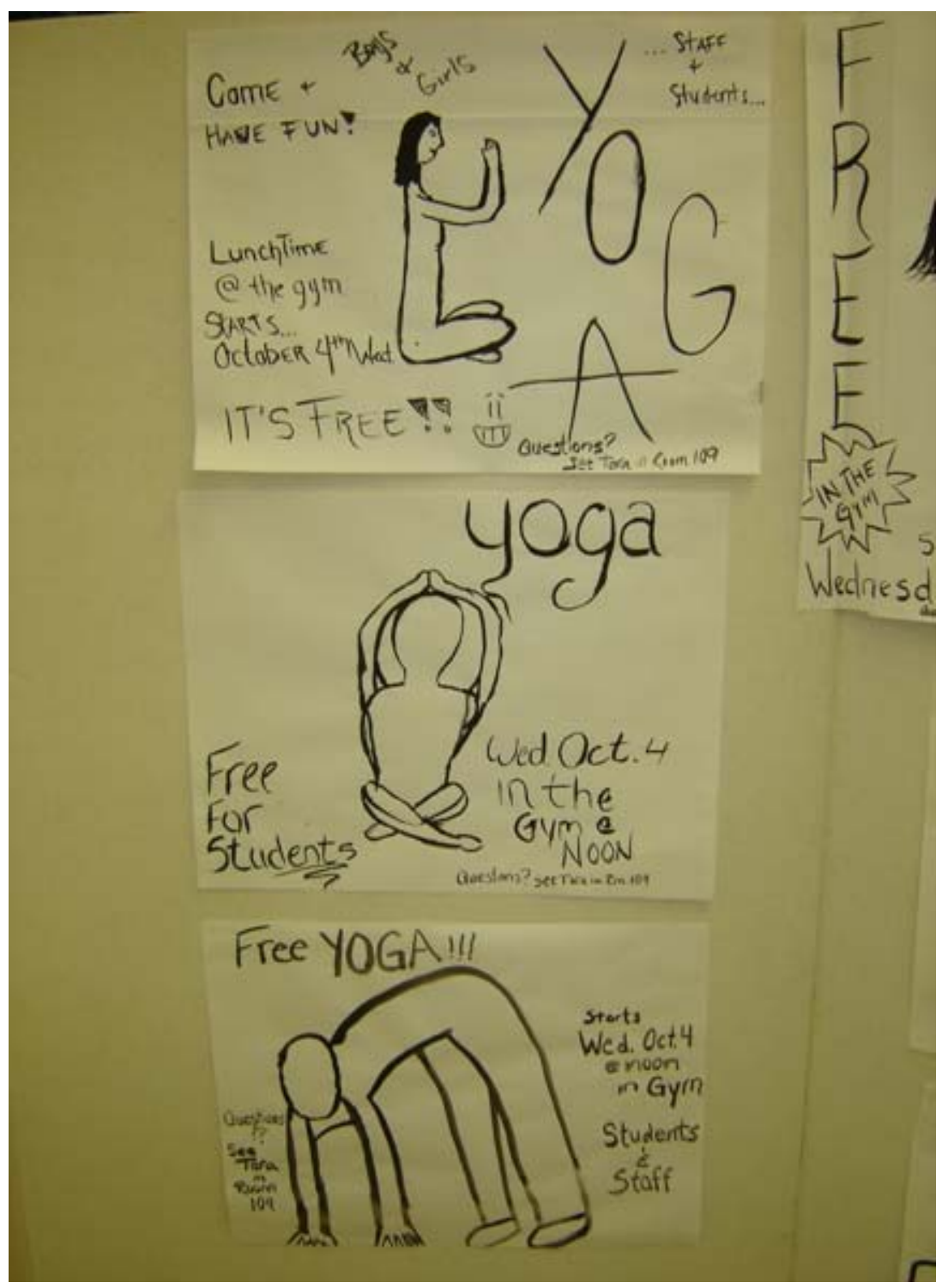

Figure 6. Gesture drawings used to advertise yoga classes.

I offered support to students through my role as an adult ally, but I was also able to offer my support to different staff and teachers. More specifically, in an effort to try to give back to the school for so readily welcoming me into their community, I shared my grant writing experience with various staff members. Through discussions with different teachers and staff over the first few months in the school, it became apparent that my experience writing grants as a graduate student could support the goals of some of the 
teachers and staff. For example, after various discussions with the art teacher her and I decided that we would apply for a provincial grant that would support young people in sharing their body image experiences through art. The art teacher wanted to apply for this grant to obtain extra funding to support students and, after talking to various students in the art class about what should be included as part of the grant, we developed a grant that would be consistent to the goals of this PAR project.

November $27^{\text {th }}, 2006$

I was kind of disappointed today because we didn't get the grant that we applied for through ArtsSmart to fund an art program whereby young people could be supported in sharing their body experiences through art. The art teacher and I spent many hours during the past few weeks putting together what we perceived to be a very competitive application, but unfortunately we were unsuccessful in receiving grant money. Despite this, I am happy that I spent time trying to obtain this funding because it was a good way for me to use my skills (i.e., grant writing skills) as a way to give back to the school.

We spent about 10 hours preparing this grant and, despite our efforts, we were not successful in being awarded funding. However, the Wellness Subcommittee and I were successful in receiving funding from a Saskatoon Health Region grant (see section 3.1.2.1.3); therefore, I felt that my grant writing experience did provide me with an opportunity to give back to the school.

In addition to supporting different teachers and staff with individual projects (e.g., applying for grants), I also gave back to the school by supporting various workshops, which were not necessarily related to this PAR project. For example, in early December I facilitated some youth discussions during Nutana's Think Tank session. The intent of this workshop was to provide youth with opportunities to share their perceptions of the strengths and weaknesses of Nutana services and programs. The students were asked for their opinions and the youth were extremely grateful to know that their opinions were valued. It was amazing to see how proud the youth were to be involved in a discussion that could lead to positive change. Being involved in this Think Tank session provided me with the opportunity to see what types of activities the youth find meaningful, and these conversations ultimately lead to the development of Art Group (see section

\subsubsection{3)}

December $7^{\text {th }}, 2006$

The youth at Nutana never fail to amaze me in terms of the knowledge that they hold and are able to express. In an effort by Nutana administrators to explore Nutana's strengths and weaknesses as a school, about 30 students were asked to be involved in a Think Tank session that explored Nutana's programs and services. This Think Tank session really allowed me the 
opportunity to see how the students view Nutana. The young people were asked a lot of questions including what types of things at Nutana 1) make them feel welcome or connected?, and 2) unwelcome or disconnected?

The students had so many stories that they shared when we addressed each question and they seemed genuinely honored that their stories were being solicited. We had a tough time getting through all of the questions because of the many stories that they wanted to share. For example, the young people explained how they felt like they could fit into Nutana because there was such diversity here, and no one looked at them because they were different (e.g., if they had a baby). They said how most of the time the teachers were really understanding about other commitments (e.g., baby being sick, commitments to family), but they explained how there was still room for improvement. All of the groups said how they like and utilize the breakfast van, and our group said how they like lunch time events that have free lunch. Today was just a perfect example of how people (especially young women) like the opportunity to share their stories.

I was also really amazed how understanding the students were in terms of other people's needs and wants. As an exercise, students were asked to hypothetically vote three programs, classes, or services out of the school; the students had a really difficult time doing this. They realized that even though they weren't utilizing certain services, it didn't mean others weren't. I think this format also gave the students the opportunity to think of ways to constructively criticize and ultimately improve Nutana. One student said "I hate Native Studies class", but then I asked her to think about what it was that she hated and how it could be improved. By thinking of it in this way, I think it gave a bit of respect to the teachers (e.g., they have to follow a certain curriculum), but it also gave her the opportunity to think of ways to work towards positive change. It was great to also hear the students' ideas on what they want and they said a "freestyle art program" at lunch time would be something they want. This is great for my own research reasons because now I know that there would be some interest if we did implement some sort of body image "freestyle art sessions".

Although my reason for volunteering to facilitate discussions with youth during the Think Tank was simply based on my effort to offer something or give back to the school, the discussions I had with youth did in turn shed light on this PAR project. More specifically, the conversations demonstrated that youth have strong opinions and ideas, which they readily like to share when there is potential to create positive change. As well, their ideas shed light on some of the positive initiatives (e.g., Art Group) that could be developed by youth in this PAR project.

Giving back to the school community was a critical process in terms of relationship building, and although I had spent 4 months working hard to support various teachers, staff, students, and school projects, by December I still had a lingering doubt as to whether I was really offering something to the school. I read many times about the importance of the process within research, and how the process is often more important than the outcomes. Nevertheless, I found this notion quite hard to fully comprehend. When I looked at my daily activities I saw that I was continually working to support school members and school programs; I realized that the support I was providing was part 
of the process. Despite this realization, I was still not convinced that I was making enough of an impact during this process.

December $13^{\text {th }}, 2006$

This afternoon we had the ISLS community partner visioning meeting from 12:303:00pm. I felt a bit awkward at first because each partner was to talk about the services they use, the students they appeal to, etc., and I am not really at the point in my research where I am actually developing initiatives with students; I am still in the process of developing relationships. Nevertheless, I was placed in a break-out group with Phyllis, along with staff from Youth Launch, Millie's, and SAKS; and Phyllis kept telling the group how it is "wonderful" to have me in the school.

Throughout the group discussion, one of the Youth Launch staff members said some statements that really seemed to resonate with me. She said that at Nutana it is the process that is important; the process being all of the services, initiatives, and programs. It is not the product that is important. As well, she said "what's important can't be measured". That is, the process can't be measured, although many of the schools are really focused on evaluation right now. I found this statement to be really powerful because it is really consistent with what Linda Smith says when she is talking about research with Aboriginal peoples. She says, it is the research process and not the outcome that is important (Smith, 1999).

Throughout our discussions I really found myself thinking about my role at Nutana to date. During my first few months at Nutana I would feel somewhat guilty because I kept being thanked for my presence in the school and for the support that I offer to certain programs (e.g., Girls' Club), but I didn't really see myself doing that much except for offering a hand wherever I could. I could not really recognize how my presence in the school was benefiting anyone. However, today it really sunk in that the process is important. So within my case, the process (e.g., support I offer) may be perceived as more important (or at least as important) as the product (the action).

Being involved in this ISLS community partner meeting really helped me to better understand the significant role of this relationship building phase, and provided me with stronger justification as to why I spent nearly four months engaging in the relationship building process. I better understood that my role in trying to give back to the school was an important part of the "process" and that my role in this process was greatly appreciated.

During the last week of school before Winter Break I was able to give back to the school in a more celebratory way. I supported the young women from the Girls' Club in preparing a Christmas lunch time celebration, in which we invited the Boys' Mentorship program. Although this lunch time celebration was not directly linked to the goals of this PAR project, it was a fun way to offer my support for a Nutana activity.

December $19^{\text {th }}, 2006$

When I got to school this morning I, along with other Girls' Club facilitators, began getting ready for the Girls' Club Christmas lunch. Between all of the facilitators, and the help of the young women, I thought we did a wonderful job. I was not sure if we were going to be able to get the girls to help much, but they did an awesome job. They moved chairs from the gym, they decorated the fiction room with table cloths, center pieces, and colored the white board, and one young woman was the master of ceremony (MC). I was super happy to see her in action. She did 
a welcome to everyone and thanked them for coming, and then she directed tables to the food. After eating, and after a young man from the Boys' Mentorship group thanked the Girls' Club for inviting them, the MC told the guests that we were going to sing carols. I really wasn't sure how this was going to go, particularly with the boys, but given the enthusiastic nature in which they participated, I think they all really enjoyed it. We had a number of special guests at the lunch including the principal, Nutana's Sasktel partner (including a Saskatchewan Rough Rider player), and some Nutana teachers and staff. Overall, I think all of our guests had a great time.

In addition to the Christmas lunch that was organized with the Girls' Club, I also supported the Christmas Donation drive that was being led by some of the Nutana students, staff, and teachers. Seeing as I did not have class commitments, I was available to help set up a donation table in the school foyer so that it would be visible during breaks and lunch time.

December $20^{\text {th }}, 2006$

Today was pretty quiet around school, but I went to school because I was committed to working the Christmas Donation table at lunch time. I am really excited with the money that we have been able to collect for our students here at Nutana. Today we gathered another $\$ 159$ and I think we are up to about $\$ 930$ in monetary donations; we also had gifts donated, as well as food. I worked with a few students from Girls' Club, and then a few staff members came by the table and we all sang Christmas carols. I think the students and staff should be super proud of themselves for all of their commitment to assisting all of those students in need at Nutana.

Having the opportunity to work with students, staff, and teachers on this Christmas Donation drive was really rewarding for me, in that my heart was filled with so much joy when I saw so many members of the Nutana community donating money so that others in their school community could have a better Christmas. Working with Nutana members on this Christmas Donation drive demonstrated to me that the members of this school are mutually supportive and ambitious, which is again my own justification for wanting to work within this school.

Although there is not an obvious link between some of the activities (e.g., Christmas Donation activity; Nutana Think Tank) I engaged in throughout these first few months within the school and the goals of this PAR project, my involvement in such activities supported the development of relationships, which was instrumental to the overall success of this research.

\section{Summary}

Various journal excerpts, along with my interpretation and summaries of these excerpts, has been provided in an effort to demonstrate the various ways in which I worked to develop relationships with students and staff at Nutana. Throughout the first 4 months at Nutana, I worked to familiarize myself and make myself familiar to students, 
staff, teachers, and programs. As well, I worked to establish connections and to give back to the school by supporting various programs and services that were offered throughout the school. My commitment to these processes demonstrated my commitment to students and staff to earn their trust; the establishment of this trust was a critical component in the building of relationships.

\subsubsection{Phase 2: Action}

Building relationships with various Nutana community members helped to set the stage for the development of action initiatives. Such relationships were founded on trust and mutual respect, which were critical components in the collaborative process of developing initiatives. Throughout this PAR project I worked to develop relationships with the young women in the core group and with various other members of the Nutana school community, with the ultimate goal of developing a strong foundation for the development of action initiatives. It was, and continues to be, my belief that by working collaboratively with young people it is possible to ensure that action initiatives are meaningful, successful, and sustainable.

As will be described in the subsections below, the action initiatives from this project emerged in a number of different ways. Suggestions or ideas for proposed action were typically generated by students; however, staff, teachers, and non-stakeholders (e.g., media) also provided ideas for proposed action initiatives. Regardless of the initial idea's source, the core group played a critical role in the general development and implementation of all action initiatives. For example, some of the action initiatives (e.g., Girls' Club, Writing Group) emerged as an extension of other initiatives formally offered by teachers and staff within the school. Body Talk and Art Group, on the other hand, emerged from the ideas put forward by students at Nutana. Despite the manner in which the initiatives emerged, the young women in the core group served as the representative voice of young people, particularly young Aboriginal women, in the school. Thus, to ensure that student voices were at the forefront of all initiatives, the core group played a critical role in shaping and defining the manner in which all initiatives were implemented.

It is difficult to provide an overall summary of the decision making processes involved with the development of each action initiative, because each initiative was 
unique in terms of the manner in which it emerged, developed, and was implemented. However, generally speaking, the young women in the core group were responsible for shaping all activities into successful initiatives. More specifically, the core group was consistently engaged in consultation processes, whereby they discussed among themselves the most appropriate way to develop and to implement initiatives. For example, they would decide when to hold the activities, who should be invited to participate, how to advertise, what supplies would be needed, and where the initiatives would be held. My role as their adult ally was primarily facilitative, in that I helped them to book school classrooms and to prepare any items that had associated costs (e.g., food). I also played a strong supportive role in that I encouraged the participants and worked with them to develop the details of the various initiatives. Even when the core group had less control over the manner in which the action unfolded (e.g., media reports), the core group was still consulted with prior to the implementation of the action initiative.

Although never articulated to me, it initially felt as though the young women in the core group were uncomfortable, or maybe simply unfamiliar, with having the power to create action initiatives and to initiate change. When this PAR project first began in September the young women in the core group seemed somewhat apprehensive about proposing ideas for action, possibly for fear that their voices and ideas would not be respected. However, as the PAR project progressed (i.e., after Winter Break) and they began to see the outcomes of their suggestions, it seemed as though the young women became more comfortable with the notion that they did have the power to create action initiatives. Thus, the young women appeared to be less inhibited about offering suggestions in terms of how each action initiative should unfold, and they gradually became much more clear and assertive in the manner in which they made decisions and recommendations regarding the implementation of initiatives.

The young women in the core group demonstrated a sense of ownership and accountability for the various initiatives. It was such a rewarding experience for me to watch these young women work to implement action initiatives, and to see the great sense of pride that was elicited when they saw the success of their efforts. The core group developed initiatives that made impacts on a number of different levels (e.g., individual, school, provincial, national), and the following subsections will provide more 
detail on the eight action initiatives that were developed as a result of this PAR project. Each initiative has been grouped together into one of three themes with each theme representing the general goal of the grouped action initiatives. The three themes described within this section are Promoting Positive Body Image Experiences (section 3.1.2.1), Self-Expression (section 3.1.2.2), and Creating Awareness (section 3.1.2.3).

By engaging in numerous informal conversations with one another, the core group identified three action goals. It is important to emphasize that the core group did not formally decide on three specific action goals during a single conversation. Instead the various goals emerged individually over the duration of the PAR project, and then the goals were used to guide each initiative. As a result, as I noticed a clear emergence of three fairly distinct action goals, the themes were developed retrospectively by me during the writing of this dissertation.

\subsubsection{Promoting Positive Body Image Experiences}

Promoting positive body image experiences was the primary goal of the three action initiatives: (1) Girls' Club, (2) Yoga, and (3) Wellness Policy. Throughout various conversations with the core group, they explained how young Aboriginal women, and all young people, need to learn to accept their bodies; thus, we (the core group and I) worked to develop programs that promoted positive body image experiences. As will be noted below, the three action initiatives within this theme emerged and worked to promote positive body image experiences in different ways; nevertheless, these three initiatives were all derived from the same general action goal to promote positive body image experiences.

\subsection{Girls’ Club}

Girls' Club promoted positive body image experiences by providing young women with an opportunity to get together on a weekly lunch time basis throughout the duration of the school year (i.e., October to June). During these weekly meetings, young women were supported in sharing their body image experiences in a respectful forum. As well, the young women engaged in various physical activities and ate healthy lunches in an effort to promote positive body image experiences. Girls' Club also played a central role in the development of other initiatives. The young women from the core

group used Girls' Club as their general meeting place whereby they would engage in 
conversations focused on developing most of the other action initiatives. Thus, in addition to promoting positive body image experiences, Girls' Club also served as somewhat of a gateway for most of the other action initiatives.

As stated in the Building Relationships section (see section 3.1.1), I became involved with the Girls' Club in an effort to begin developing relationships with young women and to identify a core group of young women who would play an instrumental role in this research project. Given my previous involvement with the school during my Master's research, I was familiar with Girls' Mentorship group and I felt that this group would be an excellent avenue whereby I could work to build relationships with young women. Thus, Girls' Club was not originally intended to be a forum that would focus on promoting positive body image experiences. However, as will be noted below, the various activities that the young women chose to engage in as part of Girls' Club (e.g., physical activities, talking about the body, eating healthy lunches) was the result of their idea to use Girls' Club as a respectful environment to promote positive body image experiences.

Girls' Club emerged as an extension of Girls' Mentorship group, which had been meeting on a weekly basis over the past few years. Girls' Mentorship was originally developed by some Nutana Staff members who felt that there was a need for senior students (i.e., grade 12 students) to mentor the younger students (i.e., grade 9 students). Although Girls' Mentorship continued for a number of years, some of the staff members identified two problems with the group: (1) some young women (i.e., those in grades 10 and 11) were disappointed that they could not take part in the group, and (2) there was a lack of commitment by the young women to regularly attend Girls' Mentorship.

My involvement in Girls' Club was welcomed by the staff and teachers of Nutana since there was a need for another woman staff member, in addition to Phyllis, to facilitate this group. Phyllis and I engaged in various informal conversations with students, staff, and teachers in an effort to address the above-mentioned problems. As a result of these conversations, Phyllis and I decided that we would facilitate a Girls' Club rather than Girls' Mentorship group; we argued that the shift from the term "Girls' Mentorship" to "Girls' Club" would suggest a more inclusive group. That is, girls from all grades would feel welcome. The second issue (i.e., lack of student commitment) did 
not seem as though it was going to be easily resolved. Given the belief by many of the teachers and staff that there was a "lack of commitment" among many students, some school members had their doubts that a consistent group of young women would regularly attend Girls' Club. As well, there was doubt that a core group for this research project could be developed from Girls' Club. Somewhat of an eternal optimist, I felt that if I could develop trusting relationships with the young women in the group then they would feel supported and encouraged to develop initiatives that they deemed meaningful and effective.

Phyllis and I spent the first few weeks of September informally talking to young women in the hallway and telling them about the newly developed Girls' Club that would be open to all young women. We also hung up signs in the school hallways inviting young women to participate in Girls' Club. Our first official Girls' Club meeting was well attended (i.e., 15 young women), and my initial optimism regarding the commitment of young women was well founded in that an average of 15 young women attended Girls' Club on a weekly basis, from October until the end of June. Of these 15 young women, the seven young women from the core group consistently attended Girls' Club, and then the eight other young women would change from week to week. However, the young women, Phyllis, and I met for Girls' Club every Monday at noon for the majority of the school year, and as the school year progressed a more consistent group of 15 young women would regularly attend.

The young women, Phyllis, and I spent the first day of Girls' Club doing introductions and brainstorming ideas for weekly activities and an attractive name for the group. Although the young women discussed other options for names (e.g., Team Cool), they decided to stick with Girls' Club as they thought it was a more encompassing and transparent group name. As well, during this initial Girls' Club meeting I had the opportunity to explain my role in the school. I was very honest about what my research goals were, and all of the young women seemed relatively interested in the process. The young women who attended this first meeting argued that Girls' Club would be the perfect forum to initiate discussions about body image and to engage in activities that support the promotion of positive body image. Therefore, these weekly meetings themselves were a form of action in that the young women identified an action goal (i.e., 
promote positive body image experiences) and they implemented activities (e.g., physical activities) that worked to achieve this goal.

The young women who attended Girls' Club recognized the important role that physical activity plays in terms of women's body image, and they explained how they wanted to use a number of our weekly meetings to engage in physical activities. Many of the young women indicated that they did not have a time in which they were physically active, and a few of the young women explained how physical education was not offered during every academic quarter. Thus, they could not always fit this course into their academic schedule. As a result of these discussions regarding physical activity, the young women engaged in various types of physical activities (e.g., dancing, badminton, volleyball) during the weekly meetings. Despite the focus on physical activity, there were days when we also engaged in other types of activities that the young women were interested in (e.g., crafts, jewelry making). The few times that we used the weekly meetings to make crafts or jewelry were typically in the week or two leading up to a holiday (e.g., Christmas, Valentine's Day), as the young women often wanted to use this time to make gifts for their families and friends.

Girls' Club made a positive impact at a number of different levels. First, at an individual level this action initiative provided young women with the opportunity to share their experiences and views on body image, and it demonstrated to each young woman that she has the power to create action (i.e., promote positive body image). Suggesting weekly activities (e.g., physical activities) that could be used to manage body image, and seeing the results of their suggestions, demonstrated to the young women that their voices were being valued. Young people are not typically provided with the power to develop and to implement activities that they feel could make a positive influence on their daily experiences, and this project demonstrated what can happen when young people are provided with such opportunities. Secondly, Girls' Club made an impact on the core group, in that the core group typically used these weekly meeting times as a safe space to discuss ideas for other proposed action initiatives. Thus, Girls' Club provided the core group, and any other young women who wanted to be involved, with the opportunity to create and/or shape the other initiatives that have been described in the following subsections. The core group facilitated the development and implementation of various 
action initiatives, and it was rewarding for this group to see the positive outcomes of all of their hard work and planning. Third, Girls' Club made an impact at the school level, in that all young women at Nutana were welcome to attend. Not all young women at Nutana attended Girls' Club but those who did, had the opportunity to participate in youth organized activities that were primarily focused on promoting positive body image.

\subsection{Yoga}

I organized for an instructor to come to Nutana once a week for 12 weeks (October to December) to teach yoga. This decision was rooted in my awareness of the positive impact yoga can have on body image experiences of young women and the excitement expressed by the group when proposed with this opportunity. Fortunately, some money was provided by the University's President's SSHRC fund to cover research-related costs associated with this project, and this money was used to cover the cost of hiring this instructor. Prior to organizing the class, I had various informal conversations with students, teachers, and staff about whether they would take part in yoga if it was offered. Through these conversations, it was agreed that a yoga program offered free of charge to school members would be well utilized, since it can be quite expensive to enroll in yoga classes in the community. I felt that offering yoga could be a rapport building opportunity and also a way for me to "give something back" to the school for welcoming me so readily into their school community and supporting my research.

Initially the idea to offer yoga classes to Nutana students for the 12 weeks leading up to Winter Break originated from me; however, after Winter Break the yoga classes transformed into an action initiative promoted by the core group as a way to achieve the action goal of promoting positive body image experiences. Recognizing the manner in which yoga positively impacted her body image experiences, a young woman from the core group asked other young women from the core group if they too felt that yoga could be used to support the action goal of promoting positive body image experiences. Little discussion arose from her question, as there was widespread agreement that yoga could support their action goal. Thus, after Winter Break the core group asked me if I could find someone to continue teaching the yoga. Coincidentally, at the same time that the young women asked for yoga to continue, I was approached by a fellow student at the 
university who is a trained yoga instructor and who was looking for an opportunity to volunteer her yoga skills. Thus, after Winter Break, yoga was offered for an additional 10 weeks.

On average, approximately nine students and staff, including three core group members, attended the yoga classes. The core group decided that yoga should be offered to all students, as they argued that yoga could promote positive body image experiences among both young women and men. Thus, young men were also invited to participate. Although men were welcome to attend, only one young man regularly participated in yoga. After each class I would informally talk to the young people who participated in an effort to better understand why they enjoyed the yoga class. Generally speaking, the students explained that they liked how it made them feel both physically and mentally. More specifically, one young woman explained how she thought that yoga was a "good workout". As well, in describing the mental benefits of yoga, another young woman said how yoga made her "feel better" about herself. Thus, yoga transformed from a rapport building activity that was originated by me, to an action initiative that supported the core group's goal to promote positive body image experiences.

\subsection{Wellness Policy}

Unlike the other action initiatives that were developed and shaped by the core group, the Wellness Policy was an initiative that was primarily driven by Phyllis and me. Although the young women from the core group were involved in various aspects of this initiative (e.g., gathering of student opinions at 411), this initiative stemmed from ideas that arose during the Wellness Committee, a group comprised of teachers and support staff. Therefore, as PAR project stakeholders who had a fairly thorough understanding of the core group's goals for this project, Phyllis and I worked to represent the core groups' goal of promoting positive body image experiences.

Nutana's Wellness Committee was comprised of various staff members from

Nutana. At the beginning of the school year all staff were asked to sign up for one of the four committees (i.e., wellness, literacy for life, community connections, and student retention) that would work to address Nutana's four strategic priorities. I volunteered to attend the Wellness Committee, and during one of our monthly Wellness Committee meetings it was brought to our attention that the school division was looking to 
implement a healthy food policy within local schools over the next five years. Our committee subsequently developed a Wellness Subcommittee, which was comprised of 6 teachers and staff, to look at Nutana's current food and physical activity guidelines in an effort to develop our own general Wellness Policy for the school.

Phyllis and I initially felt that this Wellness Policy would support the action goal of promoting positive body image experiences, since the Policy recognized the strong relationship between healthy eating, physical activity, and young women's experiences with their bodies. As well, after speaking with the core group, it was apparent that they too felt that a Wellness Policy would support the goals of this PAR project. Because everyone on the Wellness Subcommittee realized that working in a group can be difficult, I volunteered to do some ground work in terms of exploring what other schools were doing in terms of such policies. I looked at the policies of other provinces (e.g., British Columbia, New Brunswick), which were deemed successful by the respective provinces. A five-step process was outlined by the Department of Education (1991) in New Brunswick's Food and Nutrition Policy; this process supported my belief that students should be involved in all aspects of school change. The five steps were: (1) create a shared vision, (2) select priority nutrition policy issues, (3) develop a plan, (4) put the plan into action, and (5) evaluate, plan for the future and celebrate. The collaborative nature of this five-step process was very similar to the PAR plan that I proposed prior to beginning this $\mathrm{Ph}$.D. research in that there was a focus on creating a shared vision, and then developing, implementing, and evaluating action. Thus, I felt comfortable supporting this proposed five-step process for the development of our Wellness Policy. Based on the policies that I researched, I developed a similar collaborative plan of action that I then brought to the Subcommittee.

Although the Subcommittee agreed that this process would be a good plan in terms of implementing healthy changes within the school, we knew that we would need funding to support our endeavour. Therefore, the members of the Subcommittee searched for grants that we could apply for to help cover the costs of our plan. Everyone agreed that we needed to include the voices of all stakeholders in the development of the grants that would be produced in an effort to support our Wellness Policy. 
In an effort to do this, young women from the core group sat at an information booth at the biannual 411 information lunch time session. At the booth, the young women asked for student input on healthy food choices, which the core group identified as an important component of any Wellness Policy. More specifically, some of the signs at our information table said, "Hey Nutana, what are you hungry for?" and "Healthy choices, let's hear your voices"; our intent was to grab the attention of the students (see Figure 7). In addition to the 411, the school's health nurse (i.e., another Wellness Subcommittee member) and I went into some of the classes and spoke to students to get their opinions on the potential implementation of a Wellness Policy within the school. Through our informal presentation we reiterated that it is important to hear their voices, since any changes that would be implemented into the school would have a direct impact on them as students.

As a result of the interest expressed by students at the 411 and our classroom visits, it became increasingly apparent that there was fairly widespread student support for a Wellness Policy, which focused on implementing more healthy food options and physical activity into the school. Although physical activity was an important component of this Wellness Policy, the students were much more vocal in terms of the potential changes that were going to be made to their schools' food options. Students were asked to write down their opinions with respect to the potential Wellness Policy, so that their opinions could be shared to the Wellness Subcommittee. Some of the students also chose to read their opinions aloud during our classroom visit. One young woman said,

I believe it is important for people in any school to have healthy food because it is where we spend most of our time... breakfast and lunch are very important meals and if my school didn't have a Breakfast Program and a SAKS room for mothers then I would only have one meal a day...This [healthy food at schools] would also benefit kids from low income families who can't always afford the foods they need and who sometimes don't have the food at home.

Another young woman expressed similar sentiments, as she felt that students spend so much time in a school setting and the food options they have at home may not be healthy. She also stressed the importance of being educated about healthy eating. She explained,

I believe it is important to have healthier choices in this building because the way that some parents may shop at home may not be healthy...We are at school to be educated, and being educated in eating habits is important as well. 


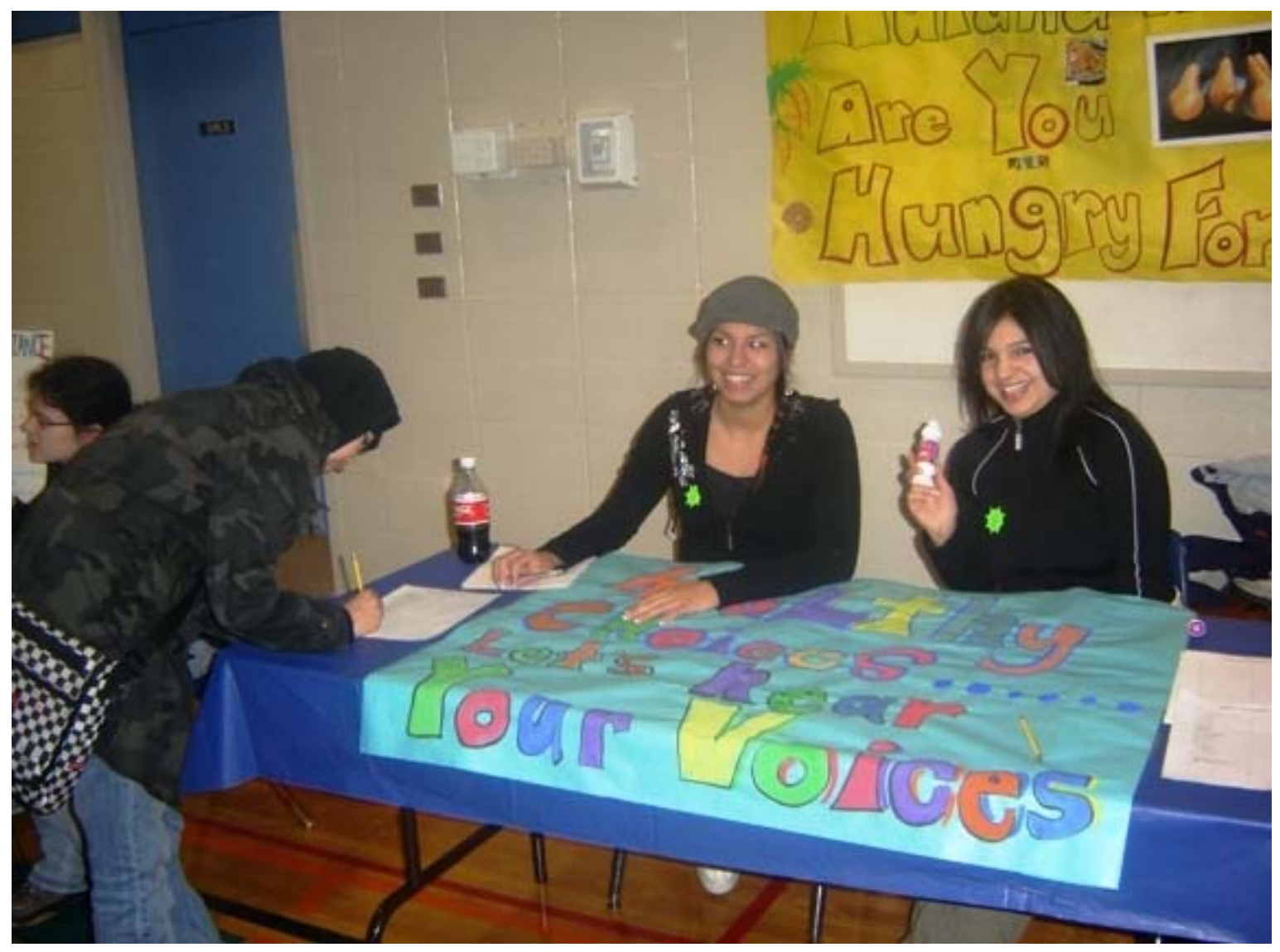

Figure 7. Two young women from the core group gathering students' opinions about healthy food options at the 411 .

Although many of the students expressed their support for such an initiative, not all students felt that small changes within the school would make a difference in terms of students' eating habits. One young woman explained,

Unless all 'unhealthy' choices are removed, I do not believe this would be beneficial. Making healthier choices available does nothing when no one will eat it. This issue is trying to send the message about healthy eating all of the time (at home, in public, as well as at school). Having potato chips and chocolate in our vending machines will deter youth from making healthier choices, even if they are available.

The Wellness Subcommittee thought that not all students, or even staff and teachers for that matter, would fully support the proposed food and physical activity changes. Nevertheless, we felt that if the majority of the school population supported such change, that it would be possible to implement this initiative. Therefore, in addition to seeking support from the students for a Wellness Policy, members from the Wellness Subcommittee also spoke to other Nutana partners (e.g., Salvation Army Breakfast Van, 
Nutana Servery) to see if they supported such an initiative. Recognizing the importance that healthy eating has on overall wellness, there was not one partner who had any doubts about the goals of this proposed Wellness Policy. Simply by speaking to various students, teachers, staff, and partners, it became clear that there was vast support for the implementation of a Wellness Policy. Therefore, the Wellness Subcommittee began to implement changes throughout the school that were based on student, teacher, staff, and partner feedback. For example, the Subcommittee contacted the vending machine operators and asked them to offer more healthy choices (e.g, more juices rather pop) in the machines. As well, given that many of the students are provided with lunches during some of the lunch time programming (e.g., Girls' Club, Art Group), a conscious effort was made to ensure that the lunches that were provided were consistent with the guidelines set forth by the Canada Food Guide (e.g., tried to eat from the various food groups and tried to eliminate junk food). More physical activity options were also offered to students during lunch time programming (e.g., Girls' Club).

Phyllis and I (as members of the Wellness Subcommittee) also developed a grant for funding through the Saskatoon Health Region. Although some of the changes that were being made within the school did not cost any money (e.g., changes to vending machines), we knew that some of the other changes that we had proposed (e.g., hiring a Nutana Collegiate Wellness Coordinator) would cost money. After looking through the guidelines of various granting opportunities, Phyllis and I felt that we stood a good chance in obtaining funding through the Saskatoon Health Region. The purpose of the Community Health Grant was to "provide an opportunity for community groups and organizations, in partnership with Saskatoon Health Region, to apply for assistance to develop, pilot, and evaluate new health-related initiatives for service/program delivery" (Saskatoon Health Region, 2007, p. 2). Given that Nutana Collegiate was already a leader in terms of the various support services and programs that are offered to students, we believed that we could also be leaders in terms of development of a new health initiative that focused on incorporating a Wellness Coordinator into the Nutana staff. Our proposed Wellness Coordinator would be in charge of organizing and facilitating the various lunch time wellness programs (e.g., Girls' Club) and would focus on the various 
wellness issues (e.g., need for affordable healthy food and physical activity opportunities) that would support the action goal of promoting positive body image experiences.

As a $\mathrm{Ph}$.D. candidate who has a relatively thorough understanding of the process of developing grants, I felt that I could "give back" to the school by sharing some of my grant writing skills on the development of this Saskatoon Health Region Grant. Although being awarded this funding was very important to me in that such funding would support the overall goals of my Ph.D. research project, I also wanted to show Nutana how appreciative I was for all of their support throughout my own research process. I thought that by sharing some of my skills, I could show them how grateful I was for all of their support.

Our Wellness Subcommittee was fortunate to be awarded $\$ 15,000$ over a one year period (i.e., 2007-2008) from the Saskatoon Health Region, with the potential for renewal for a subsequent year. Being awarded this grant highlights not only the Saskatoon Health Region's perceived importance of this action initiative, but it also highlights the manner in which we worked to secure funding in an effort to ensure the sustainability of the changes that were implemented as part of the Wellness Policy (e.g., facilitation of lunch time programs such as Girls' Club).

Overall, I the goals and actions of the Wellness Subcommittee supported the core groups' action goal of promoting positive body image, in that the changes that were made to support healthy eating and physical activity will likely have an impact on young women's body image. All of the changes that were made as part of this Wellness Policy had a focus on well-being and provided a practical example of how healthy initiatives can be implemented into a school community.

\subsubsection{Self-expression}

In addition to promoting positive body image experiences, the core group also argued, at various times throughout the school year, that it was important for young people to have opportunities to express their body image experiences in a variety of ways. Thus, their second action goal was to foster self-expression by organizing various lunch time activities that supported verbal, written, and artistic expression. Throughout the school year the core group developed three action initiatives that supported this goal. These action initiatives were: (1) Body Talk, (2) Writing Group, and (3) Art Group. As 
will be noted in the description of these initiatives, the core group believed that it was important for young people to share their body image experiences, and they recognized that not all young people feel comfortable sharing their experiences in similar ways. Thus, the development of action initiatives that supported a variety of personal expression preferences was imperative.

\subsection{Body Talk}

The Body Talk sessions, held one lunch time a month from January to May in the Students and Kids Centre (SAKS), emerged from a focus group discussion on body image that was held in early January. The focus group was attended by about eight

young women at the high school (two of whom where part of the core group). The young women described how concerns with the body and other aspects of the physical self (e.g., "hair" and "clothes") are experienced by women of all ages. All of the young women explained how it is important to talk about body image because all women think about how they look and how they are perceived by others. The young women provided me with examples about how they feel about their bodies in an effort to shed light on the type of concerns that young women experience. One young woman said, "I want bigger legs...no boney knees...then I could wear shorts." Another young woman said, "I like my boobs but I would like them smaller and firmer." All of the young women in the focus group said that it is possible to "like" their bodies, but still want to change aspects of their bodies. For example, one young woman said, "I like my body but if my boobs were two sizes bigger then it [my body] would be more evened out."

The young women highlighted the importance of talking about their feelings surrounding their bodies because they know that there are many harmful behaviors that can result from poor body image. When I asked what they could do to tackle body image concerns, the group suggested that we form a monthly group whereby young women could share their feelings about their bodies. One young woman said that this action initiative would be helpful for young women because "it is important to know what other people are thinking, so you don't feel alone." Another young woman explained, "it's nice to know that others feel the same." As part of their discussion the young women made it clear that a specific group dedicated to talking about their bodies would give 
young women the opportunity to share their thoughts with others, which they deemed valuable since, as they argued, "it is important to vent."

When trying to decide on what the discussions would be called, they decided on the name Body Talk; they felt that this name provided a clear depiction of what the discussions would consist of. I offered to bring lunch to the group, and the young women agreed that a healthy lunch would be important since we would be talking about our bodies and eating healthy would make them feel better about themselves. As well, the young women said that we should open the discussion up to all of the young women in the school. They said, "it's important to get as many girls involved as possible...they [all girls] have so many different experiences." The young women did not say that the group would be exclusive to women, but they were fairly confident that very few men would want to attend since there would be lots of women at the discussion talking about their feelings.

As previously stated, the Body Talk sessions were held once a month at SAKS, as it has comfortable couches that seemed conducive to the relaxed conversations that the young women wanted to engage in about their bodies. As well, SAKS has the facilities (e.g., fridge, microwave) that were useful for trying to make lunches for our meetings. Many of the same women attended each month but, as with most initiatives, there were always some new students who would attend. Each Body Talk session was attended by about 10 young women (including two young women from the core group). The young women were very respectful of one another in that they would speak one at a time, and they seemed to genuinely listen to the others when they were sharing their stories. Each week a different young woman initiated the discussions that took place, and the discussions covered a variety of body image topics (e.g., impact of media on body image experiences). My role in the Body Talk sessions was basically facilitative in that I was responsible for bringing lunches, and booking the meeting space. During each session the young women would express their gratitude for having a safe place where they could express their body image feelings in a non-judgmental setting. Overall, the young women argued that Body Talk allowed them to achieve their action goal of promoting self-expression.

\subsection{Writing Group}


The Writing Group, which was originally named The Power of Self Writing Group, emerged from a writing seminar that was initially facilitated by two individuals from a local organization that is a community partner of Nutana (the name of this organization has been withheld because consent was not obtained). This organization's writing seminar group was attended by an average of 6-8 students each week; the group met one lunch time a week for approximately eight weeks prior to Winter Break and for 3 weeks immediately after Winter Break. After speaking with young women from the core group, it was apparent that they wanted a formal writing group to continue meeting once a week, but they wanted to see a stronger focus on writing about body issues. More specifically, they wanted to develop a group that would focus on their action goal of fostering self-expression about body image. They felt that the Writing Group should be open to young women and men within the school, as they believed that young men would likely appreciate the opportunity to express their body image experiences. Therefore, I attended the last writing seminar that was held by the partner organization in an effort to share the ideas of the core group; I explained my research to the students and asked if they would be interested in developing a writing group that focused on body issues. Students agreed that they would like to continue the writing group, but they would like to spend more time writing about positive experiences. As well, students felt it was important to increase the number of students who were committed to regularly attending the Writing Group. The core group felt that if this new Writing Group was advertised in a way that let students know that the new group would have a positive focus, then it would be possible to maintain a consistent group of attendees.

The core group and I decided on the name The Power of Self Writing Group, as we felt that the term "The Power of Self" implied a positive writing atmosphere; however, the group quickly became known as simply the Writing Group. As well, students and I decided that it was important to ensure that all students who participated felt that they had a say in the topics that would be written about each week. Although the topics generally focused on the topic of this research project, we (the students and I) felt it was important for students to feel that they were in charge, and could take ownership over this initiative. It was important for students to know that this was their group, as we believed that this would make the initiative successful. 
The first Writing Group was held in mid-February and the original intent was to offer this group for 8 weeks. However, given the overwhelming attendance at each Writing Group (approximately 12-14 students) and the excitement that this opportunity generated among the students, the students agreed that it should be carried out until the end of the year. Therefore, rather than offering this group for 8 weeks, this action initiative was offered for almost 16 weeks. I brought lunch and provided all the students with bound journals and pens, which they used to record their weekly discussions and thoughts. I explained my research to the students, and I explained how this group could have the potential to add to this research. I wanted to ensure that the students understood my role at the high school. All of the students who attended this group expressed their interest in writing about the body, youth engagement, and youth potential to create change.

Although this initiative emerged from a previous writing group within the school, the students quickly took ownership of this initiative. The first week, the youth brainstormed topics they would like to write about. Based on their suggestions, I posed a general question (i.e., What are your positive attributes?). The students agreed that we would engage in free-style writing for approximately 15 minutes. After writing, some of the students asked if they could share what they wrote. One of the participants from the core group, who has been trained in youth facilitation through Youth Launch, explained to the group that she felt it was important to discuss confidentiality. Based on this young woman's initiation of this discussion, all of the young people agreed that what was written about and shared during Writing Group was confidential, and that all opinions shared would be respected. Although not all students chose to share their stories, most of them did. After each person shared what they wrote, the other young people would clap to show their respect. The first time the young people clapped I felt so overwhelmed by the demonstration of their maturity and consideration.

Each week different people from the group would suggest a topic that they would like to write about. There were even weeks when a young person volunteered to facilitate the discussion that took place after the writing. I was an active participant in all of the writing seminars, and I was somewhat surprised to see how interested the students were in my opinions. We usually wrote for about 15-20 minutes and then the young people 
wanted to share; the students used this writing time to write stories, poems, or song lyrics. Some of the students even used the Writing Group as a forum whereby they could share writing that they had done at home or in their school classes. I was amazed at how safe it felt in this group environment; the students were all from different peer groups yet they were respectful of the diversity of experiences among the group. Through the participants' voices it became clear that students wanted a chance to share their opinions; they realized that they are not typically given a forum whereby their voices can be heard and their opinions respected.

In an effort to shed light on some of the writing that took place within the Writing Group, the remainder of this subsection will highlight some of the participant's work. During one of our weekly writing seminars, Amber wrote a poem about her concerns about judging people based on how they look. She wrote,

When I was with child, lots of people stared.

Some young, some old, they never really cared. It wasn't loving or respectful, it was mean and judgemental. No thought No consideration No seeing past my physical state. People are just stuck in their own mental hate. They don't know who I am or what I can do. They don't know my past experiences or present shit I'm going through. They don't try to understand or get to know me like they could do All they see is what they CHOOSE to see A young girl who's changing physically.

Another young woman in the group also shared her feelings about appearances. Knowing that I am interested in young women's feelings about their bodies, this young woman decided to share with me some thoughts that she had about appearances and that she had written about in her journal. She wrote,

Piercings, black hair, ripped up clothes. Yup that's me and I love it...someone would take a look at me and think I'm a messed up person. This is who I am. Piercings are my life...I hate being judged by my clothes and appearance... most people look at me and label me as a "punk". They wouldn't see the love I have for my horse and my dog. They wouldn't be able to picture me running out to my horse, throwing my arms around his neck, and telling him how much I love him. They can't picture me out in the park on a sunny day training my dog. People never listen long enough...people just judge me by my appearance. Ya, I have piercings but that's who I am, that's what I like. And ya, I look pissed most of the time but if you took the time to get to know me you would see me for who I am.

This young woman also shared with me a journal entry in which she wrote about the importance of listening to student voices. I found this entry to be particularly intriguing 
because it ultimately sums up many of the reasons that I engage in interviews with young people, and why I work so hard to try to listen to young people to really hear what they are saying. She wrote,

You [researchers or teachers] can do all the studies you want. Write books about it [youth experiences]. Try and explain it, but you'll never be able to know exactly what goes through a teenagers mind unless you sit down and listen. You can ask all you want and jot down your own silly notes but unless you listen you'll never know.

Finally, knowing that I have a strong belief in youth in their ability to create change, this same young women shared with me her own thoughts on youths' potential to create change. At the same time, she also shared with me her discontent with young people having to obtain parental consent for many school and research activities. She argued,

Teens want rights too. Yeah, I might be just a "kid" but I have a brain and I can make my own decisions. Why do adults always have to make decisions for us? Why can't we decide if we want our picture taken or if we want to go on a school trip? Why do our parents have to make up our minds for us? All you're doing is killing our brains. Telling us what we can and can't do. Not letting us think it out for ourselves. We might want to do something but if our parents say no and don't sign the stupid little forms we can't. And why? Because we aren't aloud to make up our own minds. If we never try and fail we will never know what we can and can't do. The people tell us what we can and can't do...It's true, I may only be a "kid" as the world sees me but really I can and will make up my own mind without the help of all the adults out there that know absolutely nothing about how a teenagers mind works. I don't care what you say about me in your fake little jot notes. I am who I am and unlike everyone that judges us by our age I do have a brain and I can and will make my own decisions.

Some of the students also submitted their writing to "Word on the Street" an urban youth journal, in the hopes that it would be published. One young woman who was part of the core group had some of her writing about Aboriginal women's body image published on the front page of the journal (Veronica-Renee, 2007; see Appendix D). Therefore, not only was her writing a form of personal action in that it provided her with the opportunity to express herself, but it was also a form of community action in that she created community awareness. Through her writing, Veronica was able to articulate her thoughts on young Aboriginal women's body image experiences and what she thinks needs to be done to manage such experiences. In her article Veronica explained how "female body image in the Aboriginal culture isn't much different than what white women struggle with." She further argued,

My point of view on body image is we are all different, and we all have different styles. It shouldn't matter what someone down the road thinks about how we look, or what the kid sitting beside you in class thinks, but there are times when it does, and it really gets to us sometimes. 
In an effort to highlight what needs to be done to combat negative body image experiences she said,

I think if we all just take the time to talk about what is on our mind about how we feel about ourselves, and anything else that's bugging us, our self-esteem will rise and we will learn to love ourselves more.

Her final statement in this article really seemed to articulate the reasons why I engage in action research with young women. She said,

I'm sure if one person can try and make a change and spread the word, the problem [body image problems] will soon fade and more people will be proud of who they are, and the people around them, and in their community will soon understand what's going on.

The Writing Group was formed partially as a result of a previous writing group that was offered to students, and partially as a result of students' requests to have a nonjudgmental, respectful forum to write and express their body image experiences. There was such an overwhelming response to this initiative in terms of students' participation, and the young people tended to be particularly enthusiastic about their role in shaping (e.g., deciding on the topics to be discussed, creating a respectful and confidential group) and implementing the Writing Group. Although the young people never clearly articulated their reasons why they were so drawn to this group, it is likely that they continued to attend Writing Group because they have a lot of experiences that they wanted to share, and maybe verbally was not the most comfortable way for these students to communicate. Therefore, having this opportunity to write their feelings down and to express them in this way is something that I, and obviously they (as demonstrated through their regular attendance) perceived as a valuable opportunity.

\subsection{Art Group}

The lunch time Art Group emerged from Nutana students' requests for opportunities to engage in "freestyle art". I became aware of this request during a "Think Tank" session that was held by the administrators of Nutana Collegiate in December. Some of the students during this Think Tank indicated that there are many artistic students who attend Nutana yet there were no opportunities, outside of curriculum art classes, to express themselves artistically. This request for freestyle art was very consistent with the proposal that the art teacher and I had submitted for an Art Smart Grant (see section 3.1.1). 
One of the young women from the core group was involved in the Think Tank discussion, whereby students requested opportunities to engage in freestyle art. This young woman suggested that we bring this idea forward to the core group as a proposed form of action, and the core group agreed that we would adhere to the requests of the students. The core group, along with Phyllis and I, spoke to various students and they indicated that free-style art would be a great way for them to express their experiences, particularly their body image experiences. The students made it clear that they appreciated the opportunity to express themselves in a variety of ways, and that artistic expression should not be overlooked. In an effort to initiate this group, we verbally surveyed the interested students in an effort to identify the types of art supplies that were necessary to facilitate a successful lunch time Art Group. After purchasing the supplies, I worked with the core group to develop posters to advertise this newly formed Art Group.

Given that Girls' Club was already being offered on Mondays, and yoga was being offered on Tuesdays, Art Group was held every Wednesday at noon. An average of 12-15 young women and men attended each Art Group (including most of the young women from the core group). Similar to the Writing Group, the core group felt that Art Group would provide young women and men with the opportunity to express their body experiences. The students were not restricted to creating art about their body experiences; however, many of the young women (and some of the young men) who attended the weekly group used art as a form of body expression and their creations often generated some really interesting discussions. For example, one young woman from the core group created a collage using various magazine clippings to express her views on how women's bodies are depicted in the media. This creation led to some interesting conversations among the students about how women's bodies are depicted in the media. Her collage (see Figure 8) was included in Nutana's annual art show, which highlights the work of Nutana students and staff.

Although no other students decided to include their work in the art show, other students did use this time to create art about the body. Some other young women created collages, and one young man used this lunch time art group to draw pictures of women's physiques. This young man initially seemed quite shy when he attended the weekly Art Group; however, he became progressively more comfortable with sharing his drawings 
with some of the other students. In describing one of his pictures of a woman's physique, this young man explained how women's bodies are all so different and unique and it is important to appreciate the beauty of women's bodies by depicting them through art. Some of the young women who attended Art Group appeared to be genuinely impressed that a young man was so outwardly appreciative of the uniqueness of all women's bodies. Art Group was one of the few initiatives that had a strong male presence so it was particularly interesting to hear the discussions, such as the one just described, that arose within this initiative.

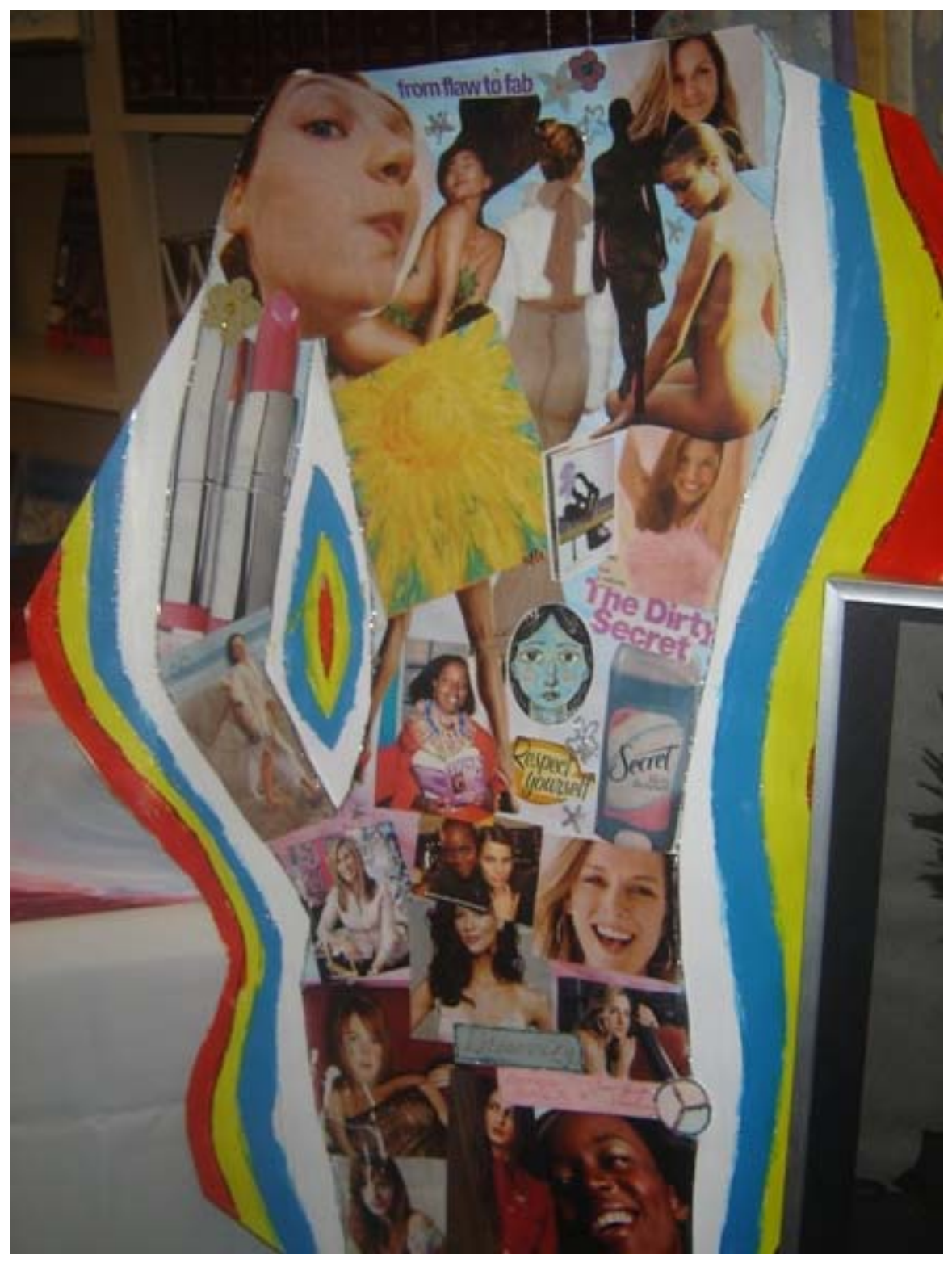

Figure 8. Collage that was entered in the Nutana Art Show. 
Similar to the Writing Group, the Art Group had strong student attendance. During the initial planning of this initiative, the young women from the core group and I were unsure how many students would attend. However, it was obvious by the regular attendance that the young people really enjoyed the opportunity to express their individual experiences creatively. As previously stated, students explained that there are not enough opportunities to express themselves in an informal and non-judgmental environment. Given that Art Group promoted an informal and respectful environment, I am quite confident that this is why it was such a successful initiative.

\subsubsection{Creating Awareness}

Creating awareness about the importance of body image issues in the lives of young people, particularly the lives of young Aboriginal women, emerged as a primary action goal of this PAR project. Through various informal conversations with the young women from the core group, they argued that all people need to be aware of the important role that body image plays in young women's lives. The young women were confident that by creating awareness it would be possible to promote acceptance. As well, creating awareness about the types of initiatives that were developed at Nutana as part of this PAR project was also deemed as important by the core group. They believed that if people from outside of the school (e.g., students and teachers from other schools across Saskatchewan and Canada) knew about the initiatives that were developed at Nutana as part of this PAR project, then it might be possible for other schools to implement similar programs.

The two action initiatives that provided opportunities for the creation of awareness were: (1) Media Requests, and (2) Youth as Leaders and Facilitators. As will be noted below, these action initiatives emerged from the requests of others from outside of the PAR project (e.g., media, local organizations); nevertheless, the young women in the core group argued that both initiatives fostered their action goal of creating awareness.

\subsection{Media Requests}

Various forms of media were utilized throughout the duration of the research project as a method of sharing with the general public the body image experiences of the young Aboriginal women who participated in this PAR project. As well, the media 
allowed the participants and I to share the exciting initiatives that were developed in an effort to manage such experiences. The media provided us with the opportunity to raise awareness on the importance of working with young Aboriginal women to manage body image experiences. More specifically, the media allowed the participants and I to create awareness among local, provincial, and national audiences, and it ultimately served as a form of action and a method of communication or knowledge translation.

In early February, CIHR contacted me and asked if they could do a "media release" on my research as they felt that this research is relevant to eating disorders, and they wanted to highlight such research during National Eating Disorders Week. I agreed to have my name included in the media release; it was primarily through this media release that I started receiving requests for interviews from various city, provincial, and national media sources.

The media was a particularly useful form of action and communication because it allowed the young women and I to share our research with communities that we likely would not have been able to share with otherwise. For example, by engaging in an interview with a reporter from Missinipi radio (see section 3.1.2.3.1.4), we were able to communicate our research to communities in central and Northern Saskatchewan; the interview was broadcast in three different languages (English, Cree, Dene). As well, hearing young Aboriginal women describe the importance of promoting acceptance with respect to Aboriginal women's body image was a particularly powerful tool, in that the messages that were being sent were coming directly from the young women themselves. The following five sub-sections provide a brief overview of the various types of media engagement that the young women and I utilized in an effort to achieve our action goal of creating awareness.

\subsection{Saskatoon Star Phoenix and Regina Leader Post}

After the CIHR media release, a journalist from the Saskatoon Star Phoenix was the first person to express interest in highlighting our research project in the provincial papers. I was particularly nervous about giving an interview on this research because I wanted to ensure that anything that was printed was respectful to the young women, as well as the entire school community. As I stated earlier in section 1.1, it is my opinion there is an invisible divide within the prairie provinces among many Aboriginal and non- 
Aboriginal peoples; thus, I wanted to ensure that this research was portrayed in the most respectful manner. As well, I wanted to ensure that Nutana was depicted in a positive manner, but since a journalist was writing the article, the final say on what was printed would be out of my control. Given that the journalist had a fairly short deadline for when the article had to be submitted, she was unable to interview any of the young women from the study. However, after receiving support from the young women and the principal of the school, I took part in a phone interview.

The article by French (2007) was printed in February in the Saskatoon Star Phoenix and in the Regina Leader Post. I was particularly relieved when the article was printed because I, along with the staff and the young women who had been participating in the study, thought the journalist did a good job of reflecting my thoughts in the printed article (see appendix E). For example, the journalist quoted me as saying, "As a health researcher, I don't have the answers, but I genuinely believe that the people we're working with in our research-the participants-are the experts." I was also quite surprised at how many people read the Star Phoenix and the Leader Post; many of my friends and colleagues commented on the article after it was printed. This article was an excellent form of action in that it shed light on the various activities that we were engaging in at Nutana, it also shed light on the importance of working with young Aboriginal women on issues of the body. However, I was most pleased with this article because it led to a number of other media opportunities in which the participants became more directly involved. For me, creating these opportunities was particularly important because one of the underlying goals of this PAR project was to promote the voices of young Aboriginal women. I wanted to support the young women in sharing their stories, and the media facilitated the sharing of their stories to broad range of audiences. These other media opportunities are described below.

\subsection{CBC Radio}

Less than a week after the interview was printed in the Star Phoenix and the Leader Post, Jennifer Gibson from CBC radio contacted me to see if I, along with one of the young women from the study, would be interested in being interviewed on her Blue Sky lunch time show. Although I was quite certain that there would be interest expressed by the core group, I indicated that I needed to talk to the young women first to see if they 
thought it would be a good opportunity. I first approached Veronica from the core group to see if she would be interested in participating, because she had been one of the most active young women in this research project. She was really excited about the opportunity and, during Girls' Club, I told the other young women that Veronica and I had been invited to participate in a radio interview. Through general conversation among all of the young women, it was agreed that Veronica would be an excellent representative of the core group, and that she would do a great job explaining our activities and creating awareness about the importance of body image in the lives of young Aboriginal women.

On the Friday that we were interviewed, it was quite a bad snow storm. Nevertheless, Veronica met me at lunch time so that we could make our way to the CBC radio station. When we arrived at the station, Jennifer introduced herself and explained to us how the interview was going to unfold, including the types of questions that she would ask. She guided us into the recording studio, she equipped us with headsets, and told us to talk "naturally" and that our voices would be recorded through the microphones in front of us.

Given that it was a live interview, and there would be no room for mistakes, I thought that the interview process would make me a lot more nervous than I actually was. Nevertheless, Veronica and I found that our words flowed quite easily. During the interview Jennifer asked Veronica to describe how she feels about her own body. She said, "I have a pretty okay self-esteem so I don't know about anyone else but I'm okay with my body but there's still those days when you want to change a few things." Building upon this question, Jennifer then asked Veronica if body image issues are different between Aboriginal and non-Aboriginal women, and Veronica said, "they're probably not that different." However, when asked if she thought that our PAR project was important Veronica explained,

I think it is pretty important to have someone to talk to and to go to these groups because there are a lot of teenagers at the school who have a problem with this [body image] and they would like to talk to... a group of people who you can just trust, talk to, and have fun with and just feel a part of something.

As well, within the interview, I explained to Jennifer that I began working with young Aboriginal women because they are the experts of their own body image and that 
they are the ones who can create change. She asked me to explain how we can work with youth to change the way that young people feel about their bodies. I said,

By talking to the young women they tell us, 'this is what influences how I feel about myself, and this is what we need to do to change it'. So I am so pleased to have the opportunity to work with such wonderful students and staff at the school [Nutana] because by engaging in these conversations we are able to start developing programs.

I also explained how many of the programs that we have developed are focused on promoting positive body image experiences. I said,

I think that it is important to promote the idea that we have to accept our bodies for what they are. And even by engaging in these conversations with young women [through body talk, writing group] I think it is creating a positive change.

In talking about change, Veronica also said, "youth really have an impact on it [change]".

After the interview Jennifer gave us each a $\mathrm{CBC}$ water bottle and key chain as a thank you, and then we headed back to school. When we arrived back at Nutana, a number of people told us that they had heard our interview and that we sounded "awesome". I was so proud of Veronica and the way that she handled herself as a Nutana representative and a representative of our research team. Although I continue to argue that these young women have powerful messages that they need to share, I am still somewhat awestruck when I am able to sit back and see them in action. I am so grateful that young women like Veronica have been provided with such opportunities; I think it gives a real boost to their confidence.

This opportunity with CBC radio also allowed us to share, with the broader Saskatchewan community, some of the exciting initiatives that had been implemented at Nutana as a result of this action research project. As well, because of her interview with CBC radio, Veronica had the opportunity to tell others in Saskatchewan that body image issues are an important health issue for young Aboriginal women. Through her stories and her voice, she was able to send a powerful message to the various listeners about the importance of body image in the lives of Aboriginal women. As a result of this interview, the core group and I thought that others would be able to learn something from our experiences, and we hoped that others would implement body image action projects that would be similar to ours. More specifically, we created awareness about the importance of body image in young Aboriginal women's lives, and we hoped that some 
of the listeners were teachers or students who were enlightened by our interview and who would try to implement similar action initiatives into their own schools.

\subsection{Sage}

In mid-February, I was contacted by Laura Suthers who is a writer and reporter for the Aboriginal Multi-media Society (AMMSA). She wanted to know if I, along with two young women from our study, would be interested in taking part in a phone interview, which would be published in one of their media outlets. I approached Kyla and Veronica, two outspoken young women who were part of the core group, and whom I knew would be interested in this opportunity. Both young women were particularly excited about the opportunity, and the three of us engaged in a phone interview with Laura that same day. All of us took a turn talking to her on the phone; she asked us questions about our research and what types of programs and initiatives we had developed and implemented. When talking to the young women, she asked them questions that were more specific to Aboriginal women's body image. She wanted to know what Kyla and Veronica felt are the biggest influences on women's body image. As well, she wanted to know why they were playing such an active role in this research project. After the interview was completed, Laura asked if we could e-mail her a picture of the three of us, which she would include along with the article. All three of us were very excited with the way the interview unfolded, and we could not wait to see the printed article.

The article by Suthers (2007) was released in the March 2007 issue of Saskatchewan SAGE: The Aboriginal Newspaper of Saskatchewan (see Appendix F). After reading the article, I was particularly happy to see the positive manner in which our stories were represented, and I was so proud to read the quotes of Kyla and Veronica that were highlighted. Although I heard what the young women were saying during their phone interviews, their messages seemed even more powerful when I saw them in print. Kyla was quoted as saying,

I joined [this research project] because I know that I'll get my word out. This group is an opportunity to hear what others have to say and get out what I have to say. It's about sharing our opinions, experiences and different ways of life with other people. It's a really great program and it makes me feel good about myself." 
Similarly, in talking about some of the programs that she is involved in as part of the PAR project, Veronica explained, "It's a really good program [Body Talk]for people to express themselves and just to talk about that kind of stuff [body image] and to know that we're not the only ones who think this."

Not only did Kyla and Veronica's quotes support my belief that it is important for young people to have a safe forum whereby they can share their experiences, but also her quote supported my initial justification for wanting to get involved in this type of a research project. Although this may sound somewhat idealistic, I knew right from the proposal stages of this PAR project that I wanted to be involved in a research project that could make a difference in the lives of the young women I was going to work with. More specifically, I wanted to feel that this PAR project could positively influence the lives of young women, either through the promotion of individual positive experiences or through the creation of activities that supported young women in managing their body image experiences. Not knowing the extent to which I could make a difference, I thought that making a positive difference in even one young woman's life would be a rewarding experience. Knowing that this research makes at least one young woman (e.g., Kyla) feel good about herself sends me the message that others likely feel the same and that this research is important and worthwhile.

I also wanted to ensure that the article accurately reflected the collaborative nature of this research project. Laura quoted me as saying,

When we talk about body image research, generally we're talking about 'white' research and I think that's common with a lot of research. The voices of Aboriginal people have often been overlooked so this study in one way is very unique in that we're celebrating the voices of these young people and the important messages that they do have to send.

I felt that this was a particularly important message to convey because I wanted people to see that this research is about highlighting the voices of young Aboriginal women on this important health topic.

Kyla, Veronica, and I were all extremely happy with the way that Laura wrote the article, and the young women were particularly happy that she included our picture with the article. Both young women explained how many of their friends had read the article and, as a result, they felt somewhat "famous". Although the initial intent of this action initiative was to use the media to create awareness and promote acceptance, I also believe 
that the perceived "fame" or popularity experienced by the young women was an important outcome of this initiative. More specifically, although this was not articulated by Kyla and Veronica, I feel that the young women experienced great pride when they thought that their stories were heard by others and that they potentially had made a difference in the lives of other young Aboriginal women by creating awareness around body image.

\subsection{Missinipi News Radio}

On the last day of February, Dave Simms from Missinipi News Radio contacted me and asked if I would be interested in being interviewed. Since it was just going to be a short interview, there was not going to be time to interview any of the young women so I wanted to make sure that they felt comfortable with me representing our group and our research. After speaking with the young women from the core group and receiving their support, I contacted Dave and took part in the interview. When I called Dave I did not realize that he was going to tape our interview during that phone call, nor did I know that it was going to be immediately broadcast. Therefore, I did not get to audio-record the interview and I was unfortunately unable to obtain a copy of the interview from the radio station. As a result, I have not provided any direct quotes from the interview.

During the short interview Dave asked me what the purpose of the research project was, and what types of initiatives we had implemented. I explained how young Aboriginal women have indicated that they experience body image concerns, and that I was working with young Aboriginal women to develop effective strategies for managing such concerns. As well, I described some of the action initiatives (e.g., Body Talk) that had been developed as part of this project. Although it was just a short interview, the young women and I were really excited to have our research broadcasted on Missinipi News Radio because the interview was presented in three languages (i.e., English, Cree, Dene) and would reach over 70 communities in Northern Saskatchewan. We were happy to know that what we had accomplished in terms of this research project was going to be communicated to communities which we likely would not be able to reach on our own.

\subsection{Aboriginal Peoples Television Network}

The last media request came in March from a woman named Cherish Francis, who is a reporter for Aboriginal Peoples Television Network (APTN). She had read the 
article that was published in the Regina Leader Post and asked if she could come to Nutana and interview me and a few of the young women for an upcoming edition of the APTN National News. Cherish had a short deadline for when the interview had to be submitted and she asked if she could come to the school the next day to do the recording. Having only been given short notice, I had to work quickly at getting the school and school board permission to have the filming take place within the school. After approval had been granted, I asked two young women from the core group (i.e., Cynthia and Danielle) who had not yet been involved in any of the media opportunities, if they would like to take part in the interview. The other young women who had already participated in media opportunities (e.g., Kyla, Veronica) agreed that it was important to include other young women from the core group in such media opportunities so that the diverse experiences of our core group were shared with broader audiences. Cynthia and Danielle were so excited about this opportunity, and they said that they could not wait to tell all of their friends that they were going to be on television. In addition, another young woman (Melissa) also volunteered to participate when she overheard me talking to Cynthia and Danielle. Melissa, although not part of the core group, was an active participant in many of our action initiatives.

The next day I met Cherish at the school's front entrance at 12:30 p.m. for the APTN interview. She seemed really friendly and easy to talk to. She conducted my interview first, and although I felt like I had originally blanked, I slowly eased my way into the interview mode and I think it went really well. I realized that the cameras made me quite nervous, and that I felt much more comfortable doing radio interviews than television interviews. Similarly, Cynthia became quite nervous when the cameras were recording and, although she did not feel comfortable speaking in front of the camera, she was happy to have her image recorded. Because Cynthia felt too nervous to speak in front of the cameras, Cherish asked me to find another young woman to participate in the interview. Fortunately, I quickly found Kyla, a core group member, and she was very excited to participate.

Prior to leaving, Cherish told the young women that if any of them were ever interested in "shadowing her for a day" she would be more than willing to accommodate their requests. She gave all of the young women her contact information, and thanked us 
all for our cooperation in the filming. I was so proud of how well spoken the girls were; despite my knowing their strengths, I was really overwhelmed by their maturity and the manner in which they articulated their thoughts. The voices and experiences of young people are typically not respected by those of older generations; however, I am confident that the self-assured manner in which they told their stories elicited admiration from many people who watched this interview. The young women were excellent ambassadors not only for this PAR project, but also for Nutana, and all young Aboriginal women. It is so remarkable how these young women are able to shine when they are provided with such opportunities.

The following weekend our interview was broadcasted on the APTN National News. Although it was just a two and half minute video clip, the young women and I thought that the story adequately reflected the type of initiatives that we were engaging in at Nutana. As well, we were excited about the manner in which the young women were able to share their own experiences with the PAR project. In describing some of the initiatives that we had developed (e.g., Body Talk, Girls' Club), Kyla was featured saying, "it is really awesome to be in a room full of girls that share the same insecurities [body image concerns], and it is an insecurity and I think that it is something that all women share." It was so powerful to hear a well-spoken young woman talk about the importance of body image issues in the lives of Aboriginal women. As well, during the interview the young women were asked what types of things they think contribute to young Aboriginal women's body image, and all of the young women agreed that media plays an important role. Having said this, the young women also explained how they understand that the pictures depicted in the media are not realistic. As part of the edited news broadcast, Melissa argued,

Really they're [models] not that skinny. The magazine has been airbrushed and they've been fixed up, and their hair doesn't look like that, and their make-up, someone else does it for them they don't do it themselves. So when I see that [media images] I kinda think of it as overkill.

During the interview Cherish asked me what types of messages the young women and I were trying to send about body image, and I was featured as saying, "One thing that we're trying to get across is this idea of body acceptance in general. I really believe that from there, if the young women do accept their bodies, then they'll engage in healthier lifestyles." I was particularly happy to see that this comment was broadcasted as it really 
sent the message that this project was focused on young women's body image and not on the "obesity epidemic" that we constantly hear about through the media.

The young women who participated in the interview did an outstanding job at articulating why they felt this was an important action research project and the types of activities that they were engaged in. Various school members, as well as family and friends from across the country saw the interview and indicated how exciting our research project sounded and how lucky I was to have such a wonderful group of young women to work with.

In retrospect, I am thankful that I had the opportunity to participate in these various media opportunities with young women from the core group. I think that by including my story, as a non-Aboriginal researcher working with young Aboriginal women on this important body image PAR project, I was able to demonstrate the manner in which researchers can work with communities to create positive change. However, I am also grateful that the young women from the project were interested in participating in media opportunities because this inclusion was very consistent with the collaborative goals of this project.

\subsection{Youth as Leaders and Facilitators}

The Youth as Leaders and Facilitators action initiative involved two provincial youth conferences that were held in Saskatoon. At each conference young women facilitated body image discussions/workshops with other young people from around Saskatchewan. The youth facilitators of these workshops shared the types of activities that were implemented at Nutana, and emphasized the types of issues that they, as young women, deem important with respect to managing body image concerns (e.g., promoting acceptance). The facilitators felt that such workshops were an excellent form of action in that they had the potential to create widespread awareness (i.e., provincial) of the prevalence of body image issues. More specifically, they felt that the information discussed in these workshops had a domino effect, in that the workshop attendees hopefully transferred this information back to their own schools. Only select students from each school came to the conferences, and it seemed that these youth were the "go getters" or the youth who could or would create action in their respective schools. 
The two conferences have been grouped together under the term Youth Leaders and Facilitators because both conferences had similar youth-driven goals, and both conferences were being facilitated by youth leaders. Given my interest in body image research, I was asked by Youth Launch and Research and Education Solutions to Violence and Abuse (RESOLVE) to facilitate discussions on body image at their respective conferences. Both groups knew about the initiatives that had been implemented at Nutana, and conference organizers asked if I would work with youth facilitators to lead conference sessions on body image. After describing this opportunity to the young women in the core group, they felt that this would be a great way to get young people from around Saskatchewan talking about body image and the type of action that can be taken within their own schools. For both conferences I worked with young women to develop a framework in which to lead the body image sessions. The Sexual Health in Youth (SHY) Conference and the Power of Youth Conference have been outlined in more detail below.

Youth Launch and its partners teamed up for a SHY Conference that was held in February in Saskatoon. The conference organizers invited high school students from across Saskatchewan to participate, and approximately 150 students registered for the conference. As previously mentioned, my position within Youth Launch was unique in that despite my role as a researcher at Nutana Collegiate, I am also viewed as a youth facilitator within Youth Launch. Given my experience surrounding issues of the body, I was asked to work with a group of young people from Youth Launch to develop a body image session for the SHY conference. This session was to be held two times during the morning of the conference.

The five young women whom I worked with to develop the SHY body image session were students from another high school in Saskatoon. Youth Launch provides facilitator training to various schools across Saskatchewan, and Youth Launch wanted to provide these newly trained young women facilitators with the opportunity to lead a session at the SHY Conference. I went to the young women's high school for four weeks leading up to the conference (i.e., for approximately 2 hours each week) to assist the young women in the development of a framework for the SHY body image session. I 
shared with them many of the action initiatives that we had developed at Nutana and they seemed excited about sharing these initiatives during the body image session.

During the various times I met with the young women, I watched as they engaged in conversations with one another to determine how they could best get their messages regarding body image across to the conference attendees. After suggesting a number of different ideas and verbally working through the pros and cons of their suggestions, the young women decided that in order to "set the stage" for discussion surrounding body image, it would be important to begin each session by reading personal narratives that they had developed regarding their own body image experiences. As well, the young women explained that by acting out a short play, which depicted a group of young women who were experiencing negative body image, it might be possible to "break the ice" and get the participants to engage in discussion. The young women also indicated that each of them (i.e., each facilitator) would then lead a "break out" group of approximately 6-8 students in a discussion about body image. They developed a list of questions to help guide the discussion (e.g., "What influences young people's body image?", "What can youth do to try to promote positive body image?"). With approximately 10 minutes left in the session, the young women explained that they would regroup, and each group leader would highlight and summarize the discussion that took place in each break out group.

On the day of the SHY conference, two body image sessions were held during the morning of the conference; approximately 35 students, including both males and females, attended each session. The young women and I were somewhat surprised at the strong reception to the body image sessions, since the students had the option to register for a number of interesting sessions. All of the students actively participated in the discussions, and many of the students indicated that it is important to promote positive body image because a poor body image can negatively influence many aspects of their lives. Consent to share information from the group discussions was not obtained; therefore, specific quotes from the session discussions have not been shared within this dissertation.

The Power of Youth Conference, organized by RESOLVE and some of its sponsors, was held in March in Saskatoon. High school students from Saskatoon and 
surrounding rural areas were invited to participate; approximately 150 students registered for the conference. Although I was originally asked to lead two body image sessions, I reiterated to conference organizers that I felt the session would be better received and more meaningful if they were led and facilitated primarily by youth. After receiving support from the organizers, I worked with two young women from the core group to develop a framework that would be used to lead the discussions during the body image sessions. Given that members from the core group would be facilitating the discussions, we thought that it would be possible to provide an in-depth overview of some of the body image action initiatives that we had developed at Nutana.

In organizing these sessions we knew that we wanted to spend the majority of time engaging in conversations with young people. Therefore, the two young women from the core group and I engaged in a few casual planning sessions prior to the conference in an effort to decide on the manner in which the workshops would be facilitated. More specifically, given that both of the young women from the core group were also members of Youth Launch, and therefore had experience facilitating discussions with youth, I basically watched as the two of them talked about the manner in which the workshops should be led. During these few short planning sessions the two young women decided that we would begin each session by introducing ourselves (the two young women and me) and describing personal experiences as to why we feel it is important to openly talk about body image. From here, we decided that we would break into small groups and each of us would lead small group discussions on body image. The guiding questions that we developed for the discussions were similar to those used within the SHY Conference (e.g, "What influences young people's body image?", "What can youth do to try to promote positive body image?").

Similar to the SHY Conference, two body image sessions were offered during the morning of the Power of Youth Conference; approximately 30 students (males and females) attended each session. Again, the young women and I were very excited about the overwhelming participation of the students in the discussion on body image. The conference attendees had the opportunity to register for workshops that addressed a number of different issues (e.g., violence); nevertheless, compared to these other workshops, our body image workshops had some of the highest registration numbers. 
The two young women explained how they believed that the large number of students who registered for these body image workshops indicated that various youth in Saskatchewan see the importance of discussing body image.

Although discussions in the SHY conference were not recorded, the workshop attendees at the Power of Youth conference gave permission to have the workshop discussions hand recorded. Therefore, during the small group discussions, the workshop facilitators (i.e., two young women from the core group and me) hand recorded direct quotes from the participants. The young people had many views pertaining to body image that they shared, and media was one of their biggest concerns. One young woman said, "I think the media influences body image in a bad way." Expanding upon this notion, another young woman said, "I think the media has made body image a way bigger issue than it should be." Another young woman explained how she does not think that the media recognizes the impact that their messages have on young people. She said, “The media really doesn't know what they are doing to a person. It can turn friends against each other or even lead to suicide. I really hope that people start to understand that it plays a big part in people's lives." In an effort to provide some advice on how young people can combat media messages, one young woman said, "People need to accept themselves, be confident, and not listen to the media."

In addition to media, the young people described a number of other factors that influence their body image. They said that their parents play a strong role in how they feel about their bodies. They explained how parents will often comment on their child's body (e.g., "you look like you're gaining a bit of weight") and that parents "often think they're helping", when really they are just making their child feel worse. They also explained how parents are strong role models in terms of behaviors that are used to manage their bodies. For example, they said that "eating habits get passed down" from parents to children. Therefore, if parents (they generally spoke about mothers), engage in dietary restraint, then the children will pick up these behaviors.

The young people who participated in these body image sessions recognized that there are a number of factors that influence their body image, and that many young people experience negative body image. Given the strong role that youth said body image plays in their lives, the two young women and I asked the young people what type 
of action could be taken to combat such concerns and how could they make changes within their own schools. Interestingly, the young people said that schools "need to promote acceptance" and that "we don't talk about it [body image] enough." They explained how the only topic of the body that is covered in their school curriculum deals with hygiene, and that there is a need for more education on positive body image in schools. They explained how schools would be a good place to try to "get away from stereotypes." They also argued that students need to learn from teachers that stereotyping can hurt a person, because not all young people will learn this from their parents. As well, they said that all people would benefit if teachers spoke more about acceptance, and that schools should be "promoting respect", a respect that is not based on clothes or looks. One young person said that compared to when their parents were teenagers, they are not living in a "more accepting culture" in terms of accepting differences in "ethnicities and cultures." This comment led to a deeper discussion, and most of the young people agreed that young people today are no more accepting than young people were thirty years ago thus, reinforcing their belief that schools should promote respect. One young person said that individuals need to take a "personal stance", because if people "can accept themselves then they'll accept others." Again, there was fairly widespread agreement on this statement.

In describing other types of action, one young woman said that we need to focus on working with young peoples" "emotions" because "body image goes with your emotions." Building upon this notion, another young woman agreed and said, "if you're angry it will influence how you feel about yourself and others." Quite a bit of discussion arose from this idea that emotions are tied to body image. The young people felt that if we could get people experiencing more positive emotions on a regular basis, then they would feel better about themselves and they would not feel the need to criticize others.

Although it was mostly young women who were contributing to the discussions (approximately $85 \%$ of the participants were young women), the men highlighted some really interesting points about men and body image. One young man explained that all young men care about their bodies and how they look, but it is "not right for guys to talk about how they look." Building upon this, another young man said that they don't talk about their concerns with their bodies because they "don't want to look insecure to their 
friends." In summary, he said that "they feel it [body concerns] but just don't say it." Hearing these young men's experiences ultimately provided justification for including young men in discussions about body image, as body image is clearly an important issue in young men's lives.

The young people also recognized a strong link between body image and physical activity; thus, in terms of action, they said that there is a "need to be more active." One young woman explained how being active makes a person feel better about themselves. Another recognized that not all people will necessarily become thin from exercising; however, the simple act of caring for the health of their bodies would lead to a better body image. Some of the students said that we need to promote being healthy, and not just the importance of losing weight, and one young woman explained how "the version of what healthy is, is distorted." She further explained that people do not have to be super skinny in order to be healthy, and that all the focus on losing weight makes people feel badly about themselves.

Similar to the SHY conference, the two young women from the core group and I left the Power of Youth Conference feeling confident that many of the young people who attended the body image sessions would take some of the messages that they received from the discussions back to their respective schools in an effort to make a positive change. Therefore, the young women from the core group and I felt that these two conferences allowed us to achieve our action goal of creating awareness.

\subsection{DISCUSSION}

The purpose of this study was to engage in a collaborative, school-based PAR project in partnership with a local high school to provide young women, primarily young Aboriginal women, with an opportunity to manage their body image experiences in an effective and collaborative manner. In an effort to demonstrate the success of this PAR project, I begin this discussion by addressing what I perceive to be the most important contribution of this PAR project, Action on Various Levels (section 3.2.1). Within this section, I outline the relevance and/or credibility of the action initiatives that were developed and their sustainability. Next, a description of some of the Methodological Considerations and Challenges (section 3.2.2) that were experienced are outlined so that 
future researchers may learn from some of the obstacles that were navigated within this project. To end this discussion, I provide a Reflection on the Role of Theory (section 3.2.3) within this PAR project.

\subsubsection{Action on Various Levels}

The development and implementation of action initiatives at various levels is what I perceive to be the most important contribution of this study. As stated by RCAP (1996), Aboriginal youth want to develop the skills and capacities that will help them to manage the challenges facing their communities. This project supported young Aboriginal women in developing action initiatives at the individual, school, provincial, and national levels, which focused on managing challenges associated with body concerns. At the individual level, young women were provided with a respectful and safe environment to share their experiences through Body Talk. Through the Wellness Policy changes were made at the school level (e.g., adding healthier options to vending machines) in an effort to promote positive body image experiences. Finally, through initiatives that were focused on creating awareness, action was created at provincial (e.g., SHY conference), and national (e.g., APTN National News) levels. However, it is important to highlight that most of the initiatives made an impact at multiple levels. For example, the CBC Radio action initiative not only made an impact at the individual level but also at the broader provincial level. As stated in section 3.1.2.3.1.2, one young woman and I went to $\mathrm{CBC}$ radio to describe the research that we were engaging in at Nutana. She was able to share her own personal experiences, and the confidence she gained from this activity made a positive impact on her. At the same time, by sharing our research on $\mathrm{CBC}$ Radio, we knew that this information was reaching other communities across Saskatchewan. Thus, this research made an impact on at least two different levels (i.e., individual and provincial levels).

Using media as a tool for creating action at various levels has been supported by other health researchers. For example, Taylor (1998) explained how the media publicity about her research "furthered activism" on postpartum illness. More specifically, by using the media to create awareness, Taylor argued that she was able to draw attention to her research, which subsequently garnered public support for postpartum illness research. Similarly, the participants in my study and I argued that by hearing our stories, and our 
examples of action initiatives, it is possible that individuals and schools in other parts of the province and country could follow our lead in addressing important body image issues that are impacting young Aboriginal women. More specifically, we believed that students and teachers who hear about our research through the media would have a better understanding of the importance and benefits of working with young Aboriginal women to address body image concerns. Recognizing this important health issue, they might be motivated to integrate similar action initiatives (e.g., Body Talk, Girls' Club) into their own schools.

In light of the perceived contributions of this PAR project, it is important to compare what type of action was anticipated and what type of action was actually developed and implemented, in an effort to demonstrate how this research project transformed from the research proposal stage to the final stage of the research process. This information could be useful for future researchers interested in engaging in PAR projects, as it provides a concrete example of how PAR is emergent.

The two rural Aboriginal women who participated in some of my recent research (i.e., McHugh \& Kowalski, in press) suggested that young Aboriginal women should be provided with more opportunities to share their body image experiences. Similarly, my Master's research suggested that young Aboriginal women want to have a place where they can go and not have to worry about their bodies, and the participants proposed activities such as "rallies towards freedom of the body" (Fleming et al., 2006, p. 24). Although the young women in this PAR project never organized any specific rallies, they did facilitate body image workshops at two conferences, which provided them with the opportunity to openly voice their opinions about body image in a safe environment. As well, in terms of creating a place where women do not have to worry about their bodies, many of the initiatives (e.g., Girls' Club, yoga) were developed so that young women could have a place that would promote positive body image experiences.

When proposing this PAR project, I felt that other potential action would stem from the recommendations outlined by Deiter and Otway (2001). In an effort to highlight ways in which the health of Aboriginal women in Saskatchewan and Manitoba could be improved, Deiter and Otway made eight recommendations based on a survey of about 100 women, as well as interviews with five Elders. One of the eight recommendations 
was that there should be the development of exercise programs and other "positive stress relievers" that target Aboriginal women. They also recommended that more research and funding be used for services that encourage women's talking circles and support groups. Many of the initiatives that were developed as part of this PAR project were consistent with the recommendations outlined by Deiter and Otway. Exercise opportunities were offered through Girls' Club and yoga, and Body Talk and Writing Group were reflective of their recommendation to encourage talking circles and support groups.

Some other general ideas for proposed action for this PAR project stemmed from the key priorities and strategies for an action plan for women's health in Saskatchewan and Manitoba that were highlighted by the Prairie Women's Health Center of Excellence (2001). They explained how researchers need to work with organizations and departments of education, which serve young women, to develop programs that promote self-esteem and work towards empowerment among young women. Similarly, Paquette and Raine (2004) explained how it is important to create supportive environments for developing positive body image. Thus, prior to beginning this PAR project, I assumed that action initiatives would adhere to these suggestions. In retrospect, the various successful action initiatives that were developed as part of this PAR project (e.g., Girls' Club, conferences) supported these recommendations.

Girls for a Change, a non-profit organization based out of San Jose, California, also described various programs that seek to support and empower young women (see www.girlsforachange.org). This organization supports young women in working towards social change by encouraging them to lead, to design, and to implement social change projects aimed at addressing problems experienced by young women. For example, the young women in the Girls for a Change program have organized a "Girl Summit" where young women have the opportunity to attend a girl's event in which they can engage in dynamic workshops that have the sole purpose of celebrating young women. Thus, prior to beginning this PAR project, I assumed that I would work with young women to develop similar workshops. Interestingly, participants within this PAR project did end up attending two health conferences and facilitating workshops that were focused on body image. In addition, some young women within Girls for a Change designed a creative website to discuss issues associated with body image, such as exercise and nutrition. 
They felt that this website could reach a large number of other young women and the website could provide a forum where young women could ask questions about issues related to body image. Although the participants in this PAR project did not develop a website, the young women did share their body image experiences through various forms of media (e.g., radio, newspaper, television), and one young women published her story about body image in a local youth newsletter.

Action can take many forms and be implemented at various levels (Reid, Tom, \& Frisby, 2006). For example, as a form of action, Taylor (1998) explained how she ensured that her research was shared with policy makers and made public through various means of media. Similarly, prior to entering this research process, I thought that the participants might be in favor of making the research findings available to policy makers and the media. Similar to Taylor, various forms of media were used within this project as a form of action. Although this research has not yet been made available to policy makers, it is possible that findings from this research may be used to inform policy once it is published and disseminated to interested audiences.

\subsubsection{Relevance and Credibility}

Given that the development and implementation of action at various levels has been identified as the most important contribution of this PAR project, it is important to take a step back from this research to explore the relevance and credibility of the action initiatives. Participatory action research has garnered support in the academic community since traditional research has often lacked relevance or failed to provide insights of social or practical use (Tindall, Clasen, \& Smith, 2003). Although a founding feature of PAR is its enhanced relevance for all participants, many academics are still unfamiliar with the defining features and overall benefits of PAR. Thus, the question "How do we know that this research is relevant to the participants?" is likely to arise in many academic circles. The most straightforward answer to this question is to say that this PAR project and the resultant action initiatives are relevant to the participants because all of the action initiatives emerged from the suggestions or support of the participants.

Engaging in PAR requires extensive resources and time, and involving young people throughout the research process ensures that the findings are relevant to other 
young people (Bostock \& Freeman, 2003). All of the participants involved in this project, particularly the core group, identified issues that needed to be addressed (i.e., issues associated with body image) and then worked collaboratively amongst themselves and other school members to develop specific initiatives or solutions to those issues (e.g., Body Talk). Regardless of where the initiatives originated, the young women were actively involved in shaping the manner in which the action unfolded. Thus, I think that the question of relevance is somewhat redundant, since all of the action initiatives were developed as a result of what the participants thought were relevant strategies to their body-related concerns.

Although I am confident that this PAR research was relevant to the participants, it is difficult to identify the impact that this research had on young Aboriginal women. In their recent participatory action research with youth with special health needs, Burstein, Bryan, and Choa (2005) described the similar difficult task of trying to quantify the impact that their research had on youth. They explained how the PAR process supported youth in their pursuit of goals. As well, the project encouraged students to share their experiences with others, and such sharing was perceived as therapeutic to the students. Thus, they argued that their research made a positive impact on youth. Similarly, through the processes of this PAR project, the participants were supported in their action goals and supported in sharing their body experiences with others. Therefore, this research likely had a positive impact on youth because, as suggested by the Centre of Excellence for Youth Engagement (2007), engagement processes support youth in the development of relationships, personal skills, and overall well-being.

Similar to exploring relevance or the impact of research, qualitative researchers and action researchers are often faced with questions about the quality and credibility of their research. However, when addressing the issue of credibility, action researchers, similar to other qualitative researchers, should not feel the need to try to justify the merit of their research using the criteria that are typically defined within postpositivist research. As Sparkes (1995) argued, different epistemological and ontological assumptions guide qualitative and postpositivist inquiry; thus, the criteria used to pass judgment on one should not be used upon the other. He further explained that, "Attempts to do so are, at best, misguided and, at worst, arrogant and nonsensical, a form of intellectual 
imperialism that builds failure in from the start so that the legitimacy of other research forms is systematically denied" (p. 181). Recognizing the need for suitable judgment criteria in qualitative research, numerous researchers (particularly in the social sciences) are constantly engaging in dialogue surrounding appropriate judgment criteria, either because they are trying to defend their own research or they feel there is a need for new criteria (Lincoln, 1995). Lincoln (1995) argued that much of the emerging criteria are relational, in that the relationships between researchers and participants are now recognized and validated. For example, she explained how researchers have begun utilizing positionality as it allows researchers to "come clean" about their personal assumptions, and thus supports the honesty and authenticity of the text. As well, she highlighted the role of "voice" as another criteria; researchers need to identify who is speaking for those (e.g., youth, Aboriginal peoples) whose voices are typically overlooked in the research literature. Although the issue of voice has been identified by Lincoln as criterion for quality, it has also been identified as an ethical issue by researchers (e.g., Battiste, 2002; see section 1.3.1) who have outlined respectful research practices for those engaging in research with Aboriginal peoples. Generally speaking, Lincoln's outline of emerging criteria for judging the quality of research are based on the relational and ethical manner in which participants are involved in research. Given that I continually outlined my position within this research project (i.e., positionality) and I paid particular attention to the role of "voice" within this research (see section 1.3.1), this research demonstrates credibility as defined by Lincoln (1995).

Although Lincoln (1995) described some emerging criteria for identifying quality or credible qualitative research, there is no definitive set of criteria for judging the quality of qualitative or PAR research. Having to address such questions of quality and credibility within his own qualitative research, and seeing that there are no definitive standards for determining the quality of research, Garratt (2003) argued that researchers should select judgment criteria that are appropriate for the story being told. Taking into account Garratt's (2003) suggestion, various forms of criteria have been outlined in an effort to demonstrate the success or quality of this project. As described in section 2.1.2.1.5, various methods of verification were employed throughout the research project in an effort to demonstrate the more conventional manner in which the trustworthiness of 
this study was established. This section, however, will provide a more basic description of the various forms of evidence that serve as evidence for the success of this project. More specifically, the remainder of this subsection outlines four different ways in which the success of this project was documented.

First, and probably most importantly, the words of the people who were involved in this project demonstrate the success of this research project. There were various instances whereby students and staff verbally recognized the success of the various initiatives. In describing why she felt Girls' Club was successful one young woman said, "It made me be active and the lunches were great and healthy." As well, over the duration of the school year, particularly near the end of the school year, many of the students repeatedly asked whether or not the various lunch time activities (e.g., Girls' Club, Body Talk, Art group) would be offered to students the following school year. Students indicated how much they enjoyed the action initiatives and wanted to ensure that they would continue to be available to students.

In addition to what was said verbally, one of the young women from the core group (i.e., Veronica), and one of the teachers (i.e., Sylvia) who was actively involved in some of the action initiatives (e.g., yoga, Writing Group), provided me with written letters that outlined their perceived success of the action initiatives and my involvement within the school community (see Appendix G). In describing her involvement with me and the research project Veronica said,

...her [Tara] and I had a lot of fun hanging out and working together. The students that she worked with in the clubs and volunteered with are going to miss her a lot. Tara really made the school a better and more exciting place to be, and to do things. There was always something to do at lunch and always something for her to tell us, or us to tell her.

I think this statement really highlights the collaborative nature of this research project and how the young women recognized that their voices are important and that their voices would be heard. Sylvia's letter also outlined how she perceived this project as successful. She explained,

...even though that group [Girls' Mentorship] had been part of Nutana Collegiate for many years, Tara added many new dimensions to our mentorship program, that it evolved into a very dynamic activity. Students, many of whom are high-risk individuals, became keenly aware and astute about 'wellness' practices... Student participation in the Girls' Club and Literacy Group [writing group] increased remarkably and the students enjoyed coming to the library to talk about the many wonderful ideas and insights they gained from their relationship with each other and with Tara. 
Although school members verbally expressed their perceived success of this PAR project, seeing written statements as to how the project was perceived really helped me to better understand the positive impact that this project had made.

Second, the establishment and continued commitment of a core group of young Aboriginal women to the goals of this PAR project, provides strong evidence that this project was successful. I am confident that this project would not have been successful without the commitment that was demonstrated by this core group, as it was the core group who played a critical role in shaping and implementing most of the initiatives. The commitment demonstrated by the young women can partially be attributed to the relationships that were established between and among the young women and me, and the power that the young women felt that they had within the group.

Third, the constant support and commitment of the various school members to the action initiatives provides evidence for the success of the various action initiatives. As suggested by Angeles (2004), research is often perceived as effective if researchers actively engage participants in all aspects of the research project (e.g., design, logistics, implementation). If the young women did not perceive the initiatives as successful or meaningful, I do not believe that they would have been committed to the various initiatives, nor would the initiatives have been successful. For example, when the young women made commitments to participate in some of the single day action initiatives (e.g., CBC radio interview, SHY and RESOLVE conferences), they always followed through with their commitments. When action initiatives were held during lunch times (i.e., Body Talk, yoga, Girls' Club, Writing Group, Art Group), the young women's regular attendance showed their commitment to the strategies, and demonstrated the importance and success of such initiatives. Their commitment was likely the result of the constant evaluation, and the subsequent revisions, of their action initiatives. Having said this, there was never a formal process of evaluation for any of the initiatives; evaluation was more informal in that if the young women did not like the way the action initiative was unfolding one week, they could simply change it the next week. For example, if a physical activity was organized for Girls' Club and few young women participated in the activity, the core group listened to the ideas of the young women from Girls' Club and organized a different activity for the next week. Thus, it was not an issue of waiting until 
the end of the project to evaluate the success of the weekly initiative; initiatives (except for single day initiatives) were evaluated constantly.

Fourth, when looking at the yoga and Writing Group initiatives, the manner in which they emerged provides evidence that these specific initiatives were successful. Both the yoga and Writing Group emerged from the direct requests of school members. Yoga, which was originally only going to be offered up to Winter Break, was continued after Winter Break as an action initiative. Students and staff explained that the yoga classes made them feel more positive about their bodies. One young woman said, "I like yoga because it calms me down a lot and I like yoga because it makes me feel better about myself." Given the manner in which it made students and staff feel about themselves, they wanted to see it offered as an action strategy for helping young women manage their body-related concerns.

With respect to the Writing Group, lunch time writing sessions were originally offered to students by a Saskatoon organization. Although that particular organization had some difficulty maintaining a consistent group of students, when Writing Group was offered (as requested by students) as part of this PAR project, there was a consistent group of students who regularly attended the group. During the last few writing sessions, the young people were asked to write down the reasons that they continued coming to writing group, and what they thought made this writing group successful. There were a variety of responses, but they were all embedded with the same ideas. One participant wrote, "I like writing group because I can feel free to write what's on my mind and share it because everyone else is willing to listen. It makes me feel good and supported." Building upon this, another young woman wrote how she liked that "everything is confidential and you can share if you want or you don't have to." Another young woman said, "I like writing group because we're not given an assignment to write; we get to write what we want to. Writing group is a positive group and I'm not judged." Finally, another young woman expressed her thoughts in point form. In describing why she enjoyed writing group she said, (1) I get to write, (2) Tara's awesome, (3) It just has a welcoming feeling, (4) There's awesome people, (5) We all get to be heard (that is, if we want to share), (6) There's food, (7) Writing group is just a wicked place." 
The request by participants to extend the Writing Group for an additional 8 weeks (to a total of 16 weeks) also demonstrates the success of this initiative. Similar evidence of success was recorded by Daigneault (2000), who also completed her research within a high school. She developed a school-based intervention that was focused on working with high school students on issues of the body (e.g., body image, eating disturbances), and she argued that the evidence of success of her intervention was demonstrated by the active role of the school participants to keep the group "alive".

To summarize, the relevance of this project to the participants is obvious in that it was the participants who were the driving force behind all action strategies; their continued input and dedication to this project made this project relevant to them. As well, the strongest evidence for the success of this project has been presented by highlighting the words of participants, the commitment of the core group, the constant support of various school members, and the active role that participants played in transforming previous opportunities into action initiatives.

\subsubsection{Need for School-based Body Image Programs}

The perceived success of this action research project makes a clear statement that there is a need for school-based body image programs. In addition to the support that was voiced from many Nutana members throughout the duration of this research project, Dunlop-Robertson (2006), a former Superintendent of Schools from the Thames Valley District School Board in Ontario also recognized the need for school-based health interventions that focus on body image. She explained how students play a strong role in the overall social construction of what constitutes "accepted body image" (p. 21). As well, she argued that although body image concerns are not restricted to school-aged individuals, a significant number of school-aged young women are impacted by body image issues. Given the various health consequences that are associated with body concerns (e.g., dieting, substance abuse), Dunlop-Robertson highlighted the need for school-based body image programs. She argued that such programs could "provide students of all ages with support and guidance to understand and accept body-based differences" (Dunlop-Robertson, 2006, p. 22). She further asserted that students need to learn to accept their bodies and to develop healthy attitudes toward their bodies,

particularly as they enter adolescence. Although she highlighted the need for such 
programs, she recognized that body image programs are not typical within most school curricula. Thus, it is important for teachers and researchers alike to find ways to implement body image programs into the school setting.

In addition to Dunlop-Robertson (2006), researchers such as Daigneault (2000) and Heilman (1998) have advocated for the use of schools as areas for implementing change. In an effort to address issues of body image, weight, self-esteem, and eating disturbances among female high school students, Daigneault explained how she worked with students to design a school-based group called Body Talk. Interestingly, without being aware of the work of Daigneault, the participants in this PAR project also developed an initiative called Body Talk, which had the similar goal of providing a space for young women to talk about their concerns about body image. Heilman also argued that schools can serve as sites for deconstructing issues of body image identity, among a number of other things. She explained how schools could be used to promote support systems that try to eliminate social, class, and gender difference.

Other researchers (i.e., Champagne \& Halas, 2003; Humbert, 1995; James, 2001) have also identified the school setting as a place where one's body can be placed on display and/or ridiculed, thus providing justification for schools as areas for implementing change related to body image. By implementing positive body image programs into schools, it would be possible to work with young people so that they can learn how to manage their experiences when they feel that their bodies are on display. Although they did not specifically refer to schools, Bostock and Freeman (2003) recognized that youth need to be involved in promoting recommendations and generating change. They argued that youth need to feel that they have control over change processes and outcomes, especially when it comes to change that will be impacting them. Thus, regardless of the issues that must be addressed, schools have been recommended as sites for change, and young people should be involved in the development of the change initiatives.

This project provides a practical example of how PAR methodologies can be used to successfully implement body image initiatives into school settings. Although not specifically focused on body image research, other researchers (e.g., Dickson, 2000; Macauley et al., 1999) have argued that there are many strengths of utilizing PAR 
frameworks when engaging in health research with Aboriginal peoples. Dickson explained how she was part of a PAR project with Aboriginal grandmothers, which focused on developing health promotion programs. She explained how her project was successful in that grandmothers "experienced success in advocating for improvement in their personal and collective lives" (p. 212). Similarly, Macauley et al. described the success of a research project that involved a Mohawk community near Montreal, Canada. Their project was a school-based program focused on promoting healthy eating and increasing physical activity in an effort to prevent Type 2 diabetes. They explained that through PAR, it was possible to generate "collective wisdom"; this diverse and collective wisdom could then be used to develop relevant health strategies that would subsequently increase the project's effectiveness. The perceived success of the above mentioned PAR projects, in addition to the perceived success of this current PAR project, provide support for my argument that PAR methodologies should be used when working with Aboriginal women to implement body image programs into school settings.

If researchers are going to work with young Aboriginal women to develop body image programs into school settings, it is also important that they explore how they can support the sustainability of such programs. As suggested by Ho (2002), it is not only the perceived success that is important within PAR but also the sustainability of the initiatives. As demonstrated in Ho's PAR family-school intervention study, having stakeholders actively involved in the development of the intervention, resulted in the acceptability and sustainability of the program. Similarly, having young women from the core group activity involved in this PAR project led to the sustainability of the action. For example, participants played an active role in shaping and implementing the Writing Group, in that they decided on the topics to be written about and the format for leading discussions. As a result of their active involvement and, what I saw as their perceived sense of ownership, it was extended from 8 weeks until 16 weeks. Given that the action strategies for this research were generally implemented and evaluated by the core group and various school members, their sustainability within the school beyond this 2006-2007 school year are more likely than they would have been had they been developed without consideration of participants' suggestions.

\subsection{Role of Adult Allies}


The important role of the "adult ally" should not be overlooked when trying to determine if the action that was developed as part of this PAR project will be sustainable over the next few years. Most of the action initiatives that were developed (e.g., yoga, Girls' Club, Body Talk) required little or no funding and were easily facilitated by participants or volunteers, which would lead one to think that the strategies would carry over from year to year. However, despite the active involvement of the participants in this PAR project, my experiences in the school over a 10 month period leads me to believe that there was, and still is, a strong need for an adult ally who could work with the young women on sustaining such initiatives.

The Centre of Excellence for Youth Engagement (2007) explained how "an adult ally helps youth have their voice heard through meaningful engagement" (p. 2). As an adult ally within this PAR project, I was committed to ensuring that the youth were engaged in the various aspects of this research so that the results of the project would be more meaningful to them. The Centre further asserted that "being an ally to young people involves a combination of positive attitude, skill, and awareness to help in advocating for a youth leadership and empowerment agenda" (p. 2). Despite the overall positive intentions of this adult ally definition, Gore (1992) argued that there are three problematic assumptions associated with the term "empowerment". First, Gore asserted that the term empower denotes the ability to give authority. She explained that if this is indeed the case, then this process of empowering requires an agent (e.g., researcher) or someone to give power. Gore considered this belief to be particularly problematic because an agent of power would indicate that the researcher has extraordinary abilities. Researchers engaging in collaborative research programs, especially when in crosscultural contexts, must be wary not to assume such power because, as stated by Battiste and Henderson (2000), this mode of thought is consistent with that of Eurocentric thought and European superiority.

A second problematic assumption associated with the term empowerment is that it supports the notion of power as property (Gore, 1992). Gore explained how the assumption of power as property subsequently suggests that there is only so much power to give and if power is given to one person, someone else must give up some of his or her power. This notion of power as property could be problematic for those individuals 
involved in collaborative programs because the power and responsibility is to be shared among all collaborators. Gore explained how power would be better understood in terms of a process rather than a property. If power were visualized as a process or an exercise, researchers would not be faced with the dilemma of having a limited amount of power to "give".

The assumption that empowerment ends with a desirable end state is the third problematic assumption that Gore (1992) argued is associated with the term empowerment. She explained how the vision of empowerment should be that of empowerment. Similarly, Smith (1999) explained how the process of research is often more important then the outcome of research. She explained how researchers need to engage in processes that allow people to heal. Empowerment research or collaborative research may foster an environment in which people are able to heal. Having said this, Gore explained how the contexts in which the act of empowerment will proceed must be defined in terms of the unique struggles that characterize the particular context. To assume that the process of empowerment is the same within all contexts would be misleading.

Aside from the problematic assumptions associated with the term empowerment, Gore (1992) explained how she also has a major concern about the politics of empowerment. As previously stated, the term empowerment fosters the belief that there is an agent (researcher) of power, which Gore believes set ups an immediate distinction between "us" and "them". Recognizing that this dichotomous way of thinking is common among those researchers involved in cross-cultural contexts, Harrison (2001) explained how the insider-outsider (us-them) dichotomy is not particularly useful in defining status because a researcher's "insider-outsider status" may change over time. Along the same lines, and advocating for the avoidance of a discourse that focuses on such a dichotomy, Denzin (2004) explained how "frequently writers are positioned outside, yet alongside, those Others they write about, never making clear where they stand in these hyphenated relationships that connect the Other to them" (p. 452). In light of the above assertions, the relationships formed when engaging in collaborative research methodologies in cross-cultural contexts should encourage all collaborators to work 
together in a manner that does not require individuals to define their respective "us" or "them" status.

By trying to eliminate the insider-outsider distinction that is so common within collaborative research in cross-cultural contexts, researchers may be able to avoid what Hughes and Sharrock (1997) calls a "God's eye view" of things. Battiste and Henderson (2000) explained how the insider-outsider dichotomy is rooted in Eurocentric thought, which assumes that Europe is at the center (inside) and everyone else (e.g., Aboriginal peoples) is at the periphery (outside). This mode of thinking fosters the belief of European superiority and if collaborators continue to think in terms of the insideroutsider or us-them dichotomy, they are in danger of supporting the belief of European superiority. Collaborative research methodologies can be undertaken within crosscultural contexts without thinking in dichotomous terms.

In addition to the problems associated with the term empowerment that have been identified by Gore (1992), Bishop (2005) also explained how researchers engaging in collaborative programs in cross-cultural contexts should no longer attempt to empower others. He explained it is only when nothing is wanted for the self, not even the desire to empower "others", that complete participation in collaborative research is possible. Building upon Gore's (1992) notion that empowerment requires an agent, Bishop explained how participants must develop views of themselves as the agents of power and those who have the authoritative voice; researchers must facilitate this development. $\mathrm{He}$ further explained how the development of participants' authoritative voice should not be the result of the researcher empowering the participants. As stated by Gore, power should not be viewed as property that can be given to participants.

In recognizing some of the problematic assumptions associated with the term empowerment, the intent of Gore (1992) and Bishop (2005) was not to discourage researchers from engaging in practices that are deemed empowering (e.g., collaborative research). Instead, they want researchers to critically examine the underlying assumptions of empowerment and consider the consequences, if any, associated with utilizing such terms. In doing so, the strengths and weaknesses associated with collaborative and empowerment research methodologies can emerge. 
Despite some of the problematic assumptions associated with the term empowerment, adult allies can play a critical role when working collaboratively with youth, particularly in cross-cultural contexts. The Centre of Excellence for Youth Engagement (2007) explained that adult allies can work with youth to implement change at individual, social, and system levels. For example, at an individual level, adult allies can support youth in building skills and sharing their voices. Youth can also benefit at a social level in that they can be provided with opportunities to expand their social networks. On a system level, organizations can become more responsive and create more effective youth programs. Our PAR project provides a strong example of how an adult ally (i.e., me) worked with youth to develop initiatives that made an impact on a number of these different levels.

In their guide to social change with young people, Fletcher and Vavrus (2006) also explained how youth do not typically work in isolation with the individuals and communities whose actions or perceptions they seek to transform. Instead, youth often work alongside adults or adult allies who seek to support and advocate for the young people. In retrospect, I see myself as the adult ally who was working alongside these young women, and although the young women were active agents in the implementation of the action initiatives, I do not think that the initiatives would have been as successful if they had not had the support of an adult ally. As their ally, I was consistently supporting the initiatives (e.g., booking spaces for meetings, providing lunches, reminding young people about the lunch time initiatives), which I think was critical in the success of the action initiatives. Thus, I think that it is important to identify an adult ally who works within the school and is committed to the sustainability of this research project.

Recognizing the potential need for an adult ally who would be committed to the goals of this research project, Phyllis and I hired a Wellness Coordinator for the 20072008 school year. Funding for this position was provided by a grant that we received from the Saskatoon Health Region (see section 3.1.2.1.3). This Wellness Coordinator position is particularly focused on physical activity and nutrition, which both were identified by the participants as important factors contributing to their body image experiences. Although support for the various action initiatives was demonstrated by numerous staff and teachers at Nutana, throughout my time there it became increasingly 
clear that there would need to be a person, someone like myself, who was committed to ensuring sustainability. Teachers and staff have so many work commitments that it is difficult for them to dedicate extended amounts of time and energy into maintaining such programs. Thus, the primary goal of the Wellness Coordinator is to continue to support the hard work of the young people by ensuring their action initiatives are continued from year to year.

\subsubsection{Methodological Considerations and Challenges}

Despite the perceived success of this PAR project, it is important to highlight some of the methodological challenges and considerations that are associated with this particular PAR project. More specifically, this section will highlight the Integration of the Five Phase Research Plan (section 3.2.2.1), in an effort to demonstrate how the methodology was adapted to more adequately reflect the needs of this project. As well, an exploration of the challenges and considerations associated with Working within a Community School (section 3.2.2.2), and the development and termination of research Relationships (section 3.2.2.3) has been presented. By exploring the manner in which such challenges were navigated, it may be possible to provide some insight for future researchers who are interested in engaging in PAR projects with similar goals.

\subsubsection{Integration of Five Phase Research Plan}

Participatory action research is not a static or fixed research approach; it is a process that is dynamic and often changes over time or throughout the research project (Gibbon, 2002). The dynamic nature of the research process became apparent throughout my own journey with this project. Although I had outlined a proposed framework for engaging in the research process (i.e., the five phase model presented by Stringer \& Genat [2004]), the manner in which the actual project unfolded was quite different.

Despite understanding the overlap among the five phases that were presented by Stringer and Genat (2004), when first entering the school I was quite confident that this PAR project would unfold in a fairly sequential manner from Phase 1 to Phase 5. However, as noted in the Results section, I ultimately see this project as having two distinct phases in which the participants were collaboratively involved, the Relationship Building phase and the Action phase. Although I never really thought that there would be a clear, singular method for engaging in PAR, in retrospect I think that I did have an 
underlying hope that the methods would unfold in a fairly linear and straightforward manner. However, every school or community within which a researcher works is unique; therefore, to think that a single method will work for all communities is probably unrealistic. Numerous researchers have written about the dynamic nature of PAR (e.g., Gibbon, 2002); nevertheless, it was difficult to fully comprehend this until I was actually involved in such a project. Thus, after I entered the PAR process I realized that I would have to adapt Stringer and Genat's (2004) five phase model to fit the unique school context within which I was working.

It is difficult to try to envision this PAR project unfolding as a five phase model, mostly because there was so much overlap among the five phases. For example, as highlighted in section 3.1.2.3.1, the media requests were not only a form of action but also they were a form of communication. As well, the manner in which each phase unfolded was not necessarily consistent with what Stringer and Genat (2004) outlined. More specifically, in terms of the "act phase" of their five phase model, they explained how it is important for researchers to set action priorities, construct a work plan, review the plan, support and monitor progress, and constantly to evaluate. Although I worked with the young women to develop action priorities, not all of the action initiatives originated from us. For example, it was the media that originally contacted us and asked us for an interview; we did not initially identify this as an action priority. Having said this, after we were contacted by the media, the young women and I did decide that this would be an effective form of action in that it would allow us to achieve our action goal of creating awareness about body image. As well, since the media opportunities were single day initiatives, the participants and I were unable to monitor progress of this priority and engage in the process of evaluation with the intent of improving the initiative. Although the young women and I were not able to consistently follow the specific steps outlined by Stringer and Genat for the act phase, the participants and I still perceived the various action initiatives as successful.

Given that this project did not unfold like the five phase model outlined by Stringer and Genat (2004), one must consider whether it is beneficial to try to view the research process in this manner. Similar to Frisby, Crawford, and Dorer (1997), I recognized the benefits of working within a PAR framework, but I also recognized the 
importance of adjusting models to fit the emergent nature of PAR. Reflecting on their PAR project with low-income women, Frisby et al. (1997) explained how Green et al.'s (1995) model for participatory research in health promotion was a useful framework for developing and evaluating their participatory action project. Frisby et al. recognized the "user-friendly format" of this model, yet they also highlighted aspects of the model that could be strengthened. For example, they argued that the importance of the action phase should be emphasized within the framework. As well, similar to the challenges that I faced in trying to adhere to Stringer and Genat's (2004) model, Frisby et al. also recognized some overlap between the categories outlined in Green et al.'s framework. Despite such challenges, Frisby et al. argued that following a framework (such as Green et al.'s) is beneficial as such frameworks highlight many important questions (e.g., purpose of the research) that must be addressed when engaging in PAR projects.

Similar to Frisby et al. (1997), it was important to have a plan as to how the research process would unfold, and the process outlined by Stringer and Genat seemed to be most consistent with the research that I had proposed to do. Despite having a plan, I am pleased that my commitment to this model was flexible so that I was not forcing the research project to fit this specific mold. Some of the initiatives developed in the action phase (e.g., media requests) resulted from the requests or ideas of individuals from outside the project (e.g., CBC radio); thus, this action phase did not flow sequentially from the phases of data collection and data analysis. Despite this, the young women viewed media requests as an important action initiative that allowed us to create awareness, and we were able to develop initiatives that might not have been possible if we were too concerned about adhering to the specific model outlined by Stringer and Genat. As suggested by Gibbon (2002), PAR should be viewed as a dynamic process that can change with time and, therefore, it was important for me to be flexible.

Although this PAR project did not necessarily fit neatly within the overall five phase model that I had originally proposed, there were various aspects of the project that were consistent with Stringer and Genat's (2004) model. Similar to the first phase (i.e., Building the Picture) described by Stringer and Genat, this PAR project was framed and focused, a core group of participants was established, and issues of ethical consideration were outlined. As well, similar to Stringer and Genat's model, our PAR research 
involved different types of data collection. Young women were involved in various informal interviews and group discussions in an effort to shed light on their body image experiences. Although communication and action were often intertwined (e.g., conferences), many of the components of this research project were consistent with the model outlined by Stringer and Genat.

In summary, is important to compare the five phase model that was originally proposed for this research to the two phase model that actually emerged, in an effort to determine whether there is value in using one over the other. Shortly after this project began in September of 2006, I began to conceptualize this PAR process in terms of two phases, as these two phases provided a more adequate representation of how the research was unfolding. I recognize that Stringer and Genat (2004) emphasized the emergent and cyclical nature of the PAR process within their five phase model; nevertheless, the visual depiction of their separate five phases seemed to send a subtle message to me that the components of each phase should be specifically followed. However, as suggested by McIntyre (2000), it is possible that predetermined programs can restrict the emergence of participant experiences; the same can likely be said for predetermined PAR models or methods. As a researcher who recognizes that Aboriginal women's experiences have not received enough attention in the body domain, I wanted to ensure that I engaged in a research process that fostered, and did not constrain, the illumination of participant experiences.

Consequently, I strayed away from Stringer and Genat's (2004) model and I supported the processes that naturally occurred (i.e., relationship building and action) as part of this PAR project. As argued by Smith (1999), the methodology process is highly important in community research. Building relationships was identified by Stringer and Genat as one of the working principles of PAR; nevertheless, their five phase model seems to place relatively little focus on the importance of relationship building. Contrary to the five phase model, my two phase model highlights this relationship building process as a primary component. Overall, Stringer and Genat's five model serves as a strong starting point for identifying the important components (e.g., communication, action) of PAR research. Nevertheless, as a result of my personal experiences, future researchers 
may want to consider placing a stronger focus on the importance of the relationship building process in PAR research.

In retrospect it may have been useful to follow Frisby et al.'s (2005) five phase PAR framework for this PAR project, given the focus that they placed on "building trust", and hence the need for the development of relationships. The five phases of their PAR framework were: setting the research questions, building trust, data collection, data analysis, and communicating results for action. Aside from the stronger focus that Frisby et al. placed on building trust, the other components are very similar to those in Stringer and Genat's (2004) PAR model. Frisby et al. argued that it was important to build trust with participants and community members because this trust encouraged participation and fostered an environment that respected the diversity of participants' experiences. Although this strong focus on building trust reflects the relationship building processes that occurred within my PAR project, Frisby et al.'s framework has its methodological challenges. They described how their research process incorporated five major components, or five phases, but they argued that the phases did not unfold in a linear fashion. Similar to Stringer and Genat's (2004) model, the phases or stages of Frisby et al.'s framework were integrated into the overall functioning of the PAR project, and the participants and community members had a difficult time envisioning the stages as distinct components. Therefore, although Frisby et al.'s framework could have added some additional guidance in terms of the importance of building relationships, it is likely that I would have encountered similar methodological challenges associated with the cyclical nature of PAR had I followed their framework.

\subsubsection{Working within a Community School}

The experiences that were gained from engaging in this research project at Nutana Collegiate confirmed my initial beliefs that a community school would be an ideal location for a PAR project aimed at working with young Aboriginal women in developing effective initiatives for managing body image experiences. As suggested by Tymchak (2001), schools are "the most immediate and the most natural contexts for addressing the needs of the whole child" (p. 44). Furthermore, Senge et al. (2000) argued that if a school is successful, then community will be successful and vice versa. While there is ample literature to support my justification for working within a school for this 
PAR project, I am aware of little literature that highlights the specific benefits of engaging in a PAR project within a community school. Compared to non-community schools, community schools provide a variety of resources and services to students. The resources and services available at Nutana often supported the success of the action strategies. For example, two of the young women who were part of the core group were also members of Youth Launch at Nutana; thus, these young women learned facilitation skills which were very useful when leading some of our action initiatives (e.g., Writing Group). Despite the many benefits of working within a community school, one challenge did arise. That is, the participants and I had to determine how "community" is defined when working within a community school.

Given that there are many definitions associated with the term community, a number of challenges can arise when trying to define the 'community' and appropriate community representatives. Nutana has a large Aboriginal population; thus, I originally assumed that it would be important to identify an Aboriginal community and Aboriginal representatives for this community-based PAR project. However, given that the school has representation from a number of different Aboriginal communities, I knew this was going to be a difficult task. Recognizing this challenge, I spoke with the Aboriginal Elder associated with Nutana and sought his advice on how to define community. He argued that because there are a number of different communities within Nutana, I should consider working with students to define community. He also offered his support for the goals of this PAR project. Similarly, Smith (1999) in her book on research and indigenous peoples argued that people can belong to a number of different communities, and these various layers of belonging are often referred to as "nested identities". She also explained how the term community implies an intimate and self-defined space. By engaging the core group in conversations about community, it was possible to identify a definition of community that was agreed upon by the participants and me.

Despite various definitions, the young women from the core group and I decided that we agreed with Smith's (1999) and Robertson and Minkler's (1994) conceptualizations of communities. Smith argued that communities can form around the goals and interests of a particular group. Similarly, Robertson and Minkler described community as "a group of people living in the same defined area sharing the same basic 
values and organization" (Robertson \& Minkler, 1994, p. 303). Put more simply, Robertson and Minkler explained how a community can be any group of people who share the same central interests; the core group and I used this basic definition when trying to identify our research community. Because this was a school-based PAR project and we wanted to be inclusive of all who might want to participate in the various initiatives, the community was initially defined as Nutana Collegiate. More specifically, the students, teachers, support staff, and principals of Nutana constituted our community. By defining Nutana as a community, we ultimately supported Harrison's (2001) belief (discussed in her book on collaborative programs in indigenous communities) that a community may be a school.

Although we originally defined Nutana as our community, as the action project progressed throughout the school year it became apparent that there were other smaller communities embedded within Nutana. Again, this recognition of multiple communities supports Smith's (1999) argument that people have nested identities. In terms of this PAR project, the young women in the core group identified themselves as a community because it was the core group who was specifically focused on the goals and interests of the research project. The core group was comprised of young Aboriginal women who were all interested in developing action initiatives focused on managing body image experiences. By defining themselves as a community, the core group supported Smith's contention that communities do not need to be defined by geographical space and that indigenous women may constitute their own community. In summary, although the inclusion of the broader school community within various action initiatives was important, it was the smaller community or the core group that played an instrumental role in the overall productivity of this PAR project.

\subsubsection{Relationships}

Strong relationships were identified by Stringer and Genat (2004) as key factors in the success of action research projects. Similarly, Boog (2003) argued that the relationship between the researcher and the participants is crucial for the success of action research. The critical need for the development of relationships was also outlined by Bishop (1996), who explained how non-Aboriginal researchers engaging in research with Aboriginal peoples must establish relationships at the beginning of research. 
Various researchers (e.g., Bishop, 1996; Stringer \& Genat, 2004) have written about the critical need for developing and nurturing relationships; yet it is hard to have a solid understanding of the prominent need for such relationships until actually placed in a research situation whereby relationships ultimately form the foundation of the project's success.

Now that the research project has concluded, I realize how instrumental those first few months were in developing relationships with the young women. Although there were days within the first few months that I had concern that the project was not moving along at an appropriate speed, in retrospect I realize that those first few months of earning participants' trust played a critical role in this research process. Such trust formed the foundation of the relationships that were critical in enabling me to work collaboratively with the participants to develop initiatives. As argued by Smith (1999), the research process is often more important than the outcome; the process, particularly in terms of relationship building played an important role in the development of effective initiatives. For example, if I had not taken these first three to four months for relationship building, the young women might not have felt as comfortable sharing their experiences in the Body Talk session. Thus, the initiative likely would not have been as effective because it would not have supported the action goal of promoting self-expression. I also think that the commitment of the young women to the development and implementation of the various action initiatives (e.g., SHY Conference) was enhanced by the trust and respect that they had established with me alongside their commitment to the overall goals of the project. As suggested by Stringer (1999), the quality of relationships will impact people's experiences, and I am confident that the successful development of action initiatives was largely the result of the participants' positive experiences with this project.

Until I was engaged in the research process, I was not certain how important the relationships would be or how difficult it would be to end relationships at the conclusion of the project. However, I knew from my previous research experience that newly developed personal relationships would likely make it difficult to leave the field at the end of the research process. Similarly, Aitken and Burman (1999) explained that it is common for personal relationships to develop when a project runs over an extended amount of time. As a result, they claimed that participants will likely have questions 
about whether the relationship will extend beyond the research project. Having engaged in a school-based group intervention for young women with eating disorders, Daigneault (2000) argued that it is likely that some group members will experience a sense of loss when a group inevitably comes to an end. She argued that a good termination of a group needs to be planned by the group facilitator so that students are protected from such feelings. In an effort to guard against possible feelings of betrayal, Haverkamp (2005) suggested that researchers monitor and clarify expectations throughout the duration of the research project. Cutcliffe and Ramcharan (2002) argued that researchers should approach their research using an "ethics-as-process approach", so that they remain cognizant of the possible ethical issues (e.g., ending of relationships) that can arise at any point in the research process.

Fortunately, I was not faced with such expectations from the participants, despite having established many relationships throughout the duration of this research project. There are likely two primary reasons as to why participants did not ask about the manner in which our relationship would play out after the research project ended. First, because I was constantly communicating with the participants, they understood that I was only going to be part of the school community until the end of the project in June. Second, this research project was a 10 month project coinciding with the September to June school year, and the participants were familiar with the reality that many teachers, staff, and community partners, like myself, change from year to year. Thus, the participants understood that I would not be involved in the school the following year and, therefore, there was no real sense of loss (as suggested by Daigneault[2000]) when this group came to an end in June. In retrospect, I am happy that there was an open dialogue between the participants and I about the relationships that were developed as part of this PAR project. This open dialogue fostered the successful development and end to the various relationships that were developed.

\subsubsection{Reflection on Role of Theory}

When this research was originally proposed it was stated that feminist theory and Lazarus' (1991) emotion theory were going to guide this PAR project. As well, justification for engaging in this research was based on current literature or theories of body image. Therefore, to end this discussion, it is important to reflect upon the role of 
theory in my research. A number of scholars (e.g., Friedlander, 2001; Wadsworth, 1998) have argued that theory allows researchers to develop deeper understandings about phenomenon and that these new understandings are important if action is to be effective. Taking this one step further, Friedlander (2001) argued that theory plays a critical role in PAR because, without theory, there is no reason to include or exclude action strategies. Somewhat contrary to this argument, Wolcott (2001) stated that developing theoretical implications is an important component of the research process, but "it should not be regarded as a condition" (p. 77). He further argued that rather than trying to find a "place for theory" in their research, researchers should "keep theory in its place" (p. 81). Given that the young women who participated in this PAR project had little to no interest in discussing the contributions of this research to theory, some may question if the contributions to theory are really meaningful when presented alongside the exciting action initiatives that were collaboratively developed with participants. However, it is important not to dichotomize theory and practice. As argued by Frisby, Maguire, and Reid (in press), theory informs our practices, whether it is explicitly acknowledged or not. Similarly, Brydon-Miller, Greenwood, and Maguire (2003) explained how theory not only can, but should, be generated through practice. In other words, theory can inform and arise from our actions (Frisby, Reid, \& Ponic, 2007), and the local knowledges that are generated from feminist PAR approaches highlight potential avenues for change (Frisby et al., in press). In light of this, the remainder of this section will briefly highlight the role that theory played in guiding this PAR project, and the manner in which this research contributes to the above-mentioned three theories.

Feminist theory played a role in this PAR project, in that it served as a guide for me to engage in research that is grounded in the experiences of women (Way, 2001), alleviates power imbalances (Alway, 1995; Taylor, 1998; Way, 2001), and is commited to action (Olesen, 2000; Taylor, 1998). Within this PAR project, I worked with young women to develop trusting relationships so that they understood that I was not involved in this research project as a "typical researcher". By building these relationships I worked to alleviate any power imbalances, and to foster the belief that this was a collaborative research project in which we were all equal partners. As well, within this project, the majority of the action initiatives were developed as a result of the young 
women sharing their body experiences. Thus, this project was grounded in the experiences of women.

By using feminist theory to guide this PAR project, I recognized that it was possible to engage in research that is committed to action. As suggested by Maguire (1996), without the explicit incorporation of feminist perspectives, it is not possible to have genuine emancipatory research. By using feminist theory as a guiding perspective, this PAR project was able to address some of the concerns expressed by Nichter (2000). She argued that despite the widespread concern that adolescent women are dissatisfied with their bodies and that such experiences are associated with a number of health consequences (e.g., eating disorders), few people are focusing on prevention. She explained how young women receive relatively little information on healthy eating and physical activity, and school time is rarely spent on developing the skills to critically evaluate media images. Similarly, Marchessault (2000) explained how researchers continue to "focus on girls' and women's enslavement to the thin ideal" (p. 206) and that there is a surprising omission of literature that focuses on women's strengths in the face of such overwhelming pressures. This PAR project, on the other hand, focused on young women's strengths and their capacity to create change. The young women in this study recognized that body image concerns are commonplace, and they took the initiative to develop strategies for managing such concerns. Therefore, feminist theory played a role in this PAR project in that it supported my engagement in a research project that was committed to action. At the same time, this PAR project contributes to feminist theory in that it provides a practical example of a research project that was committed to action.

This PAR project also contributes to feminist theory in that it enlightens the debate on whether or not feminist theory can and should be used when engaging in research with Aboriginal peoples. There was strong justification for using feminist theory to guide a PAR project focused on body image experiences. For example, Piran (1996) argued that feminist theory has the potential to play a strong role in supporting young women in sharing stories about their bodies. Similarly, Piran (2001) argued that transformation lies within the lived experiences of young women and that this is often discovered through dialogue. However, there seems to be less consensus in the literature as to whether feminist theory should be used in a research project with young Aboriginal 
women. More specifically, some researchers (e.g., Weenie, 2000) have argued that the experiences of Aboriginal women cannot be reflected by white feminists, and Ouellette (2002) suggested that the beliefs of many Aboriginal women are incompatible with many feminist theories. Despite some contestation, Cannon (1995) argued that those who distinguish between "Aboriginal rights" and "women's rights" have constructed a false dichotomy. He argued that the discrimination that women often endure takes place at the intersection of gender and race. Feminist theory recognizes the intersection of gender, class, and ethnicity, and the role that such intersections have in shaping women's experiences.

Prior to engaging in this research project, I was aware of the contentious issue of using feminist theory to guide research with young Aboriginal women. Nevertheless, the works of various Aboriginal scholars who are women (e.g., Battiste, 2002; Smith, 1999) supported my decision to use feminist theory to guide this research project. Although Battiste (2002) and Smith (1999) do not specifically talk to the issue of using feminist theory, they do highlight the importance of employing collaborative research processes when engaging in research with Aboriginal peoples. Given that feminist research is grounded in the experiences of women and focuses on the alleviation of power imbalances between the researcher and participant, I felt that feminist theory had the potential to support the collaborative processes that were recommended by Battiste and Smith. The young women who were part of the core group were committed to the feminist goals of this research project, and by sharing their experiences they were able to develop action initiatives that created change on a number of different levels. Thus, the success of this project provides a practical example of how feminist theory can be successfully used to guide research with young Aboriginal women, particularly when the research relates to issues of the body.

The body image literature also played a role in guiding this PAR project. Rather than focusing on more specific body constructs that run the risk of masking the unique experiences of all women (e.g., body dissatisfaction, social physique anxiety), the body image literature supported our contention that women's experiences with their bodies needs to be conceptualized using broader, and more encompassing terms. Cash and Pruzinsky (2002) described body image as a complex, multidimensional construct that is 
typically comprised of affective, perceptual, and cognitive components of body experience. Similarly, Paquette and Raine (2004) argued that body image is very dynamic and fluctuating and it should not be viewed as a static construct. By recognizing the complexity and fluctuating nature of body image experiences, and by not forcing the participants to identify singular experiences (e.g., body dissatisfaction), the participants in this PAR project were supported in sharing their diverse body image experiences. A wide range of experiences that encompass both negative and positive experiences were described throughout the results section; therefore, this body image research moves beyond what McNaughton and Rock (2003) referred to as the "epidemiological emphasis on the negative" in Aboriginal research.

This current PAR project is also unique to the body image literature in that it moved beyond the typical studies that have quantified Aboriginal women's body image experiences (e.g., Gittelsohn et al., 1996; Neumark-Sztainer, Story, Resnick \& Blum, 1997; Story et al., 1994; Story et al., 1995). Although some researchers (e.g., Poudrier \& Kennedy, 2008) have begun to engage Aboriginal women in discussions around body image, and some researchers (e.g., Wilson, 2004) have demonstrated the strength of using qualitative methodologies when engaging in exploratory health research with Aboriginal women, it is still relatively uncommon for researchers to use qualitative methods when exploring Aboriginal women's body image experiences. Given the successful initiatives that were developed, our PAR project provides a practical example of the strength of using qualitative methodologies (e.g., informal one-on-one and group interviews) for gathering insight into Aboriginal women's body image experiences.

Although body image literature played a role in guiding this PAR project, this PAR project also makes contributions to the body mage literature. Maybe most importantly, this PAR project mobilized Fox's (1997) suggestion to shift away from outcome to process objectives in body research. In describing body research, he argued that adolescents need support systems that will foster the development of successful programs. With my support as an adult ally, participants within this PAR project were able to develop successful body image initiatives. This PAR process supported Sparkes (1997) contention that exploration of body experiences should not be limited in scope, hope, or ability for social change. Through an exploration of women's body experiences, 
this PAR project did lead to change on a number of different levels and, as I articulated in my guiding perspective for this research (see section 1.2), this project was by no means limited in its scope or hope.

Lazarus' (1991) emotion theory also played an important role in this PAR project. It was argued in some of my previous research with young women (i.e., McHugh et al., 2008) that researchers should explore young women's experiences with their bodies using a broader theoretical framework, such as emotion theory. In that research, we argued that such a framework could support the diverse and complex nature of women's experiences with their bodies. Therefore, similar to my justification for focusing this current PAR project on body image, the encompassing nature of Lazarus' emotion theory allowed for the complexities of young women's body experiences to be illuminated. In terms of the more specific role that Lazarus' theory played in this research, it was used as a theoretical guide for my own interpretations of participant experiences, and it allowed me to "make sense" of their experiences.

Emotion theory also played an important role in this PAR project allowing me the opportunity to better understand the manner in which young women navigated the appraisal and coping processes that Lazarus (1991) argued are inherent in all emotional experiences. Although the young women did not use these terms (i.e., appraisal, coping), their discussions led me to believe that these were the processes that they were exploring. For example, in trying to make sense of their emotional experiences, participants would try to figure out why they cared what others were thinking; this thought process is reflective of what Lazarus (2000) called the appraisal process. More specifically, he explained how individuals appraise situations based on what is at stake as the result of a certain encounter. Although the young women tried to understand their own appraisal processes, they could not easily understand or describe such processes, which is consistent with my findings in my previous research with young Aboriginal women (i.e., Fleming et al., 2006). The difficulty that the young women had in describing their appraisal processes can likely be attributed to Lazarus' (1991) notion that appraisal processes are not necessarily deliberate or conscious cognitive processes involved in emotion. Therefore, although the young women explained how they cared what others 
were thinking, this appraisal process was not a conscious process; thus, they could not describe the reasons why they cared what others were thinking.

Although the young women had a difficult time understanding and articulating their appraisal processes, they were much more aware of the types of strategies they used or wanted to use to manage their body image experiences. This supports Lazarus' (1991) contention that people play an active role in coping processes, and it supports my justification for using emotion theory to guide this PAR project, that focused on working with young Aboriginal women to actively manage their body image experiences. More recently, Lazarus (2000) explained how people will engage in problem-focused coping (i.e., directly changing the situation) or emotion-focused coping (i.e., directly handling the emotion). The young women did not use these specific terms (e.g., problem-focused coping), when deciding upon the types of action strategies that they wanted to develop; however, they described both types of coping strategies. For example, Body Talk provided young women with the opportunity to vent and to share their body image experiences. Thus, this initiative may be viewed as emotion-focused coping in that participants were provided with a forum to directly handle their emotions. However, Body Talk may also be viewed as a form of problem-focused coping in that, depending upon to whom they were venting or sharing their experiences with, they may have been able to directly change the situation (e.g., change others' views on women's body image). Regardless of how each initiative is classified, the participants seemed to use both types of coping strategies that were described by Lazarus. Thus, this research contributes to Lazarus' emotion theory in that it provides a practical example of how cognitive and behavioural strategies can be used by young Aboriginal women to manage their body image experiences. 


\section{CHAPTER 4}

\subsection{SUMMARY}

Prior to beginning my Ph.D. program, I knew that I wanted to engage in research that would "make a difference". Although some people said that my goals reflected those of an idealist, I knew that there were ways, such as PAR, to engage in research that would help me to achieve such goals. Many researchers (e.g., Gittelsohn et al., 1996; NeumarkSztainer et al., 1997) have highlighted women's concerns with their bodies as important, yet PAR in the body domain is not common. Not only did I want to "make a difference", but I knew that I wanted to contribute something unique to the body literature. Given my research goals, I knew that a PAR project was the best option for my Ph.D. program.

Despite facing some challenges throughout this PAR project, the overall research experience was extremely positive. In saying this, it is important to reflect on this research process and to explore some of the qualities that I possess that may have attributed to the success of this project. Although it is somewhat of a difficult task to write about one's own perceived strengths, it is important to do so because not all researchers would enjoy engaging in a PAR project, nor do all people have the skills that are necessary to engage in a successful project. I believe that I possess two qualities that were instrumental to the success of this research. First, I believe in the power of youth to create change. This quality has been highlighted by Kemmis and McTaggart (2000) who argued that participatory action researchers believe that people are knowledgeable and thus can take a "realistic" approach in changing their lives. It is my assumption that young people have the "answers" to many of the questions that drive PAR research. With respect to this project, young Aboriginal women have the knowledge that was needed to create positive body image initiatives; however, they needed to be supported in facilitating this change. Young people are rarely provided with opportunities to make positive changes within their communities, and they need the strong support of an adult ally to facilitate this change. 
Second, I am a very outgoing person and I am approachable, understanding, and nonjudgmental. I think that there is a strong interconnectedness between these attributes, and that they all played a critical role in the development and maintenance of strong relationships. By openly sharing my experiences with participants and by having a genuine interest in their experiences, it is likely that participants felt that I was someone with whom they could develop relationships and, in time, trust. I am confident that these attributes supported my success as a participatory action researcher.

I knew that I was going to enjoy this research process, but I did not anticipate how difficult it would be to leave the research site. I was confident that this research project was founded on honest intentions, yet I was amazed at the interest shown, particularly among the media, for this project. Many days I would leave the school with an overwhelming sense of contentment because I could sense that this research project was creating change at so many levels. It felt amazing and worthwhile to do research that I thought was benefiting people. To "give back" to a group of young people who is consistently having their voices overlooked and disrespected by researchers and other adults felt amazing. I will be forever thankful to the young people with whom I worked for so generously sharing their knowledge with me.

Primarily, I am thankful that I was able to engage in a project that I was passionate about, while at the same time receiving partial requirement for my Ph.D. Similar to Gibbon (2002), I wanted a doctorate, yet I wanted to engage in a process that led to useful action. I also hope that the young people who participated feel that they gained from this project. They experienced what it feels like when their voices lead to actions that make a difference. I hope that in the future they will reflect back on this experience and take pride in their accomplishments.

After spending 10 months at Nutana, I left the school with a sense of fulfillment, as I believed that my attempt to genuinely collaborate with Aboriginal women on a body image PAR project was successful. Despite this, and as noted in my final journal entry below, I was apprehensive about leaving the school. I was so proud of what the young women and I had accomplished, and I was sad to have to leave this all behind.

June 27, 2007

I handed in my keys today and I had a really sad feeling in my stomach. I can't believe I have been at Nutana for 10 months, and I can't believe that I am now leaving. I am not really sure what this mix of emotions really is. I spent a lot of time this year trying to get young women to 
articulate their emotions and now I can't even figure out my own feelings. I think I am sad to leave this chapter of my research behind. Although we accomplished a lot this year and I know I gave $100 \%$ commitment to this project, I don't feel like I am ready to leave. Relationships were built and I feel a bit of anxiety in that I don't know for sure how sustainable these relationships and action initiatives will be once I leave. We worked so hard to create action and to shed light on this important area of research, and I am worried that this focus could be lost when I, the "body image girl", is no longer at the school full-time.

I am also nervous about my next step. I want to ensure that the stories and initiatives are described and portrayed in the most respectful and accurate manner, but I am worried about how to even begin to take so much information and compile it into dissertation format. I understand the importance and value of this research, and the participants have also voiced this, but how do I describe this research in a way that best depicts the meanings that it had for all of the participants?

I walked away from the school today and it looked like the first couple of days of school. The sun was shining, there was a bit of a breeze, and there was not one other person on the school grounds; I was very emotional. I could not have asked for a better experience. I am certain that the people I have met and the action that we have created will continue to influence the decisions I make and the projects that I engage in as a future researcher.

In conclusion, conversations with the young women in combination with the literature, lead me to believe that researchers need to shift their focus from the question, "Do women experience body image concerns?" to "How can we work with young women to develop strategies to manage their body image concerns?" As suggested in some of my previous research (i.e., McHugh et al., 2008), researchers continually present alarming statistics on the large number of young women who experience body concerns. Nevertheless, young women are rarely provided with opportunities to provide insight into such experiences, and are even less likely to be presented with opportunities to work with researchers to manage such experiences. This project is an example of how young Aboriginal women, school communities, and researchers can benefit by engaging young women in projects aimed at effectively managing body image experiences.

\subsubsection{Limitations}

Despite many perceived strengths of this study, it also has its limitations. However, contrary to more traditional research approaches, the limitations associated with PAR projects are typically more general in nature as PAR is collaborative and emergent, and therefore fairly flexible in terms of methodological frameworks. The most likely question or limitation that arises from this PAR project concerns the extent to which the methodological approach and/or findings would be applicable to other high schools. As suggested by Brant Castellano (1993), it is not likely possible to make an impact in the lives of other Aboriginal peoples by translating the outcomes or the processes from one PAR project to another. I somewhat agree with this statement 
because, as stated throughout this dissertation, Phyllis and the supportive nature of the ISLS program at Nutana, were integral components in the success of this project. Therefore, I wonder about the extent to which similar action initiatives would be able to be successfully implemented into other schools that do not have such support systems. In saying this, by hiring a wellness coordinator (as we did), who is focused on working with youth on wellness issues such as body image, it might be possible to implement similar body image initiatives into other schools.

It is possible that some who read about this research will question whether this was PAR. With respect to their own PAR research, Gosin et al. (2003) considered whether participants need to be involved in all stages of the project in order for it to be PAR. They argued that this is not important; what is most important is that all partners benefit, and that the skills of all partners are maximized in order to achieve full benefit. In terms of our research project (i.e., this body image PAR project), students did not actively participate in the writing of the research results of this PAR project. Therefore, similar to Dickson (2000) who also highlighted this limitation in her own PAR research with Aboriginal grandmothers, much of the writing is based on my own interpretation. As well, given that I had to propose this research as a Ph.D. candidate prior to entering the research field, much of the planning stages of this research had to be outlined prior to entering the school. While much of the proposal development was based on findings from some of my previous research (e.g., Fleming et al., 2006), some of the planning was completed prior to entering the school.

When looking at all aspects of this research project from the planning to the final writing stages, some may not consider this project to be PAR in that participants were not actively involved in all aspects of the project. For example, throughout the research process I asked various participants if they would be interested in working with me to write about the action initiatives that were developed or implemented. However, aside from the contributions made from Writing Group, none of the participants ever volunteered to participate in the writing process. Others (e.g., Macauley et al., 1999), have argued that PAR can involve various degrees of participation, and the specific roles and contributions of participants and researchers may change throughout the duration of a project. Boog (2003) also said that although all research partners (i.e., participants, 
researcher) are equal in terms of the contributions they make to research, they all have expertise in different domains. The researcher typically has expertise in the application of research methods, while a participant is "an expert in the matters of his or her everyday life" (p. 435). Despite differences in expertise, Hughes (2003) argued that neither type of expertise is dominant over the other. Furthermore, although participants did not engage in some of the PAR processes (e.g., writing), researchers must realize that there may be different levels of participant involvement within PAR projects, and "participation may be more valuable at certain stages of the research process than at others" (Gosin et al., 2003, p. 366). Based on these arguments that provide justification for varying levels of participant participation in PAR, this project should still be considered a true PAR project.

Another possible limitation of this PAR project is that there were few guidelines available to support me in the writing of this dissertation. As suggested by Gibbon (2002), "a PAR process is not linear and is therefore difficult to report on in a conventional way" (p. 555). Given the lack of guidance within the academic literature, I engaged in conversations with some research participants and mentors from my doctoral committee in an effort to develop a framework that would respectfully and accurately depict the entire research process. Building upon the idea of hooks (1994), I wanted to write my research in a way that would allow for the various ideas to be accessible to individuals beyond academia. Therefore, although I knew I needed to adhere to specific university dissertation writing guidelines (e.g., formatting guidelines), I made an effort to accurately describe the research process (e.g., detailed description of the relationship building phase and action initiatives) so that various audiences, and not just academic audiences, could understand or make sense of this research project.

In addition to wanting to present the research in a way that most accurately reflected the research process, I also wanted to be certain that I wrote in a manner that was respectful to all research participants. For example, I wanted to ensure that I was honest in my descriptions of the strengths and weaknesses associated with the school programs, but I did not want such descriptions to be viewed as disrespectful to the school or any of its members. The school and all of its members welcomed me very readily into their community as a community partner, and I did not want to violate my relationship 
with them by being disrespectful. The issue that I faced regarding writing in an ethically sound manner, has been addressed by a number of scholars interested in PAR processes (e.g., Conrad, 2004; Stringer \& Genat, 2004) and ethics of research with Aboriginal peoples (e.g., Battiste, 2002; Haig-Brown, 2001; Smith, 1999). As previously stated, these scholars recommend including participants in the writing process. Although I wanted to ensure that participants were provided with this opportunity, researchers need to be cognizant of participants' interests and their possible time constraints.

Given the inherent power that one often assumes in the role as researcher, we as researchers must ensure that participants do not feel that they have to take part in the writing process, or other research processes that they may not find particularly attractive. At the same time, it is also our responsibility as researchers to write about projects such as this so that others will become more aware of the exciting action that can be developed when working alongside youth. As well, as their research partner, I made it my responsibility as the participatory action researcher to consult with participants throughout the writing process in an effort to be respectful of the manner in which this project and the participants were represented. I also used various direct quotes from the participants in an effort to adequately reflect their experiences. It is my hope that others may learn from the challenges that I faced in trying to write this dissertation, and subsequently use this format as a framework for their own future PAR dissertations.

Another possible limitation of this research is that I had limited resources to engage in this research process. Although my own personal $\mathrm{Ph}$.D. funding through CIHR provided me with the opportunity to commit full-time to this project, and the project received some funding from the University of Saskatchewan's President's SSHRC Research Fund, I had relatively limited resources available for the development of action initiatives. I am confident that I am not the only researcher who imagines how their project could have been improved with more resources. If there had been unlimited resources it would have been possible to hire one or two more people to work alongside. I was always engaged in some sort of relationship building activity or the development of action initiatives, and if there were more adult allies who were committed to this project, it may have been possible to develop more action initiatives or to improve the initiatives that were developed (e.g., more funding for food, equipment). Having said this, if I had 
had unlimited resources available, it likely would have been difficult to keep the project to a size that was manageable for a Ph.D. dissertation.

Finally, the amount of time that I spent at Nutana for this PAR project can be viewed as both a strength and a weakness. As suggested by Macauley et al. (1999), the time needed for a project may exceed what the researcher can commit. Similarly, Frisby et al. (2005) argued that FPAR is very energy and time consuming, and Gibbon (2002) suggested that university time constraints often serve as institutional obstacles for students engaging in PAR for their doctorate. The amount of time that I could engage in the research process was somewhat restricted by university guidelines for doctoral students, and my own goals to progress through the Ph.D. program. In light of such guidelines and my own goals, I committed a substantial amount of time to this research project. However, one has to wonder whether the action that emerged from this project, or the sustainability of the action initiatives, would have differed if I had been able to commit more than 10 months to the research project. For example, if I was to engage in a similar project when I have my own independent research program that allows me to dedicate my time to a multi-year project, would the benefits be more substantial or make an impact at more levels? Although there is not an easy answer to this question, I am doubtful that I will ever be provided with another time in my research career to focus solely on research without other academic time commitments (e.g., university committee work, teaching). Thus, I am grateful that I had the opportunity to engage in this PAR project as part of my doctoral program.

\subsubsection{Future Recommendations}

Findings from this study have highlighted a number of research areas that future researchers may want to consider exploring. Most importantly, and consistent with Berg (1999), future researchers interested in body image should consider shifting their focus to a more integrated approach on health. A new integrated health approach would focus on the promotion not only of physical health, but also of emotional, social, intellectual, and spiritual health (Berg, 1999). More specifically, Berg explained how this comprehensive approach sends the message that there can be "health at any size" and suggests that individuals need to receive consistent messages that promote feeling good about themselves and others, active living, and eating well. This approach is particularly 
important for researchers interested in working with Aboriginal peoples. As argued by Marchessault (1999), there is so much focus on preventing the "obesity epidemic" among Aboriginal peoples, yet there is relatively little consideration of the negative emotions that are experienced by Aboriginal peoples as a result of their weight. Similarly, in another study (i.e., Marchessault, 2004) she argued that it is important not to emphasize weight issues as they may promote unhealthy behaviours (e.g., eating disorders). By promoting an integrated health approach within body image research, it may be possible to work with young people to develop healthy coping skills while at the same time supporting them to take pride in their bodies at any size (Berg, 1999).

Future researchers may also want to consider working with schools to develop school-university partnerships, so that body image strategies can by implemented directly into school curricula. Women's dissatisfaction with their bodies has been coined "normative discontent" (Lafrance, Zivian, \& Myers, 2000), which has subsequently highlighted the need for schools to provide young people with everyday opportunities to learn how to effectively manage body image concerns. It is common for health practitioners to employ more medicalized or therapeutic approaches for managing body dissatisfaction, but by integrating student-driven body image initiatives into school curriculum it may be possible to reduce the need for such medicalized approaches. As suggested by McVey, Lieberman, Voorberg, Wardrope, and Blackmore (2003), schoolbased comprehensive approaches that promote positive body image have the potential to prevent the consequences associated with severe body image concerns (e.g., dieting, disordered eating). They further argued that regular school-setting peer initiatives (e.g., support groups, communication of health promotion messages) have the potential to create changes at both the individual and subcultural levels, and therefore should not be overlooked as an effective approach for enhancing a positive sense of self. In her recent publication, Dunlop-Robertson (2006) explained how some Canadian schools have recognized the need for school-based body image interventions. She described how the provincial physical and health education curricula of Alberta focus on body image. Similarly, she explained how Ontario teachers in the Elementary Teachers' Federation (ETFO) developed a body image program for students in grades K-8 called "Reflections of Me", which allows teachers to address body image concerns through interactive 
lessons and literature. She explained how the program was developed in response to concerns expressed both by teachers and health science researchers. Ultimately, she suggested that the teachers and researchers engaged in a school-university partnership.

Researchers, such as Wilbur, Lambert, and Young (1998) have identified the critical need for school-university partnerships. They argued that some of the most significant issues faced by youth today will not get solved if universities and schools work independently. Nearly 20 years ago, Wilbur et al. developed a monograph, which provided an overview of programs that demonstrated the manner in which schools and universities can work collaboratively and successfully on issues of mutual concern. Despite this presentation of various successful programs, it is still common to see universities and schools working independently on issues that may be better handled if working together. However, by developing partnerships between teachers and researchers, or schools and universities, it might be possible, as suggested by DunlopRobertson (2006), to address the pressing need for body image intervention in school curriculum.

If future researchers do begin to engage in more collaborative projects with teachers, it will be important to develop ethical guidelines, particularly guidelines surrounding informed consent that are consistent with both university and school settings. Recently, universities and funding agencies have encouraged partnerships between university and community-based organizations; however, the ethical guidelines that are typically developed by the universities and funding agencies are not always easily carried out in the community. The issues that I experienced in trying to acquire the participants' parent/guardian informed consent, highlighted one example of how university developed guidelines sometimes serve as a constraint when engaging in community-based research. As noted in the results section (see section 3.1.2.2.2), one young woman expressed how teenagers' should have the "right" to determine for themselves whether they want to participate in certain activities, and that they should not have to ask their parents for consent. She expressed her discontent when she said that young people may want to participate in an activity but if their parents say no and "don't sign the stupid little forms", then they cannot take part. The concerns expressed by this young woman provide support for Haverkamp's (2005) argument that the "process of consent is 
inherently hierarchical" (p. 154). She explained how researchers often work to develop collaborative relationships with participants, yet hierarchical processes of consent can serve as a barrier to the establishment of such relationships. She further asserted that despite genuine attempts to transform participants into "coresearchers", there is an asymmetrical power relationship that exists between the researcher and participant, which often serves as a barrier to this transformation. Although Haverkamp recognized the hierarchy that is established between the researcher and participant with consent forms, the words of the participant within this study lead me to believe that there is another hierarchy that should be considered. That is, when parental consent is required, the participant has to face two hierarchical obstacles, the parent and the researcher.

Participatory action researchers, such as me, strive to break down the power hierarchy that is so prevalent in more traditional research. We want the participants to view themselves as the experts and to recognize their power to create change. By making it a requirement that young people under the age of 18 need to have parental/guardian consent to participate in research studies, we might be sending a message to the young people that they are somewhat powerless without the support of their parent/guardian. Findings from this research, which suggest that such guidelines may restrict access to some participants, are similar to the work of Knight, Bentley, Norton, and Dixon (2004) who also found that parent/guardian consent may hinder access to research participants. However, in their work with Latino/Latina youth, it was the parents not the youth who demonstrated resistance towards the consent forms. The parents felt that the consent form lacked "awareness of the realities as well as the cultural norms, values, and expectations of reciprocity and trust" (p. 400). Although they did not state this, it is possible that the youth who participated in this study did not feel that the consent form demonstrated reciprocity and trust, which could have fostered their discontent with the whole consent form process.

As a health researcher I recognize that informed consent is required so that the university or institution, as well as the participants, have their rights protected. Despite good intentions, this does not eliminate the manner in which the process of consent sometimes serves as a barrier. Thus, as stated in section 1.3.1, it was important for me to adhere to Smith's (1999) suggestion to constantly negotiate notions of respect and ethical 
conduct. By continually engaging in conversations with participants about institutional justifications for consent forms, and by listening to participants concerns over such processes, it was possible for me to better understand everyone's perspective. Knight et al. (2004) explained how researchers often assume that the process of acquiring consent is a "nonevent", yet by recognizing consent forms as something that may cause great concern among participants, it may be possible to negotiate stronger relationships with participants that are founded on trust. Knight's statement strongly resonated with me; thus, throughout the research project I was constantly aware of the diverse perspectives that the young people would potentially have about consent forms. When engaging in their own research projects, future researchers might also want to consider Knight et al.'s suggestion to view consent forms as something that may cause concern for participants. By doing so, and by adhering to Smith's suggestion to constantly negotiate consent, it might be possible for future researchers to navigate this often sensitive process of obtaining informed consent

Future researchers may also want to consider ways in which they could facilitate the development of adult allies who are committed to supporting youth, particularly Aboriginal youth, on issues of body image. These adult allies could play important roles in the proposed university-school partnerships that were outlined above. As argued by the Centre of Excellence for Youth Engagement (2007), adult allies acknowledge their biases and push them aside when they enter into partnerships so that they have an open mind. As well, the Centre explained how adult allies support youth in taking ownership of projects, and they work within the partnership as an "adult-as-partner" rather than an "adult-as-mentor". Given that the voices and knowledge of youth, particularly Aboriginal youth, have generally been overlooked within body image research, it is important to facilitate the development of adult allies so that it is possible to address this significant research gap. Adult allies would be able to enter into school-research partnerships with youth and teachers, and such partnerships could facilitate the development of body image initiatives that are meaningful and effective for youth. Although I present a somewhat idealized picture of the benefits of adult allies within a school setting, I recognize that there could potentially be some resistance from school members (e.g., teachers) who may not be overly comfortable with the role of adult allies. 
The Centre of Excellence for Youth Engagement (2004) argued that adult allies must be willing to share power and such adults should not take the traditional role as teacher or preacher. Having said this, there does not need to be a total reversal of traditional power structures (Centre of Excellence for Youth Engagement, 2004). Given that the benefits of integrating adult allies into a school setting have the potential to strongly outweigh the challenges, school administrators may want to strongly consider the strong role that adult allies could play in supporting the voices of Aboriginal youth.

Future doctoral students, especially those interested in working with young women on body image issues, should consider engaging in PAR as part of their doctoral program. I am confident that there are graduate students, other than myself, who are motivated to engage in research projects that can immediately and directly benefit communities of interest. As argued by Hughes (2003), one of the primary benefits of PAR is that it typically facilitates the development of community capacity whereby people are equipped with the resources to make their own positive changes within their communities, which subsequently results in effective community interventions. Thus, to me, it seems that PAR is the most obvious process for supporting some graduate students in achieving their research goals. Many students are likely deterred from engaging in PAR processes because, as suggested by Gibbon (2002), very few other students engage in PAR processes. She explained how PAR is very time-consuming and few universities offer participatory methods courses. As well, she argued that most students who choose to engage in PAR as part of their graduate research are required to defend such an approach, whereas those engaged in more quantitative studies are rarely faced with such questions. As a result of such barriers, it is likely that many students are discouraged from engaging in PAR processes for their graduate work. Based on my own doctoral experience, I understand that engaging in PAR can be a fairly long process, and that it is not always the most systematic. Nevertheless, the benefits (which have been outlined throughout this dissertation) of engaging in such a process strongly outweigh the challenges, and working in PAR projects, particularly alongside young people, is truly a rewarding experience.

Finally, future researchers who work with Aboriginal peoples, particularly around issues of the body, need to ensure that their research programs adhere to current 
guidelines on respectful research with Aboriginal peoples. Without going into too much detail (as this issue was addressed in section 1.3.1), various leaders and scholars (e.g., Battiste, 2002; Battiste \& Henderson, 2002; Smith 1999, 2005) who focus on research with Aboriginal peoples have highlighted the importance of engaging in respectful research practices. As a result of colonization, it has been argued that Aboriginal peoples view research as a colonizing tool (Smith, 2005). Thus, Aboriginal peoples need to have control over their own knowledge and to be collaboratively involved in the entire research process (Battiste, 2002). Some researchers (e.g., Macauley et al., 1999) have engaged in collaborative projects that focus on healthy eating and physical activity with Aboriginal communities. Despite this, I am unaware of any Canadian body image projects other than this one that have actively involved Aboriginal peoples in a collaborative PAR project that seeks to benefit the people involved in the research. Researchers may have genuine intentions to further their inquiry into important health issues, but this does not mean that they are engaging in respectful research projects. It is important for researchers to have a thorough understanding of the reasons why it is important to engage in ethical or respectful research with Aboriginal peoples, and to incorporate such ethics into their own research practices. From here it may be possible for researchers to earn the trust that is needed to engage in successful and effective research projects. Within this PAR project I tried my best to engage in respectful research with young Aboriginal women; nevertheless, it is ultimately up to the reader to judge my success in doing so. 


\section{REFERENCES}

Adelson, N. (2005). The embodiment of inequality: Health disparities in Aboriginal Canada. Canadian Journal of Public Health (Supplement), 96, 45-61.

Aitken, G., \& Burman, E. (1999). Keeping and crossing professional and racialized boundaries: Implications for feminist practice. Psychology of Women Quarterly, 23, 277-297.

Alway, J. (1995). The trouble with gender: Tales of the still-missing feminist revolution in sociological theory. Sociological Theory, 13, 209-228.

Angeles, G. (2004). 'Health research...let's get something right before the sun goes down.' Pimatisiwin: A Journal of Aboriginal and Indigenous Community Health, 2, 51-57.

Ashcroft, B., Griffiths, G., \& Tiffin, H. (2000). Post-colonial studies: The key concepts. London: Routledge.

Bane, S., \& McAuley, E. (1998). Body image and exercise. In J. L. Duda (Ed.), Advances in sport and exercise psychology measurement (pp. 311-322). Morgantown, WV: Fitness Information Technology.

Battiste, M. (2000). Introduction: Unfolding the lessons of colonization. In M. Battiste (Ed.), Reclaiming Indigenous voice and vision (pp. xvi-xxx). Vancouver: UBC Press.

Battiste, M. (2002). Decolonizing university research: Ethical guidelines for research involving Indigenous populations. In G. Alfredsson \& M. Stavropoulou (Eds.), Justice pending: Indigenous peoples and other good causes (pp. 33-44). The Hague: Martinus Nijhoff Publishers.

Battiste, M., A., \& Henderson, J. H. (2000). Protecting Indigenous knowledge and heritage: A global challenge. Saskatoon, SK: Purich.

Bayer, B. M., \& Malone, K. R. (1996). Feminism, psychology and matters of the body. Theory \& Psychology, 6, 667-692. 
Bent, K., \& Ross, L. (2004). Anishinaabe Ik-We Mino-Aie-Win Aboriginal women's heath issues: A holistic perspective on wellness. Winnipeg, Manitoba: Prairie Women's Center of Excellence.

Berg, F. M. (1999). Integrated approach: Health at any size. Healthy Weight Journal, September/October, pp. 74, 80.

Berthelette, G., Raftis, Y., \& Henderson, G. (2001). The sharing circle. A culturally appropriate format for a focus group? The Aboriginal Nurse, 16, 17-18.

Bishop, R. (1996). Collaborative research stories: Whakawanaungatanga. Palmerston North, New Zealand: Dunmore Press.

Bishop, R. (2005). Freeing ourselves from neocolonial domination in research. In N. K. Denzin \& Y. S. Lincoln (Eds.), The SAGE handbook of qualitative research $\left(3^{\text {rd }}\right.$ ed, pp. 109-138). Thousand Oaks: Sage Publications.

Blood, S. K. (2005). Body work: The social construction of women's body image. London: Routledge.

Boog, B. W. M. (2003). The emancipatory character of action research, its history and the present state of the art. Journal of Community \& Applied Social Psychology, 13, 426-438.

Bordo, S. (1993). Feminism, Foucault and the politics of the body. In C. Ramazanoglu (Ed.), Up against Foucault: Explorations of some tensions between Foucault and feminism (pp. 179-202). London: Routledge.

Borland, K. (2004). “ “That's not what I said"': Interpretive conflict in oral narrative research.” In S. N. Hesse-Biber \& P. Leavy (Eds.), Approaches to qualitative research: A reader on theory and practice (pp. 522-534). New York, NY: Oxford University Press.

Bostock, J., \& Freeman, J. (2003). 'No limits': Doing participatory action research with young people in Northumberland. Journal of Community \& Applied Social Psychology, 13, 464-474.

Bowling, A. (2005). Quantitative social science: The survey. In A. Bowling \& S. Ebrahim (Eds.), Handbook of health research methods: Investigation, measurement, and analysis (pp.190-214). Berkshire, England: Open University Press. 
Brant Castellano, M. B. (1993). Aboriginal organizations in Canada: Integrating participatory research. In P. Park, M. Brydon-Miller, B. Hall, \& T. Jackson (Eds.), Voices of change: Participatory research in the United States and Canada (pp. 145-156). Toronto, Canada: Ontario Institute for Studies in Education.

Brydon-Miller, M., Greenwood, D., \& Maguire, P. (2003). Why action research? Action Research, 1, 9-28.

Burstein, K., Bryan, T., \& Choa, P.-C. (2005). Promoting self-determination skills among youth with special health needs using participatory action research. Journal of Developmental and Physical Disabilities, 17, 185-201.

Canadian Institutes of Health Research (2005). CIHR guidelines for health research involving Aboriginal peoples-Draft for consultation. Retrieved May 15, 2006, from www.cihr-irsc.gc.ca/e/29234.html

Canadian Institutes of Health Research (2007). Guidelines for health research involving Aboriginal peoples. Retrieved April 22, 2008, from http://www.cihr.ca/e/documents/ ethics_aboriginal_guidelines_e.pdf

Cannon, M. J. (1995). Demarginalizing the intersection of "race" and gender in First Nations politics. Unpublished master's thesis, Queen's University, Kingston, Ontario.

Cannon, M. (1998). The regulation of First Nations sexuality. Canadian Journal of Native Studies, 18, 1-18.

Cannon, M. J. (2008). Revisiting histories of gender-based exclusion and the new politics of Indian identity. National Centre for First Nations Governance. Ottawa: ON.

Cash, T. F., \& Pruzinsky, T. (eds.) (2002). Body image: A handbook of theory, research and clinical practice. New York, NY: Guilford.

Centre of Excellence for Youth Engagement (2004). Allies in action: Two workshops for adults who want to be allies to young people. Toronto: ON.

Centre of Excellence for Youth Engagement (2007). Youth engagement: Adult allies in action. Toronto: ON.

Champagne, L., \& Halas, J. (2003). "I Quit": Aboriginal youth negotiate the "contact zone" in physical education. In V. Paraschak \& J. Forsyth (Eds.), North 
American Indigenous Games Research Symposium (pp. 85-93). Winnipeg, MB: University of Manitoba.

City of Saskatoon (n.d.). Quick facts. Retrieved March 19, 2008, from http://www.city. saskatoon.sk.ca/org/quick_facts/index.asp

Collins, P. H. (1986). Learning from the outsider within: The sociological significance of black feminist thought. Social Problems, 33, 14-32.

Conrad, D. (2004). Exploring risky youth experiences: Popular theatre as a participatory, performative research method. International Journal of Qualitative Methods, 3 (1). Article 2. Retrieved August 11, 2005 from http://www.ualberta.ca/ iiiqm/backissues/3_1/pdf/conrad.pdf

Creswell, J. W. (1998). Qualitative inquiry and research design: Choosing among five traditions. Thousand Oaks, CA: Sage Publications.

Creswell, J. W. (2003). Research design: Qualitative, quantitative, and mixed methods approaches ( $2^{\text {nd }}$ ed.). Thousand Oaks, CA: Sage Publications.

Cross, S. E., \& Gore, J. S. (2003). Cultural models of the self. In. M. R. Leary \& J. P. Tanguay (Eds.), Handbook of self and identity (pp. 536-564). New York, NY: The Guilford Press.

Crotty, M. (1998). The foundations of social research: Meaning and perspective in the research process. London: Sage Publications.

Cutcliffe, J. R., \& Ramcharan, P. (2002). Leveling the playing field? Exploring the merits of the ethics-as-process approach for judging qualitative research proposals. Qualitative Health Research, 12, 1000-1010.

Daigneault, S. D. (2000). Body talk: a school-based group intervention for working with disordered eating behaviors. Journal for Specialists in Group Work, 25, 191-213.

Deiter, C., \& Otway, L. (2001). Sharing our stories on promoting health and community healing: An Aboriginal women's health project. Winnipeg, MB: Prairie Women's Health Centre of Excellence.

Denzin, N. K. (2004). The art of politics of interpretation. In S. N. Hesse-Biber \& P. Leavy (Eds.), Approaches to qualitative research: A reader on theory and practice (pp. 447-472). New York: Oxford University Press.

Denzin, N. K., \& Lincoln, Y. S. (1994). Handbook of qualitative research. Thousand 
Oaks, CA: Sage Publications.

Denzin, N. K., \& Lincoln, Y. S. (2000). Handbook of qualitative research $\left(2^{\text {nd }}\right.$ ed.). Thousand Oaks, CA: Sage Publications.

Dickson, G. (2000). Aboriginal grandmothers' experience with health promotion and participatory action research. Qualitative Health Research, 10, 188-213.

Doucet, A., \& Mauthner, N. (2002). Knowing responsibly: Linking ethics, research practice and epistemology. In M. Mauthner, M. Birch, J. Jessop, \& T. Miller (Eds.), Ethics in qualitative research (pp.123-145). London: Sage Publications

Dryfoos, J. (1994). Full service schools-A revolution in health and social services for children, youth and families. San Francisco: Jossey-Bass.

Dunlop-Robertson, L. (2006, Fall/Winter). Body image: Is there a need for school-based health interventions? Health \& Learning Magazine, 21-22.

Esterberg, K. G. (2002). Qualitative methods in social research. Boston, MA: McGraw Hill.

Fleming, T.-L., Kowalski, K. C., Humbert, M. L., Fagan, K. R., Cannon, M. J., \& Girolami, T. (2006). Body-related emotional experiences of young Aboriginal women. Qualitative Health Research, 16, 517-537.

Fletcher, A., \& Vavrus, J. (2006). The guide to social change led by and with young people. Olympia, WA: CommonAction. Online at www.freechild.org/ publications.htm

Fowler, P. (n.d.). Integrated school-linked services. Retrieved March 19, 2008, from http://schools.spsd.sk.ca/Nutana/Isls.html

Fox, K. R. (1997). The physical self and processes in self-esteem development. In K. R. Fox (Ed.), The physical self: From motivation to well-being (pp.111-139). Champaign, IL: Human Kinetics.

French, J. (2007, February 15). A new view of body image. The StarPhoenix. Retrieved February 20, 2008, from http://www.canada.com/saskatoonstarphoenix /news/ local/story.html?id=eed9a79f-a837-45a8-80a8-093816d1bcda\&k=40125

French, S. A., Perry, C. L., Leon, G. R., \& Fulkerson, J. A. (1994). Weight concerns, dieting behavior, and smoking initiation among adolescents: A prospective study. American Journal of Public Health, 84, 1818-1820. 
Frideres, J. S., \& Gadacz, R. R. (2001). Aboriginal peoples in Canada: Contemporary conflicts ( $6^{\text {th }}$ ed.). Toronto, ON: Prentice Hall.

Friedlander, F. (2001, July 23-24). Participatory action research as a means of integrating theory and practice. Paper presented at the Fielding Graduate Institute Action Research Symposium. Retrieved March 28, 2006, from www.fielding.edu/research/ar_papers/ friedlander.pdf

Friedstad, C., \& Klepp, K. I. (1997). Smoking, body image and reducing diet. A threeyear follow-up of adolescents aged 15-18 years. Nordic Medicine, 112, 334-338.

Frisby, W., Crawford, S., \& Dorer, T. (1997). Reflections on participatory action research: The case of low-income women accessing local physical activity services. Journal of Sport Management, 11, 8-28.

Frisby, W., Maguire, P., \& Reid, C. (in press). The " $\mathrm{f}$ " word has everything to do with it: How feminist theories inform action research. Action Research.

Frisby, W., Reid, C. J., Millar, S., \& Hoeber, L. (2005). Putting "participatory" into participatory forms of action research. Journal of Sport Management, 19, 367386.

Garratt, D. (2003). My qualitative research journey: Researching against the rules. Cresskill, NJ: Hampton Press Inc.

Gibbon, M. (2002). Doing a doctorate using a participatory action research framework in the context of community health. Qualitative Health Research, 12, 546-558.

Gillies, V., \& Alldred, P. (2002). The ethics of intention: Research as a political tool. In M. Mauthner, M. Birch, J. Jessop, \& T. Miller (Eds.), Ethics in qualitative research (pp. 32-52). London: Sage Publications.

Girls for a Change (n.d.). Retrieved March 19, 2008, from http://www.girlsforachange. org/

Gittelsohn, J., Harris, S. B., Thorne-Lyman, A. L., Hanley, A. J., Barnie, A., \& Zinman, B. (1996). Body image concepts differ by age and sex in an Ojibway-Cree community in Canada. Journal of Nutrition, 126, 2990-3000.

Gore, J. (1992). What we can do for you! What can "we" do for "you"?: Struggling over empowerment in critical and feminist pedagogy. In C. Luke \& J. Gore (Eds.), Feminisms and critical pedagogy (pp. 54-69). New York: Rutledge. 
Green, L. W., George, M. A., Daniel, M., Frankish, C. J., Herbert, C. J., Bowie, W. R., et al. (1995). Study of participatory research in health promotion: Review and recommendations for the development of participatory research in health promotion in Canada. University of British Columbia: Institute of Health Promotion Research.

Gosin, M. N., Dustman, P. A., Drapeau, A. E., \& Harthun, M. L. (2003). Participatory action research: Creating an effective prevention curriculum for adolescents in the Southwestern US. Health Education Research, 18, 363-379.

Guba, E. G., \& Lincoln, Y. S. (2004). Competing paradigms in qualitative research: Theories and issues. In S. N. Hesse-Biber \& P. Leavy (Eds.), Approaches to qualitative research: A reader on theory and practice (pp. 17-38). New York, NY: Oxford University Press.

Haig-Brown, C. (2001). Continuing collaborative knowledge production: Knowing when, where, how and why. Journal of Intercultural Studies, 22, 19-32.

Harding, S. (2004). How standpoint methodology informs philosophy of social science. In S. N. Hesse-Biber \& P. Leavy (Eds.), Approaches to qualitative research: A reader on theory and practice (pp. 62-80). New York, NY: Oxford University Press.

Harrison, B. (2001). Collaborative Programs in Indigenous communities: From fieldwork to practice. Walnut Creek, CA: Alta Mira Press.

Haverkamp, B. E. (2005). Ethical perspectives on qualitative research in applied psychology. Journal of Counseling Psychology, 52, 146-155.

Heilman, E. E. (1998). The struggle for self: Power and identity in adolescent girls. Youth \& Society, 30, 182-208.

Ho, B. S. (2002). Application of participatory action research to family-school intervention. School Psychology Review, 31, 106-121.

Hooks, b. (1994). Outlaw culture: Resisting representations. New York: Routledge. Hughes, J. N. (2003). Commentary: Participatory action research leads to sustainable school and community improvement. School Psychology Review, 32, 38-43.

Hughes, J., \& Sharrock, W. (1997). The philosophy of social research ( $3^{\text {rd }}$ ed.). New York: Addison Wesley Longman. 
Humbert, M. L. (1995). On the sidelines: The experiences of young women in physical education classes. Avante, 1, 58-77.

James, K. (2001). "I just gotta have my own space!": The bedroom as a leisure site for adolescent girls. Journal of Leisure Research, 33, 71-90.

Kemmis, S., \& McTaggart, R. (2000). Participatory action research. In N. K. Denzin \& Y. S. Lincoln (Eds.), Handbook of qualitative research (pp. 567-605). Thousand Oaks, CA: Sage.

Knight, M. G., Bentley, C. C., Norton, N. E. L., \& Dixon, I. R. (2004). (De)constructing (In)visible parent/guardian consent forms: Negotiating power, reflexivity, and the collective within qualitative research. Qualitative Inquiry, 10, 390-411.

Lafrance, M. N., Zivian, M. T., \& Myers, A. M. (2000). Women, weight and appearance satisfaction: An ageless pursuit of thinness. In B. Miedema, J. M. Stoppard, \& V. Anderson (Eds.), Women's bodies: Women's lives (pp. 227-36). Toronto, ON: Sumach Press.

Laroque, E. (1993). Three conventional approaches to Native people in society and in Literature. In B. Balon \& P. Resch (Eds.), Survival of the imagination: The Mary Donaldson memorial lectures. Regina, SK: Coteau Books.

Lather, P. (1991). Getting Smart: Feminist research and pedagogy within the postmodern. New York, NY: Routledge.

Lazarus, R. S. (1991). Emotion and adaptation. New York: Oxford University Press.

Lazarus, R. S. (2000). Cognitive-motivational-relational theory of emotion. In Y. L. Hanin (Ed.), Emotions in sport (pp. 39-63). Champaign, IL: Human Kinetics.

Leary, M. R. (1995). Self presentation: Impression management and interpersonal behavior. Madison, WI: Brown and Benchmark.

Lincoln, Y. S. (1995). Emerging criteria for quality in qualitative and interpretive research. Qualitative Inquiry, 1, 275-289.

Lincoln, Y. S., \& Guba, E. G. (1985). Naturalistic inquiry. Beverly Hills, CA: Sage Publications.

Lloyd, K. E. (2008). maskosis: The healing journey of little bear: A narrative analysis analysis of the life of an Aboriginal man with quadriplegia (Master's thesis, 
University of Saskatchewan, 2008). Electronic Thesis \& Dissertations (urn03062008-130729).

Luke, C. (1992). Feminist politics in radical pedagogy. In C. Luke, \& J. Gore (Eds.), Feminisms and critical pedagogy (pp. 25-53). New York, NY: Routledge.

Maar, M. (2004). Clearing the path for community health empowerment: Integrating health care services at an Aboriginal health access centre in rural north central Ontario. Journal of Aboriginal Health, January, 54-64.

Macauley, A. C., Commanda, L. E., Freeman, W. L., Gibson, N., McCabe, M. L., Robbins, C. M. et al. (1999). Participatory research maximizes community and lay involvement. North American Primary Care Research Group. British Medical Journal, 319, 774-778.

MacMillan, H. L., MacMillan, A. B., Offord, D. R., \& Dingle, J. L. (1996). Aboriginal Health. Canadian Medical Association, 155, 1569-1578.

Madriz, E. (2000). Focus groups in feminist research. In N. K. Denzin \& Y. S. Lincoln (Eds.), Handbook of qualitative research ( $2^{\text {nd }}$ ed., pp. 835-850). Thousand Oaks, CA: Sage Publications.

Maguire, P. (1987). Doing participatory research: A feminist approach. Amherst, MA: The Centre for International Education, University of Massachusetts.

Maguire, P. (1996). Considering more feminist participatory research: What's congruency got to do with it? Qualitative Inquiry, 2, 106-118.

Maguire, P. (2001). Uneven ground: Feminisms and action research. In P. Reason \& H. Bradbury (Eds.), Handbook of action research: Participative inquiry and practice (pp.59-69). London: Sage Publications.

Marchessault, G. (1999). Weight perceptions and practices in Native youth. Healthy Weight Journal, September/October, 71-79.

Marchessault, G. D. M. (2001). Far from ideal: Talking about weight with mothers and daughters from Winnipeg, Southern Manitoba and a First Nations community (Doctoral dissertation, University of Manitoba, 2001). http://www. collectionscanada.gc.ca/obj/s4 /f2/dsk3/ ftp04/NQ62653.pdf 
Marchessault, G. (2004). Body shape perceptions of Aboriginal and non-Aboriginal girls and women in Southern Manitoba, Canada. Canadian Journal of Diabetes, 28, 369-379.

McBride, C. (2001). Canada's response to the Royal Commission on Aboriginal Peoples. In P. Sherlock (Ed.), Blind Spots: An examination of the federal government's response to the Report of the Royal Commission on Aboriginal Peoples (pp. 2331). Ottawa: Bonanza Printing.

McHugh, T.-L. F., Kowalski, K. C (in press). Body-related experiences of Rural Aboriginal Women. Journal of Aboriginal Health.

McHugh, T.-L. F., Kowalski, K. C., Mack, D. E., Crocker, P. R. E., Junkin, S. E., Lejbak, L., \& Martin, S (2008). Young women's experience of social physique anxiety. Feminism \& Psychology, 18, 231-252.

McIntyre, A. (2000). Constructing meaning about violence, school, and community: Participatory action research with urban youth. The Urban Review, 32, 123-154.

McIntyre, L., Wien, F., Rudderham, S., Etter, L., Moore, C., MacDonald, N., et al. (2001). An exploration of the stress experience of Mi'kmaq on-reserve female youth in Nova Scotia. Halifax, NS: Maritime Center of Excellence for Women's Health.

McNaughton, C., \& Rock, D. (2003). Opportunities in Aboriginal research: Results of SSHRC's dialogue on research and Aboriginal peoples. Social Sciences and Humanities Research Council of Canada (SSHRC).

McVey, G. L., Lieberman, M., Voorberg, N, Wardrope, D., \& Blackmore, E. (2003). School-based peer support groups: A new approach to the prevention of disordered eating. Eating Disorders, 11, 169-185.

Meadows, L. M., Lagendyk, L. E., Thurston, W. E., \& Eisener, A. C. (2003). Balancing culture, ethics and methods in qualitative health research with aboriginal peoples. International Journal of Qualitative Methods, 2 (4). Article 1. Retrieved February 12, 2006 from http://www.ualberta.ca/ iiqm/ backissues/2_4/pdf/ meadows.pdf 
Morse, J. M. (2001). Types of talk: Modes of responses and data-led analytic strategies. In P. L. Munhall (Ed.), Nursing Research: A Qualitative Perspective ( $3^{\text {rd }}$ ed., pp. 565-578). Boston: Jones and Bartlett Publishers.

Morse, J. M., \& Field, P. A. (1995). Qualitative research methods for health professionals $\left(2^{\text {nd }}\right.$ ed.). Thousand Oaks: Sage Publications.

Morse, J. M., \& Richards, L (2002). Readme first: for a user's guide to qualitative methods. Thousand Oaks: Sage Publications.

Munhall, P. L. (2001). Ethical considerations in qualitative research. In P. L. Munhall (Ed.), Nursing research: A qualitative perspective ( $3^{\text {rd }}$ ed., pp. 537-549). Boston: Jones and Bartlett Publishers.

Newhouse, D. R. (2000). From the tribal to the modern: The development of modern Aboriginal societies. In R. F. Laliberte, P. Settee, J. B. Waldram, R. Innes, B. Macdougall, L. McBain, F. L. Barron (Eds.), Expressions in Canadian native studies (pp. 395-409). Saskatoon: University of Saskatchewan Press.

Neumark-Sztainer, D., Story, M., Resnick, M. D., \& Blum, R. W. (1997). Psychosocial concerns and weight control behaviours among overweight and nonoverweight Native American adolescents. Journal of the American Dietic Association, 97, 598-604.

O'Brien, R. (2001). An overview of the methodological approach of action research. Retrieved March 28, 2006, from http://www.web.ca/ robrien/papers/arfinal.html Olesen, V. L. (2000). Feminisms and qualitative research at and into the millennium. In N. K. Denzin \& Y. S. Lincoln (Eds.), Handbook of qualitative research $\left(2^{\text {nd }}\right.$ ed., pp. 215-255). Thousand Oaks, CA: Sage Publications.

O'Neill, P. (2005). The ethics of problem definition. Canadian Psychology, 46, 13-20.

Orbach, S. (1998). Fat is a feminist issue: And it's sequel. London: Arrow Books Limited.

Ouellette, G. J. (2002). The fourth world: An Indigenous perspective on feminism and Aboriginal women's activism. Halifax, NS: Fernwood Publishing.

Page, A., \& Fox, K. R. (1997). Adolescent weight management and the physical self. In K. R. Fox (Ed.), The physical-self: From motivation to well-being (pp. 229-258). Champaign, IL: Human Kinetics. 
Paquette, M.-C., \& Raine, K. (2004). Sociocultural context of women's body image. Social Science \& Medicine, 59, 1047-1058.

Park, P. (2001). Knowledge and participatory research. In P. Reason \& H. Bradbury (Eds.), Handbook of action research: Participative inquiry and practice (pp. 8190). London: Sage Publications.

Patton, M. Q. (1990). Qualitative evaluation and research methods (2nd ed.). Newbury Park, CA: Sage.

Patton, M. Q. (2002). Qualitative research \& evaluation methods (3 ${ }^{\text {rd }}$ ed.). Thousand Oaks, CA: Sage Publications.

Paxton, S. J. (1993). A prevention program for disturbed eating and body dissatisfaction in adolescent girls: A one-year follow-up. Health Education, 8, 43-51.

Piran, N. (1996). The reduction of preoccupation with body weight and shape in schools: A feminist approach. Eating Disorders, 4, 323-333.

Piran, N. (2001). Re-inhibiting the body from the inside out: Girls transform their school environment. In D. L. Tolman \& M. Brydon-Miller (Eds.), From subject to subjectivities: A handbook of interpretive and participatory methods (pp. 219238). New York: New York University Press.

Poudrier, J., \& Kennedy, J. (2008). Embodiment and the meaning of the "healthy body": An exploration of First Nations women's perspectives of healthy body weight and body image. Journal of Aboriginal Health, 4, 15-24.

Prairie Women's Health Centre of Excellence (2001). Action plan for women's health in Manitoba and Saskatchewan: Key priorities and strategies. Retrieved March 16, 2006, from http://www.pwhce.ca/leaflet.htm

Prairie Women's Health Centre of Excellence (2004). Ethical guidelines for Aboriginal women's health research. Retrieved March 16, 2006, from http://www.pwhce.ca/ethical Guidelines.htm

Public Health Agency of Canada (n.d.). What determines health? Retrieved March 16, 2006, from http://www.phac-aspc.gc.ca/ph-sp/phdd/determinants

Reid, C. J. (2000). Seduction and enlightenment in feminist action research. Resources for Feminist Research, 28, 169-188.

Reid, C. J. (2004). Advancing women's social justice agendas: A feminist action 
research framework. International Journal of Qualitative Methods, 3 (3). Article 1. Retrieved July 22, 2005 from http://www.ualberta.ca/ iqqm/backissues/3_3 $/ \mathrm{html} /$ reid.html

Reid, C., Tom, A., \& Frisby, W. (2006). Finding the 'action' in feminist participatory action research. Action Research, 4, 315-332.

Reinharz, S. (1992). Feminist methods in social research. New York, NY: Oxford University Press.

Robertson, A., \& Minkler, B. (1994). New health promotion movements: a critical examination. Health Education Quarterly, 21, 295-312.

Royal Commission on Aboriginal Peoples (1996). Report of the Royal Commission on Aboriginal Peoples. Ottawa, ON: Government of Canada.

Sarto, G. E. (1998). How race, ethnicity, and culture influence women's health. Women's Health in Primary Care (Supplement), 1, 7-14.

Saskatchewan Learning (1994). Integrated school linked-services for children and youth at risk-implementation guide. Retrieved March 19, 2008, from http://www.sasked.gov. sk.ca/admin/pub_pdf/isls_guide.pdf

Saskatchewan School Boards Association (2004). Research report: Nutrition guidelines for schools (Research Centre Report \#04-01). Regina: SK.

Saskatoon Aboriginal Women's Health Committee (2004). Naspici miyomahcihowin: Continuous good health. Winnipeg, MB: Prairie Women's Health Center of Excellence.

Saskatoon Public Schools (2006). Nutana Collegiate: School planning document "20062007”. Saskatoon, SK.

Schlenker, B. R. (2003). Self-presentation. In M. R. Leary \& J. P. Tangney (Eds.), Handbook of self and identity (pp. 492-518). New York: The Guilford Press.

Secord, P. F., \& Jourard, S. M. (1953). The appraisal of body-cathexis: Body-cathexis and the self. Journal of Consulting Psychology, 17, 343-347.

Senge, P. M. (2000). The industrial age system of education. In P. M. Senge, N. Cambron-McCabe, T. Luck, B. Smith, J. Dutton, \& A. Kleiner (Eds.), Schools that learn: A fifth discipline fieldbook for educators, parents, and everyone who cares about education (pp. 27-58). New York: Doubleday. 
Smith, G. H. (2000). Protecting and respecting Indigenous knowledge. In M. Battiste (Ed.), Reclaiming Indigenous voice and vision (pp. 209-224). Vancouver, BC: UBC Press.

Smith, L T. (1999). Decolonizing methodologies: Research and Indigenous peoples. London: Zed Books Ltd.

Smith, L. T. (2005). On tricky ground: Researching the Native in the age of uncertainty. In N. K. Denzin \& Y. S. Lincoln (Eds.), The SAGE handbook of qualitative research ( $3^{\text {rd }}$ ed., pp. 85-107). Thousand Oaks: Sage Publications.

Sparkes, A. C. (1995). Writing people: Reflections on the dual crisis of representation and legitimation in qualitative inquiry. Quest, 47, 158-195.

Sparkes, A. (1997). Reflections on the socially constructed physical self. In K. R. Fox (Ed.), The physical self: From motivation to wellbeing (pp. 83-110). Champagne, IL: Human Kinetics.

Stake, R. E. (1995). The art of case study research. Thousand Oaks, CA: Sage Publications.

Statistics Canada (n.d.). Standard classification. Retrieved April 8, 2008, from http://www.statcan.ca/english/concepts/definitions/ethnicity01.htm

Statistics Canada (2003). Aboriginal peoples survey (2001): Initial release-supporting tables. Ottawa, ON: Minister of Industry.

Steckley, J. (2003). Aboriginal voices and the politics of representation: In Canadian introductory sociology textbooks. Toronto, ON: Canadian Scholars Press Inc.

Stein, J. S. (1997). Empowerment and women's health: Theory, methods, and practice. London: Zed Books.

Stevenson, W., Johnson, R., \& Greschner, D (Eds.) (1992). "Peekiskwetan." Commentaries/Commentaires, CJWL/RFD, 6, 153-173.

Story, M., French, S.A., Resnick, M.D., \& Blum, R.W. (1995). Ethnic/racial and socioeconomic differences in dieting behaviors and body image perceptions in adolescents. International Journal of Eating Disorders, 18, 173-179.

Story, M., Hauck, F. R., Broussard, B. A., White, L. L., Resnick, M. D., \& Blum, R. W. (1994). Weight perceptions and weight control practices in American Indian and 
Alaska Native Adolescents. Archives of Pediatrics and Adolescent Medicine, 148, 567-571.

Stringer, E. (1999). Action research $\left(2^{\text {nd }}\right.$ Ed. $)$. Thousand Oaks, CA: Sage.

Stringer, E. T., \& Genat, W. J. (2004). Action research in health. New Jersey: Pearson Education Inc.

Suthers, L. (2007, March). High school girls voice their body image concerns. Saskatchewan SAGE: The Aboriginal Newspaper of Saskatchewan, 11 (6), 12.

Sweeney, M. L. (2001). The self-image of adolescent females: A group exploration. In K. A. Fall \& J. E. Levitou (Eds.), Modern applications to group work (pp. 69-96). Huntington, NY: Nova Science Publishers Inc.

Taylor, V. (1998). Feminist methodology in social movements research. Qualitative Sociology, 21, 357-379.

Thompson, J. L., Allen, P., Cunningham-Sabo, L., Yazzie, D. A., Curtis, M., \& Davis, S. M. (2002). Environmental, policy, and cultural factors related to physical activity in sedentary American Indian women. Women \& Health, 36, 59-74.

Thornhill, E. (1989). Focus on Black women! Race, class, gender: Bonds and barriers. Socialist Studies, 5, 26-36.

Tindall, W. N., Clasen, M. E., \& Smith, C. A. (2003). Building a truly engaged community through participatory research. Retrieved April 8, 2008, from the Research Enterprise: Wright State University Boonshoft School of Medicine Web site: http://www.med. wright.edu/ra/re/2003/tindall.html

Totten, F. (1972). Power of community education. Midland: Pendall Co.

Tymchak, M. (2001). School ${ }^{\text {LUUS }}$ - A vision for children and youth - Toward a new school, community and human service partnership in Saskatchewan, final report. Task force report to the Minister of Education, government of Saskatchewan. Regina, Canada: Saskatchewan Instructional Development \& Research Unit. Vasquez, M. J. T., \& Fuentes, C. (1999). American-born Asian, African, Latina, and American Indian adolescent girls: Challenges and strengths. In N. G. Johnson, M. C. Roberts, \& J. Worell (Eds.), Beyond appearance: A new look at adolescent girls (pp. 151-173). Washington, DC: American Psychological Association. 
Veronica-Renee (2007, April). Be yourself! An article about body image. Word on the Street: A Free Journal for Youth and Urban Saskatoon, 3 (4), 1.

Wadsworth, Y. (1998). What is participatory action research? Action Research International, Paper 2. Retrieved March 28, 2006, from http://www.scu.edu.au/Schools/gcm/ar/ari/p-ywadsworth98.html

Walby, S. (1989). Theorising patriarchy. Sociology, 23, 213-234.

Walters, K. L., \& Simoni, J. M. (2002). Reconceptualizing Native women's health: An "Indigenist" stress-coping model. American Journal of Public Health, 92, 520524.

Way, N. (2001). Using feminist research methods to explore boy's relationships. In D. L. Tolman \& M. Brydon-Miller (Eds.), From subjects to subjectivities: A handbook of interpretive and participatory methods (pp. 111-129). New York: New York University Press.

Weenie, A. (2000). Post-colonial recovering and healing. In J. Reyhner, J. Martin, L. Lockard, \& W. Sakiestewa (Eds.), Learn in beauty: Indigenous education for a new century (pp. 65-70). Flagstaff, Arizona: Northern Arizona University.

Wheeler, W. (2001). Thoughts on the responsibilities for Indigenous/Native studies. Canadian Journal of Native Studies, 21, 97-104.

Wilbur, F. P., Lambert, L. M., \& Young, M. J. (1988). School college partnerships: A look at the major national models. Reston, VA: National Association of Secondary School Principals.

Wilson, A. (2004). Living well: Aboriginal women, cultural identity, and wellness. Winnipeg, Manitoba: The Prairie Women's Health Center of Excellence.

Wilson, K., \& Rosenberg, M. W. (2002). Exploring the determinants of health for First Nations peoples in Canada: Can existing frameworks accommodate traditional activities? Social Science \& Medicine, 55, 2017-2031.

Wolcott, H. F. (2001). Writing up: Qualitative research ( $2^{\text {nd }}$ ed.). Thousand Oaks, CA: Sage.

Young, T. K. (2003). Review of research on Aboriginal populations in Canada: relevance to their health needs. British Medical Journal, 327, 419-422. 
APPENDICES 
APPENDIX A

Ethical Approval 


\section{Certificate of Approval}

\begin{tabular}{lll}
\hline PRINCIPAL INVESTIGATOR & DEPARTMENT & Beh \# \\
Kent C. Kowalski & Kinesiology & $06-127$
\end{tabular}

INSTITUTION(S) WHERE RESEARCH WILL BE CARRIED OUT

University of Saskatchewan

Saskatoon SK

STUDENT RESEARCHER(S)

Tara-Leigh Fleming

SPONSORING AGENCIES

CANADIAN INSTITUTES OF HEALTH RESEARCH (CIHR)

TITLE

The Body-Related Emotional Experiences of Young Aboriginal Women: From Research to Action
APPROVAL DATE
EXPIRY DATE
10-May-2006
01-May-2011

APPROVAL OF

APPROVED ON

Will ask participants to sign a release form allowing the researcher to use direct quotations $\quad 16-A p r-2007$

and photographs when results are disseminated.

\section{CERTIFICATION}

The University of Saskatchewan Behavioural Research Ethics Board has reviewed the proposed revisions to your study. The revisions were found to be acceptable on ethical grounds. The principal investigator has the responsibility for any other administrative or regulatory approvals that may pertain to this research project, and for ensuring that the authorized research is carried out according to the conditions outlined in the original protocol submitted for ethics review. This Certificate of Approval is valid for the above time period provided there is no change in experimental protocol or consent process or documents.

Any significant changes to your proposed method, or your consent and recruitment procedures should be reported to the Chair for Research Ethics Board consideration in advance of its implementation.

\section{ONGOING REVIEW REQUIREMENTS}

In order to receive annual renewal, a status report must be submitted to the REB Chair for Board consideration within one month of the current expiry date each year the study remains open, and upon study completion. Please refer to the following website for further instructions: http://www.usask.ca/research/ethics_review/
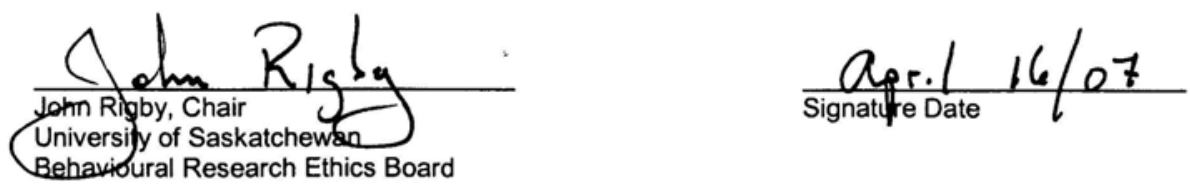

Please send all correspondence to:

Ethics Office

University of Saskatchewan

Room 306 Kirk Hall, 117 Science Place

Saskatoon SK S7N 5C8

Tephon: (306) 966-2084

Fax: (306) 966-2069 


\section{APPENDIX B}

Informed Consent 


\section{UNIVERSITY OF SASKATCHEWAN \\ Informed Consent}

You are invited to participate in a study entitled: The body-related emotional experiences of young Aboriginal women: From research to action. Please read this form carefully and feel free to ask questions you might have.

Researchers: Tara-Leigh Fleming and Dr. Kent Kowalski, College of Kinesiology, University of Saskatchewan, 966-1079.

Purpose and Procedures: The purpose of this research is to develop a collaborative, school-based participatory action research project in partnership with a local high school (i.e., Nutana Collegiate) to provide young women, primarily young Aboriginal women, with an opportunity to manage their feelings surrounding their bodies in a healthy, effective, and collaborative manner.

Given the emergent nature of participatory action research, it is quite difficult to accurately describe the methods and procedures because it is you who will be deciding upon the methods and activities to be developed. However, over the next 10 months it is requested that you participate in the five phases of this research study. It is anticipated that you will meet with the researcher and other participants approximately two or three times per month during the school year. Meetings will consist of informal discussions and more structured interviews, and will take place at a time (lunch, break, after school) and place (e.g., school) that is convenient for you.

The first phase will involve Building the Picture. During this phase it is anticipated that you will engage in discussions with the researcher and other participants to help to identify the key issues and the people who are affected by young Aboriginal women's body-related concerns.

The second phase will involve Data Gathering. During this phase it is anticipated that you will help to shed light on young Aboriginal women's feelings surrounding their bodies, and the strategies that could be used to manage these feelings, by engaging in interviews (one-on-one and focus group). Interviews may be formally organized or they may take place during a more natural social interaction over the 10 month period. Therefore, not all interviews will be recorded. However, those interviews that are formally organized will be recorded using an audio-recorder. The audio tape recordings will be transcribed (typed out) word for word. As a participant, you will also be asked to provide feedback on the accuracy of interview transcripts.

In addition, within the second phase, you will likely assist in the creation of a survey in which we try to further understand the perspectives of young Aboriginal women. The survey will be utilized as a method to acquire information from a larger group of young Aboriginal women about their body-related experiences.

The third phase will involve Data Analysis. During this phase it is anticipated that you will help to identify the information that appears to be most pertinent to young Aboriginal women's body-related experiences. In addition, it is likely that you will help to identify the strategies that should be implemented to assist young Aboriginal women in managing their body-related emotional experiences in a healthy, effective, and collaborative manner. 
The fourth phase will involve Communication. During this phase it is anticipated that you will be involved in the sharing of the methods and outcomes of investigation with various public, professional, and academic audiences. You will be asked to work with the other participants to decide on the most appropriate methods to share this information.

The fifth and final phase will involve Action. During this phase it is anticipated that you will work with the other participants and proceed with the new understandings and knowledge to immediate resolution of the research issue. The action will depend upon your suggestions, and the suggestions of all participants and the researcher.

Potential Risks: You will not be subjected to any physical risk, but there may be minimal psychological risk as a result of discussing issues or feelings about the body. You have the right to refuse to answer any question, at which time the discussion will be redirected. Information regarding topics that the researcher must disclose (e.g., child abuse, intent to do harm) will be shared with you prior to the interviews. Likewise, if certain information is shared, the researcher will be legally obliged to disclose the information to the appropriate parties. In the event that you would like the support of a health professional, the appropriate health care provider will be recommended. In addition, if necessary, you may utilize the 24-hour Sask. Health line phone number (1877-800-0002).

Potential Benefits: Your participation may lead to a better understanding of young Aboriginal women's body-related experiences. In addition, your participation may lead to the development of a number of individual and community-based strategies and activities for managing body issues. Your participation may also lead to an increased community awareness surrounding the role of body image on overall health. It is important to note however, that these benefits are not guaranteed through participation in the study.

Storage of Data: All research material will be securely stored in the office of Dr. Kent Kowalski, at the University of Saskatchewan, for a minimum of fives years after study completion.

Confidentiality: The data from this study will be written as a Doctoral thesis. The data will also be shared with various public, professional, and academic audiences by way of publications and presentations; however, your identity will be kept confidential.

Although reports may include direct quotations from the interviews, you will be asked to choose a pseudonym (made up name) and all identifying information (name, address) will be removed from any report. In addition, the majority of data will be reported anonymously in aggregate form.

You will take part in all phases of this research project, and confidentiality will be of utmost importance throughout the whole research process. Interviews may be audio taped, and any audio tapes will be identified by a code number and stored in a secure locked office. The audio tapes, transcripts, and any other data, will be stored separately from the master sheet identifying names, pseudonyms, and code numbers. 
There are, however, limits on the level of confidentiality that we as researchers can ensure. Because you will take part in small focus groups with the other participants, you will be identifiable to other people in the group on the basis of what you have said. The researcher will be sure to safeguard the confidentiality of the group discussion, but cannot guarantee that other members of the group will do so. Please respect the confidentiality of the other members of the group by not disclosing the contents of discussions outside the group, and be aware that others may not respect your confidentiality. Also, it is important that you are aware that there are certain types of information that the researcher may be obliged to report to relevant authorities (e.g., child abuse, intent to do violence).

Right to Withdraw: Participation in this study is voluntary and you may withdraw from the study for any reason, at any time, without penalty of any sort, including current or future participation in this or any other program. Should you decide to withdraw from the study, any data that you have contributed will be destroyed at your request. Seeing as this study will take place over a 10 month period, the researcher will continuously (e.g., at least once a month) remind you about the voluntary nature of this study and your right to withdraw at any point.

Questions: If you have any questions concerning the study, please feel free to ask at any point; you are also free to contact the researchers at the numbers provided above if you have questions at a later time. This study has been approved on ethical grounds by the University of Saskatchewan Behavioural Research Ethics Board on (insert date). Any questions regarding your rights as a participant may be addressed to that committee through the Ethics Office (966-2084).

You will be involved in the communication of results, and you may request copies of all published reports and manuscripts.

Consent to Participate: I have read and understood the description provided above; I have been provided with an opportunity to ask questions and my questions have been answered satisfactorily. I consent to participate in the study described above, understanding that I may withdraw this consent at any time. A copy of this consent form has been given to me for my records.

Participant's Name

Participant's Signature

Researcher's Name

Researcher's Signature

Parental/Guardian Consent: My signature on this sheet indicates that I have received information regarding the nature of the study, its purpose, and procedures, and I will allow my daughter, , to participate in the study The body-related emotional experiences of young Aboriginal women: From research to action.

Signature of parent or guardian Date 


\section{APPENDIX C}

Data Release Form 


\title{
UNIVERSITY OF SASKATCHEWAN
}

\author{
Data Release Form
}

Title of the study: The body-related emotional experiences of young Aboriginal women: From research to action

Researchers: $\quad$ Tara-Leigh Fleming and Dr. Kent Kowalski

University of Saskatchewan

College of Kinesiology

87 Campus Drive

Saskatoon, SK

S7N 5B3

966-1079

$\mathrm{I}$, photographs) from my participation in this study and have been provided with the opportunity to add, alter, and delete data from the study as appropriate. I acknowledge that the data accurately reflects my participation in the study. I hereby authorize the release of my name, direct quotations, and photographs to Kent Kowalski to be used for the educational purposes outlined in the consent form (i.e., publications, presentations). I have received a copy of this Data Release Form for my own records.

Participant

Parent/Guardian

Researcher
Date

Date

Date 


\section{APPENDIX D}

Word on the Street 


\section{Word on the Street}

\section{A Free Journal for Youth and Urban Saskatoon Volume 3 Issue 4, April 2007}

\section{Be yourself!}

An article about Body image

emale body image in the Aboriginal culture isn't much different than what Caucasian women struggle with, or Asian and African women struggle with. There are a lot of different ideas young women have about their bodies, how it looks, and how to change it. Young aboriginal women, like all

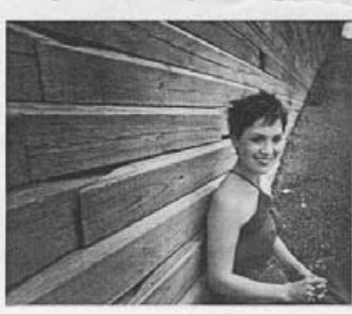

Susan Aglukark teenagers, and young adults who are female, like to look good. It's nice to do your hair in the morning and pick a nice outfit, and

like everyone-including males-we often struggle with having "good looks" and trying to get skinny, or skinnier. We criticize our appearance nearly everyday when we look at ourselves in the mirror.

My point of view on body image is we are all different, and we all have different styles. It shouldn't matter what someone down the road thinks about how we look, or what the kid sitting beside you in class thinks, but there are times when it does, and it really gets to us sometimes.

Media and today's society has changed what beauty used to be. Things are beginning to change, though. There are strong females to look up to in the media who are trying to change how appearance is idolized, and one of them is Tyra Banks. She is a big influence on a lot of teenagers and young women around North America and the world, and she portrays a positive body image, and discusses an important variety of topics on her talk show.

I think if we all just take the time to talk about what is on our mind about how we feel about ourselves, and anything else that's bugging us, our selfesteem will rise and we will learn to love ourselves more. Having a good self-esteem doesn't just change because we've changed our appearance or because of how many compliments we get in a day, but it changes how we feel about life, our friends, family, goals, and also what we deal with in everyday living. I'm sure if one person can try and make a change and spread the word, the problem will soon fade and more people will be proud of who they are, and the people around them, and in their community will soon understand what's going on.

"For me, it might sound cliche, but beauty for me really does start on the inside. It's like a state of mind, a state of love if you will. Then, whatever you can do on the outside is all like a bonus." -Queen Latifah

\section{Veronica-Renee}

\section{Contact Word on the street}

Editors: Taya Raine Kerry Buswell

Phone: 665-3889

Email: taya@cryc.ca kerryecnyc.ca

905 20th Street West

INSIDE THIS ISSUE

Street Speak

Dirt Biking

Wrong Place

My Story

Rap Music

Drugs or a Life

Favorite Place

Where is the Child?

Buses

Being Jacked

Community Events

\section{About Word} on the Street

Word on the Street is written by young people in and out of school. It provides a forum for Saskatoon youth to express issues and ideas.

\section{Writers for} this Issue

Veronica-Renee, Steven, Anonymous, Georgina, Chantelle, Whitney, Lynelle, Andrea, M.P.,

\section{Do you like to Write?} Do you like Money? wors is looking for youth writers. We'll even pay your. 665-3389 


\section{APPENDIX E}

Star Phoenix Newspaper Article 


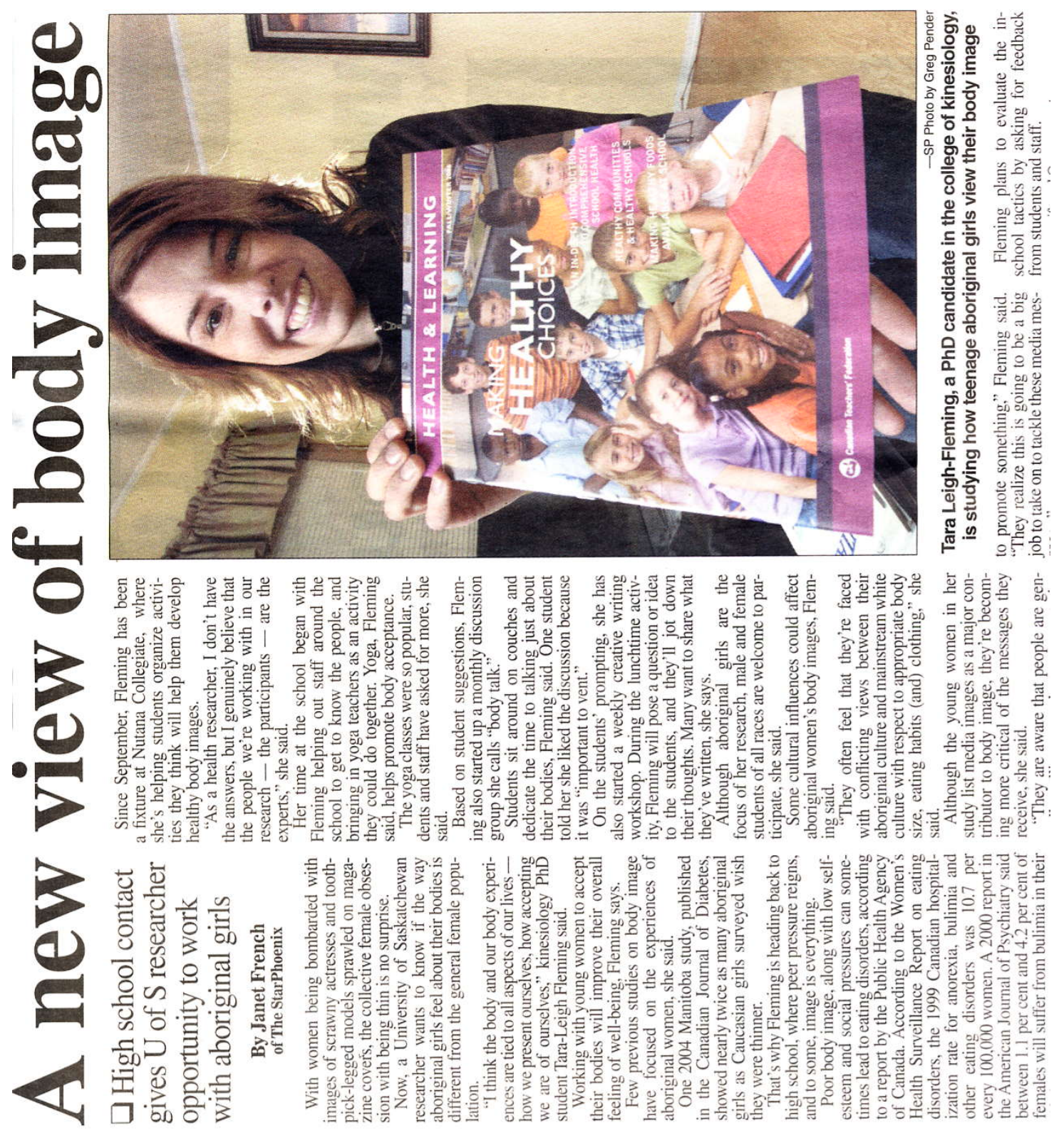




\section{APPENDIX F}

Sage Newspaper Article 


\section{High school girls voice their body image concerns}

By Laupa Suthers $\underline{\text { Sage Writer }}$ SASKATOON

Tara Leigh-Fleming has gone back to high school, not as student but as a researcher.

Leigh-Fleming, a kinesiology PhD candidate at the University of Saskatchewan, wants to fin out about the views of teenage Aboriginal girls when it comes to body image. She's gathering this information through an interactive discussion group called Body Talk.

According to Leigh-Fleming. there have been a couple large scale studies relating to body image conducted in the Unite States and there's been on study that she knows of done in Canada, "but they were reall more of a survey type research. so they never really spoke to the young women to find out what they really felt."

"I just recognized that if we really wanted to understand how these young women feel, it's important to engage them importantions" said the thin conversations," "whe the thirdyear student. "What see or what t know is that there's little if any research that has allowed for their voices to be heard, that's where I'm going with

Since September, Leigh Fleming has been working wit the students from Nutan Collegiate, organizing activitic based on the student suggestions. Body Talk is on activity that has been implemented as a monthly discussion group.

"Not only is it a way for us to Not unly is it a way for us better understand how these young women feel but it's positive experience because they're able to sit around in a
group with young women and vent, talk about how they feel about themselves," said Leigh Fleming. "Also, through the us of the Body Talk discussion we're really realizing how complex their experiences are. Some days they may be happy with themselves and other days there not as happy with themselves, so we're beginning to uncover all of the complexities about their experiences."

Sixteen-year-old Kyla George is doing just that, expressing her is doing just that, expressing her
point of view and experiences point of view and experiences
through the programs Leighthrough the programs Leigh
Fleming has helped create.

Fleming has helped create.
"I joined because I know that

"I joined because I know that
I'll get my word out," said the I'll get my word out," said the Grade 10 student. "This group is an opportunity to hear what others have to say and get out what I have to say. It's about sharing our opinions, experiences and different ways of life with other people. It's a really great program and it makes me feel good about makes ,"

George believes the obsession George beliemel comes from the attitude o accepted.

"I think women and men enjoy or want to be liked and loved and they probably think the only way to be like that is to be thin," said George.

Self-acceptance is one of the focuses of the program, which puts the spotlight on healthy eating and physical activity such as yoga classes.

Obesity is another contributing factor to young girls' obsession with being thin. "There's such an obesity scare right now that our young people become so focused on obesity," said Leigh-Fleming. "I think that what we have to do is focus that what we have to do is focus more on just general acceptance of the body as it is and from there learn to respect our bodies. I think those other things like healthy eating and physical
activity kind of come along with activity kind of come along with that because once we're respecting our bodies then we learn how to treat our body well. If we can promote this general level of acceptance and respect of our bodies then even the general population might be able to learn from it and not just have a focus on young Aboriginal women."

Leigh-Fleming admits the media, with its images of super media, with its images of super also have an impact on the way young girls view themselves. young girls view themselves.
"Of course, media always "Of course, media always he young women always say that the media is an importan factor, they are becoming more critical. They are recognizing that someone's pushing these messages.

"The young women do recognize that their peers also have important influences as to how they feel about themselves, so that's where role memselves, so that's where role models can como in. Role models can be anyo of course, from the parents, guardians, teachers and parents, guardians, teachers and ust anyone."

Like George, 16-year-old Veronica Keith joined the Body Talk program to be able to express her views in a nonudgmental environment. But she also joined to meet new people and learn what other people her age are dealing with.

“' It's a really good program for people to express themselves and just to talk about that kind of stuff and to know that we're not the only ones who thinks this," said Keith.

Although this study is focused on feedback from Aboriginal girls, Leigh-Fleming said tudents from all races are welcome to participate.

"When we talk about body image research, generally we're alking about "white" research and I think that's common with a lot of research," she said. "The voices of Aboriginal people have often been overlooked so with this study in one way is very unique in that we're celebrating the voices of these young people and the important messages that they do have to send."

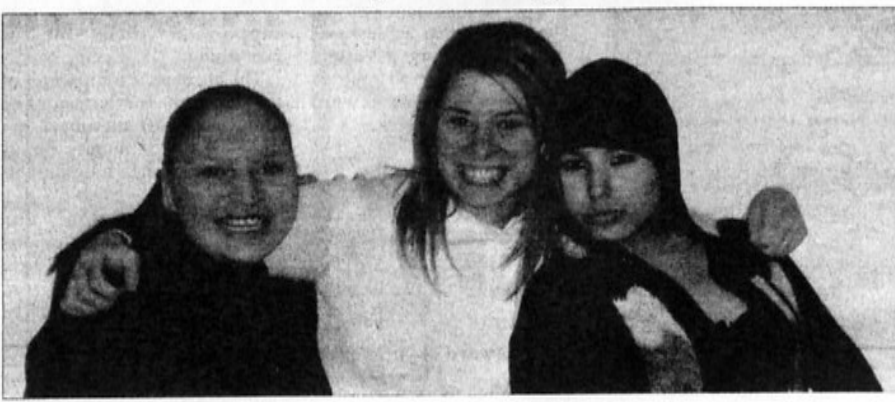

Tara Leigh-Fleming (centre) poses with Kyla George and Veronica Kelth, two students in the Body Talk program Leigh-Fleming runs at Nutana Collegiate in Saskatoon.

Although Leigh-Fleming's be able to carry it through." research with the Nutana In order to graduate from the students ends in June, it Noesn't mean that the activities willend.

"I think thatheides would be "I love being involved and four-year kinesiology program, really started to realize that since four-year kinesiology program, really started to realize that since werite a feming will have to write a tesis, we for these activities to be experiences and the information sit behind a desk or not. I really
sustainable," said Leigh- learned through her work with enjoy being involved with the Fleming. "They're not difficult the students and other people who are in our research. activities to continue but it's just information gathered through I love the idea of maybe working that the students will need, I other sources. Her original goal for a community organization or think, an adult overseer. There was to complete her PhD and government organization that's are so many support systems then become a professor, but her focused on community based and so much eager staff that $\mathrm{I}^{\prime} \mathrm{m}$ experiences working with the research, but I'm not a 100 per really optimistic that they will young women at Nutana have cent sure."

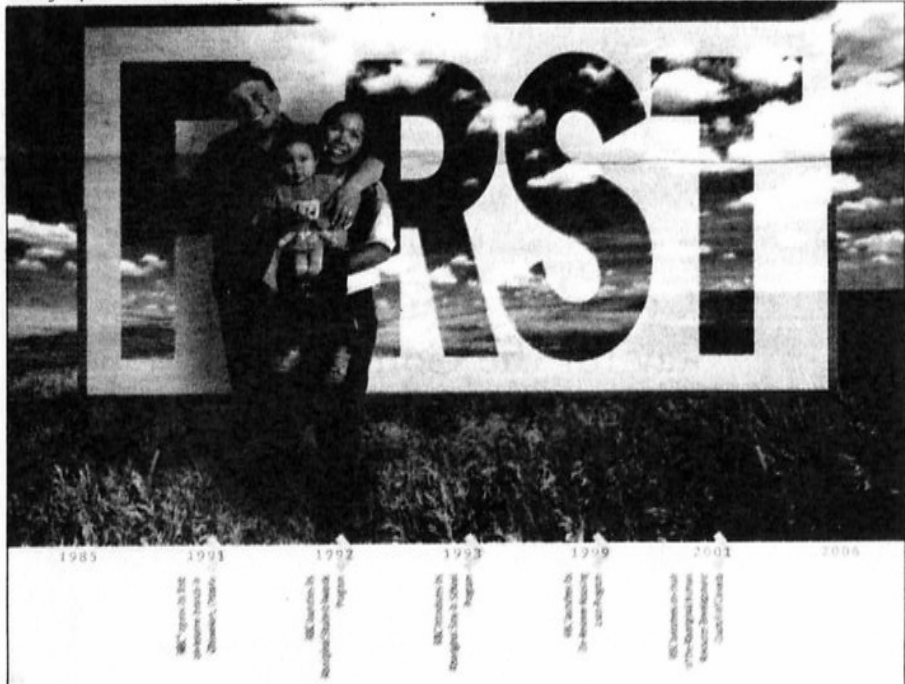

We are committed. To learning.

To leam. Together, To create
communities and businesses,

At RBC Royal Bank" we have a strong history of support for Aboriginal peoples across Canada. From stay-in-school programs to supporting programs that create jobs and enhance economic and community well.being... these are just some of the ways we put you first.

The power of learning togethes.

To find out more about our commitment to Aboriginal communities, visit your local branch or unw.rbcroyalbank.com/aboriginal.

Congratulations to all of the 2007 reclipients of the Natlonal Aboriginal Achlevement Awards, and a special acknowledgement to Jack Poole of Saskatchewan for winning the award in business and commerce.

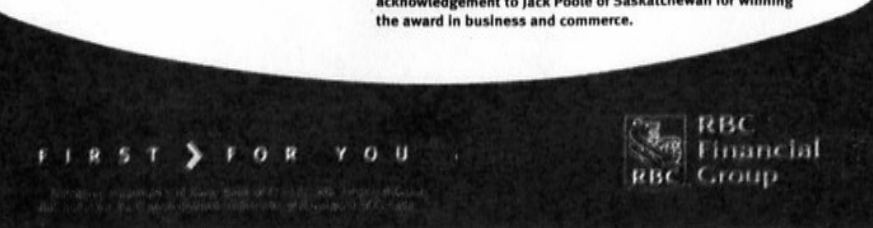




\section{APPENDIX G}

Letters Outlining Perceived Success of Action Initiatives 


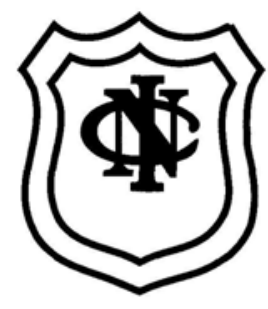

NUTANA COLLEGIATE INSTITUTE

$411-11$ TH STREET EAST
SASKATOON, SASKATCHEWAN STN SASKATCHEWAN S7N OES TELEPHONE (306) 683-7580
FAX (306) 683-7587

June 27, 2007

To Whom it May Concern,

Since the first day of the 2006-2007 term I have had the amazing opportunity to meet with Tara Fleming, a Ph. D student from the College of Kinesiology. Her volunteer participation in the many support system and curricular aspects of our Schools Plus initiatives has been exemplary.

Tara informally met with every professional and support staff personnel and shared her deep commitment and enthusiasm. More importantly, Nutana students benefited from her sincere appreciation of their adolescent issues and her ethical involvement with their academic, social and emotional concerns.

Not only did Tara volunteer to become involved with the Friday noon hour literacy group she also created a noon hour Yoga class. Teachers and students eagerly looked forward to the Tuesday exercise event. She also became involved with the Girls Club. Even though that group had been a part of Nutana Collegiate for many years, Tara added so many new dimensions to our mentorship program, that it evolved into a very dynamic activity. Students, many of whom are high-risk individuals, became keenly aware and astute about 'wellness' practices. They concentrated on art, planning healthy lunches and embraced the 'power of self-expression, and forgot to pursue some of the more selfdestructive habits. Student participation in the girls club and the literacy group increased remarkably and the students enjoyed coming to the library to talk about the many wonderful ideas and insights they gained from their relationship with each other and with Tara. She brought fresh insights and joy to our students. Then she initiated an art club on Wednesdays. Again, the record number of students who participated astounded me.

Ms. Fleming's energy was boundless. Besides bringing zest and vibrancy to our students, Tara still managed to exude a deep calm.

With Tara's involvement, self-conscious students began to embrace gymnasium activities. She empowered marginalized individuals by introducing them to a range of activities by inviting them to talk, practice and chose the weekly events. I saw joy in students' faces and remarkably improved attendance. 
In addition to her amazing interactions with students, Tara demonstrated consistent congeniality with every single person on the Nutana Collegiate team. Her delightful personality touched the imagination of administrators and cafeteria staff, daycare workers and educational assistants.

I sincerely thank the University of Saskatchewan for supporting Tara's initiatives to engage our adolescent students in this meaningful body image study. It clearly improved their young lives and helped students make positive wellness choices. Working with Tara also renewed my own enthusiasm for teaching and seeking innovative means of reaching our young learners.

Sincerely yours,

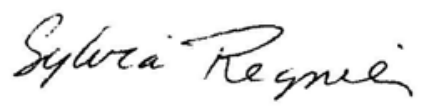

Sylvia Regnier

Teacher Librarian 
Tara's Thesis Stuff $(;$

Well first off, let me introduce myself; I am Veronica Renee B. Keith, a student at Nutana Collegiate. I am 16 years old and going into grade 10/11 for the 2007-2008 school year. I've been attending Nutana since April of 2006. I am also apart of the Aboriginal Culture, from the Loon Lake and Onion Lake First Nations (Saskatchewan).

I first met Tara-Leigh Fleming during a Student-Teacher Forum in December 2006, being held in the Nutana Library. The forum was to discuss with the students about the Public School Division's new "Academies" goal. I was one of the students put into Tara's break-out group. Tara was very outgoing during our break-out discussion.

At the end of the forum I got involved in a youth organization at the school called "Youth Launch". I also got involved in a lot of other groups and clubs around the school. During this time I started doing yoga and there was a Yoga group at lunchtime at the school, which Tara helped organize. That's where I first started to see Tara more often and got to know her more.

Tara did a lot of work and helped organizing with school projects and her own projects, which was Healthy Body Image (more so in young aboriginal women). Tara held monthly discussion groups for the girls in the school to talk about their issues and understandings around Body Image. She also helped with the Girls' Mentorship Club where she encouraged healthy eating habits and living a healthy lifestyle.

Other clubs Tara helped to organize were the Writers' Club, and the Art Club. The Writers' Club was organized so students could express their opinion on topics that were chosen and discussed by the students in the club (who was anyone who cared to join). Students were able to write about anything on their minds and were also allowed to submit their work to "Word on the Street", a Saskatoon Journal published and written by youth, if they wanted to express themselves to a more public-spread organization. The Art Club was something to do and to give students an opportunity to show their work in a couple of art shows near the end of the year. All these clubs were very successful through-out the year and are all hoped to continue this year, which the school will try keep going.

In February 2007 Tara organized her own workshop for the 2007 Sexual Health for Youth (S.H.Y.) Conference. Her workshop was on Body Image. Unfortunately I wasn't able to attend her workshop, but I was still at the conference working with Youth Launch as a facilitator. Another thing that happened in February was CBC Radio asked Tara if she would like to be interviewed on an article that was published on Tara and her study in Body Image, in the StarPhoenix. Tara asked me if I wanted to go with her and be interviewed as well. The interview went good, and it was a great experience for me, and I bet it was for her too.

Tara did another workshop near the end of the school year on Body Image at the Annual R Conference, held at Centennial High School. I worked with her there too and helped facilitate her workshop. There was a lot of feedback from the students and delegates at that conference and it also did well.

Through-out the year there were dinners, and banquets, and ceremonies that Nutana did a lot of volunteering for. Tara was always apart of these and helped volunteer during these occasions. 
Tara did a lot during this passed school year and the students and staff are really disappointed that she has to leave. Especially me; her and I had a lot of fun hanging out and working together. The students that she worked with in the clubs and volunteered with are going to miss her a lot. Tara really made the school a better and more exciting place to be, and to do things. There was always something to do at lunch and always something for her to tell us, or us to tell her.

One more thing Tara did this year was help nominate me for a Leadership award. It was a great honor, especially to be nominated by Tara. I never won the award at the Award show, but I did win a different Leadership award at the Nutana End of the Year Lunch in, that she handed to me. I wouldn't have anyone else give me that award than her.

I guess this concludes this "Thesis Stuff” for Tara. I hope you liked reading this and I hope Tara gets a good mark in her research study! (;)

$\sim$ Veronica Renee B. Keith 